MURILO ULIANA

ESTUDO DO PROBLEMA INVERSO EM BALANÇO POPULACIONAL APLICADO A DEGRADAÇÃO DE POLÍMEROS

\author{
Tese apresentada à \\ Escola Politécnica da \\ Universidade de São Paulo \\ para obtenção do título de \\ Doutor em Engenharia \\ Área de Concentração: \\ Engenharia Química
}

Orientador: Prof. Reinaldo Giudici

São Paulo/SP

Janeiro -2012 


\section{Uliana, Murilo}

Estudo do problema inverso em balanço populacional apli cado a degradação de polímeros / M. Uliana. -- São Paulo, 2012. $214+$ xvi p.

Tese (Doutorado) - Escola Politécnica da Universidade de São Paulo. Departamento de Engenharia Química.

1. Balanço populacional 2. Polímeros 3. Modelagem matemática 4. Degradação I. Universidade de São Paulo. Escola Politécnica. Departamento de Engenharia Química II. t. 
MURILO ULIANA

ESTUDO DO PROBLEMA INVERSO EM BALANÇO POPULACIONAL APLICADO A DEGRADAÇÃO DE POLÍMEROS

\author{
Tese apresentada à \\ Escola Politécnica da \\ Universidade de São Paulo \\ para obtenção do título de \\ Doutor em Engenharia \\ Área de Concentração: \\ Engenharia Química
}

Orientador: Prof. Reinaldo Giudici

São Paulo/SP

Janeiro -2012 


\section{SUMÁRIO}

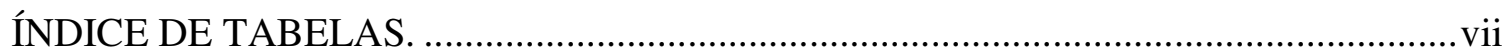

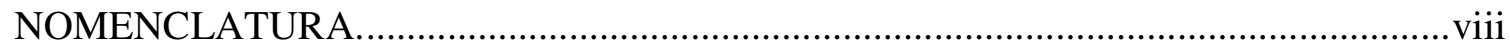

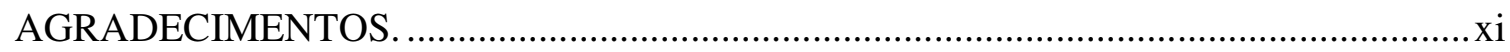

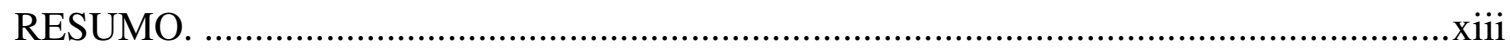

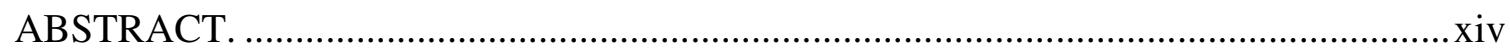

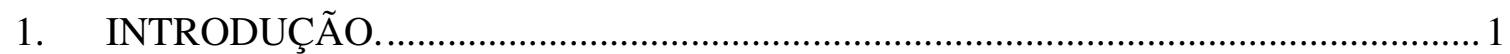

1.1 Equacionamento do Balanço Populacional. ............................................................. 2

1.2 Taxa de quebra, e, distribuição de partículas filhas................................................. 6

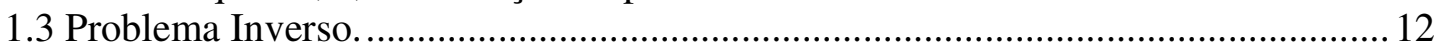

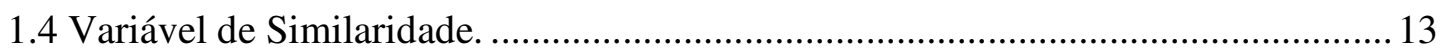

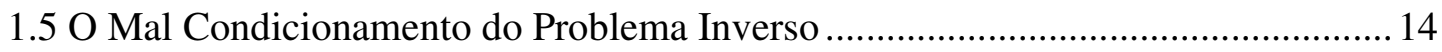

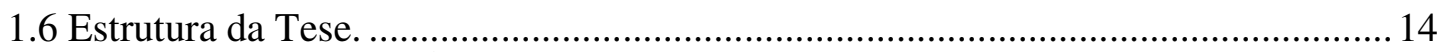

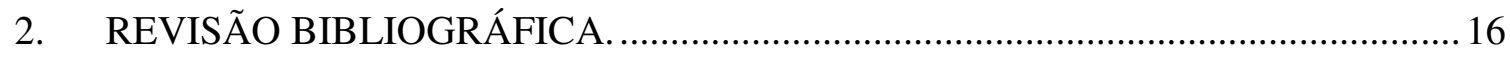

2.1 Estudos sobre Soluções da equação de Balanço Populacional..................................16

2.2 Estudos sobre as taxas de quebra e sobre as distribuições de partículas filhas. ....... 17

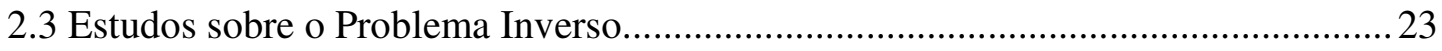

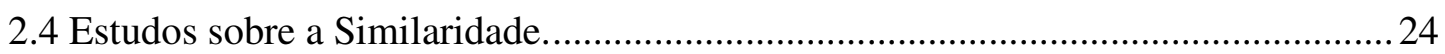

2.5 Estudos sobre o Mal Condicionamento do Problema Inverso.................................. 28

2.6 Estudos sobre alguns usos das equações de Balanço Populacional e abordagens

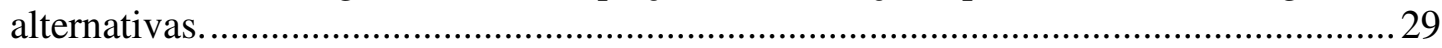

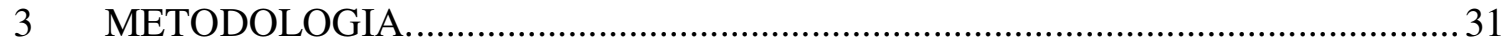

3.1 Estruturação da equação de Balanço Populacional. .................................................. 31

3.2 Discretização e Solução do Balanço Populacional pelo método dos pivots fixos. .. 35

3.3 Equacionamento das taxas de quebra e das funções de distribuição de partículas

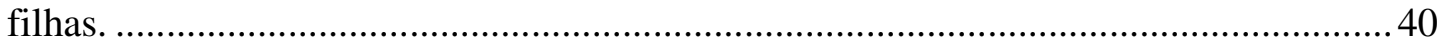

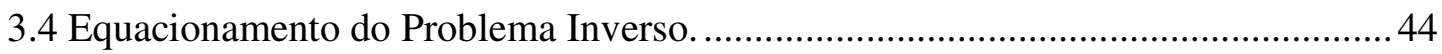

3.4.1. Verificação da auto-similaridade das distribuições ................................................46

3.4.2. Obtenção da função de taxa de quebra e da distribuição de partículas filhas 56

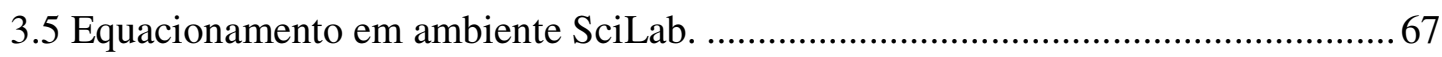

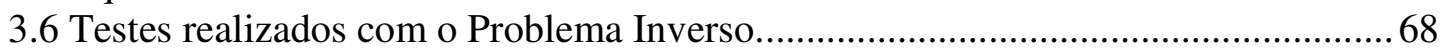

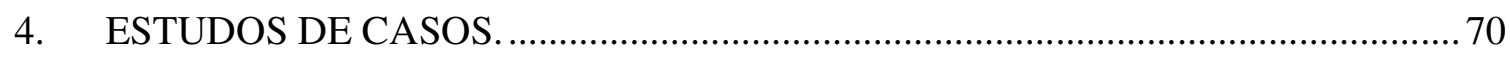

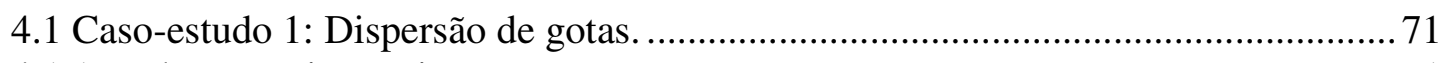

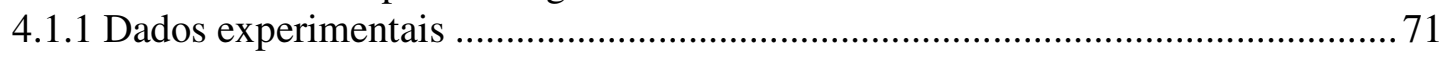

4.1.2. Solução do Problema Inverso. ........................................................................... 74

4.2 Caso-estudo 2: Quebra radicalar de cadeias lineares de polipropileno. .................... 81

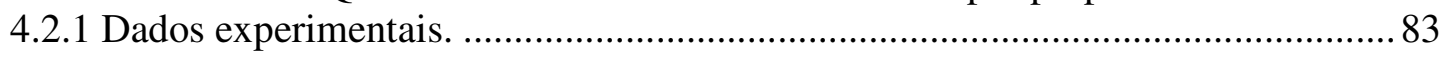

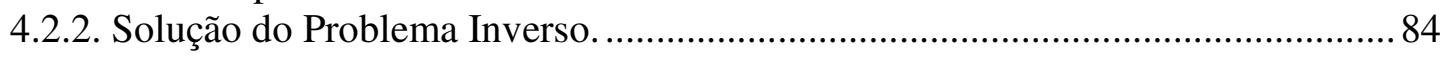

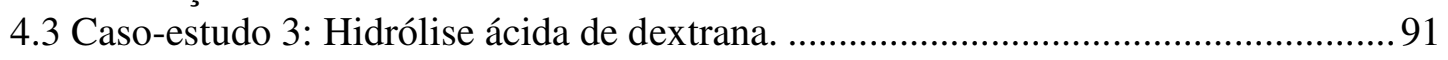

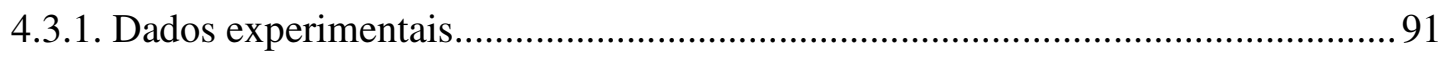

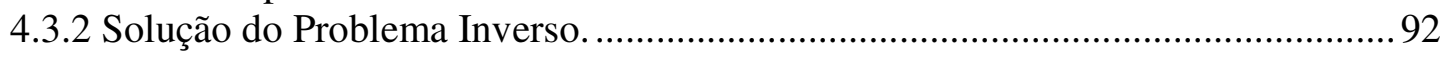

4.4. Degradação mecânica de poliestireno dissolvido por cisalhamento. .......................99

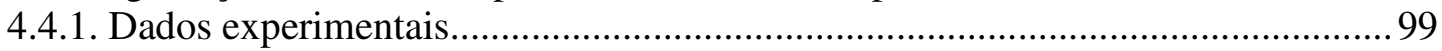

4.4.2. Solução do Problema Inverso. ........................................................................ 101

4.5 Degradação ultrassônica de dextrana. .................................................................. 112 
4.5.1. Dados experimentais

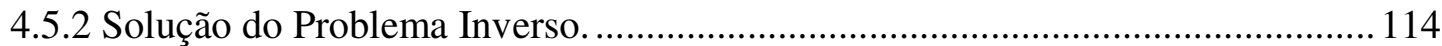

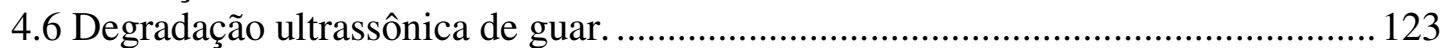

4.7 Degradação por hidrólise ácida de guar. ............................................................ 127

4.8. Procedimento alternativo para o modelo de degradação de polímeros. ................. 131

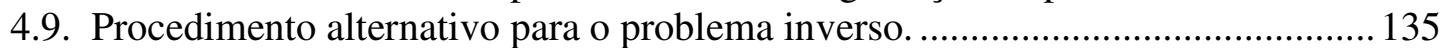

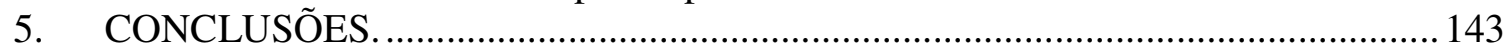

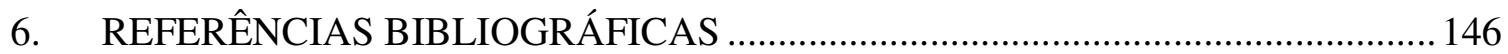

APÊNDICE A: ADIMENSIONALIZAÇÃO DA DISTRIBUÇÃO DE PARTÍCULAS. . 159 APÊNDICE B: COMPORTAMENTO ASSINTÓTICO DA DISTRIBUIÇÃO DE

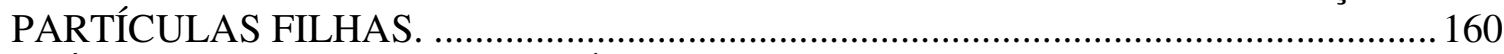

APÊNDICE C: SOLUÇÃO ANALÍTICA PARA BALANÇO POPULACIONAL. ......... 163

APÊNDICE D: SOLUÇÃO ANALÍTICA COM VARIAVÉIS DE SIMILARIDADE

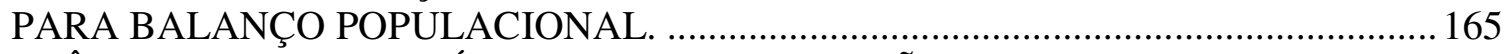

APÊNDICE E: COMENTÁRIOS SOBRE AS FUNÇÕES DE QUEBRA FORMULADAS

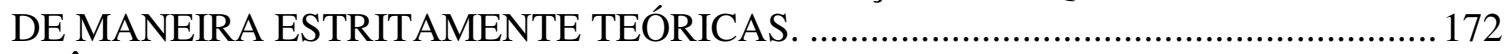

APÊNDICE F: PROBLEMAS MAL CONDICIONADOS EM BALANÇO

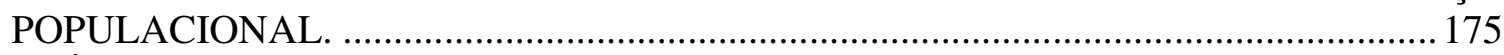

APÊNDICE G: SIMULAÇÃO DE MONTE CARLO (MC) ........................................... 182

APÊNDICE H: ABORDAGEM MATRICIAL PARA O BALANÇO POPULACIONAL E

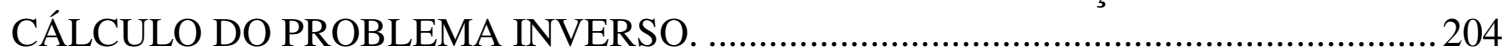

APÊNDICE I: METODOLOGIA PARA O CÁLCULO DAS DISTRIBUIÇÕES DE

PARTÍCULAS FILHAS POR (KOSTOGLOU;KARABELAS, 2001) ..............................211

APÊNDICE J: CÁLCULOS QUE DEMOSNTRAM UM AUMENTO DA SIMILARIDADE PARA REATORES, DO TIPO, BATELADA, EM RELAÇÃO À REATORES CONTÍNUOS (NARSIMHAN;NEJFELT;RAMKRISHNA,1984) .............213

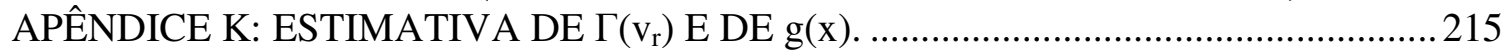




\section{ÍNDICE DE FIGURAS}

Figura 1.2.1: Exemplo da função distribuição de partículas filhas, para um caso em que a quebra resulta em diversas partículas, provenientes da partícula original quebrada. FONTE: BOVE; SOLBERG; HJERTAGER (2005).

Figura 1.2.2: Tipos de taxa de quebra com relação ao (a) tempo, e com relação ao (b) volume. FONTE: (RAO; DATTA, 2006). .............................................................. 11

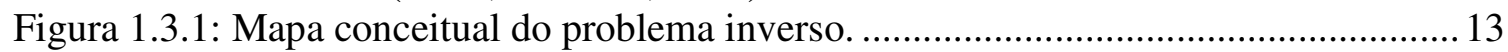

Figura 2.2.1: Quebra binária, representação esquemática..................................................20

Figura 2.2.2: Comportamento da distribuição de partículas filhas de acordo com o tipo de quebra, no sistema. FONTE: RAMKRISHNA;NARSIMHAN;GUPTA (1980)......... 23

Figura 3.2.1: Distribuição dos pivôs fixos, quando o tamanho de partícula formada pela quebra não coincide com os pivôs. FONTE: CHAKRABORTY;KUMAR (2007) e NOPENS;BEHEYDT; VANROLLEGHEM (2005).

Figura 3.3.1: Exemplo de taxas de quebra auto-similar como a descrita pela equação (3.3.2).

Figura 3.4.1.1: Distribuições ao longo do tempo para a dispersão de gotas, para o sistema, benzeno-tetracloreto de carbono.

Figura 3.4.1.2: Função cumulativa para dispersão de gotas, para o sistema: benzenotetracloreto de carbono.

Figura 3.4.1.3: Valores de v obtidos para o mesmo $\mathrm{F}$ e usados no cálculo da variável de similaridade.

Figura 3.4.1.4: Exemplo dos ajustes $y=\ln (\mathrm{t})$ por $\mathrm{x}=\ln (\mathrm{v})$ e sua extrapolação para vr, para uma distribuição experimental para o sistema: benzeno-tetracloreto de carbono........54

Figura 4.1.1: Esquema do tanque de mistura usado nos estudos de quebra. Fonte: (SATHYAGAL e RAMKRISHNA, 1996).

Figura 4.1.2: Distribuições ao longo do tempo para a dispersão de gotas, para o sistema, benzeno-tetracloreto de carbono. Dados de Sathyagal et al. (1996).

Figura 4.1.3: Distribuição experimental dos ajustes $\operatorname{Ln}(\mathrm{t})$ por $\operatorname{Ln}(\mathrm{v})$, para o sistema: benzeno-tetracloreto de carbono.

Figura 4.1.4: Exemplo para um caso em que é possível um ajuste exponencial do comprimento de arco: (a) escala logarítmica, e, (b) escala normal, para o sistema: benzeno-tetracloreto de carbono.

Figura 4.1.5: Sobreposição das distribuições para o caso de dispersão de gotas, para o sistema: benzeno-tetracloreto de carbono, confirmando a auto-similaridade das distribuições

Figura 4.1.6: Função de quebra transacional obtida no trabalho de RAMKRISHNA (2000).

Figura 4.1.7: (a) Comparação entre a taxa de quebra obtida por SATHYAGAL et al. (1995) e a obtida no presente trabalho usando o algoritmo do problema inverso, para o casoestudo 1; (b) Distribuição de partículas filhas obtida no presente trabalho para o casoestudo 1

Figura 4.1.8: Comparação entre: os valores experimentais, e, a simulação do problema direto: (a) distribuição de partículas, e, (b) função cumulativa.................................... 80

Figura 4.2.1: (a) $\operatorname{Ln}(\mathrm{t})$ por $\ln (\mathrm{v})$ dos dados experimentais, e, (b) Comprimento de arco pelo volume, ambos, calculados com os dados experimentais de

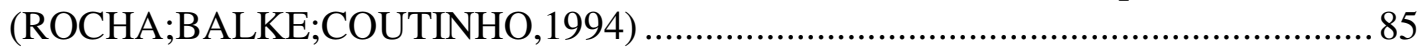


Figura 4.2.2: Sobreposição das curvas de distribuição ao longo do tempo, para a quebra radicalar de cadeias lineares, de polipropileno.

Figura 4.2.3: Comparação dos dados experimentais com as curvas calculadas pelo problema inverso: (a) distribuições diferenciais e (b) funções cumulativas. ................ 87

Figura 4.2.4: (a) Funções de quebra, e, (b) distribuição de partículas filhas obtidas pela solução do problema inverso, para a quebra radicalar de cadeias lineares de polipropileno.

Figura 4.2.5: Valor igual a dois correspondente ao valor, $\mathrm{n}_{\mathrm{i}, \mathrm{k}} \mathrm{b}\left(\mathrm{x}_{\mathrm{k}}\right)=\beta\left(\mathrm{v}, \mathrm{v}^{\prime}\right) v(\mathrm{v}) \Gamma\left(\mathrm{v}^{\prime}\right)=2$, esperado de acordo com a análise das equações de balanço populacional....................90

Figura 4.3.2: (a) Curvas de $\ln \mathrm{t}$ versus $\ln \mathrm{x}$ e (b) curvas de comprimento de arco mostrando a similaridade para o caso de hidrólise ácida de dextrana.

Figura 4.3.3: Teste de distribuição de similaridade das curvas em diferentes tempos, para o caso de hidrólise ácida de dextrana.

Figura 4.3.4: Resultado do problema inverso para (a) a taxa de quebra e (b) para a distribuição de cadeias filhas para o caso de hidrólise ácida de dextrana.................... 94

Figura 4.3.5: Distribuições de massas molares diferenciais e cumulativas medidas (símbolos) e calculadas (curvas) para o processo de hidrólise ácida de dextrana........ 95

Figura 4.3.6: Gráfico do termo $\beta\left(\mathrm{v}^{\prime} \mathrm{v}^{\prime}\right) v(\mathrm{v}) \Gamma\left(\mathrm{v}^{\prime}\right)$, do balanço populacional, obtido pelo problema inverso, pelas distribuições de massa molecular, para hidrolise ácida de dextrana. 96

Figura 4.4.1: Esquema do aparelho utilizado por BALLAUF; WOLF (1984) para estudar a degradação de poliestireno por cisalhamento

Figura 4.4.2: Curvas de $\ln (\mathrm{t})$ versus $\ln (\mathrm{v})$, para a degradação mecânica de poliestireno em meio com a presença de: (a) DPPH, e, (b) oxigênio. 102

Figura 4.4.3: Comprimento de arco para a degradação mecânica de poliestireno, em meio com a presença de: (a) DPPH e,(b) oxigênio.

Figura 4.4.4: Distribuição de similaridade para a degradação mecânica de poliestireno em meio com a presença de: (a) DPPH e (b) oxigênio.

Figura 4.4.5: Distribuições de partículas filhas (a), e, da taxa de quebra (b), nas condições de degradação mecânica de poliestireno em meio com presença de: oxigênio, e, DPPH.

Figura 4.4.6: (a) Distribuições diferencias e (b) funções cumulativas obtidas por meio do problema inverso e medidas experimentalmente, para degradação mecânica de poliestireno, em meio com a presença de DPPH e oxigênio....................................... 106

Figura 4.4.7: Valores de $\beta\left(\mathrm{v}^{\prime} \mathrm{v}^{\prime}\right) v(\mathrm{v}) \Gamma\left(\mathrm{v}^{\prime}\right)$ obtidos pelo problema inverso para a degradação mecânica de poliestireno em meio com a presença de DPPH e oxigênio. 107

Figura 4.4.8: (a) Distribuição de partículas filhas equivalentes e (b) taxas de quebra equivalentes para a degradação mecânica de poliestireno, na presença de oxigênio e DPPH.

Figura 4.4.9: (a) Distribuições diferenciais de pesos moleculares e (b) distribuições cumulativas para a degradação mecânica de poliestireno, na presença de oxigênio e DPPH, para o caso em que se utiliza uma taxa de quebra e uma distribuição de partículas filhas equivalentes.

Figura 4.4.10: Preferência de quebra para a degradação mecânica de poliestireno na presença de oxigênio e de DPPH, para o caso em que se utiliza uma taxa de quebra e uma distribuição de partículas filhas equivalentes obtidas com o uso de funções dinâmicas estimadas por tentativa e erro. 
Figura 4.5.1: Sistema de irradiação de ultra-som (EDERER et al., 1981).

Figura 4.5.3: (a) Curvas de $\ln (\mathrm{t})$ versus $\ln (\mathrm{v})$ e (b) curvas de comprimento de arco para o caso de degradação ultrassônica de dextrana.

Figura 4.5.4: Sobreposição das curvas experimentais, obtidas pela transformação de similaridade, para a degradação ultra-sônica de dextrana.

Figura 4.5.5: Taxas de quebra (a) e distribuição de partículas filhas (b) obtidas para o caso de degradação ultra-sônica de dextrana.

Figura 4.5.6: (a) Distribuições de partículas ao longo do tempo de irradiação, e, (b) funções cumulativas, para o caso de degradação ultra-sônica de dextrana.

Figura 4.5.7: Gráfico de, $\beta\left(v^{\prime}, v^{\prime}\right) v(v) \Gamma\left(v^{\prime}\right)$, que corresponde a um termo existente no cálculo do balanço populacional obtido após solução do problema inverso, para a degradação ultra-sônica de dextrana.

Figura 4.5.8: Distribuição de partículas filhas ajustada manualmente, para a degradação ultrassônica de dextrana.

Figura 4.5.9: (a) Distribuição de pesos moleculares, e, (b) funções cumulativas, após ajuste manual da distribuição de partículas filhas, e, com o uso da taxa de quebra experimental.

Figura 4.4.10: Preferência de quebra esperada quantitativamente, de acordo com estudos experimentais, para a degradação mecânica de poliestireno, na presença de oxigênio, e, DPPH, para o caso em que se utiliza uma taxa de quebra e uma distribuição de partículas filhas equivalentes.

Figura 4.6.3: Cálculo por meio de otimização das (a) distribuições de partículas filhas e (b) taxas de quebra, para degradação mecânica de poliestireno em meio com a presença de oxigênio e de DPPH. 138

Figura 4.6.4: Cálculo por meio de otimização da (a) distribuição de partículas filhas e (b) da taxa de quebra para degradação ultrassônica de dextrana.

Figura 4.6.5: Distribuições obtidas pela otimização para: (a) quebra ultra-sônica de dextrana, e, para (b) degradação mecânica de poliestireno, em meio com a presença de DPPH, e, oxigênio.

Figura 4.6.6: (a) resultados da preferência de quebra para a otimização na degradação ultrassônica de dextrana, e (b) na degradação mecânica de poliestireno, em meio com oxigênio e DPPH.

Figura F.1: Sequiência de solução geral de um balanço populacional................................ 175

Figura F.2: Taxas de quebra utilizadas em um balanço populacional em que a média irá variar. 176

Figura F.3: Resolução do balanço populacional para diferentes taxas de quebra e médias como condições iniciais

Figura F.4: Taxas de quebra para um balanço populacional, em que a distribuição é larga

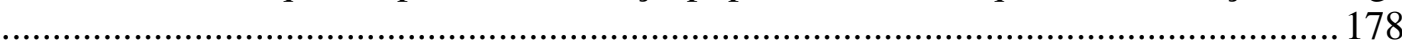

Figura F.5: Distribuições finais diferentes com distribuição inicial larga.......................... 179

Figura F.6: Taxas de quebra para solução de balanço populacional com média em que as taxas apresentam valores semelhantes............................................................ 180

Figura F.7: Distribuições finais próximas com taxas de quebra diferentes..........................181

Figura G.1: Relação entre o Método de Monte Carlo e alguns métodos para sistemas particulados

Figura G.2: Processo de transferência de cadeia para polímero, levando a uma quebra de cadeia longa e a uma cisão de cadeia.FONTE: (TOBITA,2000) 
Figura G.3: Número de possíveis pontos de cisão obtidos, de um polímero, cujo GP é 12. Tendo 2 quebras. Ocorridas pela quebra, de uma molécula polimérica, cujo GP é 14. $\mathrm{E}$, tendo dois possíveis pontos de quebra. O número de possíveis pontos de cisão muda de 0 para 4 dependendo da estrutura do polímero. FONTE: (TOBITA,2000)........... 185

Figura G.4: Exemplo esquemático de uma molécula de polímero formada em polimerização por radical livre que envolve reação de cisão aleatória. A molécula polimérica escolhida é encontrada por segmentos baseados nos níveis de conversão inicial. FONTE: (TOBITA,2000).

Figura G.5 Funcionamento do método de Monte Carlo ...................................................... 194

Figura G.5: Simulação de Monte Carlo e comparação com os momentos para o caso,

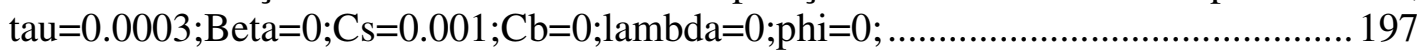

Figura G.6: Simulação de Monte Carlo e comparação com os momentos, para o caso

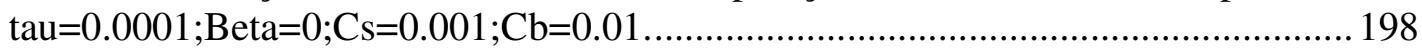

Figura G.7 Simulação de Monte Carlo e comparação com os momentos para o caso tau $=0.0005 ; \mathrm{Beta}=0 ; \mathrm{Cs}=0.001 ; \mathrm{Cb}=0.01 ;$ lambda $=0.2$; 199

Figura G.8: Comparação dos dados experimentais com as curvas calculadas pelo problema inverso: (a) distribuições diferenciais e (b) funções cumulativas................................2203

Figura H.1: Metodologia para a obtenção da quebra e das matrizes de seleção por otimização direta. FONTE:(BERTHIAUX;DOODS, 1997)......................................206

Figura H.2: Determinação da quebra e dos parâmetros de seleção para o método de diferenciação seqüiencial. FONTE:(BERTHIAUX;DOODS,1997). 


\section{ÍNDICE DE TABELAS.}

Tabela 1: Taxas de quebra e distribuições de partículas filhas encontradas por diversos

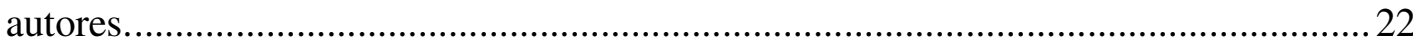

Tabela 2: Distribuições experimentais utilizadas para o cálculo do problema inverso.........70

Tabela 3: Propriedades físicas do liquido usado no experimento de quebra da figura 3.4.173 


\section{NOMENCLATURA.}

$\mathrm{B}\left(\mathrm{v}, \mathrm{v}^{\prime}\right)$ - distribuição de quebra cumulativa, $1 / \mathrm{cm}^{3}$

PD - polidispersidade apresentada na equação (3.1.13).

d- diâmetro de partícula, $\mu \mathrm{m}$

$\mathrm{f}_{\mathrm{r}}$ - Fração do número de gotas com volume entre $\mathrm{v}$ e $\mathrm{v}+\mathrm{dv}$

f - Função de distribuição cumulativa de similaridade.

$\mathrm{F}(\mathrm{v}, \mathrm{t})$ - Função cumulativa da distribuição.

FM - Fração mássica definida no APÊNDICE D na equação (D.28), \% mássica.

f' - Função de densidade de distribuição de similaridade ou derivada de f.

G,g -Função de distribuição das partículas filhas definidos na equação (3.3.2), $\mathrm{s}^{-1}$.

Gamma - função gama

$\mathrm{h}$ - tamanho do parâmetro de normalização, apresentada abaixo da figura (1.2.1).

$\mathrm{i}_{\max }$ - número total de elementos discretizados em elementos finitos existentes.

J - Polinômio de Jacobi detalhado na equação (3.4.2.18) e (3.4.2.19).

$\mathrm{K}$ - função multiplicativa da taxa de quebra.

$\mathrm{L}_{2}$-espaço vetorial de funções estritamente monotônicas definido abaixo da equação

$\ln$ - logaritmo neperiano.

$\log$ - logaritmo natural.

$\mathrm{M}_{\mathrm{w}}$ - momento de ordem $\mathrm{w}$

$\mathrm{M}$ - subespaço vetorial de $\mathrm{L}_{2}$ definido abaixo da equação (3.4.2.28)

MM - Média mássica apresentada conforme a equação (3.1.12).

MN - Média numérica apresentada conforme a equação (3.1.11).

$\mathrm{N}_{\mathrm{i}}$ - número de partículas em determinada classe discretizada $\mathrm{i}$.

$\mathrm{n}(\mathrm{v}, \mathrm{t})$ - distribuição de partículas, densidade de probabilidade volumétrica , $1 / \mathrm{cm}^{3}$

$\mathrm{n}_{\mathrm{b}}$ - número de funções bases da equação (3.4.2.16).

$\mathrm{n}_{\mathrm{i}, \mathrm{k}}$ - coeficientes de redistribuição no método de discretização por pivôs fixos de (KUMAR;RAMKRISHNA,1996)

$\mathrm{p}(\mathrm{v}, \mathrm{t})$ - número de partículas, número médio por unidade de volume, $1 / \mathrm{cm}^{3}$.

s - comprimento de arco para mudança de variável como descrito na equação (3.4.1.1)

$\mathrm{t}$-tempo, s 
v,v' - volume de uma partícula, $\mathrm{cm}^{3}$.

$\mathrm{x}$ - função que usa o volume de duas partículas $\Gamma(\mathrm{v}) / \Gamma\left(\mathrm{v}^{\prime}\right)$, como definido na equação (3.3.2), adimensional.

$\mathrm{x}_{\mathrm{i},} \mathrm{x}_{\mathrm{k}},-$ pivô de determinada classe de partículas

x1- igual a $\operatorname{Ln}(v)$ como definido na equação (3.4.1.1), adimensional.

$X$-função inserida, para otimização da função objetivo, e descrita na equação (3.4.2.24)

w - número inteiro $1,2,3 \ldots$

wj -parâmetro de peso do polinômio de Jacobi apresentado acima da equação (3.4.2.18).

$\mathrm{z}$ - transformação de similaridade apresentada como exemplo abaixo da equação (3.4.1.16)

\section{Letras Gregas}

$\alpha$ - índice que caracteriza o polinômio de Jacobi nas equações (3.4.2.18) e (3.4.2.19).

$\beta\left(v, v^{\prime}\right)$ - função densidade de probabilidade, probabilidade de formação de partículas de volume $\mathrm{v}$ pela quebra de partículas de volume $\mathrm{v}^{\prime}$.

$\beta a$ - índice que caracteriza o polinômio de Jacobi nas equações (3.4.2.18) e (3.4.2.19).

$\Gamma(v) \quad$ - taxa de quebra independente do tempo, fração de partículas de volume v

quebrando por unidade de tempo, $\mathrm{s}^{-1}$.

$\gamma$ - constante relacionada à taxa de quebra conforme equação (3.4.8).

$\gamma_{c}$-Função gama incompleta

$\delta$ - função delta de Dirac.

$\delta_{\mathrm{i}, \mathrm{k}}$ - função delta de Kronecker

$\lambda_{\text {reg }}$ - parâmetro de regularização.

$\mu$-média

v - número médio de partículas provenientes da quebra de partículas pais.

$v\left(v^{\prime}\right)$ - o número de partículas filhas formadas pela quebra de partículas de volume v',

$1 / \mathrm{cm}^{3}$

$\xi$ - Variável de similaridade, s.

$\xi f^{\prime}(\xi)$ - Distribuição de similaridade, s.

$\sigma$ - desvio padrão

$\phi$ - Função para minimização na equação (3.4.2.28) dentro da função objetivo. 
$\Psi$ - grau de homogeneidade apresentado abaixo da figura (1.2.1).

\section{Símbolos}

II II - indica norma conforme explicado abaixo da equação (3.4.2.27).

\section{Sobrescrito}

d - função escrita em termos do diâmetro das partículas.

$\mathrm{T}$ - transposto de uma matriz.

' - derivada de primeira ordem.

\section{Subescrito}

$\mathrm{i}, \mathrm{j}, \mathrm{k}$ - índices relacionados a discretização em classes.

max - tamanho máximo

$\mathrm{r}$ - indica propriedade de referência

t - indica o total de certa propriedade em certo domínio.

$\mathrm{s}$ - estabilidade de determinada propriedade como tamanho de partículas

tipo 1, tipo 2 - tipo de norma que se utiliza como definido abaixo da equação (3.4.2.27).

$\mathrm{w}$-ordem dos momentos, das constantes, ou, da taxa de quebra.

0 - no instante inicial

2 - designa funções estritamente monotônicas em um espaço vetorial

\section{Siglas}

DSS - Dodecil Sulfato de Sódio

L-M - Levenberg - Marquadt

DPPH - 2,2-difenil-1-picrilhidrazil

$\mathrm{O} 2$ - Oxigênio

MC - Monte Carlo

GP - Grau de Polimerização

FDC - Fluído Dinâmica Computacional

EDO - Equações diferenciais ordinárias 


\section{AGRADECIMENTOS.}

Agradeço, primeiramente, ao Divino Pai Eterno, pela oportunidade.

Agradeço ao Prof. Reinaldo Giudici pelos esclarecimentos.

A CAPES pela bolsa concedida.

Aos amigos do LSCP, pela ajuda durante a elaboração desta tese. 
Sobre o ombro de gigantes

(Isaac Newton) 


\section{RESUMO.}

Algoritmos computacionais e análise matemática têm sido grandes aliados na determinação de informação quantitativa extraída de observações experimentais. No presente trabalho, estudou-se a aplicação da metodologia do problema inverso em balanço populacional que descreve como varia a distribuição de tamanhos de moléculas poliméricas durante diferentes processos de degradação de polímeros. A evolução da distribuição durante o processo de quebra pode ser descrita matematicamente por equação de balanço populacional. No assim chamado problema inverso, as distribuições medidas experimentalmente são usadas para estimar os parâmetros do balanço populacional que descrevem, por exemplo, como as taxas de quebra variam ao longo do comprimento da cadeia e como variam com o tamanho da cadeia. Este problema inverso é conhecido por seu intrínseco mal condicionamento numérico. Um algoritmo previamente desenvolvido na literatura para problemas de quebra de gotas em emulsões líquidas, baseado no conceito de auto-similaridade das distribuições, foi adaptado e aplicado no presente trabalho para o problema de quebra de cadeias poliméricas durante a degradação do polímero. Dados experimentais de diferentes processos de degradação, obtidos da literatura, foram testados: degradação de polipropileno por radicais livres gerados por peróxidos, degradação de dextrana por hidrólise ácida, degradação ultra-sônica de dextrana, degradação mecânica por cisalhamento de poliestireno, degradação enzimática de guar, e degradação ultrassônica de guar. As distribuições de taxa de quebra obtidas para os diferentes sistemas foram analisadas e interpretadas em termos das particularidades e do mecanismo de cada tipo de processo de degradação, visando um melhor entendimento fundamental dos processos.

Palavras-chave: taxa de quebra, balanço populacional, problema inverso, polímeros, modelagem. 


\begin{abstract}
.
Computational algorithms are used to obtain quantitative information from experimental observations. The aim of the present work was the application of the methodology of inverse problem in population balance used to describe the evolution of the chain length distribution in different polymer degradation processes. The time evolution of the chain length distribution during the polymer breakage can be mathematically described by a population balance equation.

In the so-called inverse problem, experimentally measured distributions are used to estimate the parameters of the population balance, such as the distribution of breakage rate along the chain and as function of the chain length. The inverse problem is known to be an ill-conditioned numerical problem. An algorithm previously developed in the literature for liquid droplet breakage in liquid emulsions, based on the concept of self-similarity of the distributions, was adapted and applied in the present work for the problem of polymer scission during polymer degradation.

Experimental data of degradation of different polymers were taken from the literature and used to test the procedure: free-radical degradation of polypropylene acid hydrolysis of dextran, ultrasonic degradation of dextran, shear-induced mechanical degradation of polystyrene, enzymatic hydrolysis of guar; and ultrasonic degradation of guar. The breakage rate distribution obtained for the different systems were analyzed and interpreted in terms of the particularities and chemical mechanisms involved in the different degradation processes, aiming at a better understanding of the fundamentals governing the processes.
\end{abstract}

Keywords: breakage kernel, population balances, inverse problem, polymers, modeling 


\section{INTRODUÇÃO.}

A equação de balanço populacional é uma ferramenta largamente empregada para descrever variações de propriedades de uma população de elementos. Tais elementos podem ser, por exemplo, partículas em um sistema particulado, moléculas de polímero em sistemas de polimerização, células de microorganismos em processos fermentativos. As propriedades distribuídas nos elementos da população podem ser, por exemplo, o tamanho (volume) das partículas, o tamanho (grau de polimerização) das cadeias poliméricas, a idade das células de microorganismos, etc.. O balanço populacional também pode ser empregado para descrever mais de uma propriedade (variável), embora sua utilização mais usual seja a de descrever uma propriedade apenas.

A solução de equação de balanço populacional permite obter como a propriedade (ou variável interna) varia dentro da população ao longo do tempo em função das condições de operação do processo em estudo. Para isso, é necessário conhecer as características dos eventos ou fenômenos que ocorrem no sistema, que possam modificar a distribuição. Usualmente, estes fenômenos são a nucleação (formação de novos elementos), o crescimento (como o valor da propriedade de um dado elemento ou partícula varia), a quebra (evento em que um elemento se divide formando outros elementos com valor diferente da propriedade) e a coalescência (dois elementos/partículas se juntam formando um único elemento com propriedade igual à soma das propriedades dos elementos originais).

O assim chamado problema direto consiste efetivamente na solução da equação do balanço populacional, a partir da distribuição inicial e das características conhecidas dos fenômenos envolvidos (as taxas de nucleação, crescimento, quebra e coalescência). Como a equação de balanço populacional é usualmente uma equação do tipo integro-diferencial parcial, matematicamente complicada, é frequentemente necessário utilizar métodos numéricos para sua solução.

Já no chamado problema inverso, objetiva-se determinar as taxas dos fenômenos envolvidos a partir das medidas experimentais das distribuições ao longo do processo em estudo. O problema inverso é, portanto, basicamente, um problema de estimação de parâmetros. A dificuldade neste caso, é que os parâmetros não, em princípio, são valores constantes, mas sim funções distribuídas (valores diferentes para cada valor da 
propriedade). Além disso, este problema inverso é usualmente um problema mal condicionado (respostas muito sensíveis a pequenas variações nos dados de entrada).

No presente trabalho estudou-se o procedimento de solução do problema inverso do balanço populacional do problema de quebra, exclusivamente (problemas sem nucleação, sem crescimento e sem coalescência), através do uso de um algoritmo descrito na literatura, o qual é baseado no conceito de autossimilaridade das distribuições As aplicações estudadas foram voltadas principalmente à degradação de polímeros por diferentes tipos de processos. Com este procedimento de problema inverso, foram obtidas as funções de quebra para estes diferentes processos de degradação de polímeros, buscando um melhor entendimento de como o tipo de processo afeta a quebra das cadeias poliméricas.

\subsection{Equacionamento do Balanço Populacional.}

A equação de balanço populacional (BP) descreve o comportamento (isto é, as variações) de uma (ou mais) propriedade(s) de uma população de elementos. Pode ser aplicada para uma ou mais propriedades, contínuas ou discretas. A forma usual de emprego do BP é a descrição do número de partículas de tamanho $d$ ao longo do tempo, $0 \leq \mathrm{t}<\infty$, por meio da síntese do comportamento de partículas individuais, e deve seguir logicamente a equação geral (1.1.1).

$\left[\begin{array}{l}\text { Mudança no } \\ \text { número de partículas } \\ \text { de tamanho d por } \\ \text { unidade de tempo no } \\ \text { volume de controle }\end{array}\right]=\left[\begin{array}{l}\text { Taxa de partículas } \\ \text { de tamanho d } \\ \text { entrando no volume } \\ \text { de controle }\end{array}\right]-\left[\begin{array}{l}\text { Taxa de partículas } \\ d e \text { tamanho } d \\ \text { saindo do volume } \\ \text { de controle }\end{array}\right]+\left[\begin{array}{l}\text { Taxa de geração } \\ \text { de partículas de } \\ \text { tamanho d dentro } \\ \text { do volume de controle }\end{array}\right]$

Ao tentar encontrar o comportamento individual de partículas é importante frisar o quão restrito essa solução pode ser, quando incorporada aos parâmetros da população total, já que existem diferenças no comportamento de partículas individuais e daquelas reais. As reais estão sujeitas não só aos efeitos das outras partículas, mas também do sistema em que estão inseridas, em geral. Além disso, os rearranjos internos da população de partículas podem resultar em uma variedade grande de comportamentos. Com frequiência, resultam nas mudanças da forma da distribuição, na medida em que o tempo avança, resultando às vezes em distribuições mais complexas ou multimodais. Uma distribuição de partículas 
muda muito dependendo do seu tamanho, resultando em variações significativas em relação ao estado inicial. O desempenho geral dos fenômenos de transporte em um sistema pode depender da distribuição das partículas; portanto o sistema é também afetado tanto pela mistura inicial quanto pelo curso das reações, como explicado no trabalho de RAMKRISHNA; NARSIMHAM; SATHYAGAL (1995).

A abordagem do balanço populacional nos fornece um método conveniente para descrever um sistema com distribuições de partículas em estado transiente. Existem descrições para diversos sistemas e configurações de equipamentos, como os químicos ou os bioquímicos, como mostram DUDUKOVIK; LARACHI; MILLS (1999), nas colunas, de dispersão líquido-líquido pesquisada por ATTARAKIH; BART; FAQIR (2004), e nos tanques agitados, como no trabalho de CHATZI; GAVRIELIDES; KIPARISSIDES (1989). Nestes estudos têm se observado que, para um tempos longos $(t \rightarrow \infty)$, a distribuição atinge o estado estacionário sem ocorrer mais mudanças. Para uma fragmentação binária, dois fragmentos por partículas, a restrição acima é simplificada. Sendo equivalente a uma taxa simétrica como, $\beta\left(\mathrm{v}, \mathrm{v}^{\prime}\right)=\beta\left(\mathrm{v}^{\mathrm{v}} \mathrm{v}^{\prime}, \mathrm{v}^{\prime}\right)$.

Uma expressão para a taxa, em que as partículas de tamanho v são formadas devido à quebra, pode ser deduzida para um caso simples de quebra binária:

$2\left(\begin{array}{l}\text { Taxa em que } \\ \text { partículas de tamanho } \\ v^{\prime} \text { se quebram }\end{array}\right)=\left(\begin{array}{l}\text { Taxa em que partículas } \\ \text { são formadas provenientes } \\ \text { da quebra de uma partícula } \\ \text { até o tamanho } v^{\prime}\end{array}\right)$

A taxa de geração de partículas de tamanho v é igual à soma de todos os tamanhos maiores que $\mathrm{v}$, visto que, partículas menores são formadas pela quebra, de partículas maiores: 


$$
\begin{aligned}
\left(\begin{array}{l}
\text { Taxa de geração } \\
\text { de partículas de tamanho } \\
v
\end{array}\right) & =\sum_{v^{\prime} \geq v}\left(\begin{array}{l}
\text { Fração de partículas de } \\
\text { tamanho } v^{\prime} \text { que quebram } \\
\text { até um tamanho entre } v \\
e v+d v
\end{array}\right)\left(\begin{array}{l}
\text { Taxa em que } \\
\text { as partículas são } \\
\text { formadas pela } \\
\text { quebra de } v^{\prime}
\end{array}\right) \\
& \left.=\sum_{v^{\prime}=v}^{v_{\max }} \beta\left(v, v^{\prime}\right) v\left(v^{\prime}\right)\left[\begin{array}{l}
\text { Taxa que uma } \\
\text { partícula de tamanho } \\
v^{\prime} \text { quebra }
\end{array}\right)\right] \\
& =\int_{v}^{v_{\max }} \beta\left(v, v^{\prime}\right) v\left(v^{\prime}\right) d v^{\prime} \Gamma(n) n(v, t)
\end{aligned}
$$

Com as equações (1.1.2) e (1.1.3), podemos escrever um balanço populacional de quebra em (1.1.5) ou, de outro modo, uma formulação para o caso da quebra dominante, como descrito por PATRUNO et al. (2009). Este balanço só será apresentado mais adiante, após outras considerações.

Os métodos de diferença finita no domínio das partículas são usados com muita freqüência na literatura para a discretização, como nos ensina RIBEIRO et al. (1995). Recentemente para a solução do BP foi desenvolvido no trabalho de HAGESAETHER; JAKOBSEN; SVENDSEN (2002) um método alternativo. Neste método, também é permitido a discretização espacial em diversas secções. Este método, porém, não será abordado no presente trabalho.

De acordo com o trabalho de KUMAR; RAMKRISHNA (1996), a distribuição pode ser representada por uma soma de partículas discretas $\mathrm{v}_{\mathrm{i}}$, com concentração numérica $\mathrm{N}_{\mathrm{i}}$, $\left(\mathrm{i}=1,2,3, \ldots, \mathrm{i}_{\max }\right), \mathrm{ou}$, matematicamente:

$$
n(v, t)=\sum_{i=1}^{i_{\max }} N_{i}(t) \delta\left(x-x_{i}\right)
$$

Dessa forma, a função de quebra também será discretizada, e resultando em $\beta\left(\mathrm{v}_{\mathrm{i}}, \mathrm{v}_{\mathrm{j}}\right)$. $\mathrm{O}$ domínio $\left[\mathrm{V}_{\min }, \mathrm{V}_{\max }\right]$ pode ser discretizado uniformemente com espaçamento dado por $\left(\mathrm{v}_{\max }-\mathrm{v}_{\min }\right) / \mathrm{L}\left(\mathrm{i}=1,2,3 \ldots ., \mathrm{i}_{\max }\right)$ ou não. Um exemplo de espaçamento diferente do uniforme, que poderia ser utilizado, seria o espaçamento geométrico, $2^{\text {(i-imax)/rg }}$, onde rg é a razão geométrica, um número positivo e inteiro.

O sucesso no uso das equações fundamentais de balanço populacional para predizer quantitativamente a distribuição de partículas em um sistema em que a quebra é dominante requer duas funções chave: a taxa de quebra que corresponde a um valor para cada volume 
de partícula, e a distribuição cumulativa de partículas filhas proveniente de uma quebra de uma partícula de determinado volume. Essas funções podem ser fenomenológicas, parametrizadas, ou discretizadas: Esta última, muitas vezes é função da taxa de quebra, e em geral o problema se simplifica, sendo necessária a obtenção apenas da taxa de quebra de partículas em um sistema onde a quebra é dominante.

O termo comportamento de partículas se refere à taxa em que certos eventos, como a quebra de partículas, são descritos sem a perda de suas características fundamentais, resultando na destruição de determinadas partículas, com certo tamanho e com mudanças contínuas no estado das partículas. Esses fenômenos de quebra devem ter um equacionamento diferente, dependendo de suas características; em determinado sistema, por exemplo, em reatores de combustão, de leito fluidizado, etc.... A quebra, durante a queima de partículas isoladas acaba influindo em todas as outras partículas e na distribuição como um todo, como nos ensina SUNDBACK; BEER; SAROFIN (1984). Portanto, o sistema e as partículas envolvidas podem modificar as funções dinâmicas envolvidas no equacionamento.

A idéia geral de examinarmos e entendermos diretamente o comportamento das partículas é muito intuitiva, mas não é possível, nem viável. Isto acontece porque parece não ser viável, em muitos casos, medir todos os tipos de interação, quando ocorrem e, em que tipo de partículas, embora seja uma abordagem bastante intuitiva para partículas em sistemas em que existam muitos fatores que gerem suas interações. Portanto, sendo assim, a observação direta, partícula por partícula, uma abordagem muito complexa, é, muitas vezes, impraticável.

Em outros trabalhos (p.ex., GELBARD ,1982; GELBARD;PETERSON, 1985 apud PETERSON,1986) foram negligenciados os termos que não pertençam à quebra de partículas. O crescimento de partículas ocorre quando em um reator com polímeros na reação de polimerização, ou com células em crescimento, as partículas/elementos aumentam de tamanho. A nucleação é o surgimento de novas partículas de determinado tamanho, muito comum de ocorrer em processos de polimerização e de cristalização. A entrada e a saída de partículas, quando não estamos trabalhando em um reator, batelada, mas com um reator contínuo ou semi-contínuo em que existe um fluxo de entrada e/ou de saída de partículas, ou ambos. O termo de coalescência corresponde, em uma dispersão de 
gotas, quando duas partículas se unem para formar uma única com a soma dos respectivos volumes das partículas originais. Mais detalhes sobre todos os termos do balanço populacional podem ser encontrados nos trabalhos de RAMKRISHNA (2000) e QAMAR; WARNECKE (2007).

No presente trabalho, todos os termos que não pertençam ao fenômeno de quebra serão anulados. Portanto teremos uma equação com menor número de termos, como a descrita em (1.1.5):

$$
\begin{aligned}
& \frac{\partial n(v, t)}{\partial t}
\end{aligned}
$$

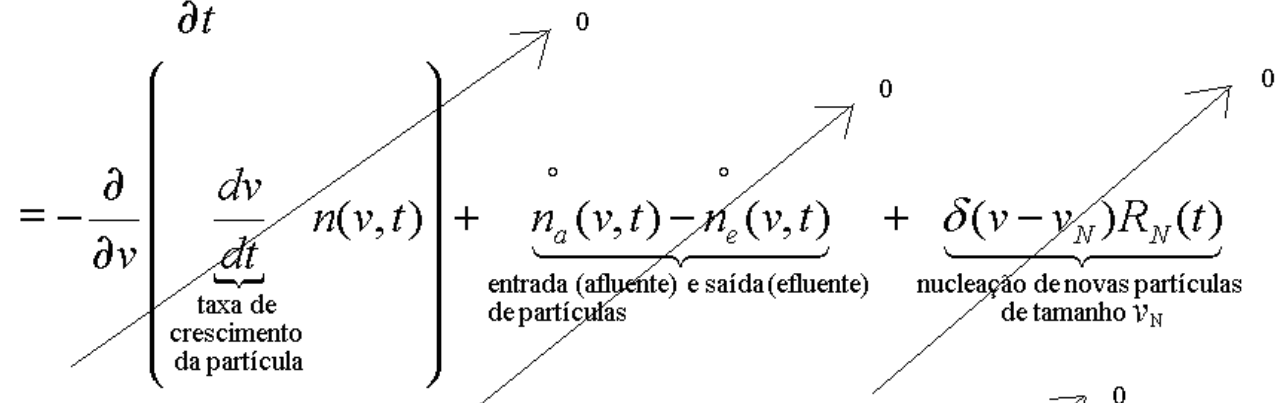

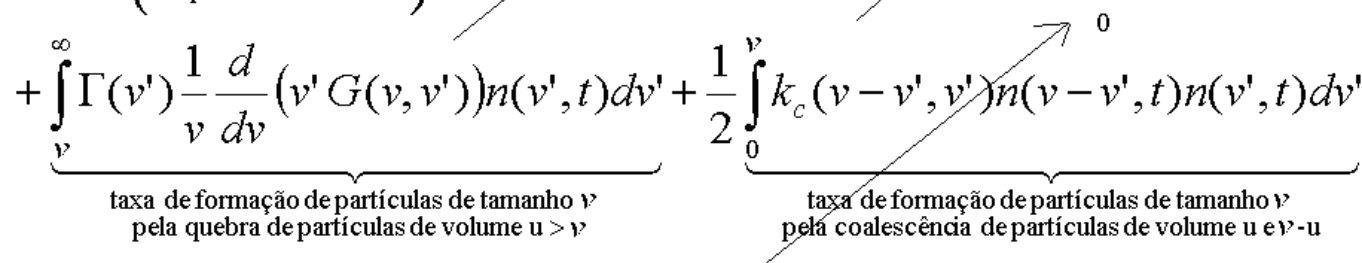

$$
\begin{aligned}
& -\underbrace{n(v, t) \Gamma(v)}_{\begin{array}{c}
\text { taxa de consumode partículas } \\
\text { de volume } v \text { pela quebra }
\end{array}} \\
& -\underbrace{n(v, t) \int_{0}^{\infty} k_{c}\left(v, v^{\prime}\right) n\left(v^{\prime}, t\right) d v^{\prime}}_{\begin{array}{c}
\text { taxa de consumode partículas de volume } v \\
\text { pela coalescêncá com partículas de volume u qualquer }
\end{array}}
\end{aligned}
$$

Note, na equação (1.1.5), que os termos de quebra são baseados em (1.1.2) e (1.1.3). A equação (1.1.5) pode ser adimensionalizada, e detalhes desse cálculo são apresentados no APÊNDICE A.

\subsection{Taxa de quebra, e, distribuição de partículas filhas.}

O processo de quebra de material particulado é importante em muitas operações unitárias encontradas em processos químicos (RUMSCHEIDT; MASON, 1962 ; STONE; LEAL, 1989; TJAHJADI; STONE; OTTINO,1992). Alguns, exemplos, incluem, o transporte gás-líquido e líquido-líquido de dispersões. A quebra ocorre normalmente em escoamento turbulento. Nesta situação a turbulência local força e é responsável pela quebra, 
a qual varia com a posição e com o tempo. O escoamento em estado estacionário padrão é complexo, com diversidade espacial em diversas propriedades do escoamento. Isso pode levar a uma dependência espacial da quebra, que faz com que a sua solução do balanço populacional seja mais difícil. Em alguns casos, a dependência com a temperatura também é bem evidente, como na degradação de polímeros. A degradação de polímeros, que é um fenômeno também de quebra, possui dentre todos os seus possíveis usos, por exemplo, a reciclagem de lixos plásticos..

Em geral, o entendimento quantitativo da quebra de partículas é necessário para o controle da evolução do tamanho de partículas. Neste trabalho, o foco será em fenômenos de quebra de partículas, assim como foi realizado também por RAMKRISHNA; NARSIMHAM; SATHYAGAL (1996).

Neste trabalho, o objetivo é investigar aproximações para as funções: taxa de quebra, $\Gamma(\mathrm{v})$, e, distribuição de partículas filhas, $\mathrm{g}(\mathrm{x})$.

As taxas de quebra, alternativamente chamadas de fragmentação ou, em algumas literaturas, de função de seleção, se dividem nas seguintes: podem ser fenomenológicas ou podem ser algorítmicas. As taxas fenomenológicas são baseadas em modelos físicoquímicos. Portanto, não incluem parâmetros desconhecidos para ajuste. Embora, em muitos casos até as taxas fenomenológicas em geral dependam de parâmetros, inclusive, aquelas deduzidas de maneira exclusivamente teórica. Como por exemplo, as taxas derivadas da primeira tentativa de se deduzir uma taxa conhecida teórica, que foi proposta por BENNETT (1936) e BENNET; BROWN; CRONE (1941), apud AUSTIN (1971). Podemos verificar seus detalhes históricos no APÊNDICE E deste texto. Nelas, portanto, apenas os parâmetros físico-químicos do sistema são necessários. Já as taxas algorítmicas são famílias de funções parametrizadas. Elas são consideradas de forma a incluir, apenas, valores próximos da função verdadeira. Mas, também, podem ser uma função simplesmente discretizada em classes, sendo que cada classe pode assumir um valor para determinada propriedade. Todos os parâmetros desconhecidos devem ser determinados por ajuste a dados experimentais. O procedimento de ajuste pode ser: por meio da solução direta da quebra e comparação da distribuição teórica com a experimental, ou, pela metodologia do problema inverso. Mas em ambos os casos, mesmo as taxas obtidas por métodos de regressão como o problema inverso, devem obedecer a regras fenomenológicas básicas para 
sistemas conhecidos; por exemplo, o fato de que a quebra de volumes grandes é mais favorecida que a quebra de partículas de volumes próximos de zero, ou pequenos.

São raros, para as taxas de fragmentação, casos em que se requer uma taxa não analítica e sim numérica, que descreva esse fenômeno. Muitas taxas já foram descritas ponderando-se, tempo computacional, simplicidade conceitual, e generalidade, como foi proposto por KOSTOGLOU; KARABELAS (2004). O que faz uma taxa ser diferente de outra são os diferentes modos de interação que estão implícitos no modelo.

A taxa de quebra descrita pela função $\Gamma(\mathrm{v})$, junto com a distribuição de partículas filhas $\mathrm{G}\left(\mathrm{v}, \mathrm{v}^{\prime}\right)$. são necessárias para a solução do balanço populacional de quebra. A distribuição de partículas filhas está relacionada com a maneira como as partículas são geradas pela quebra. Em uma quebra binária, por exemplo, a soma dos volumes das partículas resultantes será igual à partícula inicial. Quando a quebra de partículas não é simplesmente uma quebra binária, a função distribuição de partículas filhas descreverá como é a distribuição de tamanhos das partículas formadas pela quebra. Essa característica da distribuição de partículas filhas é exemplificada na figura 1.2.1:

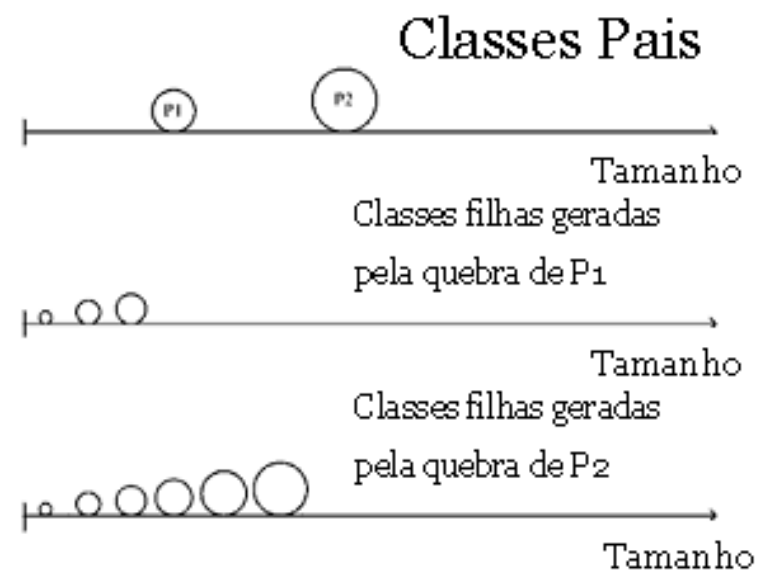

Figura 1.2.1: Exemplo da função distribuição de partículas filhas, para um caso em que a quebra resulta em diversas partículas, provenientes da partícula original quebrada. FONTE: BOVE; SOLBERG; HJERTAGER (2005).

Diferentes formas, com diferentes graus de sofisticação matemática, tem sido criadas e usadas na literatura para descrever as taxas de quebra fenomenológicas. 
Uma classificação usual da taxa ou freqüência de quebra, que é geralmente representada pela letra grega $\Gamma$, é com respeito a sua homogeneidade. Dizemos que são

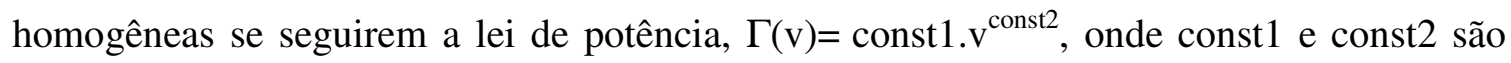
parâmetros constantes. A função de quebra só é homogênea se tiver a forma, $\beta\left(\mathrm{v}, \mathrm{v}^{\prime}\right)=\theta\left(\mathrm{v} / \mathrm{v}^{\prime}\right) / \mathrm{v}$, obedecendo, portanto, a seguinte propriedade, $\beta\left(\mathrm{hv}, \mathrm{hv} \mathrm{v}^{\prime}\right)=\mathrm{h}^{\psi} \beta\left(\mathrm{v}, \mathrm{v}^{\prime}\right)$, onde h é parâmetro de normalização e $\psi$ é chamado de grau de homogeneidade, com $0 \leq \psi<1$ e $\psi=1$ para uma solução perfeita, como nos ensina LUSHNIKOV (1973). Sendo que $\theta$ pode representar uma enorme classe de funções. Essas funções, em princípio, podem descrever as características não lineares da quebra, sem precisarmos nos restringir a uma única forma funcional. Portanto, tipos de funções homogêneas seriam todas aquelas descritas como $\beta\left(\mathrm{v}, \mathrm{v}^{\prime}\right)=\mathrm{v}^{\text {'m }} \theta\left(\mathrm{v} / \mathrm{v}^{\prime}\right)$, como descrito no trabalho de MURALIDHAR; RAMKRISHNA (1989). Isso significa que, com respeito à distribuição de partículas pai, a distribuição de quebra normalizada não é dependente dela, de acordo com PETERSON (1986). Sob estas condições descritas, ou seja, para a taxa de quebra homogênea, todos os momentos atingem assintoticamente o valor, $\mathrm{M}_{\mathrm{w}}(\mathrm{t}) \cong \mathrm{t}^{(1-\mathrm{i}) / \mathrm{b}}$, mas apenas, para uma quebra simples do tipo $\Gamma(\mathrm{v})=\mathrm{Av}^{\mathrm{b}}$.

Outra classificação comum diz respeito à ordem das taxas de quebra em relação ao número de partículas de tamanho $\mathrm{d}$ em um tempo $\mathrm{t}, \mathrm{n}_{\mathrm{d}}(\mathrm{d}, \mathrm{t})$, com uma constante $\mathrm{k}$, reescrevendo de forma geral a taxa de quebra:

$\Gamma(v)=f\left(k, n_{d}(d, t)\right)$

A equação (1.2.1), por exemplo, representaria uma taxa de primeira ordem. Ou seja, a taxa de desaparecimento de partículas de um determina do tamanho, devido à quebra, é proporcional ao número das partículas presentes. Este será o tipo de taxa estudada neste trabalho. Note que é possível adicionar uma restrição de estabilidade, ou seja, caso $d_{s} \geq d$, a taxa seria zero. Isto indicaria que determinado tamanho de partícula $\mathrm{d}_{\mathrm{s}}$ é estável, e ocorreria quebra de primeira ordem caso a partícula fosse instável $d>d_{s}$. Na prática, isso não é necessário, pois a função de ajuste geralmente já se comporta dessa maneira, zerando a taxa de quebra para partículas com baixa chance de se quebrarem. Os valores de $\mathrm{k}$ foram estudados em possíveis relações, nos trabalhos de HESKETH;ETCHELLS, RUSSELL (1991), DELICHATSIOS (1975), DELICHATSIOS; PROBSTEIN (1976), 
COULALOGLOU; TAVLARIDES (1971) e ROSS (1971). Neste trabalho, a dinâmica será sempre de primeira ordem, pois existem indícios de que cinéticas de quebra que não sejam, de primeira ordem possivelmente ocasionem a ausência de similaridade, como nos explica BILGILI (2007).

Muitas correlações generalizadas para a taxa de quebra e para a distribuição de partículas filhas, que levam em conta os efeitos das propriedades físicas e experimentais, podem ser obtidas com a solução do problema inverso.

$\mathrm{O}$ equacionamento das taxas de quebra em um processo de quebra como, por exemplo, a degradação de polímeros, essencialmente determina a evolução da distribuição de tamanhos das moléculas nesse sistema. Algumas expressões, para essas funções, já foram desenvolvidas por VALENTAS; BILOUS; AMUNDSON (1966) e VALENTAS; AMUNDSON (1966), muitas delas fenomenológicas, como as apresentadas por LUO; SVENDSEN (1996).

Em geral existem, com relação ao tempo, três tipos de taxa de quebra em um sistema particulado conforme apresentado na figura 1.2.2 (a), e cinco tipos com relação ao volume, que podemos visualizar na figura 1.2.2 (b).

Neste trabalho iremos estudar apenas as taxas lineares com relação ao tempo $\Gamma(\mathrm{v}, \mathrm{t})=$ $\Gamma(v)$. Portanto, embora elas tenham uma dependência com o volume, são constantes ao longo do tempo. Porém em relação ao volume todas serão crescentes e geralmente não lineares, favorecendo a quebra de grandes partículas ou moléculas, e, limitando a quebra de pequenas. Sendo que, partículas muito pequenas dificilmente se quebram. 
(a) Tipos de taxas de quebra, com relação ao tempo

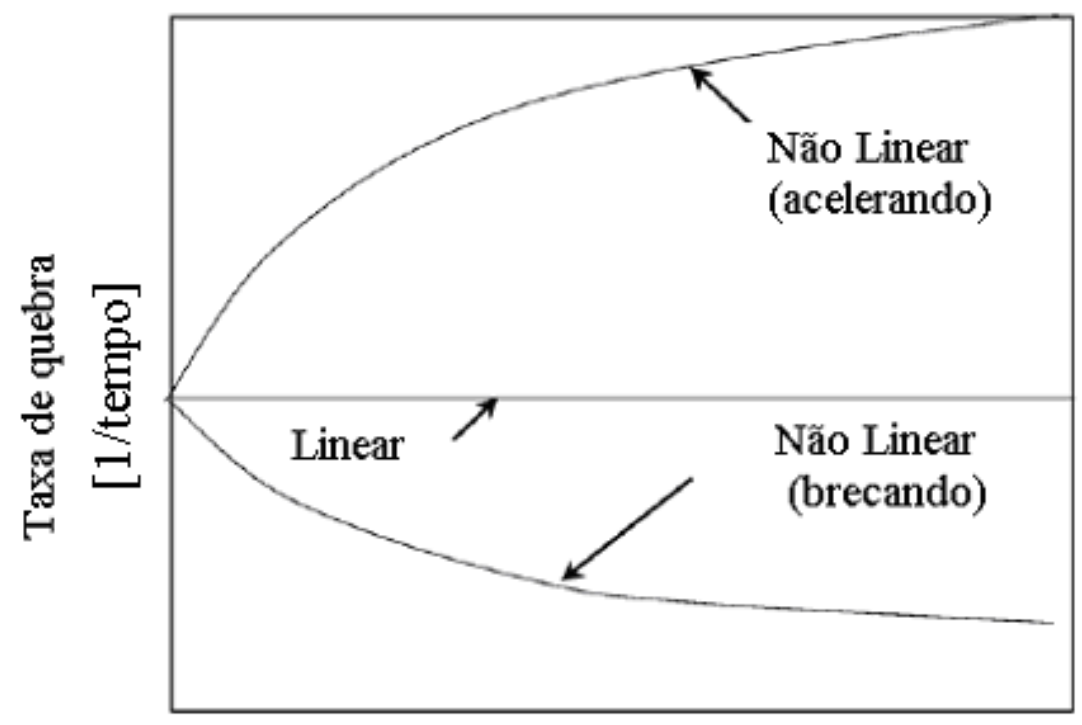

Tempo

(b) Tipos de taxas de quebra, com relação ao volume

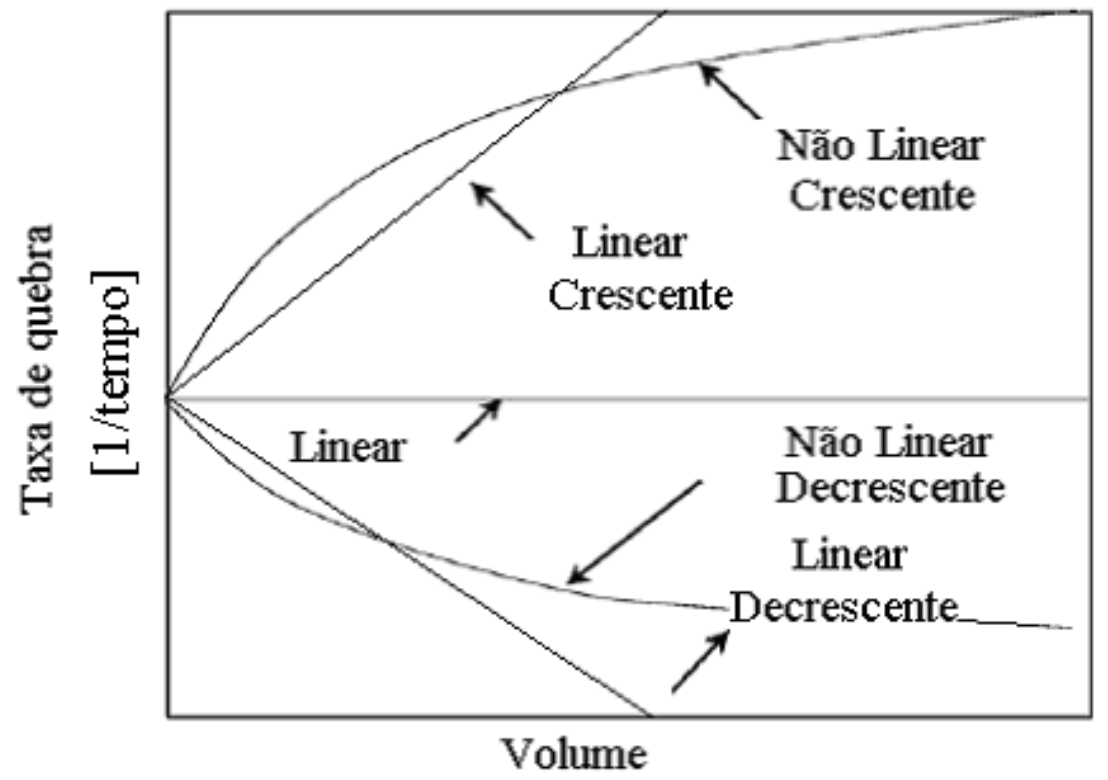

Figura 1.2.2: Tipos de taxa de quebra com relação ao (a) tempo, e com relação ao (b) volume. FONTE: (RAO; DATTA, 2006). 


\subsection{Problema Inverso.}

O problema inverso no balanço populacional é o procedimento para se obter os parâmetros cinéticos envolvidas no balanço populacional, por procedimento similar a uma regressão não linear. Tal procedimento pode ser simplificado, às vezes, como neste trabalho, com o uso de variáveis de similaridade.

Neste trabalho será apresentada uma técnica de solução de problema inverso para o problema de balanço populacional de quebra, baseada no uso de variável de similaridade, que combina, para a sua solução, métodos analíticos e computacionais. Têm como intuito o de extrair informações importantes a partir das medidas experimentais da população. $\mathrm{O}$ modelo apresentado na equação (1.1.5) é baseado na solução assintótica de similaridade, como explicado no APÊNDICE B. Sua simulação resultará em aproximações de dados experimentais, por meio do procedimento de inversão. A resolução de um problema inverso nos fornece uma ferramenta poderosa para se obter a informação quantitativa, proveniente de medidas de distribuições experimentais medidas em estado transiente. Em princípio, é até possível estimar as funções de quebra desconhecidas (taxa de quebra e distribuição de partículas filhas) com base em apenas duas distribuições, medidas em dois instantes de tempo diferentes do processo (RAMKRISHNA; WRIGHT, 1992).

Em alguns casos, já foram propostos modelos para a formulação da inversão de problemas na dinâmica de um balanço populacional mais complexo, por exemplo, em um sistema multidimensional em que existam mudanças nas coordenadas espaciais (ou seja, onde os parâmetros dependem também da coordenada espacial). Um exemplo de estudo deste tipo de problema foi apresentado no trabalho de RAMKRISHNA; MAHONEY (2002), resultando inclusive em taxas dependentes dessas coordenadas internas dentro de um reator.

Por fim, podemos resumir a relação entre o problema direto de BP e o problema inverso de forma simples, como está ilustrado na figura 1.3.1. 


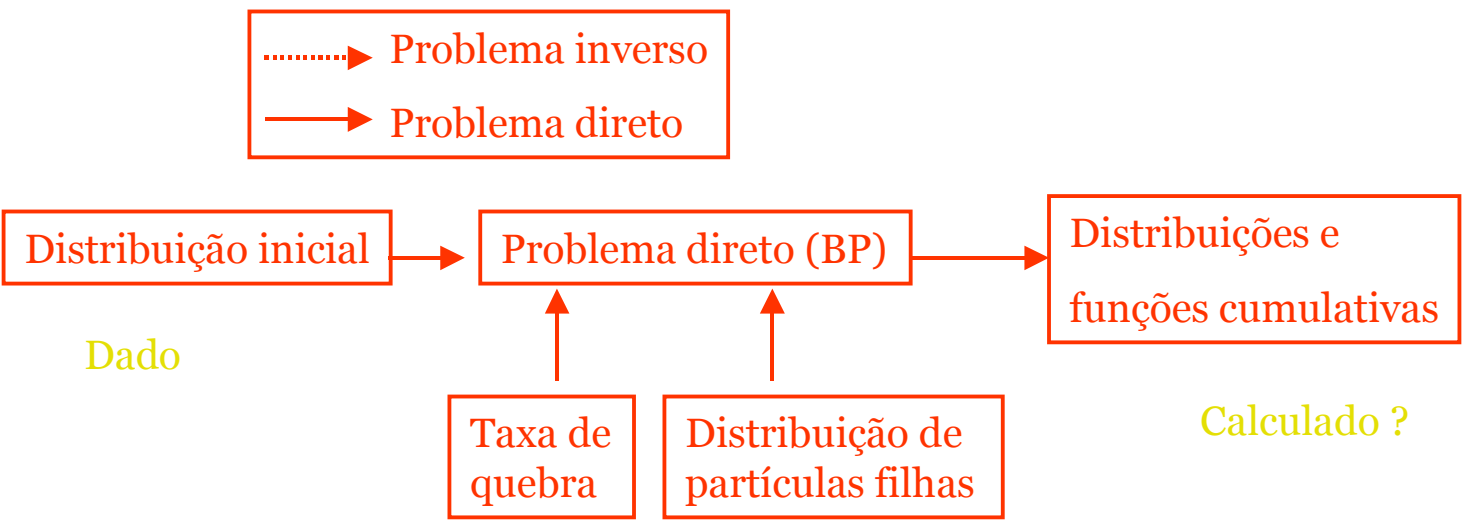

Dado Dado

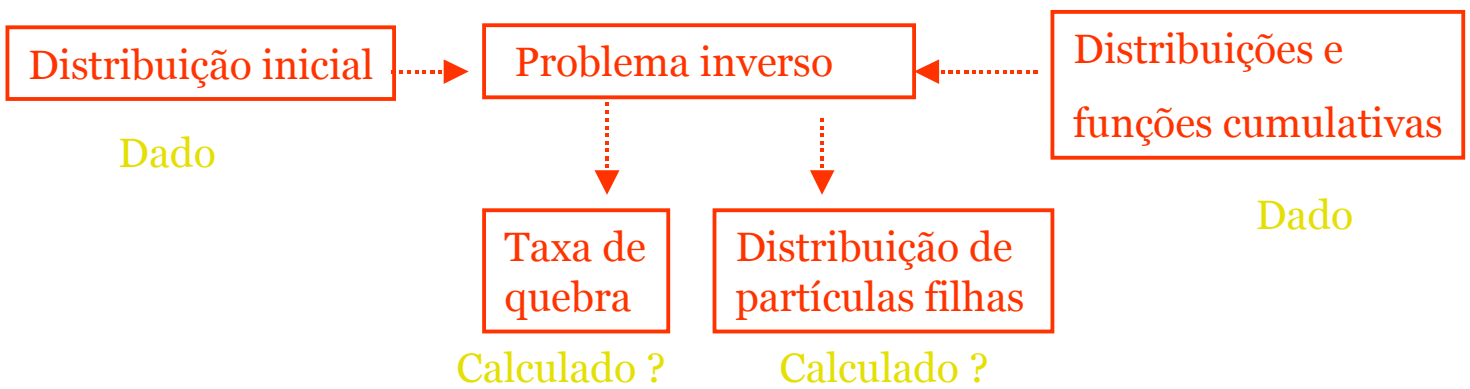

Figura 1.3.1: Mapa conceitual do problema inverso.

O problema inverso, na forma que foi estudado no presente trabalho, utiliza um procedimento baseado na idéia de distribuições auto-similares. Este algoritmo pode ser dividido em três partes: (1) testar a hipótese de similaridade para as distribuições experimentais disponíveis; (2) determinar a taxa de quebra caso o teste de similaridade seja válido; e (3) determinar a distribuição de partículas filhas, por meio da distribuição de similaridade resultante.

\subsection{Variável de Similaridade.}

A formulação do algoritmo de problema inverso usado neste trabalho se baseia, como já mencionado, na idéia de que as distribuições são auto-similares. Para testar se esta hipótese é verdadeira ou não, é necessário converter as distribuições experimentais em termos de uma nova variável, chamada de variável de similaridade. Se as distribuições medidas forem autossimilares, quando transformadas em função da variável de similaridade as diferentes distribuições devem se superpor. (Caso não seja possível obter-se uma 
distribuição única, o problema claramente não apresenta similaridade. Neste caso, pode-se, em princípio, resolver o problema inverso via um procedimento de regressão não linear convencional, porém à custa de um maior esforço computacional).

A abordagem com uso da variável de similaridade na distribuição de partículas deve levar em conta a preservação da "forma" da distribuição de tamanho de partículas. Essa possibilidade já foi notada por FRIEDLANDER (1977) e FRIEDLANDER; WANG (1967) em seus estudos de coalescência browniana em partículas de aerossol. A auto-preservação da distribuição de tamanho de partículas, nome dado por Friedlander como teoria de autopreservação, é também citada na literatura como distribuição auto-similar de tamanhos de partículas, tamanhos com distribuição similar, ou distribuição de partículas escalonada. A evolução da distribuição transiente de tamanhos de partículas é determinada pela hierarquia do produto das equações de densidade volumétrica de partículas, conforme o trabalho de RAMKRISHNA; WRIGTH (1992).

\subsection{O Mal Condicionamento do Problema Inverso}

Uma das questões importantes relativas ao problema inverso é se solução encontrada é única ou não para determinado problema. Ou, em outras palavras, se diferentes funções de quebra e distribuições de filhas (diferentes soluções do problema inverso) poderiam resultar praticamente na mesma distribuição final (como mostrado no trabalho de KOSTOGLOU; KARABELAS, 2005). Quando este tipo de problema ocorre, dizemos que o problema inverso é mal condicionado. Esta dificuldade em geral ocorre em problema inverso de balanço populacional, como mostrado no APÊNDICE F.

\subsection{Estrutura da Tese.}

O texto do presente trabalho está organizado da seguinte forma:

- No capítulo 2 será apresentada uma revisão da literatura sobre o problema inverso em balanço populacional, o uso de variáveis de similaridade e seu mau condicionamento. Além de possíveis usos e aplicações do balanço 
populacional e abordagens alternativas, como por exemplo, a abordagem matricial.

- No capítulo 3 será apresentada, primeiramente, uma introdução das equações básicas de balanço populacional. Depois, a metodologia de cálculo para a obtenção da solução do problema inverso, seu equacionamento geral e sua implementação em ambiente SciLab. Esta apresentação é ilustrada com alguns resultados de testes para verificar a coerência da solução obtida.

- No capítulo 4 serão apresentados os dados experimentais de diferentes casos estudados (dados retirados de trabalhos da literatura de diferentes sistemas de degradação de polímeros), e os resultados da aplicação do problema inverso a estes dados e a interpretação e discussão dos resultados.

- Finalmente, no capítulo 5 são sumarizadas as conclusões deste estudo.

Diversos apêndices são também incluídos no final do trabalho, para ilustrar com mais detalhes alguns pontos específicos do tema em estudo. 


\section{REVISÃO BIBLIOGRÁFICA.}

Neste capitulo são revisados estudos da literatura a respeito do balanço populacional de quebra, do problema inverso e as diversas soluções possíveis para esse problema encontradas na literatura, procurando mostrar o estágio em que se encontra o desenvolvimento desse tipo de problema, os avanços existentes, e o entendimento geral, e as aplicações mais freqüentes para esse tipo de problema já reportadas na literatura.

\subsection{Estudos sobre Soluções da equação de Balanço Populacional.}

O balanço populacional (BP) pode ser solucionado analiticamente em alguns casos, conforme apresentado no APÊNDICE C. Porém, a forma mais usual de resolver a equação de balanço populacional é por métodos numéricos. Neste caso, usualmente a variável interna do BP é discretizada em n pontos ou em $\mathrm{n}$ classes, a a solução (a distribuição de tamanhos) é obtida para este pontos/classes discretas.

No caso do problema envolvendo exclusivamente a quebra, os parâmetros do BP são as funções de degradação, que são duas: a taxa de quebra e a distribuição de partículas filhas. Essas são obtidas pela observação de experimentos, ou pela descrição de mecanismos cinéticos de forma fenomenológica. O balanço populacional foi proposto por volta de 40 anos atrás e é amplamente aceito. Porém, seu uso prático em alguns domínios é extremamente limitado pela dificuldade em encontrar-se as taxas de quebras, ou de se selecionar suas funções, como nos explica EPSTEIN (1948) apud BERTHIAUX; DOODS (1997).

Um número grande de estudos pode ser encontrado sobre diferentes sistemas de degradação de polímeros, como nos trabalhos de STAGGS $(2005,2007)$ que trabalhou com degradação térmica de poli(metacrilato de metila) e em vaporização de polímeros lineares; CLAUDE; UBBINK (2006) descrevem a degradação de polietileno em meios em que se encontram as partículas amorfas; MCCOY; STERLING; WALLINE (2001) estudaram a termólise de poliestireno; MCCOY; MADRAS (1998) estudaram o efeito de doadores de hidrogênio no processo de degradação de polímeros; BOCKHORN et al. (1998) descreveram a degradação térmica de polipropileno e polietileno. Porém em nenhum desses 
estudos foram obtidas medidas da distribuição de tamanhos de cadeisa finais, apenas algumas medidas a respeito da massa molecular média do polímero.

São possíveis, em geral, duas abordagens, para se calcular um balanço populacional: A primeira é a analítica. Já a segunda aceita as definições das taxas de quebra e das funções, relacionadas com a dinâmica do balanço populacional baseado em um incremento diferencial. E usa procedimentos matemáticos padrões para lidar arbitrariamente com as aproximações em diferenças finitas de um equacionamento integral-diferencial fundamental. Entretanto, o uso de intervalos finitos de tempo elimina a vantagem da solução em tempo contínuo, nesse tipo de solução, que não usa o fator importante de que as funções básicas devem ser determinadas experimentalmente. Isso acaba resultando em uma correção necessária de ser feita, no incremento da distribuição de tamanhos diferenciais. E, correções dessa natureza não são simples de serem usadas ou justificadas, como nos ensina REID (1965).

Com respeito ao tratamento feito com relação às variáveis dependentes, no balanço populacional, foram realizadas até hoje duas distintas formulações: a primeira é a diferencial. Essa primeira formulação é baseada na distribuição do número de partículas em densidade de probabilidade, e é semelhante à apresentada por FRIEDLANDER (1977) para a coalescência. A segunda, que é a utilizada, neste trabalho, é a integração. Essa segunda formulação é baseada na fração de volume cumulativo. A respeito dessas duas formulações, apenas PETERSON (1986) utilizou exclusivamente a primeira formulação. Muitos autores apresentam as duas formulações embora apenas usem a segunda, visto que parece mais fácil a qualquer tratamento matemático.

\subsection{Estudos sobre as taxas de quebra e sobre as distribuições de partículas filhas.}

Muitos mecanismos químicos possíveis estão presentes na degradação de polímeros. Geralmente, esses mecanismos incluem uma dependência da estrutura molecular. Nas condições experimentais, a simulação desse processo se torna complexa, pela mistura inicial de polímeros. Essa mistura é de um número grande de moléculas e contém diferentes 
tamanhos, ou pesos moleculares. Além de existir o efeito da temperatura nas constantes cinéticas, que governam esses mecanismos. Quanto aos principais tipos de quebra de cadeia que existem, estão presentes duas possibilidades principais: (1) a degradação aleatória de polímeros, que ocorre em qualquer ponto de uma cadeia polimérica; e (2) a despolimerização, que acontece a partir das extremidades da cadeia de polímeros, gerando, como resultado, os monômeros.

Numerosos estudos têm sido feito sobre quebra de gotas, tanto experimentalmente quanto, computacionalmente, a respeito das funções de quebra, que são a taxa de quebra e a distribuição de partículas filhas. Elas foram estudadas para números baixos de Reynolds e com escoamentos muitos bem definidos pela literatura de mecânica dos fluidos. Exemplos típicos desses tipos de estudos são os trabalhos de RUMSCHEIDT; MASON (1962), STONE; LEAL (1989) e TJAHJADI; STONE; OTTINO (1992). Nesses trabalhos fica demonstrada a complexidade dos fenômenos de quebra, mesmo para os escoamentos muito bem definidos. Estudos têm mostrado que, no escoamento turbulento em um tanque, muitas vezes seu interior pode ser não homogêneo, como apresentado no trabalho de CUTTER (1966). Isso faz com que seja muito difícil de se especificar o perfil de escoamento. E, portanto, torna-se difícil de se usar softwares de mecânica dos fluidos, FDC, para determinar as funções, de quebra, das partículas. Enquanto esses estudos contribuem para termos alguma idéia a respeito da fragmentação de partículas, eles são claramente irrelevantes para alguns sistemas com determinados comportamentos como, por exemplo, a degradação de polímeros.

A quebra ou fragmentação é um fenômeno de grande importância para inúmeras aplicações. Ela é responsável pela distribuição de partículas em dispersões líquido-líquido, bolhas em dispersões gás-líquido, agregados de partículas coloidais em dispersões, sólidolíquido, e o peso molecular no caso da degradação térmica de polímeros, estudada por KOSTOGLOU; KARABELAS (2005).

Para um dado sistema, alguns fenômenos envolvidos na dinâmica das partículas, como nas funções de quebra e de coalescência, podem não ser completamente elucidados. Porém, é possível por meio de algumas medidas experimentais, obtermos as informações quantitativas necessárias para que possamos fazer predições futuras das distribuições, como nos ensina RAMKRISHNA (1973). 
Existem formas de se modelar diretamente as funções de quebra (taxa de quebra e distribuição de partículas filhas). Essas formas já foram estudadas. Sua modelagem é obtida por meio de equações fundamentais para as partículas individuais que estão em determinado meio. Essas funções de quebra para o meio em que se encontram as partículas devem ser suficientes para conseguirmos descrever o fenômeno de quebra, como são as funções do trabalho de KOTOULAS; KIPARISSIDES (2006). Portanto, neste caso, o que se tentou fazer foi obter uma modelagem fenomenológica do problema, que pudesse ser robusta para situações em que se variam diversas propriedades físicas, como a viscosidade, a tensão interfacial, os parâmetros de operação, a velocidade do agitador. Nesta modelagem todos esses parâmetros devem ser levados em conta. Porém, esses modelos apresentam muitas hipóteses simplificadoras a respeito da natureza da quebra e do escoamento. Isso devido à dificuldade da modelagem em situações de escoamento turbulento. E, embora estes modelos sejam condizentes com muitos dados experimentais para determinadas condições de processo, estes modelos não foram testados rigorosamente sob condições mais amplas, de modo que são necessários ajustes para cada situação experimental diferente em que o modelo é aplicado.

Pode-se notar, também, que uma modelagem fenomenológica pode incluir, em alguns casos, a variação da taxa de quebra ao longo do tempo, descrevendo melhor, assim, as mudanças no meio para o caso, em que sejam adicionados novos reagentes. Mas muitas vezes, as funções fenomenológicas também, dependem de se adequar o modelo aos dados experimentais, por meio do ajuste de um ou mais parâmetros, dependendo da robustez do modelo utilizado.

Como explicado por NAMBIAR; KUMAR; GANDHI (1992), muitos desses modelos fenomenológicos com hipóteses, simplificadoras são aproximações unidimensionais. Neles, o intuito é o de capturar apenas as características principais, mais visíveis e notáveis, do processo de quebra. É muito provável que, para partículas grandes, elas quebrem em mais de duas partículas filhas, e não a quebra binária descrita pela figura 2.2.1. A quebra binária é um mecanismo é muito comum na divisão celular, mas não necessariamente em outras situações. No caso da quebra binária, menos energia é necessária, em média, do que para a quebra em muitas pequenas partículas. Isso pode 
indicar a forte dependência entre a taxa de quebra e os tamanhos de partículas (RAMKRISHNA; NARSIMHAM; SATHYAGAL, 1996).

$$
\operatorname{Partícula}(v) \stackrel{\Gamma(v)}{\longrightarrow} \operatorname{Partícula}\left(v^{\prime}\right)+\operatorname{Partícula}\left(v-v^{\prime}\right)
$$

Figura 2.2.1: Quebra binária, representação esquemática.

Além disso, outros fatores que podem ser incorporados nesses modelos, incluem a interação entre as partículas/gotas quando elas já estão deformadas. Portanto, em determinada situação, gera-se um mecanismo de quebra, mais real. Por exemplo, a tensão superficial dirigida, que por deformação de partículas pode acelerar a quebra, nesse caso levando em conta os efeitos das propriedades físicas e das condições experimentais. Temos ainda a chamada erosão, em que a deformação força a partícula original a soltar diversas partículas minúsculas, e portanto ao se quebrar a partícula tem um volume muito menor que o original. Existe ampla evidência de que esse mecanismo de erosão não ocorre com frequiência e que sua ocorrência é muito desfavorecida em determinados fenômenos físicos, como demonstrou LASHERAS et al. (2002). Suas consequiências nunca foram observadas, em um grande número de experimentos controlados com gotas e bolhas realizados por ANDERSSON; ANDERSSON (2006). Entretanto, em outras áreas da quebra de partículas, é possível que o mecanismo de erosão esteja realmente atuante. Por exemplo, nos agregados de pequenas partículas esféricas. Estas, geralmente se formam em interfaces gáslíquido ou líquido-líquido, e estão sujeitas a taxas definidas de cisalhamento com evidência de um mecanismo erosivo mais forte que as forças de capilaridade, resultando que pequenas partículas sejam arrancadas das bordas do agregado. No trabalho de VASSILEVA et al. (2006) o movimento gradual da distribuição de partículas e do diâmetro médio de Sauter aparentam ser consistentes com uma pequena redução no tamanho dos potenciais volumes pais, que geram as partículas nesta dispersão. Isto provavelmente ocorreu pela forma de quebra semelhante à observada por EASTWOOD; ARMI; LASHERAS (2004) e ANDERSSON; ANDERSSON (2006), onde, particularmente no caso de gotas viscosas, uma deformação significativa ocorre e é mantida por um tempo da ordem de milissegundos antes da sua fratura. Quando pequenas gotas são formadas nestas 
circunstâncias, parece que elas resultaram da quebra da conexão, de união, pela capilaridade, de duas gotas maiores que estavam sendo deformadas de forma complexa.

A mudança da definição de uma função, de quebra de forma fenomenológica, ou por investigação do problema inverso, é capaz de mudar apenas a física que é manifestada no processo de quebra, caso a taxa seja fenomenológica. Muitas vezes não há diferenças nas formas das funções de quebra. Sendo que nas funções não fenomenológicas, a física e a química que estão envolvidas nesses fenômenos podem não estar contidas na estrutura matemática ou apenas não serem apresentadas de forma, explicita, no equacionamento.

Uma tentativa de se obter as taxas e as funções dinâmicas representativas de um fenômeno que possa ser formulado utilizando-se o balanço populacional, mas sem utilizar a solução do problema inverso, foi realizada por MURALIDHAR; RAMKRISHNA (1989). Nesse caso, foi relaxada a hipótese de homogeneidade da freqüência em questão, mas ao custo de se obter dados adicionais, na taxa de tempo da mudança do tamanho médio das partículas. A disponibilidade de tais dados não pode sempre ser garantida. E isso também requer uma minimização com restrição ao longo do tempo. Portanto, a taxa extraída pode mudar dependendo dos intervalos de tempo em que o meio em que se encontram as partículas, é observado.

Outro esforço, também, foi feito, para se conseguir prever as distribuições finais, que podem ser multimodais ou não. Esse esforço foi baseado na forma da taxa de quebra. CANU (2005) estudou como a formulação da taxa de quebra pode alterar as distribuições resultantes. Dessa forma, baseado apenas nas funções correspondentes aos fenômenos predominantes no meio em que se encontram as partículas, poder-se-ia predizer com antecedência a forma da distribuição. $\mathrm{O}$ método usa equações diferenciais ordinárias para predizer a evolução da distribuição com poucas funções desconhecidas. Com este método é possível obter uma abrangência maior com a sua posterior melhora pela consideração de novas funções, como as correspondentes à coalescência, ao crescimento, à nucleação, etc. Esse método é baseado em uma abordagem numérica, com argumentos físicos.

O processo de quebra também apresenta detalhamentos em relação às partículas individuais, conforme tratado por alguns autores. Por exemplo, as partículas não serem exatamente esféricas, o que deve complicar mais os cálculos em dispersão de gotas (SATHYAGAL; RAMKRISHNA; NARSIMHAM, 1995). No modelo de NARSIMHAM; 
RAMKRISHNA; GUPTA (1979), as partículas oscilam em torno de uma forma esférica, devido à presença de turbulência. NAMBIAR et al. $(1992,1994)$ vêem a partícula como um elemento não linear e elástico que pode restaurar sua forma. A turbulência interage com a partícula, ocasionando cisalhamento e deformação. $\mathrm{O}$ modelo de TSOURIS; TAVLARIDES (1994) assume a quebra como um produto da colisão e da eficiência da quebra.

Um pequeno número de taxas de quebra e de distribuições de partículas filhas encontradas na literatura estão apresentadas na Tabela 1.

Tabela 1: Taxas de quebra e distribuições de partículas filhas encontradas por diversos autores.

\begin{tabular}{|c|c|c|}
\hline Taxa de quebra & Distribuição de partículas filhas & Autor \\
\hline$\Gamma(v)=\sqrt{\frac{\rho v}{\sigma}} 5,75\left[W e\left(\frac{v}{D^{3}}\right)^{\frac{5}{9}}\right]^{3,2}$ & $g(x)=\left\{\begin{array}{ccc}0 & x<0,5 \\
& 0,38 \quad 0,20 \\
3,01 \int_{0.5}^{x}(y-0,5)^{1-y} & \end{array}\right.$ & $\begin{array}{l}\text { NARSIMHAN et al. } \\
\text { (1984) }\end{array}$ \\
\hline$\Gamma(t, v)=A A(t) v f_{n}(t, v)$ & $G(G P 1, G P 2)=\left[\begin{array}{ll}\text { desvio } & \text { padrão })(2 \pi)^{\frac{1}{2}}\end{array}\right]^{-1} \exp \left[\frac{-\left(\frac{G P 1-G P 2}{2}\right)^{2}}{2(\text { desvio padrão })^{2}}\right.$ & KODA et al. (1994) \\
\hline$\Gamma(v)=$ cons $\tan t e 1 v^{\text {cons } \tan t e 2}$ & $G\left(v, v^{\prime}\right)=\frac{p\left(\frac{v}{v^{\prime}}\right)^{q-1}\left(1-\left(\frac{v}{v^{\prime}}\right)\right)^{r-1}}{B(q, r)} \quad$ onde $\quad r=q(p-1)$ & $\begin{array}{l}\text { DIEMER;OLSON } \\
(2002)\end{array}$ \\
\hline$\Gamma(v)=$ cons $\tan t e 1 v^{\text {cons } \tan t e 2}$ & $G\left(d, d^{\prime}\right)=\sum_{i=1}^{2} w_{i} p_{i} \frac{3\left(1-\left(\frac{d}{d^{\prime}}\right)^{3}\right)^{r_{i}-1}\left(\frac{d}{d^{\prime}}\right)^{3 q_{i}-1}}{B\left(r_{i}, q_{i}\right)}$ & $\begin{array}{l}\text { (O’ROURKE; } \\
\text { MACLOUGHLIN,2010) }\end{array}$ \\
\hline
\end{tabular}

De uma forma geral, como descrito em alguns dados da literatura, a distribuição de partículas filhas se comporta como na figura 2.2.2,dependendo de algumas formas gerais, que podem ser assumidas para a quebra.

Pelo que é apresentado na figura 2.2.2, podemos razoavelmente resumir que partículas grandes tendem a quebrar como no caso II, enquanto partículas pequenas tendem a quebrar como no caso III, na figura 2.2.2. E, também, representado na figura 2.2.1. Para o caso em que colocamos em um gráfico $\mathrm{G}^{\prime}\left(\mathrm{x}^{\prime} \mathrm{v}^{\prime}\right) \approx \mathrm{G}\left(\mathrm{v}, \mathrm{v}^{\prime}\right), \mathrm{e}, \mathrm{x} \approx \mathrm{v} / \mathrm{v}^{\prime}$. 


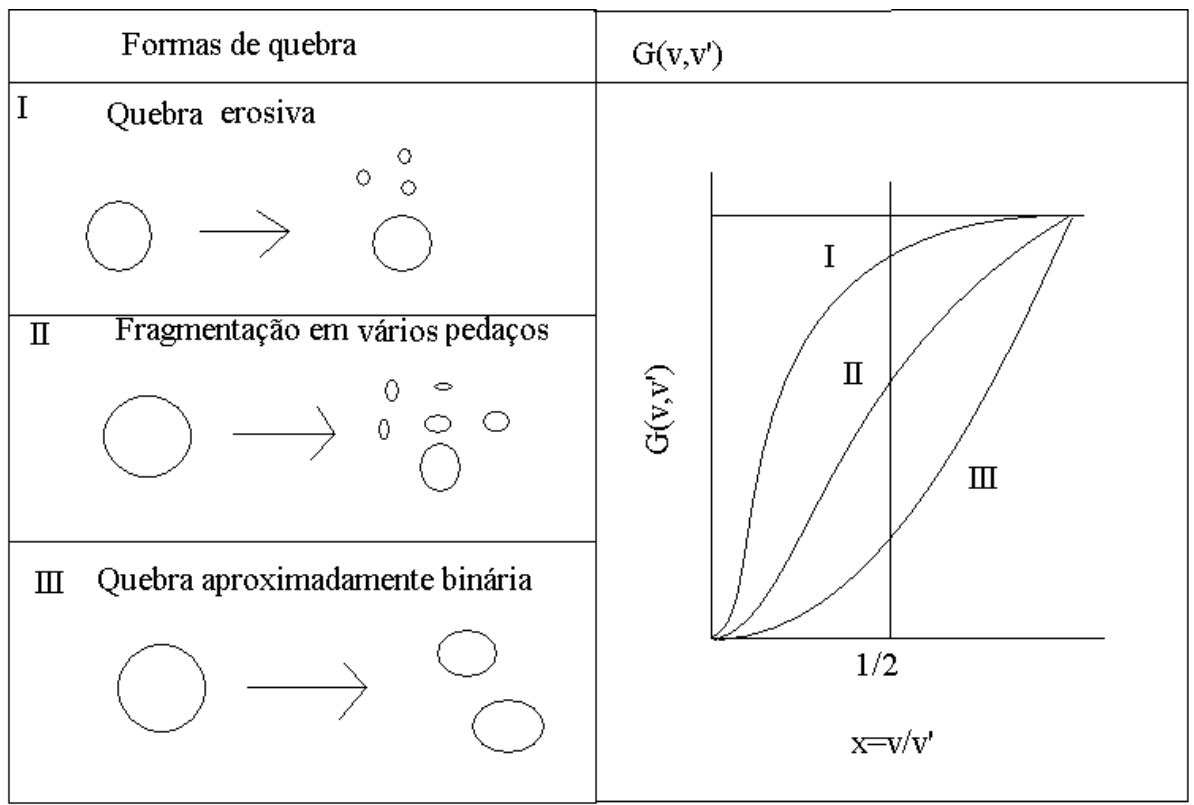

Figura 2.2.2: Comportamento da distribuição de partículas filhas de acordo com o tipo de quebra, no sistema. FONTE: RAMKRISHNA;NARSIMHAN;GUPTA (1980).

\subsection{Estudos sobre o Problema Inverso.}

Embora o entendimento quantitativo da evolução de tamanhos de partículas é um passo necessário para um apropriado controle de processos e possível otimização, em geral, muitas vezes, é difícil de se obter por visualização todas as possíveis interações físicas entre as partículas em um meio e entendê-las completamente, conforme foi estudado por ZIFF; MCGRADY; MEAKIN (1985) e KONNO; AOKI; SAITO (1983). O número de experimentos fotografados por esses pesquisadores, com fotografia de alta velocidade, não resultou em um número que pudesse ser representativo estatisticamente. $\mathrm{E}$, portanto, a modelagem ou inversão do problema ainda parece ser mais atrativa.

Um estudo inicial foi feito a respeito do problema inverso e da obtenção das funções de quebra. Com isso, podemos obter essas funções para um sistema qualquer cuja dinâmica seja descrita por um balanço populacional, ou seja, uma dinâmica que leva em conta todas as equações fundamentais. Esse estudo utiliza-se de um teste para verificar a similaridade do sistema. Com o uso desse teste, podemos verificar se é possível a obtenção da inversão e, conseqüentemente, nós podemos obter as funções de quebra para determinados dados experimentais. O estudo realizado nesse sentido foi proposto por RAMKRISHNA; 
NARSIMHAM; SATHYAGAL (1995) e também por KOSTOGLOU; KARABELAS (2001). O primeiro é apresentado, com detalhes, ao longo deste trabalho, e o segundo está apresentado APÊNDICE I. Entre eles, a única diferença está na abordagem do procedimento, isto é, na metodologia de como é realizado o cálculo da distribuição de partículas filhas.

O problema inverso, ou inversão de dados experimentais, nada mais é do que a obtenção das cinéticas envolvidas na equação de balanço populacional, a partir de duas ou mais distribuições medidas ao longo do tempo. A solução do problema inverso tem atraído muita atenção recentemente. Os métodos para a solução do problema inverso são parte de uma estratégia de modelagem de determinado fenômeno que leva em conta o meio em que se encontram as partículas. Tais métodos incluem ajustes de parâmetros para determinadas mudanças que possam ocorrer nesse meio. Esses métodos também são altamente sensíveis a erros na medida experimental, pois estas podem conter algum ruído que deve passar por alguma padronização para tornar o algoritmo estável. Uma outra dificuldade comum que pode ocorrer é a relação entre os dados experimentais disponíveis e os necessários para se simular determinada dispersão em determinada situação ainda não ajustada inicialmente, como nos apresenta VIKHANSKY et al. (2005).

\subsection{Estudos sobre a Similaridade.}

Uma dificuldade para a obtenção da solução do problema inverso é o fato de inicialmente o problema de que as distribuições também têm um fator tempo embutido que deve ser levado em conta na regressão. Porém, com a transformação de similaridade, esse problema é resolvido pois se adiciona o tempo e o tamanho em uma variável na regressão, tornando-a relativamente mais simples do que no caso em que essa variável não tivesse sido utilizada para se incorporar nela duas outras, no caso o tempo e o tamanho. Sendo assim, para verificar o quão robusta é a solução do problema inverso, nós podemos fazer essa verificação utilizando-se as funções de quebra obtidas por meio do problema inverso, e verificando através da modelagem do problema direto se as distribuições simuladas são iguais ou próximas às distribuições experimentais. Assim, como o balanço populacional, em casos especiais, tem solução analítica, é possível também solucioná-lo por meio, do problema inverso com o uso de uma transformação de similaridade especifica, 
analiticamente, isto é, sem a necessidade de se discretizar o domínio. Um caso em que isso é possível é apresentado em detalhes no APÊNDICE D. É preciso lembrar que esse caso apresentado é sujeito a diversas hipóteses simplificadoras.

Em muitos casos, foi demonstrado que para um determinado meio particulado é possível verificar que existe alguma similaridade durante o tempo nas mudanças de tamanhos de partículas em um reator. Alguns experimentos em um sistema líquido-líquido demonstram ser possível a regressão e a obtenção de todas essas distribuições ao longo do tempo por meio de uma cinética específica para cada fenômeno. Esses experimentos nos mostram, inclusive, que a taxa de quebra não segue uma lei simples, como por exemplo, uma função de potência, de acordo com o que nos ensina RAMKRISHNA (1980, 1984, 1996).

Neste trabalho foi estudado um método para a solução do problema inverso. O problema inverso consiste, por exemplo, em achar as funções de quebra (a distribuição de partículas filhas e a taxa de quebra) de uma equação de balanço populacional, a partir das medidas experimentais de distribuições de tamanho de partículas em diversos instantes. Com respeito a essas taxas, muitas são homogêneas e muitas outras são não homogêneas. A não-homogeneidade geralmente ocorre pela presença de mudanças nas probabilidades, altas ou baixas, localizadas em tamanhos específicos de partículas, como nos mostra em sua pesquisa FUCHS (1964). FRIEDLANDER; WANG (1967) foram os primeiros a mostrar que taxas não homogêneas podem apresentar comportamento auto-similar, no caso em que existam nelas certos parâmetros dependentes da concentração total de partículas.

Em alguns casos estudados, por exemplo no trabalho de WILLIANS; MELOY (1997), foi demonstrado como as variáveis de auto-similaridade podem ajudar a encontrar erros nas abordagens ou na modelagem de um balanço populacional.

Alguns estudos têm sido feitos a respeito da representação da distribuição e de suas mudanças ao longo do tempo, como sendo um dos usos das variáveis de similaridade. Um exemplo é o estudo de BILGILI (2007), que apresenta o uso de variáveis de similaridade para quantificar o impacto de cinéticas que não sejam de primeira ordem. Nesse estudo se concluí que é possível utilizar os gráficos da distribuição de similaridade e separar o efeito de forma do tamanho médio. Com isso, fica demonstrado que cinéticas que não sejam de 
primeira ordem afetam ambos, tanto o tamanho médio quanto a forma da distribuição de partículas.

Outro estudo a respeito das variáveis de auto-similaridade é o apresentado por RAO; DATTA (2006). Nele, os autores obtêm expressões analíticas para a distribuição cumulativa em porcentagem mássica e também as distribuições para as equações, de balanço populacional com o tamanho e o tempo mantidos constantes. Neste tipo de transformação de similaridade, utilizou-se o primeiro momento da distribuição para a normalização.

As variáveis de similaridade devem ao final resultar em uma distribuição de similaridade. O estudo de HOYER (1995) mostrou muitos métodos possíveis para se gerar uma distribuição final auto-similar, sendo possível, portanto, ao final, encontrar os parâmetros para as funções de quebra (taxa de quebra e distribuição de partículas filhas).

Muitos estudos a respeito das variáveis de similaridade foram feitos em que estas variáveis não se mostram únicas. A variável independente pode ser criada pela normalização: com o inverso da área do volume específico, como nos mostra o trabalho de APUR (1970), com o tamanho médio de diâmetro de partículas, como nos apresenta a pesquisa de KAOPUR (1972), com o tamanho médio de volume de partículas como é elucidado no trabalho de FILLIPOV (1961), ou pelo tamanho de partículas correspondente a um volume particular de fração de volume cumulativo, como nos mostra o trabalho de RAMKRISHNA (1974). Foram estudados por LUSHINIKOV (1973), ZIFF (1983) e ERNEST (1988), as propriedades de normalização da equação de coalescência, e se estabeleceu um certo padrão para que exista na coalescência homogênea, um espectro de similaridade.

WRIGHT; MURALIDHAR; TOBIN (1990), usando a auto-similaridade, tomaram vantagem das restrições que a similaridade impõe na freqüência, de agregação e puderam, com isso, simplificar a formulação do problema inverso desenvolvido por MURALIDHAR; RAMKRISHNA (1989). Com isso foi criada uma formulação própria e simplificada por meio das variáveis de similaridade para o caso do problema inverso com apenas coalescência, no sistema. Além disso, eles também usaram o fato de o comportamento da distribuição de similaridade ser assintótico para construir as funções base, que são usadas para expandir a freqüência de agregação, desconhecida. A incerteza das medidas do 
tamanho de distribuição das partículas, assim como os efeitos na normalização dos parâmetros, não foram investigados por eles.

O fenômeno da auto-similaridade, ou do agrupamento das distribuições em diferentes tempos, não é um requerimento mecânico ou uma identidade matemática. Tratase de uma observação física dentro dos limites do erro experimental. Portanto para que haja similaridade, basta apenas que se encontrem distribuições observadas ou calculadas que caiam dentro do limite de erro experimental, na obtenção dessas distribuições. Em geral, e na verdade, todas as técnicas matemáticas para modelar processos físicos não podem fazer mais do que obter um resultado igual ou próximo dos dados experimentais e de seus erros de medida, como nos ensina a pesquisa de HOYER (1995).

Devemos, também, não confundir auto-similaridade com outros fenômenos, como, por exemplo, o fato de que, em algumas situações, ao final de certo período, todas as distribuições medidas podem acabar sendo iguais. Isto acontece devido a termos atingido o estado estacionário. Mas, neste caso, o que temos não é o resultado do conceito de autosimilaridade. Então, essa solução não é auto-similar, pois ela vai satisfazer apenas os primeiros momentos da distribuição, explicando de antemão porque alguns dados experimentais às vezes se sobrepõem em uma única curva, como nos mostra em seu trabalho MADRAS; MCCOY (2002). O conceito de similaridade tem sido usado em aglomeração de cristais, coalescência de aerossóis, quebra de bolhas e gotas, e em agregação de pó. PETERSON (1986) resolveu um balanço populacional para um caso simples com quebra seguindo a lei de potências. Com uma adequada transformação de similaridade, obteve uma solução analítica, como a mostrada no APÊNDICE D.

Alguns testes do problema inverso, juntamente com o método dos momentos da distribuição de similaridade, foram feitos, mas neles foi preciso ajustar uma distribuição beta na função de distribuição de partículas filhas, como nos mostra a pesquisa de RAMKRISHNA; NARSIMHAM; NEJFELT (1984).

Um esforço que também foi feito para se obter uma sobreposição de curvas e uma conseqüente obtenção das funções de quebra, foi realizado por NARSIHMAN; RAMKRISHNA; GUPTA $(1980,1979)$ e por BROWN; GLATZ (1987). Nessa técnica, eles propõem transladar as diferentes curvas na direção vertical. Isto é, por uma determinada translação, as curvas com diferentes valores de F devem se sobrepor. E, então poderíamos 
fazer a otimização, que levaria à obtenção das funções de quebra. Porém essa translação envolve escolher a curva de referência na qual todas as curvas deveriam se sobrepor, e também um volume de referência seria necessário para fazer essa translação. Entretanto, muitas das curvas não extrapolam para o volume de referência e, em muitos casos, existe uma sobreposição ínfima das diferentes curvas, o que causa problemas na determinação da distância de translação.

Também, podemos citar aqui um estudo matemático mais minucioso de NARSIMHAN; NEJFELT; RAMKRISHNA (1984), onde se mostrou matematicamente que, na medida em que mudamos a vazão de entrada e de saída de um reator até ele se tornar batelada, também aumentamos a similaridade das distribuições observadas. Os cálculos desses autores estão no APÊNDICE J. Este estudo é importante, pois todos os fenômenos estudados, neste trabalho, ocorrem em reatores do tipo batelada, conforme explicado na equação (1.1.5).

\subsection{Estudos sobre o Mal Condicionamento do Problema Inverso.}

Outra dificuldade é o fato do problema inverso ser mal condicionado. Isso significa, que pequenas incertezas nas distribuições de partículas medidas experimentalmente podem, dependendo do caso, resultar em grandes diferenças nas funções de quebra. Portanto, qualquer função de aproximação utilizada resultará numa sensibilidade muito alta à qualidade e quantidade dos dados experimentais, conforme foi investigado por HENSON et al. (2006). As incertezas presentes nesse tipo de problema foram investigadas por RAMKRISHNA; WRIGHT (1992). A viabilidade do problema inverso para determinadas situações já foi avaliada em alguns estudos como no trabalho de WILLIANS; MELOY; TARSHAN (1994). Onde se verifica como o problema, às vezes, para diferentes situações resulta em soluções diferentes, dependendo da abordagem numérica que está sendo utilizada.

Um estudo detalhado da solução do problema mal condicionado, realizado por SATHYAGAL; RAMKRISHNA; NARSIMHAM (1995), resulta na tentativa de se resolver o problema inverso, com variáveis de similaridade. Nele é apresentado como se resolver esse problema pelo método das quasissoluções. Portanto, o mal condicionamento 
da otimização pode ser resolvido utilizando-se a propriedade de que a distribuição é uma função monotônica; este tema também foi trabalhado por RAMKRISHNA (1995).

Uma tentativa recente de obter resultados consistentes mesmo na presença de mau condicionamento foi realizada no trabalho de MACLOUGHLIN; O'ROURKE (2010), utilizando dois métodos de inversão dissimilares, um proposto por SATHYAGAL; RAMKRISHNA (1996) e outro por KOSTOGLOU; KARABELAS (2001). O resultado obtido foi independente do procedimento empregado.

\subsection{Estudos sobre alguns usos das equações de Balanço Populacional e abordagens alternativas.}

Usos interessantes de sistemas particulados têm sido encontrados, por exemplo, em aplicações farmacêuticas, em que se constroem drogas hidrofóbicas e essas são encapsuladas em uma emulsão óleo-água para administração por via oral. Um critério importante, para a formulação de emulsões farmacêuticas inclui a biocompatibilidade, a biodegradabilidade, a toxicidade, tendo-se em vista como alvo um órgão específico, tentando-se aumentar a efetividade da droga, e reduzir os efeitos indesejáveis. Então, as propriedades da droga, suas características relacionadas à emulsão, e as rotas de administração, devem ser calibradas para, assim, alcançarem a respectiva aplicação, como foi pesquisado por NIELLOUD; MARTI-MESTRES (2000, 2002).

Emulsões farmacêuticas são com freqüência manufaturadas usando homogeneizadores de alta pressão em que as emulsões de moléculas pequenas, drogas hidrofóbicas, são forçadas a entrarem em pequenos orifícios sob altas pressões, dispersando em gotas pequenas. A homogeneização produz uma emulsão com a distribuição de partículas, que depende da formulação química dos reagentes, sua distribuição inicial, e condições de operação. Como qualquer outro sistema particulado, as propriedades finais das emulsões farmacêuticas são complexas e, com freqüência, uma função desconhecida de diferentes variáveis. Estudos clínicos mostram que o tamanho de partículas tem um impacto significativo nas propriedades da emulsão e na efetividade do sistema de transporte de drogas pelo corpo. Por exemplo, a biodistribuição de drogas encapsuladas é altamente afetada pelos tamanhos das partículas em meio a processos fisiológicos complexos. Em adição para exibir estabilidade em longo prazo, a droga desejada seguirá determinadas 
cinéticas e a emulsão deve usualmente ser próxima da monodispersão, em relação à distribuição de tamanhos médios escolhidos, para se atingir órgãos específicos como nos mostram as pesquisas de MALMSTEM (2002), BECHER (1983), FLOURY et al. (2004a), FLOURY; LEGRAND; DESRUMAX (2004b), SOON et al. (2001) e WALSTRA (1993) .

Foram encontrados usos recentes de balanço populacional, e obviamente possíveis aplicações do problema inverso, para casos como na cultura de células tronco em um bioreator. A diferenciação delas é equivalente ao termo de crescimento na equação do balanço, e a divisão celular, equivalente à quebra, sendo esta geralmente binária, como nos mostra o trabalho de MASSIMO; ALESSANDRO; GIACOMO (2007) .

Também, normalmente, é possível utilizar a modelagem de balanço populacional para a descrição de sistemas climáticos em existe uma distribuição característica de aerossóis atmosféricos, que são os líquidos ou partículas sólidas presentes na atmosfera. Estes aerossóis são capazes de influenciar o clima pela modificação na formação de nuvens, ou pela absorção e reflexão de radiação solar. Em meteorologia ou em sistemas climáticos, sabemos, portanto, que a distribuição de tamanhos de partículas é um fator importante (BALTENSPERGER, 2010).

Algumas considerações sobre outros métodos serão apresentadas nos apêndices. Serão, ao todo, duas considerações sobre dois métodos: o método de Monte Carlo, apresentado no APÊNDICE G, e uma abordagem matricial do balanço populacional, apresentado no APÊNDICE H. 


\section{METODOLOGIA.}

Neste capitulo é apresentado o balanço populacional para o caso de ocorrência exclusiva de quebra e o procedimento para se estimar a função de quebra e a distribuição de partículas filhas a partir das medidas experimentais da distribuição (problema inverso). Também será apresentado o procedimento para a solução numérica do balanço populacional (problema direto), que é usado para verificação do resultado obtido pelo problema inverso.

\subsection{Estruturação da equação de Balanço Populacional.}

A equação de balanço populacional descreve a evolução de uma distribuição (por exemplo uma distribuição de tamanhos das partículas de um sistema particulado, ou a distribuição de tamanhos das moléculas de um polímero) resultante de diferentes processos tais como os de formação (nucleação), crescimento, agregação (coalescência, aglomeração) e quebra. No caso presente, ficaremos restritos ao caso de interesse, que é o caso em que ocorre apenas quebra.

Apresentaremos inicialmente as equações como se descrevêssemos uma distribuição de tamanhos de partículas, nos quais estas estão caracterizadas pelo seu volume v. A razão é que esta formulação é a mais comumente encontrada na literatura. Posteriormente, aplicaremos o balanço populacional (e o problema inverso) a problemas envolvendo tamanhos (graus de polimerização) de moléculas (cadeias) de polímeros, cuja descrição, como mostraremos, é equivalente.

Seja $n(v, t) . \mathrm{d} v$ o número de partículas por unidade de volume do reator no instante de tempo $t$ com volumes entre $v$ e $v+\mathrm{d} v$. Para um reator de batelada perfeitamente agitado, a equação de balanço populacional para esta situação pode ser escrita na forma (RAIKAR et al., 2006; RAMKRISHNA, 2000; VALENTAS; AMUNDSON, 1966; PATRUNO et al.,2009; COULALOGLOU; TAVLARIDES, 1977, NARSIMHAM et al., 1979; NAMBIAR et al., 1992):

$$
\frac{d n(v, t)}{d t}=-\Gamma(v) n(v, t)+\int_{v}^{\infty} \beta\left(v, v^{\prime}\right) v\left(v^{\prime}\right) \Gamma\left(v^{\prime}\right) n\left(v^{\prime}, t\right) d v^{\prime}
$$


onde $\Gamma(v)$ é a taxa de quebra (fração das partículas de volume $v$ que quebram por unidade de tempo), $\beta\left(v, v^{\prime}\right)$ é a função densidade de probabilidade de formação de partículas de volume $v$ a partir da quebra de partículas de volume $v^{\prime}$ (obviamente $v>v^{\prime}$ ) e $v\left(v^{\prime}\right)$ é o número de partículas filhas formadas pela quebra de uma partícula de volume $v$ '. Para a solução desta equação de balanço populacional ser resolvida, é necessário fornecer a condição inicial, ou seja, a distribuição de tamanhos inicial das partículas no instante $t=0$, $n(v, 0)$. Além disso, para a solução do balanço populacional é necessário especificar as funções $\Gamma(v), \beta\left(v, v^{\prime}\right)$ e $v\left(v^{\prime}\right)$.

Define-se a função $\beta\left(\mathrm{v}, \mathrm{v}^{\prime}\right)$ como a probabilidade de formação de partículas de volume v resultantes da quebra de partículas de volume v'. Para satisfazer a condição de conservação de volume (ou de massa, para partículas de densidade constante) é necessário que (ZIFF e MCGRAGY, 1987; PETERSON, 1986):

$\int_{0}^{\infty} v \beta\left(v, v^{\prime}\right) d v=v^{\prime}$

que indica que a soma dos volumes v das partículas resultantes da quebra (partículas filhas) é igual ao volume v' da partícula mãe que sofreu a quebra. É interessante notar que muitas taxas de quebra descritas na literatura, embora obedeçam à equação (3.1.2), predizem um número de partículas infinito que podem ser formadas por quebra. Outras restrições para $\beta$ são:

$$
\begin{aligned}
& \beta\left(v, v^{\prime}\right) \geq 0 \\
& \beta\left(v, v^{\prime}\right)=0 \text { para } v^{\prime}>v
\end{aligned}
$$

A inequação (3.1.3) restringe a função de distribuição a probabilidades não negativas, e a equação (3.1.4) nos diz que partículas grandes não podem ser formadas pela quebra de partículas pequenas. Quando $\beta\left(\mathrm{v}, \mathrm{v}^{\prime}\right)=\beta_{0}$, tem-se uma taxa de quebra constante.

A conservação de massa impõe que a volume total de partículas resultante da quebra de partículas de volume $\mathrm{v}$ deve ser igual a v':

$$
\int_{0}^{z} v \beta\left(v, v^{\prime}\right) d v \geq v \int_{v-z}^{v}\left(v^{\prime}-v\right) \beta\left(v, v^{\prime}\right) d v, \quad z<\frac{v^{\prime}}{2}
$$

As funções cinéticas do balanço populacional apresentadas, taxa de quebra e distribuição de partículas filhas são dependentes, e a taxa de quebra deve ser calculada em 
primeiro lugar, ou seja, a relação entre elas é que a primeira é a base para se obter a outra, em relação ao número de partículas que teríamos provenientes da quebra de uma partícula de volume v seria:

$$
v(v)=\int_{0}^{v} \beta\left(v, v^{\prime}\right) d v=\int_{0}^{v} \frac{1}{v} \frac{d}{d v}\left(v^{\prime} G\left(v, v^{\prime}\right)\right) d v=\frac{v^{\prime}}{v} G\left(v, v^{\prime}\right)
$$

Da equação (3.1.6), podemos deduzir a expressão (3.1.7) que relaciona $G(v, v ')$ com a taxa de quebra $\beta\left(\mathrm{v}, \mathrm{v}^{\prime}\right)$, e inserindo $\mathrm{v}(\mathrm{v})$ como nos cálculos do trabalho de RAMKRISHNA (1974):

$$
g(x)=G\left(v, v^{\prime}\right) \approx \frac{1}{v^{\prime}} \int_{0}^{v} v v\left(v^{\prime}\right) \beta\left(v, v^{\prime}\right) d v
$$

O balanço populacional considerando apenas a quebra de partículas pode ser escrito na forma:

$$
\begin{aligned}
\frac{d n(v, t)}{d t} & =-\Gamma(v) n(v, t)+\int_{v}^{\infty} \beta\left(v, v^{\prime}\right) v\left(v^{\prime}\right) \Gamma\left(v^{\prime}\right) n\left(v^{\prime}, t\right) d v^{\prime} \\
& =-\Gamma(v) n(v, t)+\int_{v}^{\infty} \frac{\partial B\left(v, v^{\prime}\right)}{\partial v} \Gamma\left(v^{\prime}\right) n\left(v^{\prime}, t\right) d v^{\prime} \\
& =-\Gamma(v) n(v, t)+\int_{v}^{\infty} \Gamma\left(v^{\prime}\right) \frac{1}{v} \frac{d}{d v}\left(v^{\prime} G\left(v, v^{\prime}\right)\right) n\left(v^{\prime}, t\right) d v^{\prime} \\
& =-\Gamma(v) n(v, t)+\int_{z z z=z^{\prime}} h h h(z z z \rightarrow v) \Gamma(z z z) n(z z z, t) d z z z
\end{aligned}
$$

sendo que $n\left(v^{\prime}, t\right)$ é a distribuição de partículas, $\Gamma(v)$ é a taxa de quebra, ou, fração de partículas de volume $\mathrm{v}$ quebrando por unidade de tempo. Se $\Gamma(\mathrm{v})=0$ não há quebra em nenhuma tamanho e conseqüentemente o tamanho de qualquer partícula se torna constante e igual ao inicial, $\beta\left(v, v^{\prime}\right)$ é a função densidade de probabilidade, ou, a probabilidade de formação de partículas de volume $\mathrm{v}$ pela quebra de partículas de volume $\mathrm{v}^{\prime}, v\left(v^{\prime}\right)$ é o número de partículas filhas formadas pela quebra de partículas de volume v', B(v,v') é a distribuição de quebra cumulativa que descreve a fração de partículas de volume v e menores formada quando uma unidade de massa de partícula v' é quebrada, onde v'>v, se $\partial \mathrm{B}\left(\mathrm{v}, \mathrm{v}^{\prime}\right) / \partial \mathrm{v}=0$ então $\mathrm{B}\left(\mathrm{v}, \mathrm{v}^{\prime}\right)$ é constante e essa corresponde ao caso de um sistema em que a quebra de partículas se torna tão pequena quanto a um pó muito fino (REID,1965) e 
$\mathrm{G}\left(\mathrm{v}, \mathrm{v}^{\prime}\right)$ é a função de distribuição de partículas filhas. Em (3.1.8) hhh(zzz $\left.\rightarrow \mathrm{v}\right)$ é a probabilidade de redistribuição, conforme formulado por PATRUNO et al. (2009), e, também pode ser chamada de função de permissão de quebra. Neste caso, zzz é a coordenada interna, das partículas, com uma propriedade escolhida, no caso, o volume, que év.

Podemos calcular momentos para uma função $\mathrm{n}(\mathrm{v}, \mathrm{t})$ de distribuição, com o uso da definição (3.1.9), nela $\mathrm{M}_{\mathrm{k}}(\mathrm{t})$ são os momentos de ordem $\mathrm{k}=1,2,3 \ldots$ :

$$
M_{k}(t)=\int_{0}^{\infty} v^{k} n(v, t) d v
$$

As equações de dinâmica para os momentos são obtidas caso multipliquemos (3.1.8) por $\mathrm{v}^{\mathrm{k}}$, sendo $\mathrm{k}$ um número inteiro qualquer, e integrarmos em ambos os lados, com, $0 \leq \mathrm{v} \leq \infty$

$$
\frac{d M_{k}(t)}{d t}=\int_{0}^{\infty} \Gamma\left(v^{\prime}\right) v^{\prime k} n\left(v^{\prime}, t\right)\left[\int_{0}^{v}\left(\frac{v}{v^{\prime}}\right)^{k} \beta\left(v^{\prime}, v\right) d v-1\right] d v^{\prime}
$$

Para os momentos descritos em (3.1.10) sabe-se que, no instante t, o momento de ordem zero é o número total ou concentração de partículas e deve ser constante para um sistema fechado, como apresentado por MADRAS; MCCOY (2002), o momento de ordem um, como explicado por YANG (2006), é igual à concentração mássica.

Utilizando a definição dos momentos, podemos obter as equações (3.1.11-3.1.12), muito utilizadas para a caracterização de polímeros, em (3.1.11), se apresenta o tamanho de cadeia médio numérico.

$$
M N(t)=\frac{M_{1}(t)}{M_{0}(t)}
$$

O tamanho médio mássico é apresentado na equação (3.1.12):

$$
M M(t)=\frac{M_{2}(t)}{M_{1}(t)}
$$

A polidispersidade, ou índice de polidispersidade, na equação (3.1.13) indica o quão larga ou estreita é a distribuição:

$$
P D(t)=\frac{M M(t)}{M N(t)}
$$


Podemos notar que com auxilio de (3.1.10), o momento para $\mathrm{k}=1$, reduz a equação (3.1.11) ao valor zero. Isto é consistente com o fato que a fragmentação não deve alterar a massa total, ou volume para sistemas com densidade constante.

\subsection{Discretização e Solução do Balanço Populacional pelo método dos pivots fixos.}

Neste procedimento dos pivots fixos, a distribuição contínua $n(v, t)$ é discretizada em classes (ou "fatias") de espessura $\Delta v_{\mathrm{i}}=v_{\mathrm{i}+1}-v_{\mathrm{i}}$ e o número de partículas em cada classe é dado por:

$N_{i}(t)=\int_{v_{i}}^{v_{i+1}} n(v, t) d v$

A estas $N_{\mathrm{i}}$ partículas dentro da classe i é atribuído o volume representativo desta classe, chamado de pivot, e adotado como sendo o valor médio nesta faixa:

$x_{i}=\frac{v_{i+1}+v_{i}}{2}$

Aplicando a discretização ao balanço populacional, resulta na equação para $\mathrm{N}_{\mathrm{i}}(\mathrm{t}) \mathrm{em}$ cada pivot $\mathrm{x}_{\mathrm{i}}$, na forma:

$$
\frac{d N_{i}}{d t}=\sum_{k=i}^{i_{\max }} n_{i, k} b\left(x_{k}\right) N_{k}-b\left(x_{i}\right) N_{i} \quad\left(i=1,2,3 \ldots i_{\max }\right)
$$

onde $b\left(x_{\mathrm{k}}\right)$ é a frequiência de quebra de partículas de volume $x_{\mathrm{k}}$, sendo $b\left(x_{\mathrm{i}}\right) N_{\mathrm{i}}(t) \mathrm{d} t$ a quantidade de partículas de tamanho $x_{\mathrm{i}}$ quebradas durante um pequeno incremento de tempo $\mathrm{d} t$ e $n_{\mathrm{i}, \mathrm{k}} b\left(x_{\mathrm{k}}\right) N_{\mathrm{k}} \mathrm{d} t$ é a quantidade de partículas de tamanho $x_{\mathrm{i}}$ produzidas pela quebra de partículas de tamanho $x_{\mathrm{k}}>x_{\mathrm{i}}(\mathrm{k}>\mathrm{i})$ num intervalo de tempo $\mathrm{d} t$.

O sistema de equações (3.2.3), uma equação para cada pivot, pode ser resolvida por qualquer método conveniente para solução numérica de sistemas de equações diferencias ordinárias.

Analisando a correspondência entre o balanço populacional original, equação (3.2.4), e o balanço populacional discretizado, equação (3.2.5), pode-se perceber que: 


$$
\begin{aligned}
& b\left(x_{i}\right) N_{i}=\int_{v_{i}}^{v_{i+1}} \Gamma(v) n(v, t) d v \\
& \sum_{k=1}^{i_{\max }} n_{i, k} b\left(x_{k}\right) N_{k}=\int_{v_{i}}^{v_{i+1}} \int_{v}^{\infty} \beta\left(v, v^{\prime}\right) v\left(v^{\prime}\right) \Gamma\left(v^{\prime}\right) n\left(v^{\prime}, t\right) d v
\end{aligned}
$$

Uma condição de contorno que sempre assumimos durante a discretização é que a densidade numérica é tida como zero fora do domínio computacional. Isso significa que não existem fora da faixa de domínio escolhida.

As partículas geradas pela quebra tem um dado tamanho que não necessariamente coincidem com os tamanhos dos pivots. Para que tanto o número total de partículas como o volume total das partículas (dois momentos da distribuição) sejam conservados, as partículas formadas pela quebra devem ser "distribuídas" entre os dois pivots mais próximos, proporcionalmente à proximidade dos pivots, como ilustrado na Figura 3.2.1, e pode ser matematicamente expresso na forma:

$$
\begin{aligned}
& n_{i, k}=\left(1-\delta_{i, k}\right) Z\left(x_{i}, x_{i+1}, x_{k}\right)-\left(1-\delta_{i, k}\right) Z\left(x_{i}, x_{i-1}, x_{k}\right), \quad \delta_{j, k}=\left\{\begin{array}{l}
1 \text { para } j=k \\
0 \text { para } j \neq k
\end{array}\right. \\
& Z\left(a_{1}, a_{2}, a_{3}\right)=\int_{a_{1}}^{a_{2}} \frac{a_{2}-v}{a_{2}-a_{1}} \beta\left(v, a_{3}\right) v\left(a_{3}\right) d v
\end{aligned}
$$

Podemos ver pelas equações (3.2.6) a (3.2.7) que os pivôs, representados pela letra x, permanecem fixos e não há equação para o movimento dos pivôs durante a integração numérica, como ocorre na técnica dos pivôs móveis. A única maneira, portanto de melhorar a solução numérica é aumentando o número de pivôs em um domínio de integração.

Note que a equação (3.2.7) nos fornece como será distribuída em frações nos pivôs próximos aos valores de determinada propriedade, conforme exemplificado pela figura 3.2.1. Perceba que $\mathrm{a} 11+\mathrm{a} 12=1 \mathrm{e} a 21+\mathrm{a} 22=1$, obedecendo às frações na equação (3.2.7).

Para melhorar a discretização dos volumes e conseqüentemente o resultado final do problema é possível aumentar o número de elementos (ou classes). Outro procedimento é discretizar o volume em forma de progressão geométrica, levando-se em conta que as variações ocorrem muito mais em volumes pequenos. No caso do presente trabalho, não discretizamos desta forma geométrica, mas apenas de forma linear, pois o resultado obtido com a discretização linear se mostrou satisfatório. 


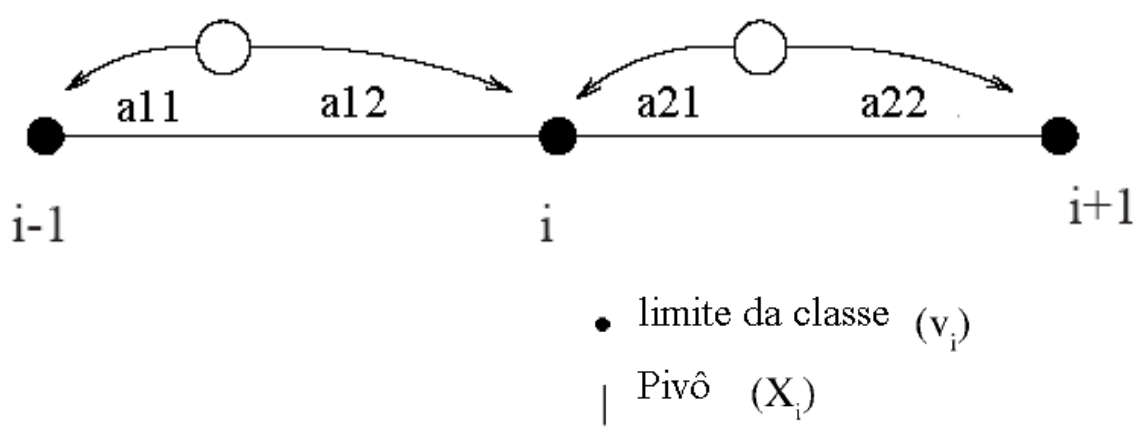

Pivô fixo mais nova partícula formada por
quebra

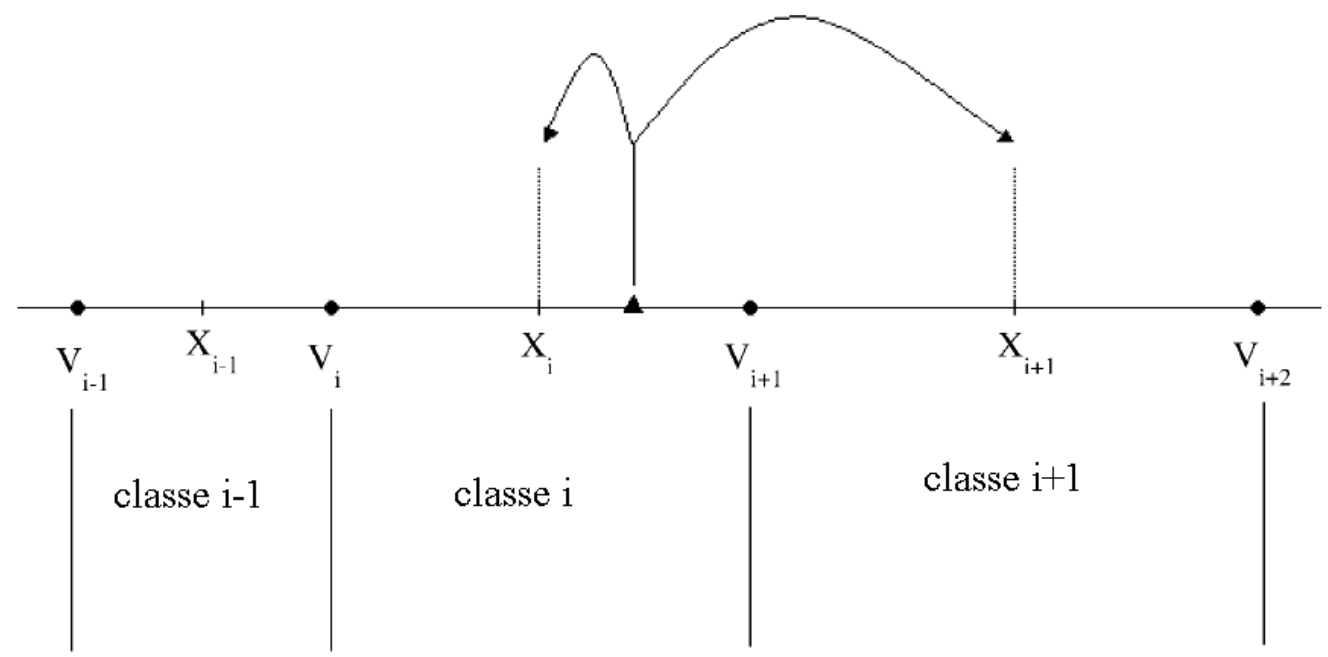

Figura 3.2.1: Distribuição dos pivôs fixos, quando o tamanho de partícula formada pela quebra não coincide com os pivôs. FONTE: CHAKRABORTY;KUMAR (2007) e NOPENS;BEHEYDT;VANROLLEGHEM (2005).

O balanço populacional (3.1.8) pode ser re-escrito em termos da distribuição acumulada $\mathrm{F}(\mathrm{v}, \mathrm{t})$, na forma da equação (3.2.8), lembrando que $\partial \mathrm{F}(\mathrm{v}, \mathrm{t}) / \partial \mathrm{v}=\mathrm{n}(\mathrm{v}, \mathrm{t})$ e $\mathrm{F}(\mathrm{v}, 0)=\mathrm{F}_{0}$ :

$\frac{d F(v, t)}{d t}=\int_{0}^{\infty} G\left(v, v^{\prime}\right) \Gamma\left(v^{\prime}\right) \partial_{v} F\left(v^{\prime}, t\right)=\int_{0}^{\infty} G\left(v, v^{\prime}\right) \Gamma\left(v^{\prime}\right) n\left(v^{\prime}, t\right)=\frac{d \int_{0}^{v} n(v, t) d v}{d t}$ 
A distribuição acumulada como descrita em (3.2.8) é uma integral de Stieljes (RAMKRISHNA,1974) e pode ser utilizada como uma forma de se estimar o impacto dos erros numéricos dentro da dinâmica da simulação já que ela deve resultar em um valor fixo unitário correspondente a área da distribuição em determinado tempo. $\mathrm{F}(\mathrm{v}, \mathrm{t})=0$ para $\mathrm{v} \leq 0$, e $\lim \mathrm{F}(\mathrm{v}, \mathrm{t})_{\mathrm{v} \rightarrow \infty}=1$, por definição.

No algoritmo implementado nesse caso, a distribuição acumulada não se calcula utilizando a equação (3.2.8), mas sim a partir da resolução do balanço discretizado (3.2.6), portanto para os tempos em que se tem uma função de distribuição de partículas a distribuição acumulada é calculada como a integral numérica das distribuições obtidas pelo uso do método dos trapézios dessa forma, $\mathrm{F}\left(\mathrm{v}_{\mathrm{i}}, \mathrm{t}\right)=\sum_{\mathrm{i}}^{\mathrm{imax}}(1 / 2)\left(\mathrm{n}\left(\mathrm{v}_{\mathrm{i}+1}, \mathrm{t}\right)+\mathrm{n}\left(\mathrm{v}_{\mathrm{i}}, \mathrm{t}\right)\right)\left(\Delta \mathrm{v}_{\mathrm{i}}\right)$, que seria a forma numérica da última igualdade da equação (3.2.8).

Claro, que se quiséssemos ser mais rigorosos, assumiríamos que a função cumulativa seria:

$$
F(v, t)=F_{0}(v, t)+t \int_{v}^{\infty} \Gamma\left(v^{\prime}\right) G\left(v, v^{\prime}\right) \frac{\partial F\left(v^{\prime}, t\right)}{\partial v} \partial v^{\prime}
$$

onde $\mathrm{F}_{0}$ é o volume cumulativo inicial alimentado, e, então reescreveríamos a função cumulativa como:

$$
F_{\max }(v)=\int_{v}^{\infty} S\left(v-v_{\max }\right) d F_{\max }\left(v_{\max }\right)
$$

onde $S(x 2)$ seria uma função degrau:

$$
S(x 2)=\left\{\begin{array}{lll}
1 & \text { para } & x 2>0 \\
0 & \text { para } & x 2<0
\end{array}\right.
$$

A vantagem de se expressar $F_{0}(v, t)$ como na equação (3.2.9) é pelo fato de que a equação (3.2.8) pode agora ser resolvida diretamente na forma discretizada, com o uso da distribuição $\mathrm{S}\left(\mathrm{v}-\mathrm{v}_{0}\right)$, que corresponde aos tamanhos idênticos das partículas de volume $\mathrm{v}_{0}$. Supondo que a solução para este problema é escrita na forma $F\left(v, v_{0}\right)$, teremos a equação:

$$
F\left(v, v_{\max }\right)=S\left(v-v_{\max }\right)+t \int_{v}^{\infty} \Gamma\left(v^{\prime}\right) G\left(v, v^{\prime}\right) d F\left(v^{\prime} ; v_{\max }\right)
$$

Então a solução da equação (3.2.5) pode ser identificada como: 


$$
\tilde{F}(v)=\int_{0}^{\infty} F\left(v ; v_{\max }\right) d F_{\max }\left(v_{\max }\right)
$$

E, disso se segue que para a linearidade da equação (3.2.12). A equação (3.2.13) deve ser resolvida discretizando-se o intervalo de tamanho de partículas. Primeiro, nós vamos reconhecer que neste caso volumes maiores que $v_{\max }$ não podem aparecer no reator de batelada, por processo de quebra. Então devemos apenas nos preocupar com o intervalo $\left\{0, \mathrm{v}_{\max }\right\}$. Então basta dividirmos $\left\{0, \mathrm{v}_{\max }\right\}$, em um intervalo $\mathrm{i}_{\max }$ com:

$$
v_{\max }=\frac{i v_{\max }}{i_{\max }}, \quad i=0,1,2, \ldots i_{\max }
$$

Deixando $\mathrm{F}_{\mathrm{i}}\left(\mathrm{v}_{\max }\right)=\mathrm{F}\left(\mathrm{v}_{\mathrm{i}} ; \mathrm{v}_{\max }\right), \Gamma_{\mathrm{j}}=\Gamma\left(\mathrm{v}_{\mathrm{j}}\right), \mathrm{G}_{\mathrm{ij}}=\mathrm{G}(\mathrm{vi}, \mathrm{vj})=\mathrm{g}\left(\Gamma_{\mathrm{i}} / \Gamma_{\mathrm{j}}\right)$, nós teremos a solução:

$$
F_{i}\left(v_{\max }\right)=t \sum_{j=i}^{i_{\max }-1} \Gamma_{j} G_{i j}\left[F_{j+1}\left(v_{\max }\right)-F_{j}\left(v_{\max }\right)\right] \quad i=1,2, \ldots,\left(i_{\max }-1\right)
$$

A solução da equação (3.2.13), expressa na forma da equação (3.2.15) pode ser identificada como uma boa discretização de (3.2.13). Então o estado estacionário da distribuição pode ser predito utilizando-se os valores das funções $\Gamma$ e G, que podem ser comparadas com medidas experimentais das distribuições.

É possível equacionar a variação de volume total utilizando-se o balanço populacional em (3.1.8) para obtermos (3.2.16) que é a variação de volume total.

$$
\frac{\underbrace{d \int_{0}^{\infty} n(v) d v}_{V_{\text {TOTAL }}}}{d t}=-\int_{0}^{\infty} \Gamma(v) n(v) d v+\int_{0}^{\infty} \int_{v}^{\infty} \beta\left(v, v^{\prime}\right) v\left(v^{\prime}\right) \Gamma\left(v^{\prime}\right) n\left(v^{\prime}, t\right) d v
$$

No caso podemos verificar se o volume total se conserva adicionalmente com a equação (3.1.16) e assim temos dois critérios para verificar que não ocorreu erro durante a integração numérica. No primeiro caso se verifica a cada integração se a equação (3.2.16) tem um valor próximo de zero. E, no segundo caso pela equação (3.2.17), nós verificamos se a área da curva de $\mathrm{n}(\mathrm{v}, \mathrm{t})$ por v é mantida constante, e, igual a 1.

$$
\text { erro }=\frac{\int_{0}^{\infty} n(v) d v-V_{\text {TOTAL }}}{V_{\text {TOTAL }}} \leq 1 \%
$$


Para completar, o modelo da equação (3.1.8), são necessárias duas funções: a taxa de quebra e a distribuições de partículas filhas. Estas são funções que regem os fenômenos físicos da quebra.

\subsection{Equacionamento das taxas de quebra e das funções de distribuição de partículas filhas.}

As funções de taxa de quebra são específicas para cada tipo de problema físico ao qual o balanço populacional está sendo aplicado. Por exemplo, para o caso de quebra de gotas de líquido, PATRUNO et al. (2009) escreveram a taxa de quebra na forma:

$$
\begin{aligned}
\Gamma(v) & =\left(\frac{1}{\text { tempo de quebra }}\right)\left(\begin{array}{c}
\text { fração de partículas } \\
\text { quebrando }
\end{array}\right)= \\
& =\sqrt{\frac{\sigma}{\rho v}\left\{0,4220 \exp \left\{-0,24775 \ln \left[W e\left(\frac{\pi d^{3}}{6 D^{3}}\right)^{\frac{5}{9}}\left(\frac{\mu_{c}}{\mu_{d}}\right)^{0,2}\right]^{2}+2,15475 \ln \left[W e\left(\frac{\pi d^{3}}{6 D^{3}}\right)^{\frac{5}{9}}\left(\frac{\mu_{c}}{\mu_{d}}\right)^{0,2}\right]\right\}\right\}}= \\
& =1,2 \exp \left(0,12(\operatorname{Ln}(v)+3,5)-0,2 \ln (v)^{2}-12,25\right)
\end{aligned}
$$

sendo que d é o diâmetro da partícula, $\mathrm{We}=\mathrm{N}^{2} \mathrm{D}^{3} \rho / \sigma$ o número de Weber, $\mathrm{D}$ o diâmetro do reator e $\mathrm{N}$ a rotação do agitador, $\mu_{\mathrm{c}}$ e $\mu_{\mathrm{d}}$ são a viscosidade da fase contínua e da fase dispersa respectivamente, e a função (3.3.1) é um ajuste de diversos experimentos realizados e a tentativa de se criar uma lei empírica nesta situação e esta função (3.3.1) deve ser crescente monotonicamente.

O conceito de similaridade será explorado repetitivamente, começando com a hipótese de que a função de distribuição filha pode ser representada como dependente da taxa de quebra.

$$
G\left(v, v^{\prime}\right)=g(x)=g\left(\frac{\Gamma(v)}{\Gamma\left(v^{\prime}\right)}\right)
$$

A equação de quebra muitas vezes já está disponível na literatura como a utilizada por SATHYAGAL;RAMKRISHNA;NARSIMHAM (1995) sem dependência com o tempo e obtida por meio de alguns experimentos:

$$
g(x)=\frac{x^{\alpha}}{\left(1-\frac{\alpha}{4}\right)+\frac{\alpha}{4} x^{4}}=\frac{8}{3} \sqrt{x}-\frac{5}{3} x^{0,8}
$$


onde $\alpha$ é dado por

$$
\ln (\alpha)=0,0577 \ln \left(\frac{\mu_{d}}{\mu_{c}}\right)-0,558
$$

$\mathrm{G}\left(\mathrm{v}, \mathrm{v}^{\prime}\right)=0$ quando $v \leq 0$ e $\mathrm{G}\left(\mathrm{v}^{\prime} \mathrm{v}^{\prime}\right)=1$ quando $v \leq v^{\prime}$ e $0 \leq \mathrm{x} \leq 1$.

Em um gráfico de G por v' deve se esperar que $\mathrm{G}$ aumente para a esquerda com o aumento de $\mathrm{v}^{\prime}$. Isso implica que $\left[\mathrm{dG}\left(\mathrm{v} \mathrm{v}^{\prime}\right) / \mathrm{dv}^{\prime}\right]_{\mathrm{v}}$ deve ter valores positivos. $\mathrm{E}$ a forma autosimilar como foi escrito $\mathrm{g}(\mathrm{x})$ implica que a posterior derivada é zero, o que significa que se deve favorecer a quebra de partículas grandes, ao passo que as partículas pequenas não devem se quebrar facilmente. Além disso outra vantagem nessa função (3.3.2) é que na formulação do problema inverso precisaremos utilizar a transformação de similaridade $\left(\mathrm{F}(\mathrm{v}, \mathrm{t}) \rightarrow \mathrm{f}(\xi), \xi=\Gamma(\mathrm{v}) \mathrm{t} / \Gamma\left(\mathrm{v}_{\mathrm{o}}\right)\right)$ que é admitida por essa forma de expressar a função de quebra.

Se considerarmos a forma da equação (3.3.2), teremos o problema de imaginar se esta forma da equação consegue admitir o aumento no gráfico de $G\left(v, v^{\prime}\right)$ por x para a esquerda à medida que v' aumenta.

$$
\frac{d G\left(v, v^{\prime}\right)}{d v^{\prime}}=g^{\prime}\left(\frac{\Gamma(v)}{\Gamma\left(v^{\prime}\right)}\right) \frac{1}{\Gamma(v)^{2}}\left(v \Gamma^{\prime}(v) \Gamma\left(v^{\prime}\right)-\Gamma(v) \Gamma\left(v^{\prime}\right)\right)
$$

Desde que g é monotônica, aumentando g' é positivo e o sinal do lado esquerdo da equação (3.3.5) é positivo se e somente se:

$$
\begin{aligned}
& \left(v \Gamma^{\prime}(v) \Gamma\left(v^{\prime}\right)-\Gamma(v) \Gamma\left(v^{\prime}\right)\right)>0 \\
& \frac{d \ln \left(\Gamma\left(v^{\prime}\right)\right)}{d v^{\prime}}>\frac{d \ln (\Gamma(v))}{d v} \quad\left(v^{\prime}<v\right)
\end{aligned}
$$

implicando que o gráfico de $\operatorname{Ln}(\Gamma(\mathrm{v}))$ por $\operatorname{Ln}(\mathrm{v})$ deve apresentar uma inclinação crescente à medida que o valor $\operatorname{Ln}(\mathrm{v})$ diminuí.

A função de distribuição de filhas $G\left(v, v^{\prime}\right)$ foi convertida utilizando $\beta\left(v, v^{\prime}\right)$, que é a probabilidade de uma partícula filha proveniente da quebra de uma partícula de tamanho v' ter seu volume entre $\mathrm{v}$ e $\mathrm{v}+\mathrm{dv}$. A função $\beta\left(\mathrm{v}, \mathrm{v}^{\prime}\right)$ é usada na função de distribuição numérica do modelo de balanço populacional, e $v(v ')$ que é o número médio de partículas filhas obtidas de uma partícula mãe de volume v', na forma (3.3.8), como uma função derivativa da outra, portanto o cálculo da função $G$ é a combinação das duas funções $\beta\left(v, v^{\prime}\right)$ e $v\left(v^{\prime}\right)$ previamente conhecidas (RAMKRISHNA;NERE,2005): 


$$
G\left(v, v^{\prime}\right)=\frac{1}{v^{\prime}} \int_{0}^{x} v^{\prime}\left(v, v^{\prime}\right) n(v) d v \Leftrightarrow \beta\left(v, v^{\prime}\right) n(v)=\frac{1}{v} \frac{d}{d v}\left(v^{\prime} G\left(v, v^{\prime}\right)\right)
$$

A função $\mathrm{G}$ da equação (3.3.8) deve representar um núcleo ("kernel”) de quebra de partículas v e v', esse núcleo para a resolução do problema inverso por auto-similaridade deve ser auto-similar, ou seja, alguma tendência deve ser mantida ao longo do tempo para as distribuições; um exemplo de núcleo auto-similar pode ser descrito na figura 3.3.1.

Podemos, também, definir o número médio de partículas filhas $\mathrm{G}_{\text {médio }}$, provenientes de uma quebra, de uma partícula mãe v' como:

$$
G_{\text {médio }}\left(v, v^{\prime}\right)=\int_{0}^{v^{\prime}}\left(\frac{v^{\prime}}{v}\right) \frac{\partial G\left(v, v^{\prime}\right)}{\partial v} d v=\int_{0}^{v_{\min }}\left(\frac{v^{\prime}}{v}\right) \frac{\partial G\left(v, v^{\prime}\right)}{\partial v} d v+\int_{v_{\min }}^{v^{\prime}}\left(\frac{v^{\prime}}{v}\right) \frac{\partial G\left(v, v^{\prime}\right)}{\partial v} d v
$$

Embora as partículas de volume menor que $\mathrm{v}_{\min }$, são de volume desprezível, para uma abstração matemática não vamos desprezar o primeiro termo da equação (3.3.9). E vamos considerar a existência da quebra de partículas de tamanho $\mathrm{v}_{\min }$.

Se usarmos a equação (3.3.2) e substituirmos em (3.3.9), poderemos reescrever a equação na forma:

$$
G\left(v, v^{\prime}\right)=\int_{0}^{1} \frac{v^{\prime}}{\Gamma^{-1}\left(x \Gamma\left(v^{\prime}\right)\right)} g^{\prime}(x) d x
$$

A função $\Gamma^{-1}$, na equação (3.3.10), seria o mapeamento inverso de $\Gamma(v)$, ou seja, $\Gamma^{-1}(\Gamma(\mathrm{v}))=\mathrm{v}$. Desta equação podemos deduzir que $\mathrm{v}^{\prime} \rightarrow \mathrm{v}_{\min }$, e, portanto teríamos uma abstração matemática da quebra da menor partícula $v_{\min }$, nela mesmo. $E$, em outras de volume igual a zero. Por isso, na figura 3.3.1 podemos verificar uma gama de valores iguais a zero, visto que, essa função obedece esta abstração matemática. Portanto é possível conciliar o conceito de similaridade dentro dos volumes muito pequenos da distribuição, $0<\mathrm{v}<\mathrm{v}_{\min }$, neles $\Gamma\left(\mathrm{v}_{\min }\right)=0$, e isso implicará que $\mathrm{G}\left(\mathrm{v}, \mathrm{v}^{\prime}\right)=0$, para $\mathrm{v}<\mathrm{v}_{\min }$. 

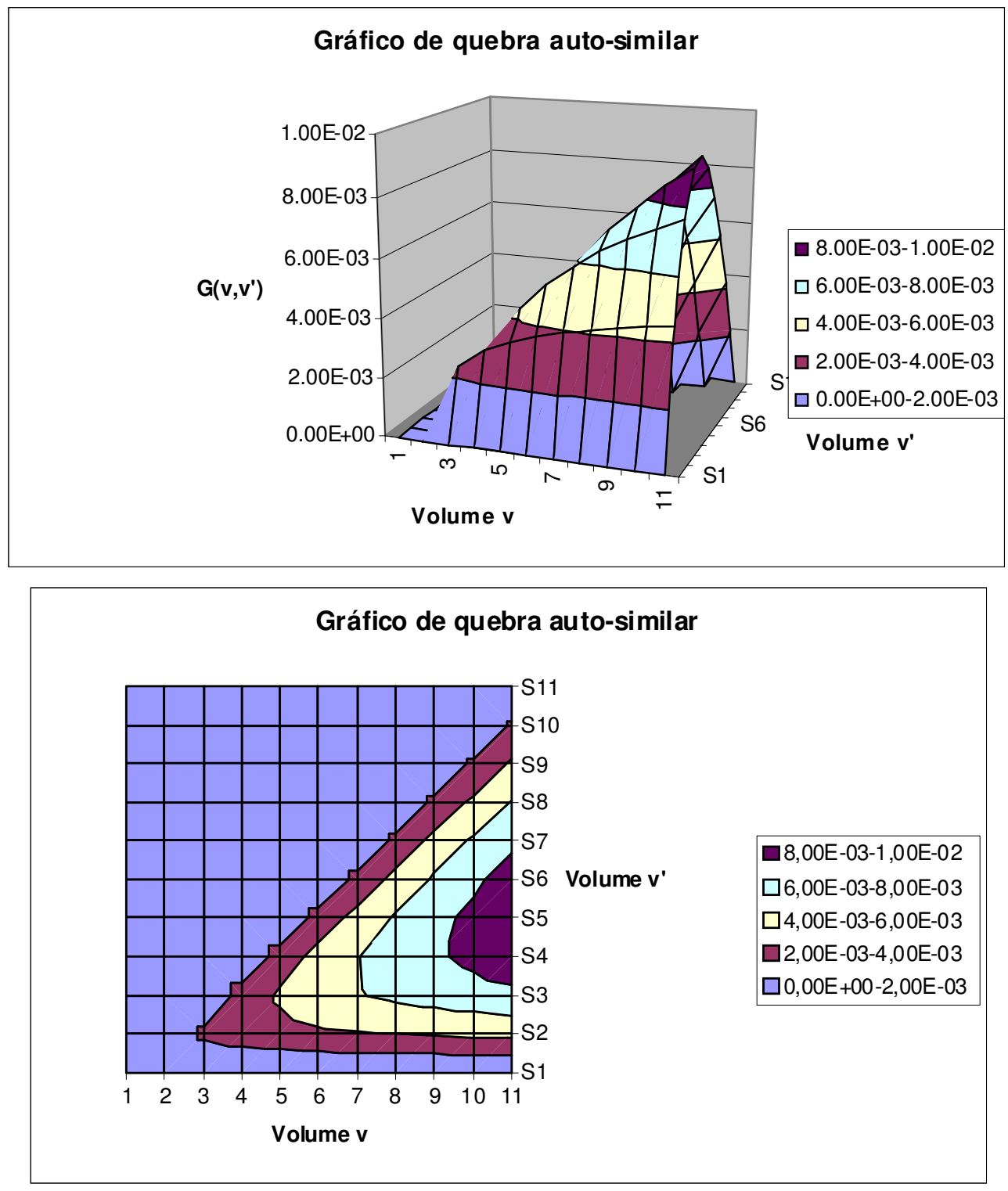

Figura 3.3.1: Exemplo de taxas de quebra auto-similar como a descrita pela equação (3.3.2).

No caso em questão, a equação (3.3.2) pode ser escrita numa forma analítica como na equação (3.3.11), bastando-se utilizar a regra da cadeia para se chegar a tal solução: 


$$
\begin{aligned}
\beta\left(v, v^{\prime}\right) n(v) & =\frac{v}{v^{\prime}} \frac{d}{d v}\left(G\left(v, v^{\prime}\right)\right)=\frac{v}{v^{\prime}} \frac{d}{d v}(g(x))=\frac{v}{v^{\prime}} \frac{d}{d v}\left(g\left(\frac{\Gamma(v))}{\Gamma\left(v^{\prime}\right)}\right)\right)=\frac{v}{v^{\prime}} \frac{d g}{d x} \frac{d x}{d v} \\
& =\frac{v}{v^{\prime}}\left(\frac{4}{3} x^{-\frac{1}{2}}-\frac{4}{3} x^{-\frac{1}{5}}\right) \underbrace{\frac{\Gamma(v)\left[\frac{0,12}{v}-\frac{4 \ln (v)}{v}\right]}{v}}_{\frac{1}{\Gamma\left(v^{\prime}\right)} \frac{d}{\frac{d v}{\frac{d}{d v}[\Gamma(v)]}}\left(\frac{\Gamma(v)}{\Gamma\left(v^{\prime}\right)}\right)}] \\
& =\frac{v}{v^{\prime}}\left(\frac{4}{3} x^{-\frac{1}{2}}-\frac{4}{3} x^{-\frac{1}{5}}\right) \underbrace{\frac{\Gamma(v)}{\Gamma\left(v^{\prime}\right)}}_{x}\left[\frac{0,12-0,4 \operatorname{Ln}(v)}{v}\right] \\
& =\frac{v^{\prime}}{v^{2}} x\left(v, v^{\prime}\right) \frac{4}{3} \sqrt{x\left(v, v^{\prime}\right)} \frac{4}{3} x^{\frac{4}{5}}(0,12-0,4 \ln (v))
\end{aligned}
$$

\subsection{Equacionamento do Problema Inverso.}

O problema inverso de balanço populacional, como já explicado, busca determinar as funções $\Gamma(v), \beta\left(v, v^{\prime}\right)$ e $v\left(v^{\prime}\right)$ a partir de dados experimentais de distribuições $n(v, t)$ medidas em diferentes instantes $t$ durante o processo de quebra. Este problema é conhecido por ser inerentemente mal-condicionado, no sentido de que os resultados obtidos para estas funções são muito sensíveis à qualidade e quantidade de dados de distribuição experimentais disponíveis (RAIKAR et al., 2006). Em geral diferentes formas destas funções podem resultar em aproximações razoáveis para um número limitado de distribuições experimentais, que usualmente são medidas e disponibilizadas para o problema inverso.

O procedimento adotado no presente trabalho é aquele baseado no conceito de soluções auto-similares (KUMAR; RAMKRISHNA, 1996, RAMKRISHNA, 2000, RAIKAR et al., 2006). As distribuições medidas em diferentes tempos de processo são inicialmente testadas quanto à auto-similaridade, e se esta propriedade é verificada, as distribuições são então usadas para a reconstrução não-paramétrica das funções de quebra e de criação de partículas filhas (partículas resultantes da quebra).

Para a aplicação do problema inverso, é conveniente reformular a equação de balanço populacional em termos da distribuição cumulativa ou acumulada, ao invés da forma de distribuição diferencial expressão pela equação (3.4.1). 
A distribuição acumulada $F(v, t)$ corresponde à fração de volume das partículas de volume menor que $v$ no instante $t$, e é definida matematicamente por:

$$
F(v, t)=\frac{\int_{0}^{v} v^{\prime} n\left(v^{\prime \prime}, t\right) d v^{\prime}}{\int_{0}^{\infty} v^{\prime} n\left(v^{\prime \prime}, t\right) d v^{\prime}}
$$

Aplicando esta definição, a equação de balanço populacional (3.4.2) fica com a forma:

$$
\frac{d F(v, t)}{d t}=\int_{0}^{\infty} \Gamma\left(v^{\prime}\right) G\left(v, v^{\prime}\right) \partial_{v} F\left(v^{\prime}, t\right)
$$

onde $\Gamma(v)$ é a taxa de quebra das partículas de volume $v$ e $G\left(v, v^{\prime}\right)$ é a fração volumétrica cumulativa de partículas de volume menor ou igual a $v$ formadas pela quebra de partícula de volume $v^{\prime}$. A função $G\left(v, v^{\prime}\right)$ combina as funções $\beta\left(v, v^{\prime}\right)$ e $v\left(v^{\prime}\right)$ apresentadas anteriormente, na forma:

$$
G\left(v, v^{\prime}\right)=\frac{v\left(v^{\prime}\right)}{v^{\prime}} \int_{0}^{v} x \beta\left(x, v^{\prime}\right) d x
$$

Esta função é uma distribuição acumulada com propriedades $G\left(0, v^{\prime}\right)=0$ e $G\left(v^{\prime}, v^{\prime}\right)=1$.

Para a solução do balanço populacional na forma acumulada (3.4.3) é necessário conhecer as funções $\Gamma(v)$ e $G\left(v, v^{\prime}\right)$. Nesta formatação, o objetivo do problema inverso é, então, obter as funções $\Gamma(v)$ e $G\left(v, v^{\prime}\right)$ a partir das distribuições $F(v, t)$ medidas durante o transiente do processo de quebra. Conforme destacam Raikar et al. (2006), a característica importante da metodologia de problema inverso baseada na auto-similaridade é que não é necessário especificar a priori as formas funcionais destas funções. A hipótese de autosimilaridade permite que a função de distribuição de partículas filhas seja representada de forma compacta por:

$$
G\left(v, v^{\prime}\right)=g(x)=g\left(\frac{\Gamma(v)}{\Gamma\left(v^{\prime}\right)}\right)
$$

Embora esta forma funcional pareça ser restritiva, ela se aplica a relações na forma de lei de potências freqüentemente empregadas na literatura para descrever processos de quebra de 
gotas de líquido (e também tem sido empregada na formulação de problemas de quebra de moléculas de polímero).

\subsubsection{Verificação da auto-similaridade das distribuições}

O procedimento se inicia pela construção do gráfico com curvas de $\ln t$ versus $\ln v$ para diferentes valores da distribuição acumulada $F$. Estes valores devem ser lidos na curvas de distribuição acumulada $F(v, t)$ para valores fixados de $F$, tomando os correspondentes valores de $t$ e $v$ que dão o mesmo valor e $F$ nas diferentes curvas.

Calculam-se então os comprimentos de $\operatorname{arco} s(x)$ das diferentes curvas de $\ln t$ versus $\ln v$ pela fórmula:

$$
s(x)=\int_{x_{0}}^{x}\left[1+\left(\frac{d y}{d x}\right)^{2}\right]^{1 / 2} d x
$$

onde $x=\ln v \quad$ e $\quad y=\ln t$. Este cálculo requer avaliação e depois a integração da derivada primeira $\mathrm{d} y / \mathrm{d} x$. Se uma única curva de comprimento de $\operatorname{arco} \mathrm{s}(\mathrm{x})$ é obtida a partir das diferentes curvas $y(x)$ de $\ln t$ versus $\ln v$, então os dados são considerados auto-similares. Tipicamente, esta verificação é realizada por inspeção visual das curvas de comprimento de $\operatorname{arcos} s(x)$.

Um exemplo desses tipos de curva é ilustrado a seguir com os dados retirados de RAMKRISHNA (2000) para dispersão de gotas no sistema formado por benzeno e tetracloreto de carbono. Temos inicialmente as distribuições diferenciais mostradas na figura 3.4.1, obtidas do arquivo de gráfico em bitmap por meio do programa "digitize.m" que faz parte do pacote do MatLab. Este recurso foi usado para "ler" os dados reportados no gráfico (já que não são reportados dados tabelados, apenas os gráficos). Isto permite coletar muitos pontos de modo a reproduzir com o melhor grau de acuidade as curvas originais da literatura.

Tendo a distribuição em termos do diâmetro de partículas, e considerando que todas as partículas são esféricas, pode-se relacionar o diâmetro de cada partícula com o respectivo volume usando a relação (3.4.1.2):

$v=\frac{\pi}{6} d^{3} \quad, \quad n(v, t)=\frac{2}{\pi d^{2}} n_{d}(d, t)$ 
Devemos notar pela figura 3.4.1.1 que tipicamente a distribuição de tamanhos de partícula é coletada em poucos (5-10) tempos de discretização, e os cálculos do problema inverso, como mostraremos adiante (como o cálculo das curvas de comprimento de arco) podem ser negativamente afetados pelo pequeno número de curvas de distribuição ao longo do tempo. Podemos calcular a partir das distribuições a suas funções cumulativas como na figura 3.4.1.2.

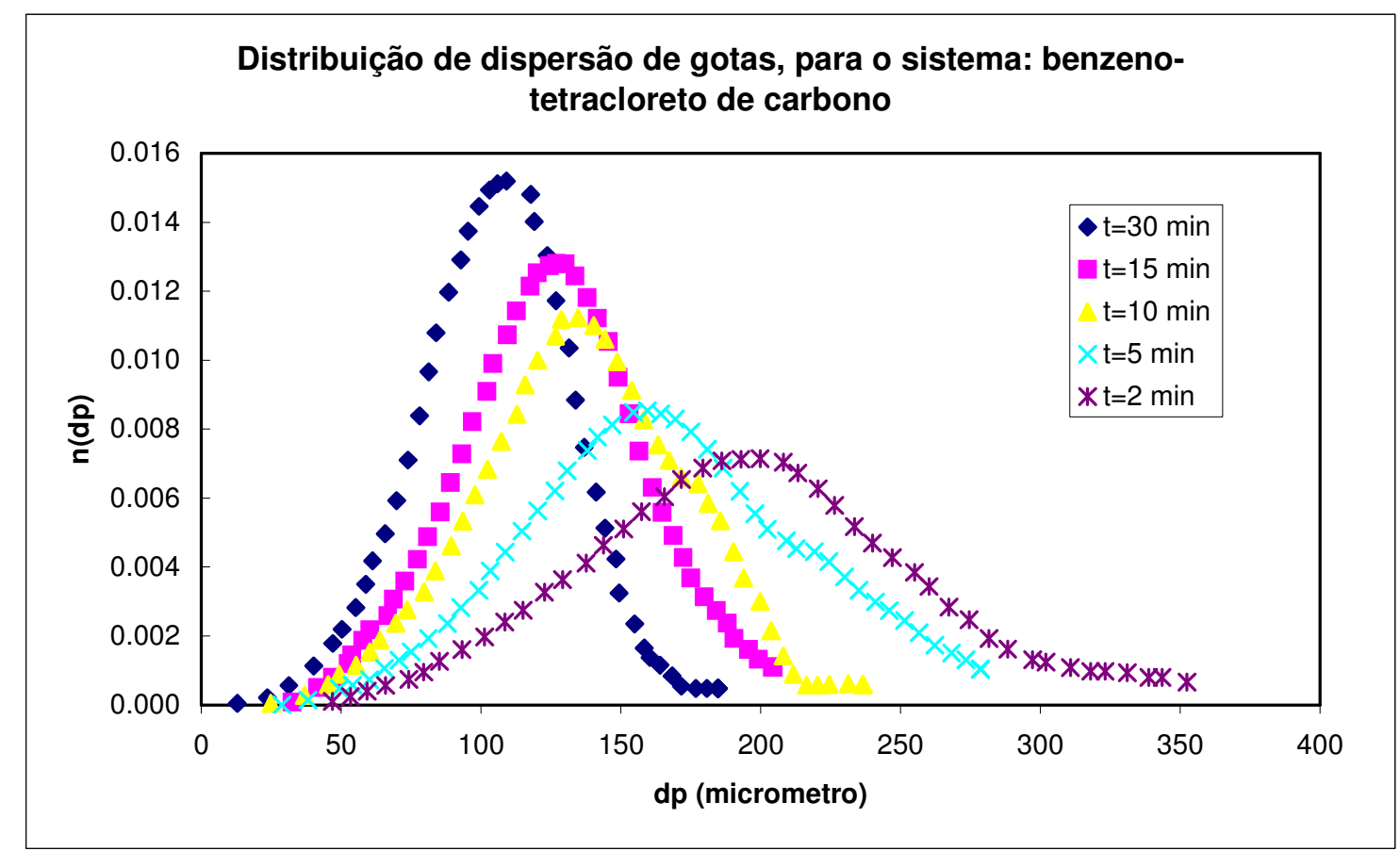

Figura 3.4.1.1: Distribuições ao longo do tempo para a dispersão de gotas, para o sistema, benzeno-tetracloreto de carbono. 


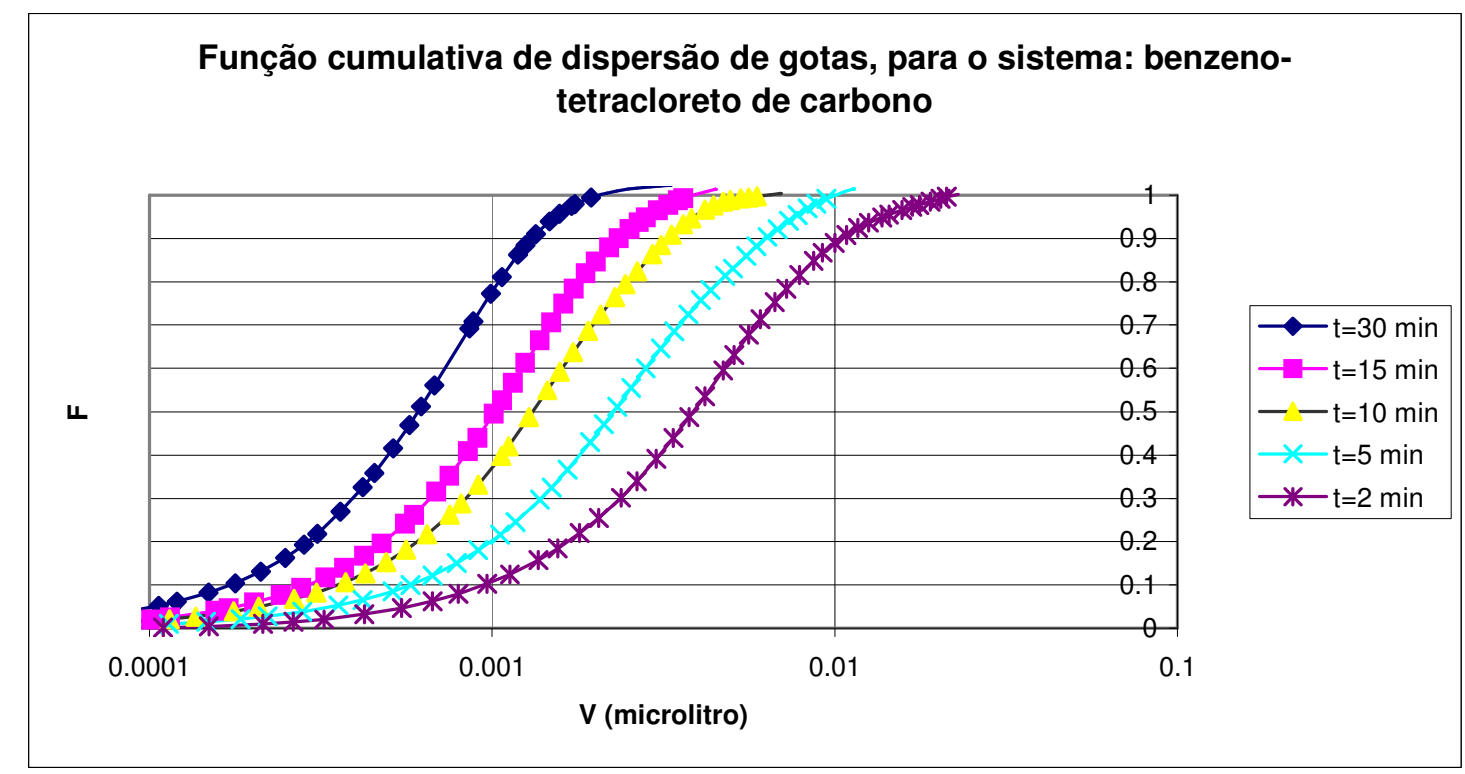

Figura 3.4.1.2: Função cumulativa para dispersão de gotas, para o sistema: benzenotetracloreto de carbono.

A partir da distribuição acumulada $F(v, t)$, valores de $t$ e $v$ devem ser lidos nas curvas de distribuição acumulada $F(v, t)$ para valores fixados de $F$, como ilustrado na Figura 3.4.1.3.

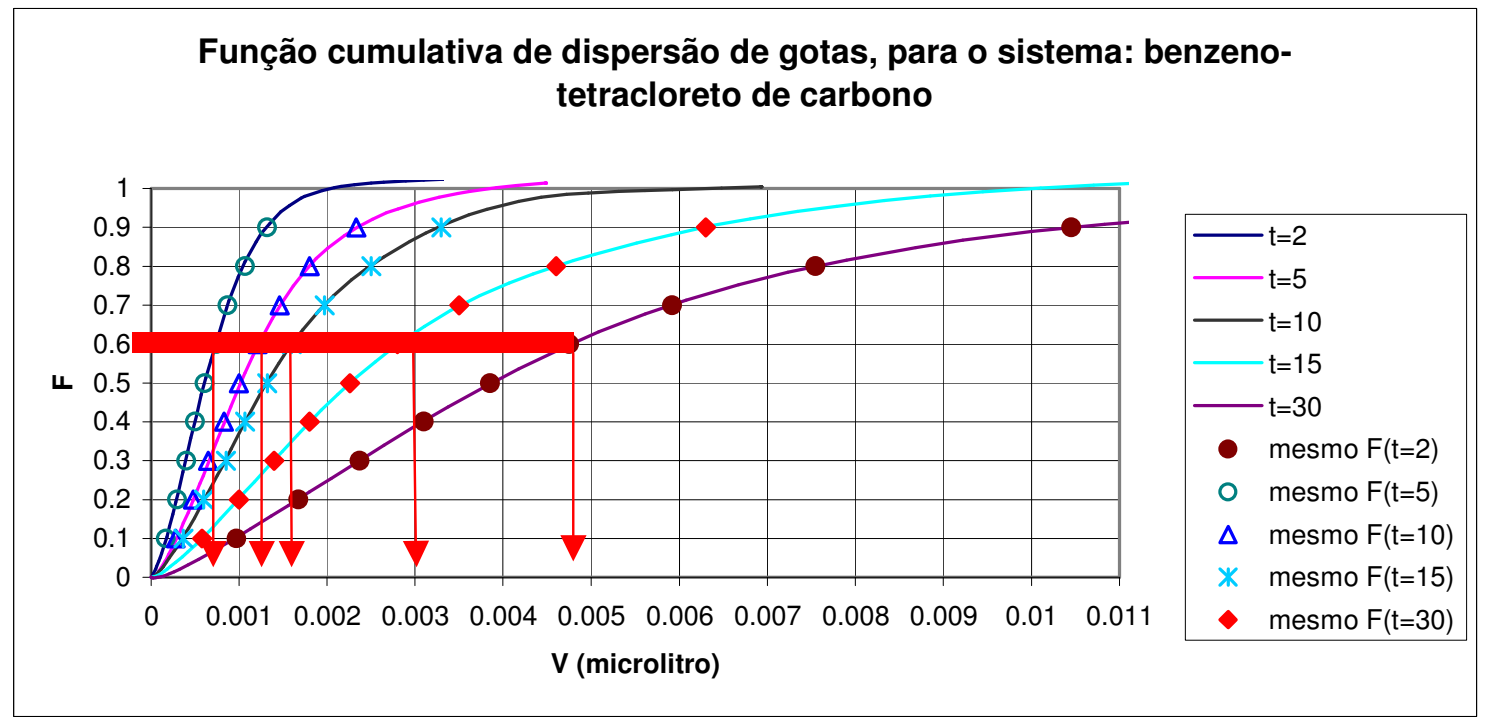

Figura 3.4.1.3: Valores de v obtidos para o mesmo F e usados no cálculo da variável de similaridade. 
Com a seguinte transformação $\mathrm{x}=\ln (\mathrm{v})$ e $\mathrm{y}=\ln (\mathrm{t})$, podemos supor que as curvas $\ln (\mathrm{t})$ por $\ln (\mathrm{v})$ devem ser ajustadas para uma forma de equação quadrática ou linear (conforme recomendam Raikar et al., 2006) para que nós possamos obter resultados aceitáveis, isso acontece, pois muitas vezes os dados experimentais se apresentam com muito espaçamento, entre os pontos, e também com muito ruído nas medidas obtidas, o que levaria a grandes erros numéricos, então, esse ajuste permite que tenhamos uma solução final mais robusta, pois podemos aumentar o número de elementos finitos de volume, o quanto, nós quisermos, e assim, não necessitamos de uma solução analítica mais complexa de se obter, como no caso em questão precisamos de um volume de referência, e no caso a extrapolação para esse volume feita pelo polinômio é muito mais precisa do que uma interpolação linear qualquer entre os pontos.

Em todos os gráficos que serão apresentados não apresentaremos todos os valores disponíveis da função cumulativa para que as figuras estejam mais limpas e fáceis para visualizarmos, como a distribuição tem muitos pontos sempre que quisermos um ponto com determinado valor de $\mathrm{F}(\mathrm{v}, \mathrm{t})$, basta interpolarmos linearmente, que teremos um resultado dentro do esperado, para interpolar vários pontos utilizamos a função "interpln.sci" do SciLab, e com isso podemos fazer os cálculos com muitos valores de $\mathrm{F}(\mathrm{v}, \mathrm{t})$ ou se quisermos para determinados valores que desejamos, no caso apresentamos apenas oito valores de 0,1 até 0,9 , porém o cálculo e as regressões que são realizadas pelo algoritmo utiliza todos os valores de $\mathrm{F}(\mathrm{v}, \mathrm{t})$ do tempo inicial, em ambiente SciLab podemos usar a função "datafit.sci" para obter os coeficientes do polinômio.

Existem, algumas, formas, de resolver, o problema inverso, ou, de se efetuar os procedimentos, de inversão com a obtenção das taxas desejadas dos respectivos balanços entre eles o proposto por BERTHIAUX; DOODS (1997) e BERTHIAUX; VARINOT; DOODS (1996), que da mesma forma que o método que será utilizado aqui utiliza uma minimização por uma rotina que utiliza uma procura direta baseada no algoritmo de Levenberg-Marquardt, o método de L-M é um método quase newtoniano e é também uma variação do método do gradiente, esse método envolve o encontro de zeros em uma função de vetores, e em geral nesses métodos as funções são simultaneamente aproximadas pelo uso de séries de Taylor, nós utilizaremos esse método sem o uso de restrições durante a 
otimização. Essas técnicas e ferramentas serão testadas em um procedimento simples que visa verificar a eficácia desse procedimento de otimização linear sem restrições.

Para a solução do problema inverso a equação (3.4.1.2) é utilizada. A propriedade de similaridade pode ser testada por ela avaliando-se os comprimentos de arco de diferentes curvas $\ln (\mathrm{t})$ por $\ln (\mathrm{v})$ expressa pela formula (3.4.1.2), para uma curva $\mathrm{y}=\mathrm{y}(\mathrm{x})$ e comparando-se com os valores da curvatura (3.4.1.3):

$$
s(x)=\int_{x_{0}}^{x}\left[1+\left(\frac{d y}{d x}\right)^{2}\right]^{\frac{1}{2}} d x=\int_{\ln v_{0}}^{\ln v}\left[1+\left(\frac{d \ln (t)}{d \ln (v)}\right)^{2}\right]^{\frac{1}{2}} d \ln (v)
$$

A hipótese de similaridade é valida quando os valores do comprimento de arco, e da curvatura, que envolvem cálculos da primeira e segunda derivadas, devem ser em diferentes curvas de $\ln (\mathrm{v})$ por $\ln (\mathrm{v})$, aproximadamente iguais, para todos os valores, de $\ln (\mathrm{v})$, isso acontece por que para qualquer curva em um plano regular, $\mathrm{y}=\mathrm{y}(\mathrm{x})$, só pode ser determinada se soubermos sua curvatura $k$ como função de seu comprimento de arco $s$, ou de $x$, e o comprimento de arco da curva com função de $x$, e que a curvatura esteja definida como uma função de $x$ :

$$
k(x)=\frac{\frac{d^{2} y}{d x^{2}}}{\left[1+\left(\frac{d y}{d x}\right)^{2}\right]^{\frac{3}{2}}}
$$

NARSIMHAM; RAMKRISHNA; GUPTA (1980) desenvolveram um procedimento para testar os dados experimentais com relação à sua similaridade e esforços anteriores demonstraram ser um indício de que exista similaridade, um gráfico típico de $\ln (\mathrm{t})$ por $\ln (\mathrm{v})$, com todos os pontos, $\mathrm{v}_{1}, \mathrm{v}_{2}, \mathrm{v}_{3}, \ldots, \mathrm{v}_{\mathrm{n}}$, em torno da ordenada, isto é, paralelo a abscissa $\ln (\mathrm{t})$. Eles seriam paralelos, e, além disso, eles seriam independentes de $\mathrm{F}$, essa independência das curvas pode ser interpretada da seguinte forma, se fizermos uma translação vertical dessas curvas num dado ponto, nós poderemos ter todas elas sobrepostas em uma única curva, basta realizar a translação de cada curva em determinado ponto diferente.

Caso a distribuição apresentar similaridade o cálculo da similaridade é conforme ilustrado pela figura 3.4.1.3, e, assim, para cada valor da distribuição cumulativa $F$, existem 
vários volumes correspondentes em diferentes tempos que devem coincidir com um único valor de uma variável de similaridade.

Caso a hipótese de similaridade seja verdadeira, isto é, se os valores calculados de $k \mathrm{e}$ $s$ para diferentes curvas são comparativamente iguais, os valores calculados de k e s podem ser utilizados para calcular a equação da curva completa de $\ln (t)$ por $\ln (v)$, usando a equação (3.4.1.2), encontramos:

$$
\frac{d \ln (t)}{d \ln (v)}=\left[\left(\frac{d s}{d \ln (v)}\right)^{2}-1\right]^{\frac{1}{2}}
$$

O resultado da equação (3.4.1.5) foi usado no cálculo das derivadas parciais da equação (3.4.1.2) para obtermos $\Gamma(\mathrm{v}) / \gamma$ que é a taxa de quebra dividida por uma constante $\gamma$, o volume de referência $v_{r}$ é a base para que calculemos o comprimento de arco, e é escolhido conforme o tipo de taxa de quebra seria esperado para o sistema particulado em questão.

Quando traçamos o gráfico de $\mathrm{s}$ por $\ln (\mathrm{v})$ podemos em todos os casos aproximar este gráfico por uma equação exponencial do segundo grau com mais precisão que uma reta, ou, por um polinômio de grau maior, ou, podemos também inverter os eixos das abscissas e das ordenada nas curvas $\ln (\mathrm{v})$ por $\ln (\mathrm{v})$, assim podemos dependendo do caso fazer uma interpolação melhor até o volume de referência.

A informação experimental que temos consiste da distribuição cumulativa $F(v, t)$ em diferentes tempos. Para um valor fixo de $F(v, t)$, v e t seriam descritos da seguinte forma $\Gamma(v) t=$ constante, desde que a transformação de similaridade for válida e a variável de similaridade seja constante em um valor de F também constante. Então como mostrado por (RAMKRISHNA; NARSIMHAM; GUPTA, 1980).

$$
t \frac{d \Gamma(v)}{d v}+\left(\frac{d t}{d v}\right)_{F} \Gamma(v)=0
$$

ou, poderíamos reescrever também na forma:

$$
\frac{d \ln (\Gamma(v))}{d v}+\left(\frac{d \ln (t)}{d v}\right)_{F}=0
$$

Pelas equações (3.4.1.6) ou (3.4.1.7), sempre que a similaridade existir as curvas do comprimento de arco $s$ vão se sobrepor, com exceção de quando as várias partes das curvas comuns $\ln (\mathrm{v})$ por $\ln (\mathrm{v})$ estejam dispostas verticalmente uma da outra. 
Para alguns casos é possível que a distribuição não seja auto-similar, porém a técnica que foi apresentada acima não nos faz apenas obter um teste de hipótese de similaridade, mesmo sem existir similaridade as curvas sobrepostas do comprimento de arco $s$ nos fornecem informação adicional sobre a taxa de quebra da qual queremos encontrar.

A taxa de quebra pode então ser recalculada como descrito em (3.4.1.8) e para tanto devemos manter constante a função de distribuição acumulada como descrito na equação (3.4.1.8), que nada mais é do que a equação (3.4.1.9) multiplicada por v.

$$
\frac{d \ln \Gamma(v)}{d \ln (v)}=-\left(\frac{d \ln (t)}{d \ln (v)}\right)_{F}
$$

A partir da curva sobreposta de $\ln (\mathrm{v})$ por $\ln (\mathrm{v}), \partial \ln (\mathrm{t}) / \partial \ln (\mathrm{v})$ pode ser determinado em vários valores de $\mathrm{v}$, podemos obter matematicamente a equação (3.4.1.8) por integração da equação (3.4.8) de um determinado volume de referência $\mathrm{v}_{\mathrm{r}}$, neste caso será o maior volume do domínio devido à natureza crescente do núcleo de quebra, até v, e então teremos:

$$
\Gamma(v)=\gamma \exp \left(\left[-\int_{\ln \left(v_{r}\right)}^{\ln (v)}\left(\frac{\partial \ln (t)}{\partial \ln (v)}\right)_{F} d \ln (v)\right]\right)
$$

A formulação desenvolvida do problema inverso até este ponto nos fornece uma taxa de quebra dependente de uma constante multiplicativa como descrito na equação (3.4.1.9), nela a taxa $\Gamma(\mathrm{v}) / \gamma$, que também pode ser chamada de quebra transacional é obtida antes do cálculo da taxa de quebra, porque no caso o valor de $\gamma$ é a função de quebra avaliada no volume de referencia $\mathrm{v}_{\mathrm{r}}$ usadas no cálculo de comprimento de arco: $\gamma=\Gamma\left(\mathrm{v}_{\mathrm{r}}\right)$, ou seja, uma constante multiplicativa a princípio desconhecida, portanto devemos notar que a rotina de cálculo deve ser implementada da seguinte forma. No caso de já escolhermos o volume de referência. Nós obteremos um valor estimado para a probabilidade de quebra transacional $\Gamma(\mathrm{v}) / \Gamma\left(\mathrm{v}_{\mathrm{r}}\right)$.

Podemos deduzir a robustez da equação (3.4.1.9) ao verificarmos, por exemplo, que caso o integrando da equação seja uma constante.

$$
\left(\frac{\partial \ln (t)}{\partial \ln (v)}\right)_{F}=-\alpha
$$


Com $\alpha$ sendo o expoente da expressão de lei de potências, toda a taxa de quebra se reduz a uma lei de potência que é o caso encontrado em alguns dados experimentais (RAMKRISHNA,1974; FILIPPOV,1962), em que os autores mostraram que em condições de quebra por lei de potências, ou seja, $\Gamma(\mathrm{v})=\mathrm{kv}^{\mathrm{n}}$, em que um valor positivo para $\mathrm{r}$ causa grande propensão de grandes partículas se quebrarem, e quebra similar, $G\left(v, v^{\prime}\right)=g\left(v / v^{\prime}\right)$, a equação (3.4.4) admitiu uma transformação de similaridade da forma $\mathrm{z}=\mathrm{v}^{\mathrm{r}} \mathrm{t}$, RAMKRISHNA (1974) formulou um problema inverso que tomou vantagem das condições em que a similaridade era válida para obter o expoente $n$, mas esses casos em que é possível resolver uma balanço populacional inverso com uma transformação explicita de similaridade sob condições especificas não é freqüentemente encontrado em todos os experimentos, uma técnica de problema inverso foi testada com dados em estado nãoestacionário por MADDEN; MCCOY (1969) e a lei de potências foi determinada apenas para um número bem limitado de dados.

O cálculo em elementos finitos da equação (3.4.1.9) foi realizado a técnica dos trapézios com a derivada para frente no tempo inicial para os volumes e com derivada para trás tempo final, mas para os elementos intermediários como o espaçamento em volume não é idêntico, como muitas das medidas experimentais, utilizamos então a fórmula (3.4.10) para diferenças centrais com pontos não necessariamente eqüidistantes:

$$
\left(\frac{d y}{d x}\right)_{i}=\frac{p^{2} y_{i+1}+\left(q^{2}-p^{2}\right) y_{i}-q^{2} y_{i-1}}{p q(p+q)}
$$

onde

$$
\begin{aligned}
& p=x_{i}-x_{i-1} \\
& q=x_{i+1}-x_{i}
\end{aligned}
$$

Os cálculos foram realizados a fim de se obter a integração em elementos finitos isso porque a solução analítica da função de quebra e o comprimento de arco têm soluções aparentemente difíceis de serem encontradas.

A equação de quebra pode ser a rigor calculada para cada variação de volume infinitesimal de partículas, basta para isso aumentar os elementos finitos envolvidos no cálculo, mas como essa função deve ser suficientemente suave podemos abrir mão disso e achar uma correlação para ela como, por exemplo, uma função exponencial. Esta, foi o tipo de função, que foi escolhido, para os cálculos, neste trabalho. E, é claro que caso estejamos 
analisando apenas medidas experimentais, o aumento no número de pontos também poderia resultar no aumento na adição de erros na medida experimental.

De acordo com a equação (3.4.1.9) precisamos de um volume de referência para as partículas, como a taxa de quebra deve ser decrescente, favorecendo volumes maiores, o volume de referência deve ser um volume maior ou igual ao máximo volume de partícula do domínio, pois isso faz com que a taxa de quebra cresça exponencialmente, o que não ocorreria caso escolhêssemos o menor volume do domínio das partículas, portanto esse volume de referência escolhido, o maior, foi usado na integração das curvas sobrepostas (RAMKRISHNA, 1980).

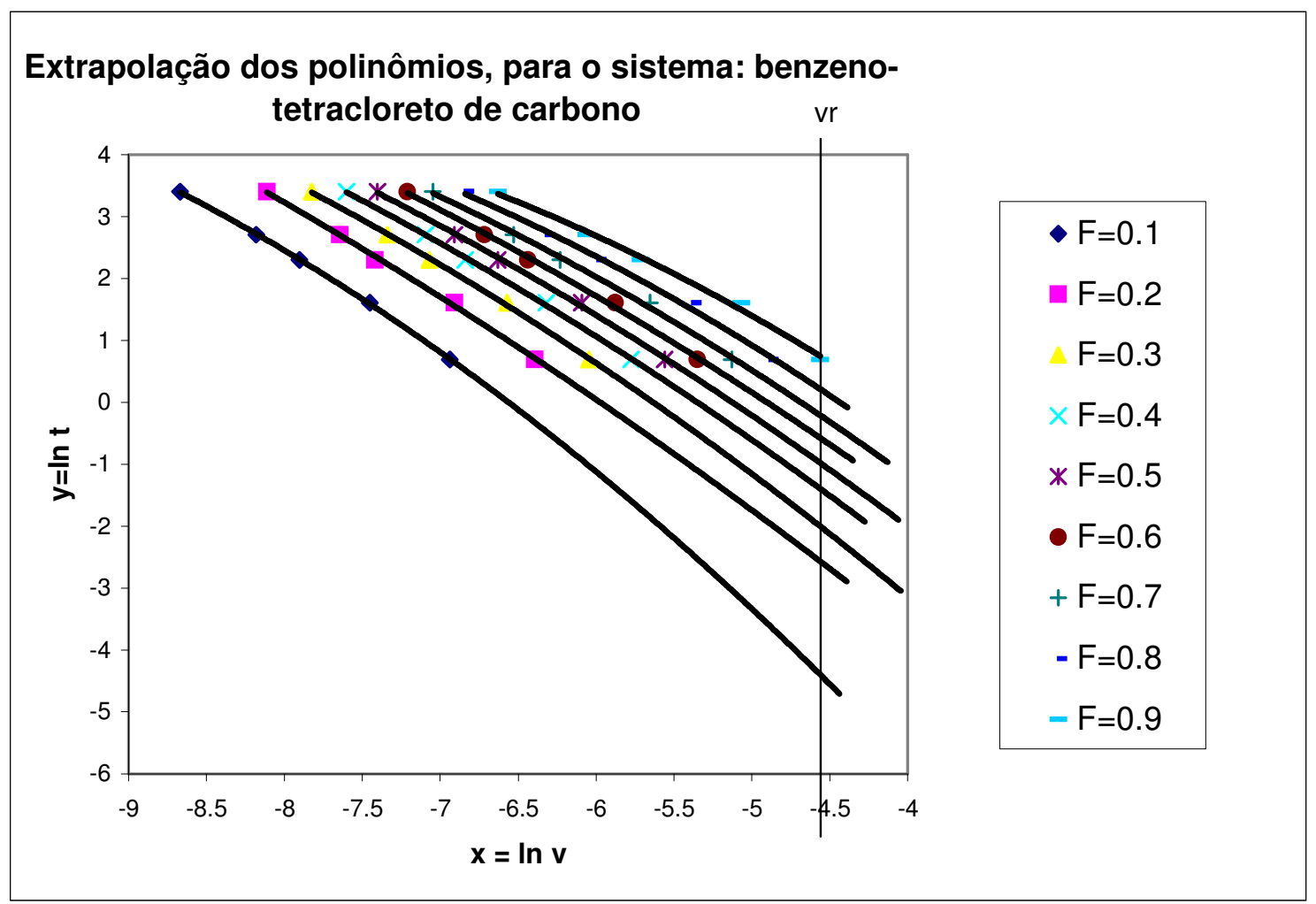

Figura 3.4.1.4: Exemplo dos ajustes $y=\ln (t)$ por $x=\ln (v)$ e sua extrapolação para vr, para uma distribuição experimental para o sistema: benzeno-tetracloreto de carbono.

Pela figura 3.4.1.4 fica claro que com esse tipo de ajuste é possível se extrapolar os pontos para o valor que escolhemos de referência. Rigorosamente para escolher o volume de referência devemos nos utilizar do coeficiente de variação de $(\partial \ln (t) / \partial \ln (v))$ em $v_{\mathrm{k}}$, e dado por: 


$$
\epsilon_{k}=\frac{\frac{1}{2^{n}}\left(\sum_{i=1}^{n} \sum_{j \neq i}^{n} U_{i j}^{k}\right)}{\frac{1}{n} \sum_{i=1}^{n} I_{i}^{k}}
$$

onde, as variáveis da equação (3.4.13) são definidas como:

$$
U_{i j}^{k}=\left[\left(\frac{\partial \ln (t)}{\partial \ln (v)}\right)_{F_{i}}-\left(\frac{\partial \ln (t)}{\partial \ln (v)}\right)_{F_{j}}\right]_{v=v_{k}}^{2} \quad e \quad I_{i}^{k}=\left(\frac{\partial \ln (t)}{\partial \ln (v)}\right)_{v=v_{k}, F_{i}}
$$

E, usando as equações (3.4.1.14), e, (3.4.1.15) um volume de referência $v_{r}$ deve ser escolhido de forma a minimizar-se $\epsilon_{\mathrm{r}}$, ou seja, encontrarmos seu menor valor possível.

Assim, o fator de translação é:

$$
\text { Fator de } \text { translação }_{i}=\ln \left(\frac{t_{r}}{t_{i}}\right)
$$

sendo $t_{r}, e, t_{i}$, os tempos, para o volume de referência, $v_{r}$. Mas como no caso conseguimos bons resultados apenas utilizando-se o maior volume existente $v_{\max }$, não utilizaremos tal rigor matemático das equações (3.4.1.14), (3.4.1.15), e, (3.4.1.16).

O conceito de autopreservação de uma distribuição foi introduzido primeiramente por SWIFT; FRIEDLANDER (1964) e é dependente da existência de uma transformação de similaridade entre a variável de tamanho de partículas e o tempo, e em grande parte dos artigos em que se estuda a similaridade a transformação de escala usada na formulação do problema inverso é do tipo $\mathrm{z}=<\mathrm{v}\rangle(\mathrm{t})$, sendo $\langle\mathrm{v}\rangle$, (t), um tamanho médio de partícula e o tempo ou $\mathrm{z}=\mathrm{v} / \mathrm{S}(\mathrm{t})$. Onde geralmente $\mathrm{S}(\mathrm{t})$ é um volume médio da distribuição, algumas escolhas comuns para essa relação podem ser do tipo: (a) $S(t)=M_{1}(t) / M_{0}(t)$, (b) $\mathrm{S}(\mathrm{t})=\mathrm{M}_{2}(\mathrm{t}) \mathrm{M}_{1}(\mathrm{t})$, ou, (c) $\mathrm{S}(\mathrm{t})=\mathrm{M}_{3}(\mathrm{t}) / \mathrm{M}_{2}(\mathrm{t})$. Sendo $\mathrm{M}_{\mathrm{w}}$ os momentos de ordem $\mathrm{w}$ (MURALIDHAR; RAMKRISHNA,1989), mas essa transformação foi estudada por WRIGHT; RAMKRISHNA (1992) e em investigações podemos considerar usar esse tipo de transformação chamada de transformação $z$ na tentativa de obtenção das taxas de quebra , porém uma analise melhor dessa transformação nos fornece a informação de ela só ser valida para o caso da quebra obedecer lei de potências, portanto para soluções mais triviais e não tão abrangentes, além disso, ela também é muito comum para casos em que ocorre coalescência, onde o volume utilizado é uma média do volume da distribuição e pode ser facilmente determinado por meio dos dados experimentais e portanto não corresponde ao 
caso que será analisado neste trabalho, para verificar se existe um outro tipo de transformação possível, ou seja, se os dados experimentais obedecem a uma transformação em que a taxa de quebra não é simples, ou não é trivial e requer uma transformação mais especifica, então para recalcular a distribuição filha utilizamos a transformação de similaridade (3.4.2.3), em termos da variável $\xi$, que é diferente da transformação em z.

\subsubsection{Obtenção da função de taxa de quebra e da distribuição de partículas filhas}

Da equação (3.4.2.1), a relação para a curva completa de $\ln t$ versus $\ln v$ pode ser obtida:

$$
\frac{d \ln t}{d \ln v}=\left[\left(\frac{d s}{d \ln v}\right)^{2}-1\right]^{1 / 2}
$$

de onde se pode avaliar as derivadas parciais a serem usadas na seguinte equação, que permite obter a função de quebra $\Gamma(v)$, a menos de uma constante multiplicativa:

$$
\Gamma(v)=\gamma \exp \left[-\int_{\ln v_{0}}^{\ln v}\left(\frac{d \ln t}{d \ln v}\right)_{F} d \ln v\right]
$$

onde $\gamma$, segundo Raikar et al. (2006), é a função de quebra avaliada no volume de referência $v_{0}$ usado nos cálculos do comprimento de arco, $\gamma=\Gamma\left(v_{0}\right)$, e o valor desta constante desconhecida é determinado como parte do procedimento de aproximação da função de distribuição das partículas filhas.

A equação (3.4.2.2) pode ser reescrita na forma:

$$
\xi=\frac{\Gamma(v)}{\gamma} t=t \exp \left(\left[-\int_{\ln \left(v_{0}\right)}^{\ln (v)}\left(\frac{\partial \ln (t)}{\partial \ln (v)}\right)_{F} d \ln (v)\right]\right)
$$

Essa variável $\xi$ da equação (3.4.2.3) é a que permitirá eliminarmos qualquer dependência no tempo que exista nas variáveis originais, ela é uma solução assintótica, conforme é apresentada no APÊNDICE B.

A vantagem desse tipo de transformação é que ela não está restrita aos casos em que a quebra obedece a uma lei de potência. Nela a quebra transacional é usada pela equação 
(3.4.2.3). Para transformar a distribuição de partículas $\mathrm{F}(\mathrm{v}, \mathrm{t})$ em diferentes tempos pela transformação de variáveis de similaridade.

A desvantagem é que como a natureza dessa transformação de similaridade não é explicita, o teste de autopreservação não é direto e prático.

Devemos notar que a transformação escolhida deve sempre obedecer a certos princípios físicos, para uma transformação em uma variável de similaridade z, por exemplo, teríamos que obedecer a equação (3.4.2.4).

$$
\lim _{z \rightarrow 0} z f^{\prime}(z)=0
$$

Caso (3.4.2.4) for violado implica que:

$$
\int_{0}^{\infty} n^{\prime}(v) d v \rightarrow \infty
$$

Isso, como descrito em (3.4.2.5), seria impossível pois sabemos que (3.4.2.6) deve ser obedecido pela conservação de massa.

$$
\int_{0}^{\infty} n^{\prime}(v) d v=1
$$

As relações em (3.4.2.7) devem ser obedecidas, pela variável de similaridade.

$$
\left(\frac{d \ln (t)}{d \ln (v)}\right)_{F}=\left(\frac{d \ln (t)}{d \ln (v)}\right)_{\zeta \gamma}=-\frac{\frac{d \xi \gamma}{d t}}{\frac{d \xi \gamma}{d v}}=-\frac{\gamma}{\Gamma(v) t}=\frac{v(t) n(v, t)}{\xi f^{\prime}(\xi)}
$$

onde $\xi=\Gamma(\mathrm{v}) / \gamma /$ t é a variável de similaridade definida como na equação (3.4.2.3), a equação (3.4.2.7), portanto implica que para diferentes volumes e diferentes tempos teríamos para um valor da função acumulada um valor idêntico sempre para a variável de similaridade ocasionando a sobreposição de todas as curvas ao longo do tempo em apenas uma única curva significando que o meio em que se encontram as partículas em questão é similar ou tem similaridade.

Portanto o valor calculado da função $\Gamma(\mathrm{v}) / \gamma$ pode então ser utilizado para calcularmos a variável de similaridade. Com a definição da variável de similaridade na equação (3.4.2.7), obtemos a expressão (3.4.2.8) para a distribuição de similaridade com a aplicação da transformação de similaridade $\mathrm{F}(\mathrm{v}, \mathrm{t}) \rightarrow \mathrm{f}(\xi)$ na forma cumulativa do balanço populacional (3.2.9). Esta função é então utilizada, para se calcular a distribuição de partículas filhas, ou seja, a equação de balanço populacional em termos de $\xi$ se torna: 


$$
\xi f^{\prime}(\xi)=\int_{0}^{1} \frac{\xi^{2}}{x^{3}} f^{\prime}\left(\frac{\xi}{x}\right) \gamma g(x) d x
$$

A equação (3.4.2.8) pode ser reescrita como:

$$
\xi f^{\prime}(\xi)=\Gamma\left(v_{r}\right) \int_{\xi}^{\infty} g\left(\frac{\xi}{x}\right) x f^{\prime}(x) d x
$$

E se definirmos os momentos como:

$$
\text { Momentos }_{w} \approx \int_{0}^{\infty} \xi^{n} f(\xi) d \xi \quad \text { para } \quad w=1,2 \ldots
$$

E, também, definirmos algumas constantes:

$$
\text { Constantes }_{w} \approx \int_{0}^{1} x^{n} g(x) d x \quad \text { para } \quad w=1,2 \ldots
$$

Se multiplicarmos a equação (3.4.2.11) por $\zeta^{\mathrm{n}-1}$ e integrarmos desde $\zeta$ igual à zero até ${ }^{\infty}$, nós encontraremos:

$$
\text { Momentos }_{w}=\Gamma\left(v_{r}\right) \text { Momentos }_{w+1} \text { Constantes }_{w-1} \quad \text { para } \quad \text { ordem }=1,2 \ldots \text { (3.4.2.12) }
$$

Ou, reorganizando os termos da equação (3.4.2.12), teríamos a equação (3.4.2.13):

$$
\Gamma\left(v_{r}\right) \text { Constantes }_{w-1}=\frac{\text { Momentos }_{w}}{\text { Momentos }_{w+1}} \quad \text { para } \quad w=1,2 \ldots
$$

Portanto à principio deveríamos ser capazes de avaliar $\gamma=\Gamma\left(\mathrm{v}_{\mathrm{r}}\right)$,e , $\mathrm{g}(\mathrm{x})$, pelos momentos $\left\{\Gamma\left(\mathrm{v}_{\mathrm{r}}\right)\right.$ Constantes $\left._{\mathrm{w}}\right\}$, como verificamos pela equação (3.4.2.13). Por meio de uma expansão polinomial razoável. Desde que $\mathrm{g}(1)=1$, fica claro que, $\Gamma\left(\mathrm{v}_{\mathrm{r}}\right)$, é obtido. Quando calculamos $\Gamma\left(\mathrm{v}_{\mathrm{r}}\right) \mathrm{g}(\mathrm{x})$, em $\mathrm{x}=1$. Entretanto, como a função de distribuição de partículas filhas, $\mathrm{g}(\mathrm{x})$, é uma função cumulativa. Apenas esperamos que momentos de ordem muito alta de $\Gamma\left(\mathrm{v}_{\mathrm{r}}\right) \mathrm{g}(\mathrm{x})$, sejam importantes nestes cálculos. Já que os momentos $\left\{\Gamma\left(\mathrm{v}_{\mathrm{r}}\right)\right.$ Constantes $\left._{\mathrm{w}}\right\}$ progressivamente diminuem, visto que $\mathrm{g}(\mathrm{x})$ é definida em um intervalo unitário. E, conseqüentemente eles não iriam diminuir rápido o suficiente para podermos justificar, ou, desprezar os momentos de ordem alta, nos cálculos de $\Gamma\left(\mathrm{v}_{\mathrm{r}}\right) \mathrm{g}(\mathrm{x})$, durante a expansão polinomial. Portanto, os cálculos dos momentos de $\Gamma\left(\mathrm{v}_{\mathrm{r}}\right) \mathrm{g}(\mathrm{x})$ requereriam um conhecimento dos momentos das distribuições de partículas, em uma ordem duas vezes maior, como podemos verificar pela equação, (3.4.2.13). Desde que erros consideráveis apareceriam nos cálculos de momentos de ordem muito alta. No fim das contas, não é 
possível calcularmos esses momentos de ordem muito alta $\Gamma\left(\mathrm{v}_{\mathrm{r}}\right) \mathrm{g}(\mathrm{x})$, com a precisão que queremos.

Porém, podemos utilizar esse equacionamento, partindo de que facilmente verificamos pelas equações (3.4.2.12), e, (3.4.2.13), que:

$$
\text { Momento }_{w}=\frac{\Gamma\left(v_{r 2}\right)}{\Gamma\left(v_{r 1}\right)} \text { Constantes }_{w} \quad \text { para } \quad w=1,2 \ldots
$$

onde $\left\{\right.$ Constante $\left._{\mathrm{w}}\right\}$, e, $\left\{\right.$ Momento $\left._{\mathrm{w}}\right\}$ são os momentos de $\Gamma\left(\mathrm{v}_{\mathrm{r} 1}\right) \mathrm{g}(\mathrm{x})$, e, de $\Gamma\left(\mathrm{v}_{\mathrm{r} 2}\right) \mathrm{g}(\mathrm{x})$, respectivamente. E, como o volume de referência, $\mathrm{v}_{\mathrm{r}}$, é utilizado na estimativa da probabilidade da quebra transacional, aleatoriamente. A consistência dos momentos de $\mathrm{g}(\mathrm{x})$ poderia ser verificada pela equação (3.4.2.14)

O procedimento sugerido por NARSIMHAN; RAMKRISHNA; GUPTA (1980) para calcular $\Gamma\left(\mathrm{v}_{\mathrm{r}}\right)$ e a função $\mathrm{g}$ foi resolvido para $\Gamma\left(\mathrm{v}_{\mathrm{r}}\right) \mathrm{g}(\mathrm{x})$ em termos dos momentos obtidos, e, computados $\left\{\right.$ Momentos $\left._{\mathrm{w}}\right\}$ para o gráfico de similaridade $\mathrm{f}(\zeta)$ por $\zeta$. Mas este procedimento não foi realizado por NARSIMHAN; RAMKRISHNA; GUPTA (1980). Uma tentativa mais detalhada desse equacionamento se encontra no APÊNDICE K. Entretanto, qualquer, esforço que podemos fazer nessa direção nos leva em dificuldades consideráveis. As dificuldades surgem da necessidade prática de truncar na equação (3.4.2.8), em seu limite superior. E, que não pode admitir uma solução trivial para $f(\zeta)$. Visto que, a equação truncada seria uma equação integral homogênea de Volterra. Deve-se reconhecer, entretanto, que a equação (3.4.2.9) é capaz de admitir uma solução não trivial, com o seu limite superior retido em $\infty$. Mas, muitos dados, experimentais, mostram uma tendência da função $f(\zeta)$ a aumentar até o seu máximo valor unitário, para valores relativamente finitos de $\zeta$. Se examinarmos o lado direito da equação (3.4.2.9), devemos concluir que $\mathrm{g}(\zeta . / \mathrm{x})$ deve tender a um valor limite pequeno $\mathrm{x}_{0}$, vindo da fração $\zeta . / \mathrm{x}$. Fisicamente isso significa que a fração volumétrica de partículas com um volume menor que uma fração $x_{0}$, proveniente da partícula mãe, deve ser zero. Então a equação (3.4.2.9) se tornaria:

$$
\xi f^{\prime}(\xi)=\Gamma\left(v_{0}\right) \int_{\xi}^{\frac{\xi}{x_{0}}} g\left(\frac{\xi}{x}\right) x f^{\prime}(x) d x
$$


A equação (3.4.2.15) não está sujeita à restrição de uma solução trivial, como foi referido anteriormente. As tentativas de se resolver a equação (3.4.2.15) geram muitas dificuldades numéricas, e, então teremos que buscar uma abordagem alternativa.

Portanto neste trabalho, para a solução do problema inverso, a equação (3.4.2.9) também conhecida com função de densidade de probabilidade normalizada será a base de todo nosso esforço para determinarmos a função $g$ e a constante $\gamma$. Porém ela não pode ser resolvida inicialmente na forma como está. Veremos que é necessário transformar esse problema em uma regressão não linear com restrições ou em uma otimização que será escrita em detalhes mais adiante, se inicialmente tivermos uma distribuição transiente e ela apresentar similaridade com relação a $\xi$, a tangente da curva $\ln (\mathrm{t})$ por $\ln (\mathrm{v})$ devem ser independentes da fração cumulativa de volume $\mathrm{F}$, e a curva de $\ln (\mathrm{t})$ por $\ln (\mathrm{v})$ para diferentes valores de $\xi \mathrm{f}(\xi)$ devem se sobrepor.

O fato de todas as distribuições se sobreporem após a transformação de similaridade resultando em uma única distribuição descrita pela equação (3.4.2.9) é um resultado de suma importância, pois é só por causa dessa natureza de autopreservação presente na distribuição que poderemos extrair as taxas de quebra que queremos encontrar.

Devemos notar que a expressão (3.4.2.9) não nos fornece diretamente a expressão que queremos, pois dentro da igualdade a mesma função está implícita e não podemos achar seu valor diretamente, portanto devemos utilizar outra estratégia para o seu cálculo, então a calculamos de maneira indireta.

A distribuição de similaridade deve se apresentar como uma distribuição qualquer e o tamanho e a posição de seu pico variam substancialmente. A região em baixo do pico contém a maior parte da informação sobre a distribuição de similaridade. Para que tenhamos mais pontos nessa região, nós podemos escolher o nosso intervalo de discretização de forma que existam áreas iguais em baixo da curva f' $(\xi)$ ou da curva $\xi \mathrm{f}^{\prime}(\xi)$ em cada intervalo. Geralmente tentamos escolher intervalos de discretização que contenham áreas iguais abaixo da curva $\mathrm{f}^{\prime}(\xi)$.

A equação (3.4.2.15) é uma equação de Fredholm de primeiro tipo e se comporta como as equações de Volterra (RAMKRISHNA; MURALIDHAR, 1989), que podem ser resolvidas em geral pelo método de substituições sucessivas (RAMKSRISHNA; SHAH, 1973), mas que porém é um problema mal condicionado. Por mal condicionado queremos 
dizer que a solução não depende de forma contínua dos dados $\xi f^{\prime}(\xi)$ e $\gamma g(x)$, isto é pequenas mudanças em $\xi f^{\prime}(\xi)$ podem causar grandes mudanças na função que quer se obter $\gamma \mathrm{g}(\mathrm{x})$. Portanto técnicas especiais devem ser utilizadas para resolver esse tipo de problema mal condicionado, e elas devem levar em conta informação da função a prior. A técnica de regularização de Tikhonov, como descrita em TIKHONOV; ARSENIN (1977), é muito conhecida para se resolver problemas mal condicionados e pode ser usada neste caso.

Sendo $\mathrm{x}=\Gamma(v) / \Gamma\left(v^{\prime}\right)$ e $f^{\prime}(\xi)=d f / d \xi$ é possível então checar em um gráfico a similaridade utilizando-se a figura de $f^{\prime}(\xi)$ por $\xi$, e, com isso mostrando toda a distribuição transiente na mesma curva, conforme exemplificado por RAMKRISHNA, NARSIMHAM; NEJFELT (1984). O seguinte produto desconhecido $\gamma \mathrm{g}(\mathrm{x})$ é obtido como em (3.4.2.16) com a expansão em polinômios, é escolhido para se utilizando neste caso polinômios de Jacobi modificados que são bases ortogonais.

$$
\gamma g(x)=\sum_{i=1}^{n_{b}} a_{j} G_{j}(x)=\sum_{i=1}^{n_{b}} a_{j} x^{\mu} J_{j}(x)
$$

onde $\mathrm{n}_{\mathrm{b}}$ é o número, de funções, bases, usadas na expansão, um número razoável é $\mathrm{n}_{b}=3$, para a função base. Esse valor permite que tenhamos em geral uma aproximação para a distribuição sem a necessidade de normalização ou regularização (SATHYAGAL; RAMKRISHNA; NARSIMHAM, 1995).

Pelo fato de $\xi f^{\prime}(\xi) \approx \xi^{\mu}$ para $\xi \approx 0$, estudos a respeito do comportamento assintótico apresentados no APÊNDICE B da distribuição de partículas filhas resultaram que $\mathrm{g}(\mathrm{x}) \cong \mathrm{x}^{\mu}$ para $\mathrm{x} \leq 1 \quad$ (RAMKRISHNA; NARSIMHAM; SATHYAGAL, 1995), $\mathrm{o}$ expoente $\mu$ pode ser obtido do comportamento da distribuição auto-similar como $\xi \rightarrow 0$, caso $\mathrm{g}(1)=1$, considerando que $\mathrm{g}(\mathrm{x})$, no intervalo, $0 \leq \mathrm{x} \leq 1$, é uma função cumulativa, portanto obedecendo o fato de que a quebra em regiões próximas de zero não deve produzir nenhuma partícula. Então a derivada da distribuição de partículas filhas deve ser zero em $\mathrm{x}=1$. Podemos verificar, também, que pequenos ajustes por tentativa e erro nessa variável $\mu$ podem produzir melhoras na predição da distribuição, o valor utilizado foi $\mu=0.4$, a constante $\gamma$ pode ser obtida instantaneamente uma vez que a equação (3.4.16) pode ser determinada como foi descrito, e então a constante desconhecida $\gamma$ pode ser determinada como parte do procedimento de aproximação da função de distribuição de partículas filhas. 
A escolha da função base é muito dependente do comportamento da distribuição de similaridade. A expansão de $\gamma \mathrm{g}(\mathrm{x})$ em termo de polinômios ortogonais convergirá muito lentamente para a função desejada em casos em que $\mu<0$, desde que nesses casos $\mathrm{g}(\mathrm{x})$ seja singular em $\mathrm{x}=0$, para superar esse tipo de problema escolhemos funções base específicas para o problema, escolhemos um espaço em que o produto interno é dado por:

$$
\langle u, v\rangle=\int_{0}^{1} x^{1-2 \mu} u(x) v(x) d x
$$

As bases ortogonais nesse espaço são os polinômios modificados de Jacobi, $x^{\mu} \mathrm{G}_{\mathrm{j}}(\mathrm{x})$.

No caso da equação (3.4.2.18) como é sugerido o número necessário para obter uma boa aproximação da distribuição sem a necessidade de nenhuma regularização é com o uso de três funções bases $\left(n_{b}=3\right)$, conforme descrito no estudo de (SATHYAGAL; RAMKRISHNA; NARSIMHAM, 1995). Esses números de funções base foram determinados, e no trabalho, deles. Eles descrevem um método para determinar o número ótimo de funções bases para se expandir a função $\gamma \mathrm{g}(\mathrm{x})$.

Sendo, que os polinômios de Jacobi são associados, ao intervalo, $[-1,+1]$, e chamam-se deslocados, ou modificados se o intervalo for, $[0,+1]$. A função peso é wj(x)= $x^{\beta a}(1-x)^{\alpha}$.

$$
\begin{aligned}
& \int_{-1}^{1} x^{\beta a}(1-x)^{\alpha a} J_{i}^{(\alpha, \beta a)}(x) J_{k}^{(\alpha, \beta a)}(x) d x=\left\{\begin{array}{l}
=0 \text { se } i \neq k \\
>0 \text { se } i=k
\end{array}\right. \\
& J_{1}^{(0,0)}(x)=1 \\
& J_{2}^{(0,0)}(x)=2 x-1 \\
& J_{3}^{(0,0)}(x)=6 x^{2}-6 x+1 \\
& J_{4}^{(0,0)}(x)=20 x^{3}-30 x^{2}+12 x-1
\end{aligned}
$$

Portanto podemos denotar por $\mathbf{J}_{\mathrm{j}}$ o polinômio de Jacobi de ordem $(\mathrm{j}-1)$ e que pode ser reduzido na formula (3.4.2.19).

$$
x^{\beta a}(1-x)^{\alpha} J_{n}^{(\alpha, \beta a)}=\frac{(-1) \operatorname{Gamma}(\beta a+1)}{\operatorname{Gamma}(n+\beta a+1)} \frac{d^{n}\left(x^{n+\beta a}(1-x)^{n+\alpha}\right)}{d x^{n}}
$$

Onde Gamma é a função gamma definida (3.4.2.20):

$$
\operatorname{Gamma}(x)=\int_{0}^{\infty} q^{x-1} \exp (-q) d q
$$


Essa função generaliza a função fatorial para números reais Gamma(h+1)=h!. Sendo h um número qualquer.

A variável de similaridade $\zeta$ é então discretizada para se obter $\mathrm{X}_{\mathrm{ij}}$ e $\{\zeta \mathrm{i}\}$ como em $(3.4 .2 .21)$

$$
X_{i j}=\int_{0}^{1} \frac{\xi^{2}}{x^{3}} f^{\prime}\left(\frac{\xi_{i}}{x}\right) G_{j}(x) d x
$$

Como a distribuição de similaridade aparece em ambos os lados da equação (3.4.2.21), nós precisamos de um método para representar essa distribuição. Este método simplificará a matriz de equações para que se determine a matriz a, que são os valores que queremos, como vamos verificar na equação (3.4.2.22), como explicaremos antes de outras considerações. Ajustando a distribuição de similaridade também resultará no efeito de limitar o erro experimental e nos fornecerá uma distribuição que será contínua. Como descrito por WRIGHT; RAMKRISHNA (1992), a forma para a qual a distribuição de similaridade é ajustada deve ser uma combinação linear de distribuições de função gama. Esta forma pode exibir todo o comportamento tanto quantitativo como qualitativo da distribuição de auto-similaridade. Então, a distribuição de similaridade é expandida em termos de funções gamas da forma como descrito em (3.4.2.22) para ajustar a distribuição de similaridade:

$$
\xi f^{\prime}(\xi)=\sum_{k=1}^{n_{\text {termo }}} A_{k} \xi^{\alpha k-1} e^{-\beta_{k} \xi}
$$

A distribuição auto-similar é ajustada a expressão (3.4.2.22), os parâmetros $\left(\mathrm{A}_{\mathrm{K}}\right.$, $\alpha_{\mathrm{K}}, \beta_{\mathrm{K}}$ ), serão usados para calcular os intervalos de discretização pelo cálculo das áreas iguais em baixo da curva $\mathrm{f}^{\prime}(\xi)$, além disso, $\mathrm{n}_{\text {termo }}$ é o parâmetro que indica o número de termos para a nossa análise e estamos expandindo a função (3.4.2.22) em dois termos $\left(\mathrm{n}_{\text {termo }}=2\right)$ então o número de parâmetros $\mathrm{n}_{\text {parâmetros }}$ será sempre múltiplo de 3 , $\mathrm{n}_{\text {parâmetros }}=3 \mathrm{n}_{\text {termo }}$, é por meio desses parâmetros e dos intervalos de discretização que será possível calcular a matriz de regressão $X$, esses parâmetros que são inicialmente desconhecidos são obtidos por meio da distribuição de similaridade conhecida utilizando-se uma regressão não-linear ponderada, o ajuste é realizado utilizando-se a função objetivo (3.4.2.23), os pesos utilizados são estimados do erro relativo em cada ponto da distribuição em uma minimização sem restrições a função utilizado foi a datafit em ambiente SciLab, as 
técnicas para estimar esse erro proveniente dos dados são descritos em detalhes por (SILVERMAN,1986):

$$
\text { erro }_{\text {distribuiç̃es de similaridade }}=\xi f^{\prime}(\xi)-F(\xi)
$$

Como podemos notar sem a adição de erros, a distribuição de tamanhos auto-similar já é parte da família de distribuições usadas no procedimento do problema inverso, isso porque a solução deve mostrar claramente propriedades auto-similares.

Assim o elemento $X_{i j}$ pode ser escrito pela expressão (3.4.2.24) e a matriz $X$ encontrada com a seguinte associação $X=\{(X i j)\}$, desde que exista a equação analítica como na forma (3.4.2.24), a matriz X pode ser calculada explicitamente. Usando a equação (3.4.2.25) para representar $\zeta \mathrm{f}^{\prime}(\zeta)$ e a conhecida forma dos polinômios de Jacobi na equação (3.4.2.26), teremos:

$$
X_{i j}=\sqrt{2 j} \sum_{k=1}^{n_{\text {temm }}} A_{k} \sum_{m=1}^{j} \frac{(-1)^{m-1}(2 j-m) ! \xi_{i}^{j-m+\mu}}{(m-1) !(j-m) !(j-m+1) !} \frac{\gamma_{c}\left(\alpha_{k}+m-j-\mu, \beta_{k} \xi_{i}\right)}{\beta^{\alpha_{k}+m-j-\mu}} \text { (3.4.2.24) }
$$

Na equação (3.4.2.24) $\gamma_{c}$ é definida como (3.4.2.25):

$$
\gamma_{c}(a, b)=\int_{b}^{\infty} q^{a-1} \exp (-q) d q=\frac{1}{\operatorname{Gamma}(b)} \int_{0}^{a} q^{b-1} \exp (-q) d q
$$

E é a função gama incompleta, que não está presente na biblioteca do SciLab, mas que foi implementada no programa como uma nova função construída, usando subrotinas especificas de acordo com (ZHANG;JIN,1996). Ela se comporta de tal forma que para b>0, assim que $\mathrm{b}$ tender a infinito a função retorna 1 , e para valores pequenos de $\mathrm{a}$ e $\mathrm{b}$ a função é $\gamma c(a, b) \cong a^{b}$, então, a função é $\gamma c(0,0)=1$ para $a=b=0$, para essa função os valores de $a$ e $b$ devem ser sempre reais, e b deve ser não negativo para o cálculo, Gamma é a função gamma explicada na equação (3.4.2.24), ou, também, na equação (B.19) do APÊNDICE B.

Neste caso foi usado um valor de $\mathrm{n}_{\text {tem }}=2$ (RAIKAR et al., 2006), e o valor de $\mu=0.4$ foi utilizado para os cálculos da equação (3.4.2.24).

Como a equação (3.2.4.24) é mal condicionada para se fazer uma minimização quadrática desse tipo de problema precisamos usar a técnica de regularização de Tikhonov, (CULLUM, 1971; TIKHONOV; ARSENIN, 1977; WAHBA, 1977; DELVES; MOHAMED, 1987), essa técnica fica mais simples se reescrevermos a equação (3.4.2.24) na forma de um operador (RAMKRISHNA; AMUNDSON, 1985):

$$
\phi=K g
$$


Neste caso g estaria representando a função de quebra, e K é um operador integral que funciona em g, a regularização de Tikhonov de ordem zero determinaria a maneira com que o vetor $\mathrm{g}$ seria determinado:

$$
\min \|K g-\phi\|_{\text {tipol }}^{2}+\lambda_{\text {reg }}\|g\|_{\text {tipo } 2}^{2}
$$

A interpretação física da regularização é que à medida que o erro na estimativa de a e K aumentam, o parâmetro de regularização $\lambda_{\text {reg }}$ deve aumentar. Como o parâmetro de regularização aumenta, a técnica de minimização efetivamente encontra a solução g que tem normas menores e então possuí flutuações menores além de serem funções mais suaves.

Em (3.4.2.27) I| I| são normas e os subescritos tipo1 e tipo2 indicam que diferentes normas podem ser usadas, o que se faz é usar a regularização de Tikhonov, essa técnica usa informação sobre a suavidade da função desconhecida. Usando normas de funções desconhecidas na minimização, a regularização de Tikhonov penaliza funções que flutuam muito e então determina funções que são suaves e como nós temos mais informação além do que a funções devem ser suaves, com isso o método de quassisoluções seria do tipo:

$$
\begin{aligned}
& \min \|K g-\phi\|_{1}^{2} \\
& g \in M
\end{aligned}
$$

Neste caso $M$ é um espaço compacto dentro de $L_{2}$ que é o espaço de funções estritamente monotonicas, e para um dado $\phi$ é o ponto $\mathrm{g}_{0} \in \mathrm{M}$ para o qual $\|\mathrm{Kg}-\phi\|$ tem o valor mínimo de $\mathrm{M}$, neste caso o espaço $\mathrm{M}$ é restrito a apenas funções monotonicas (TIKHONOV; ARSENIN, 1977; GONCARSKII; JANGOLA, 1969; IVANOV, 1962).

Sendo o vetor a contendo todos os elementos da expansão $a_{j}$ e definindo o vetor $\phi=\left\{\phi_{1}\right\}=\xi_{\mathrm{i}} \mathrm{f}^{\prime}\left(\xi_{\mathrm{i}}\right)$, ou seja colocando a equação (3.4.2.28) na forma de um operador, então assim podemos escrever o problema inverso da forma $\phi=X a$ e a solução do problema inverso então trata-se da solução da expressão (3.4.2.29) que escrita na forma de um problema de otimização é:

$$
\begin{aligned}
& \min \|X a-\phi\| \\
& a \in R^{n b}
\end{aligned}
$$


Se tivéssemos apenas informação de que a função desconhecida g é suave teríamos que utilizar a regularização de ordem zero de Tikhonov nos leva a equação (3.4.2.27), que é essa regularização em forma de minimização de matrizes.

Porém quando se deduz essa expressão (3.4.2.29) na forma de uma minimização de quadrados, esse tipo de solução é mal condicionada, pois uma mudança pequena na condição de similaridade $\xi f^{\prime}(\xi)$ pode induzir em grandes mudanças na função de aproximação $\gamma \mathrm{g}(\mathrm{x})$.

Sendo a expressão anterior sujeita às restrições (3.4.2.30), (3.4.2.31), e (3.4.2.32) para a sua solução.

$$
\begin{aligned}
& g(x)>0 \\
& g^{\prime}(x) \geq 0 \\
& g^{\prime}(l)=0
\end{aligned}
$$

Pelas equações (3.4.2.30), (3.4.2.31) e (3.4.2.32) verificamos que existem três restrições no total a duas primeiras tem a função de assegurar que a distribuição é monotonicamente crescente e a terceira resulta da suposição que a quebra não pode produzir partículas filhas de tamanhos próximos de zero e também, partículas, muito próximas, de seu próprio tamanho, de tal forma que a derivada da distribuição de partículas em $\mathrm{x}=1$ pode ser igualada a zero. Porém devemos frisar que ao assumirmos esse comportamento para esse processo não significa necessariamente que seja aplicado a outros processos de quebra.

As restrições, inseridas, são, apenas, restrições físicas devido à natureza da distribuição de partículas filhas. A distribuição filha de tamanhos de partículas é positiva em todo domínio e é monotonicamente crescente, como já foi mencionado, pois trata-se de uma função de distribuição cumulativa em seus argumentos.

A positividade e a monotonicidade das restrições são inseridas como um conjunto de restrições lineares nos coeficientes de expansão de tal forma que a positividade e a monotonicidade são mantidas em cada ponto de discretização. A restrição de igualdade também é adicionada como uma restrição linear no coeficiente correspondente a $\mathrm{x}=1$.

Podemos também ter outro problema de otimização equivalente ao da equação (3.4.40) trocando a expressão pela reescrita, na forma, padrão utilizando a matriz $\mathrm{X}$ aplicada no método de quassisoluções, com isso o problema para encontrar o valor de a fica 
como na equação (3.4.2.33), que é uma minimização quadrática com restrição e sua solução é restrita a uma função crescente monotonicamente:

$$
\begin{array}{lc}
\min a^{T} X^{T} X a-2 a^{T} X^{T} \phi \\
a \in R^{n b} & \\
\text { sujeito } a: & g(x)>0 \\
& g^{\prime}(x) \geq 0 \\
& g^{\prime}(l)=0
\end{array}
$$

Como neste caso g é função cumulativa e monotônica e como esse tipo de função é compacta no espaço $\mathrm{L}_{2}$ existe solução para este tipo de problema (SATHYAGAL; RAMKRISHNA; NARSIMHAM, 1995), a solução apresentada ainda apresenta um outro termo $\phi \phi^{T}$ que não é explicitado aqui na função objetivo, pois é independente de $a$.

A escolha, dos pontos, de discretização, deve ser determinada. E, estes devem depender, principalmente, da natureza da distribuição de similaridade. Precisamos, portanto, escolher os pontos de tal forma que haja mais pontos na região de $\xi$ em que ocorra maior variação na distribuição de similaridade em diferentes distribuições de partículas filhas. Fazendo isso nós ponderamos mais essas regiões no momento da resolução do problema inverso e então devemos ser mais capazes de discriminar de maneira adequada entre diferentes funções.

A solução da equação (3.4.2.27) é obtida quando forçamos o uso das restrições (3.4.2.30), (3.4.2.31) e (3.4.2.32), para obter a solução ótima para cada $\xi_{\mathrm{i}}$ existente.

\subsection{Equacionamento em ambiente SciLab.}

A equação (3.4.2.33) foi solucionada em ambiente SciLab por uma rotina de minimização quadrática "quapro.sci" na versão 4.0, ou, "qpsolve.sci" na versão 5.2.2, e, mais recente, a fim de encontramos os coeficientes desconhecidos da expansão dados pelo vetor a , e seu programa de otimização só aceita minimizações escritas da forma (3.5.1).

$$
0.5 a^{T} Q a-p^{T} a
$$

Portanto para adaptar a equação (3.5.1) a forma da equação (3.5.2). Devemos usar as seguintes variáveis apresentadas nas equações (3.5.4) e (3.5.5) elas são derivadas da seguinte propriedade de multiplicação de matrizes transpostas $a^{T} B=\left(B^{T} a\right)^{T}$.

$$
Q=X^{T} X
$$




$$
p^{T}=\left(X^{T} \phi\right)^{T}
$$

A única diferença é que as equações (3.5.2) em comparação com a equação (3.5.3) esta multiplicada por dois, mas isso não muda o resultado final da função objetivo após a otimização.

Da mesma forma as restrições nesse ambiente de programação devem ser escritas da forma (3.5.4) e (3.5.5), que são as aceitas pelo SciLab:

$$
\begin{aligned}
& C_{1} x \leq b \\
& C_{2} x=b
\end{aligned}
$$

É fácil notar que as restrições (3.4.2.30) e (3.4.2.31) se aplica as equações (3.5.4) e (3.5.5), para assegurar uma restrição semelhante a (3.4.2.32) em SciLab basta escrevermos uma inequação mas ao invés de igualá-la a zero igualamos a um número próximo de zero , $10^{-2}$ por exemplo.

\subsection{Testes realizados com o Problema Inverso.}

Um caso-teste foi resolvido com parâmetros conhecidos a priori para verificar o funcionamento do algoritmo. Trata-se de um problema de quebra de gotas, cujos parâmetros são dados pelas equações (3.6.1) e (3.6.2) e com a condição inicial dada pela seguinte distribuição de tamanhos de gotas, equação (3.6.1):

$$
n(v, t=0)=\frac{1}{\sigma \sqrt{2 \pi}} \exp \left(\frac{-a(v-\mu)^{2}}{2 \sigma^{2}}\right)=\frac{1}{50 \sqrt{2 \pi}} \exp \left(-5000(v-\mu)^{2}\right)
$$

Para verificar a acuidade com que o algoritmo consegue resolver o problema inverso, podemos adicionar um ruído na distribuição inicial,

$$
\bar{n}(v, t)=n(v, t)+v(r-0,05) n(v, t)
$$

e verificar os desvios das distribuições de taxa de quebra e partículas filhas obtidas pelo algoritmo do problema inverso em relação às distribuições originalmente adotadas. Os tipos de erros de medida considerados geralmente levam a uma predição pior da taxa de quebra em um valor menor e conseqüentemente uma predição de um valor maior para o número de grandes partículas. 
Também podemos simular erros de medidas experimentais, ruídos, etc.., fazendo elas parecerem maiores ou menores com o intuito de testar o problema inverso pela minimização escolhida.

$$
\bar{n}(v, t)=n(\bar{v}, t), \quad \bar{v}=v \pm \delta v
$$

O valor de $\delta=0,005$ foi utilizado. A resolução desse problema-teste foi implementado uma rotina em SciLab utilizando a função ode que resolve equações diferenciais ordinárias, sendo que a resolução da equação de balanço populacional discretizado em classes pelo método dos pivots fixos, sendo que o número desses pivôs foi de $\mathrm{i}_{\max }=250$ para representar a distribuição. $\mathrm{O}$ espaçamento entre os pivots foi uniforme, visto que, o espaçamento geométrico não apresentou muita diferença na maioria dos perfis observados, embora este seja recomendável em perfis com variação muito brusca, no inicio do domínio.

A eficácia da resolução do problema inverso pode ser verificada tanto para os testes normais, ou seja, apenas com a resolução do balanço por métodos numéricos, como para os testes com adição de ruído ou erro na distribuição calculada, pois para reconstruir a distribuição, teremos antes que encontrar funções de similaridade e usá-las para que obtenhamos a distribuição em determinado instante, sendo ela já conhecida nesse mesmo instante, como fez RAIKAR et al. (2006), geralmente esse ajuste costuma gerar bons resultados, como verificamos em alguns trabalhos: (LUO et al.,2004; CHEN; PRUSS; WARNECKE, 1998; RUIZ; PADILHA, 2004; HESKETH; ETCHELLS; RUSSELL, 1991; MARTINEZ-BAZAN; MONTANES; LACERAS, 1999a, 1999b), é de se esperar então que as distribuições obtidas pelo balanço sejam pelo menos muito próximas aos valores experimentais, sendo na melhor das aproximações a sobreposição das curvas experimentais e teóricas. 


\section{ESTUDOS DE CASOS.}

Neste capítulo serão apresentados alguns estudos de casos de aplicação da metodologia apresentada, nos quais, dados experimentais de distribuição de massas molares obtidos na literatura são usados para avaliar as funções de quebra.

Podemos notar também, que as reações descritas na tabela 2 são em geral obtidas por uso de "força". Antigamente, a química apenas focou no uso de luz ou calor, para se realizar reações químicas. Portanto a realização de reações químicas com o uso de forças é uma alternativa muito pouco popular. e também recente. Mas será, em geral, a opção de estudo deste trabalho,embora seu principio seja muito bem estabelecido. Particularmente quando a transformação que queremos obter, como nos casos estudados neste trabalho, em que queremos simplesmente uma quebra de ligações de cadeias ao longo do polímero. Um exemplo muito comum é a mastigação de borracha para se reduzir seu peso molecular. Esta é uma reação de quebra de ligações de cadeias usada muito pela industria na atualidade. Essas reações também podem ser chamadas de mecânica da química de polímeros como nos ensina (KARTHIKEYAN;SIJBESMA,2010).

Cinco casos são apresentados, cujas principais características de cada sistema estão sumarizadas na Tabela 2.

Tabela 2: Distribuições experimentais utilizadas para o cálculo do problema inverso.

\begin{tabular}{|c|c|c|c|c|c|}
\hline Autores & Tipo de sistema & Reagentes & Tipo de quebra & $\begin{array}{c}\text { Temper } \\
\text { atura }\end{array}$ & $\begin{array}{c}\mathrm{N}^{\circ} \mathrm{de} \\
\text { distribuições } \\
\text { experimentais }\end{array}$ \\
\hline SATHYAGAL et al (1995) & \begin{tabular}{|l} 
Dispersão de \\
gotas \\
(distribuição de \\
tamanhos de \\
gotas)
\end{tabular} & $\begin{array}{l}\text { Benzeno } \\
\text { Tetracloreto de Carbono } \\
\mathrm{CCl}_{4},(73-27 \% \text { em massa) }\end{array}$ & Mecânica, 500 rpm & $25^{\circ} \mathrm{C}$ & Cinco \\
\hline ROCHA et al. (1994) & $\begin{array}{l}\text { Quebra radicalar } \\
\text { de cadeias } \\
\text { lineares de } \\
\text { polipropileno } \\
\text { (Distribuição de } \\
\text { massas molares) }\end{array}$ & $\begin{array}{l}\text { Polipropileno (Pro-Fax } \\
\text { 6631), } \\
\text { 2,5 dimetil-2,5-bis- } \\
\text { tercbutilperoxi-hexano } \\
\text { (Lupersol 101), } \\
\text { 2,5 dimetil-2,5-bis- } \\
\text { tercbutilperoxi-hexino-3 } \\
\text { (Lupersol 130). }\end{array}$ & $\begin{array}{l}\text { Ataque por radicais livres } \\
20 \text { e } 40 \mathrm{rpm}\end{array}$ & $145^{\circ} \mathrm{C}$ & Quatro \\
\hline $\begin{array}{l}\text { BASEDOW; EBERT; } \\
\text { EDERER (1981) }\end{array}$ & $\begin{array}{l}\text { Hidrólise ácida } \\
\text { de dextrana } \\
\text { (Distribuição de } \\
\text { massas molares) }\end{array}$ & $\begin{array}{l}\text { Dextrana, } \\
\text { ácido sulfúrico diluído }\end{array}$ & Hidrólise ácida & $25^{\circ} \mathrm{C}$ & Quatro \\
\hline
\end{tabular}




\begin{tabular}{|c|c|c|c|c|c|}
\hline BALLAUF; WOLF (1984) & $\begin{array}{l}\text { Degradação } \\
\text { mecânica de } \\
\text { poliestireno } \\
\text { (Distribuição de } \\
\text { massas molares) }\end{array}$ & $\begin{array}{l}\text { Poliestireno aniônico, } \\
\text { DPPH, } \\
\text { oxigênio, e } \\
\text { solução semiconcentrada } \\
(4,9-20 \% \text { mássica }) \text { de } \\
\text { trans-decalina. }\end{array}$ & $\begin{array}{l}\text { Degradação mecânica } \\
\text { termodinamicamente } \\
\text { induzida pela presença de } \\
\text { solvente-theta trans-decalina }\end{array}$ & $25^{\circ} \mathrm{C}$ & Três \\
\hline BASEDOW et al. (1978) & \begin{tabular}{|l} 
Degradação \\
ultrassônica de \\
dextrana \\
(Distribuição de \\
massas molares) \\
\end{tabular} & $\begin{array}{l}\text { Dextrana } \\
\text { com } 10 \% \text { de } \mathrm{MgSO}_{4}\end{array}$ & Ultrassom, $24 \mathrm{~W} / \mathrm{cm}^{2}$ & $20^{\circ} \mathrm{C}$ & Quatro \\
\hline TAYAL; KHAN (2000) & \begin{tabular}{|l} 
Degradação \\
ultrassônica de \\
guar \\
(Distribuição de \\
massas molares) \\
\end{tabular} & $\begin{array}{l}\text { Guar galactomanana em } \\
\text { solução aquosa a 1\% } \\
\text { massa }\end{array}$ & Ultrassom, & $25^{\circ} \mathrm{C}$ & Cinco \\
\hline TAYAL; KHAN (2000) & \begin{tabular}{|l} 
Hidrólise \\
enzimática de \\
guar \\
(distribuição de \\
massas molares)
\end{tabular} & $\begin{array}{l}\text { Guar galactomanana em } \\
\text { solução aquosa a } 1 \% \text { em } \\
\text { massa e enzima endo- } \\
\text { beta-mananase (de } \\
\text { Aspergillus niger) } \\
\text { Megazyme Corp. }\end{array}$ & Hidrólise enzimática & $25^{\circ} \mathrm{C}$ & Seis \\
\hline
\end{tabular}

Além disso, também foi estudado inicialmente um sistema de dispersão de gotas no qual os dados experimentais referem-se a distribuições de tamanho de gotas. Este sistema já foi estudado por outros autores da literatura para a aplicação da metodologia do problema inverso (SATHYAGAL et al., 1995; KOUTOULAS e KIPARISSIDES, 2006; RAIKAR et al., 2006), e foi estudado no presente trabalho apenas como caso inicial para verificação da metodologia e da confiabilidade do algoritmo numérico empregado.

\subsection{Caso-estudo 1: Dispersão de gotas.}

Como explicado, este caso-estudo é o único, dentro do presente trabalho, que se refere a variações de distribuição de tamanhos de gotas, e o intuito de incluí-lo foi o de teste da metodologia e do algoritmo numérico usado na solução do problema inverso.

\subsubsection{Dados experimentais}

Os dados experimentais utilizados neste primeiro caso foram medidos experimentalmente no trabalho de RAMKRISHNA; NARSIMHAM; SATHYAGAL (1996), usando o equipamento esquematicamente ilustrado na figura 4.1.1. O tanque foi lavado com uma solução contendo $\mathrm{KOH}$ e depois com água corrente por 30 minutos e, em 
seguida, seco. Ao início do experimento, $1700 \mathrm{~mL}$ de água (destilada, deionizada e microfiltrada) contendo a fase dispersa de liquido orgânico, o benzeno, foram adicionadas a esse tanque de vidro. $\mathrm{O}$ agitador ficou rodando em velocidades de rotação baixa, 100 e 150 rpm e, enquanto isso a fase orgânica, previamente em equilíbrio com a água, foi adicionada ao tanque por meio da entrada de coleta. No experimento, $10 \mathrm{~mL}$ de fase orgânica foi adicionada, correspondendo a uma fração volumétrica de fase dispersa de $0,58 \%$. Depois que a fase orgânica foi adicionada, o agitador foi ligado em velocidade baixa por um minuto. Isso permite, que grandes gotas da fase dispersa sejam inicialmente quebradas, em gotas menores. Ao final desse minuto, a rotação foi elevada até a rotação definida para o ensaio experimental. O tempo experimental medido na amostragem de dados é o tempo contado depois dessa elevação na rotação inicial.

Em intervalos de tempo regulares, pequenas amostras da dispersão foram removidas do tanque com uma micropipeta, e inseridas em um microscópio e estabilizadas, com algumas gotas, de dodecilsulfato de sódio (DSS), que é um tenso-ativo. Em um trabalho anterior, TOBIN (1989) analisou a aplicabilidade, da amostragem para se obter a distribuição de partículas, e concluiu que a técnica fornece uma amostra representativa da dispersão dentro do tanque.

As distribuições de tamanhos de gotas apresentadas foram capturadas de um microscópio com câmera de vídeo e um analisador de imagem (Cambridge Instruments Q570 Image Analyzer). Aproximadamente 120 imagens foram capturadas em cada medida experimental e foram medidas em torno de 3000 partículas para se construir a distribuição de partículas apresentadas na figura 3.4.1, que utilizou a formulação descrita na tabela 3: 


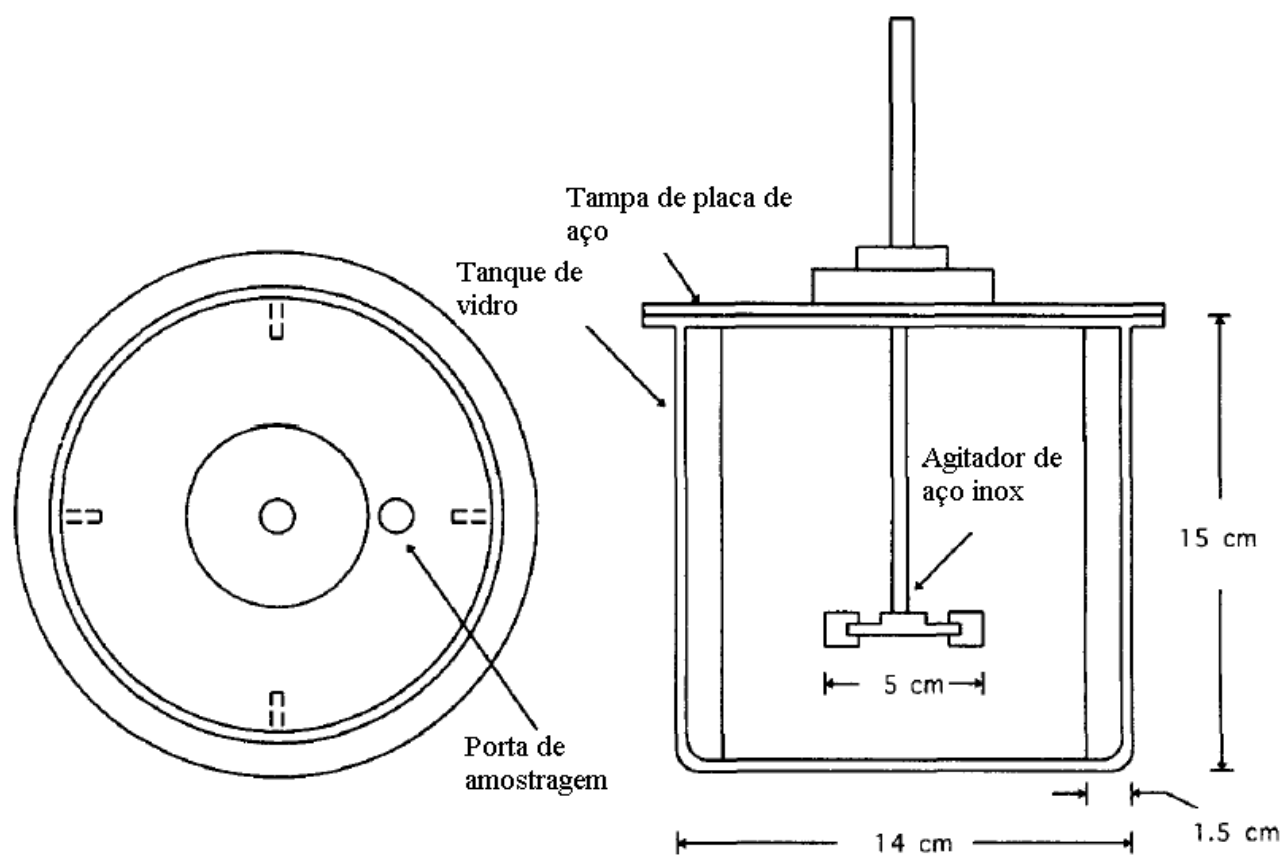

Figura 4.1.1: Esquema do tanque de mistura usado nos estudos de quebra. Fonte:

(SATHYAGAL e RAMKRISHNA, 1996).

Tabela 3: Propriedades físicas do liquido usado no experimento de quebra da figura 3.4.1

\begin{tabular}{|l|l|l|l|l|}
\hline Sistema & $\begin{array}{l}\text { Composição } \\
(\% \text { mássica })\end{array}$ & $\begin{array}{l}\text { Viscosidade } \\
(\mathrm{cp})\end{array}$ & $\begin{array}{l}\text { Tensão interfacial } \\
(\mathrm{mN} / \mathrm{m})\end{array}$ & $\begin{array}{l}\text { Rotação } \\
(\mathrm{rpm})\end{array}$ \\
\hline $\begin{array}{l}\text { Benzeno } \\
\text { Tetraclotreto de } \\
\text { Carbono }\end{array}$ & $73-27$ & 0,74 & 35,0 & 500 \\
\hline
\end{tabular}

FONTE: SATHYAGAL; RAMKRISHNA (1996)

As distribuições experimentais de tamanhos de gotas obtidas por SATHYAGAL et al. (1996) estão mostradas na Figura 4.1.2. Os dados foram digitalizados a partir de gráficos reportados no livro de RAMKRISHNA (2000) usando a rotina “digitize.m” do MatLab. 


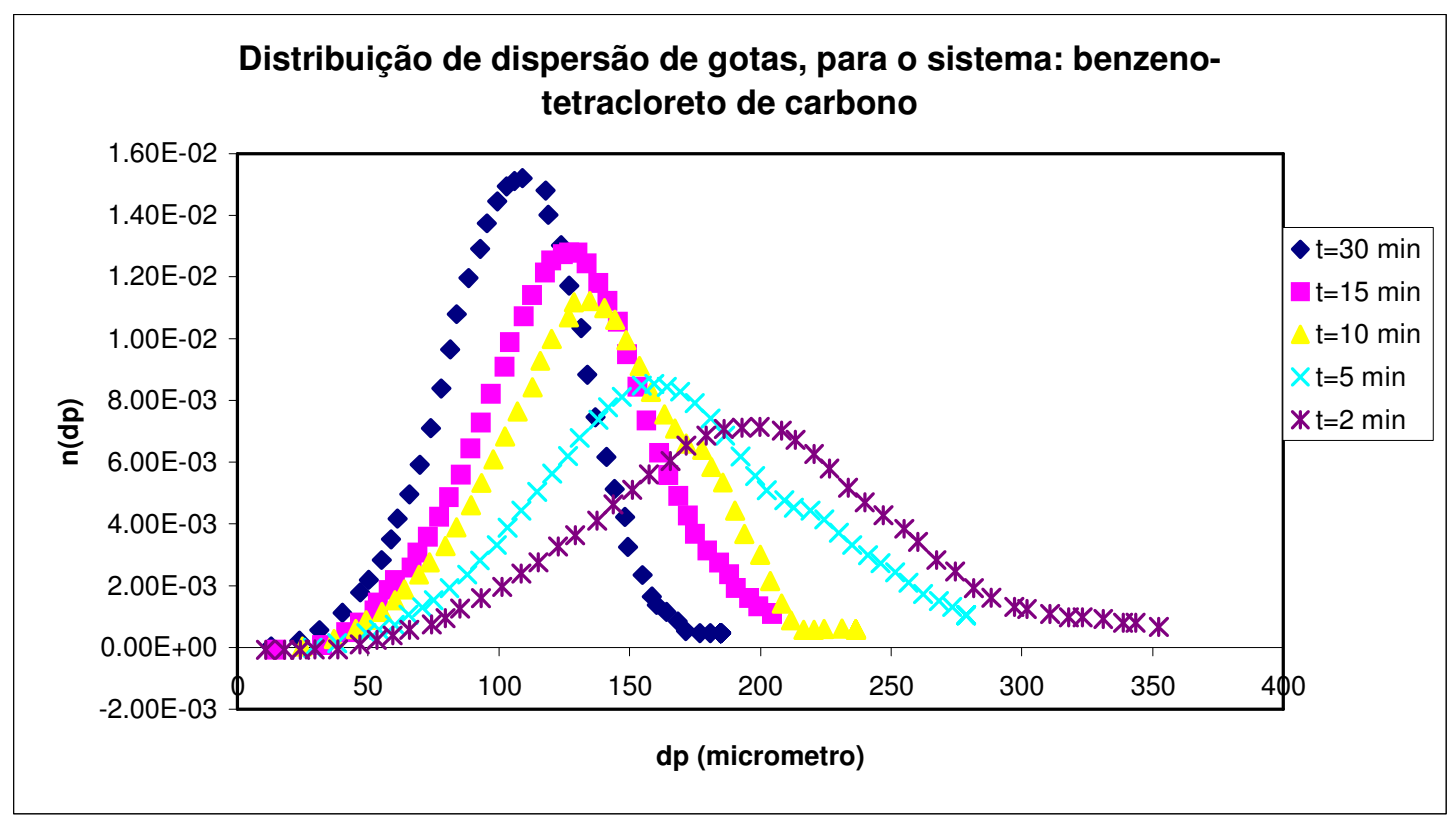

Figura 4.1.2: Distribuições ao longo do tempo para a dispersão de gotas, para o sistema,

benzeno-tetracloreto de carbono. Dados de Sathyagal et al. (1996).

\subsubsection{Solução do Problema Inverso.}

Aplicando o algoritmo apresentado no Capítulo 3, partindo-se das distribuições acumuladas F(v) correspondentes à Figura 4.1.2, que foram apresentadas na Figura 3.4.2, e interpolando-se valores de $v$ correspondentes a valores fixados de $F(v)=0,1$ $; 0,2 ; 0,3 ; \ldots ; 0,9$ nas curvas para diferentes valores de t, como ilustrado na Figura 3.4.3, foram obtidos os valores mostrados na Figura 4.1.3.

Quando traçamos o gráfico de s por $\operatorname{Ln}(\mathrm{v})$ podemos em todos os casos aproximar este gráfico por uma equação exponencial do segundo grau com mais precisão que uma reta ou um polinômio de grau maior, como mostra o gráfico 4.1.3. Observa-se que cada uma das curvas de ln t versus ln v da Figura 4.1.3 pode ser interpolado por um polinômio de grau 2 . Usando estas aproximações polinomiais, os valores de comprimento de arco s foram calculados de acordo com a equação (3.4.2) e o gráfico de s versus ln v na Figura 4.1.4 mostra que todos os conjuntos de dados podem ser adequadamente ajustados por uma única curva, o que indica que as distribuições experimentais mostradas na Figura 4.1.2 são autosimilares. 


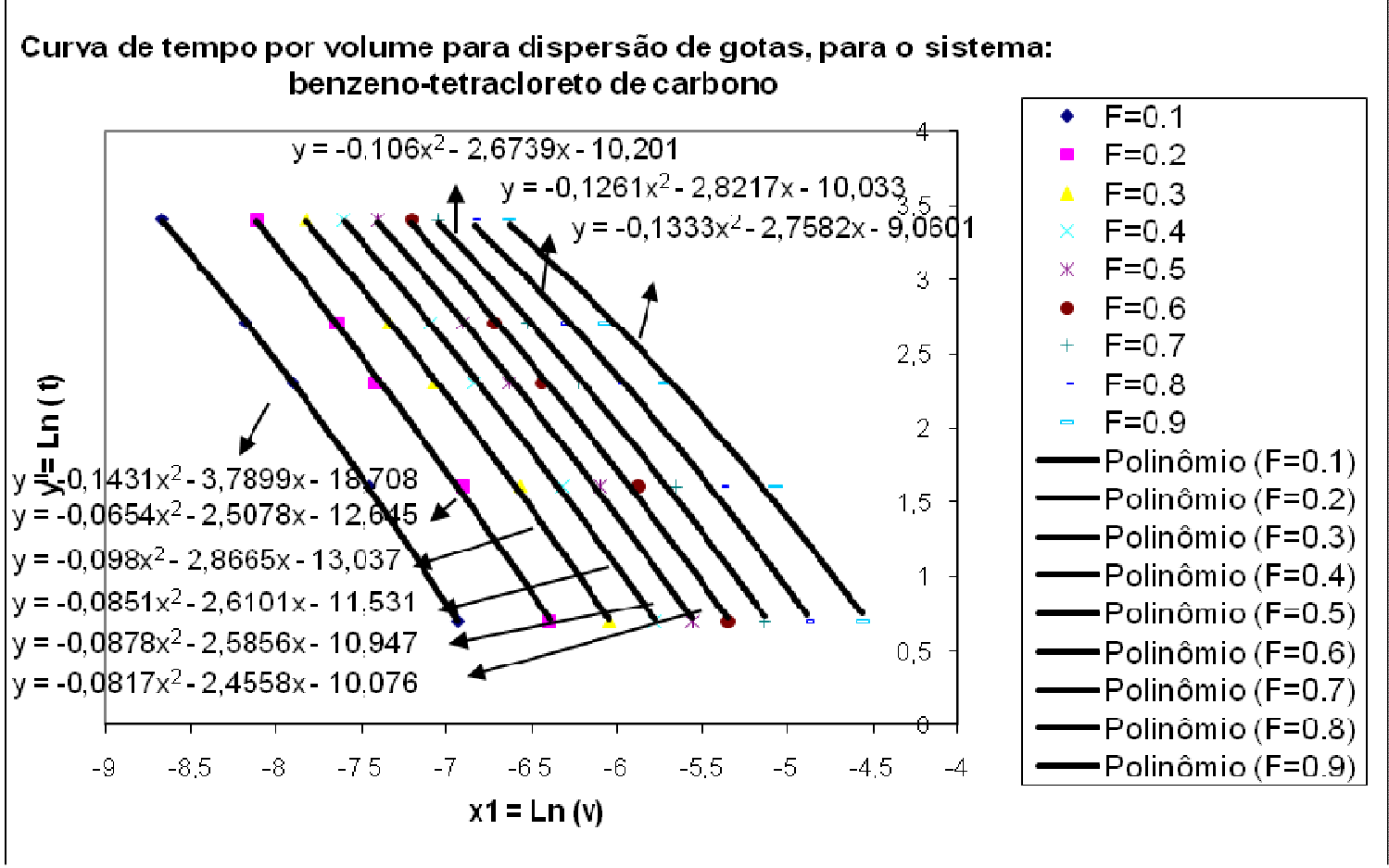

Figura 4.1.3: Distribuição experimental dos ajustes $\operatorname{Ln}(\mathrm{t})$ por $\operatorname{Ln}(\mathrm{v})$, para o sistema: benzeno-tetracloreto de carbono.

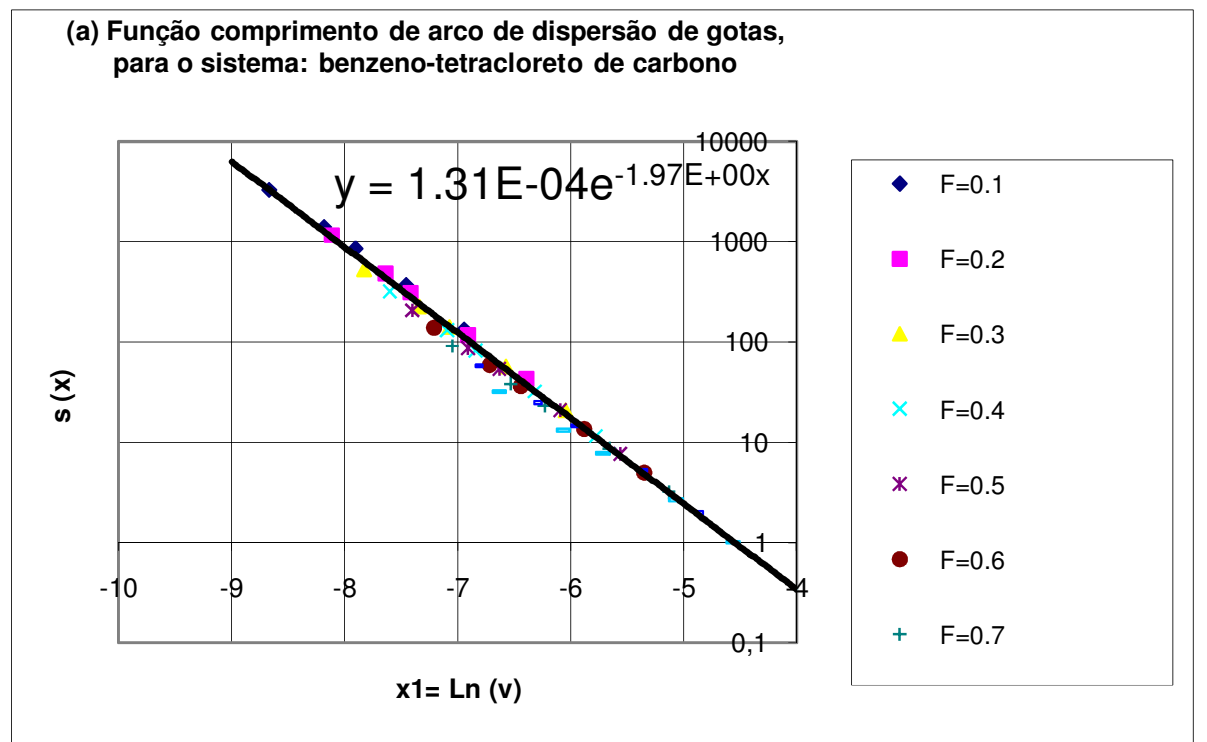




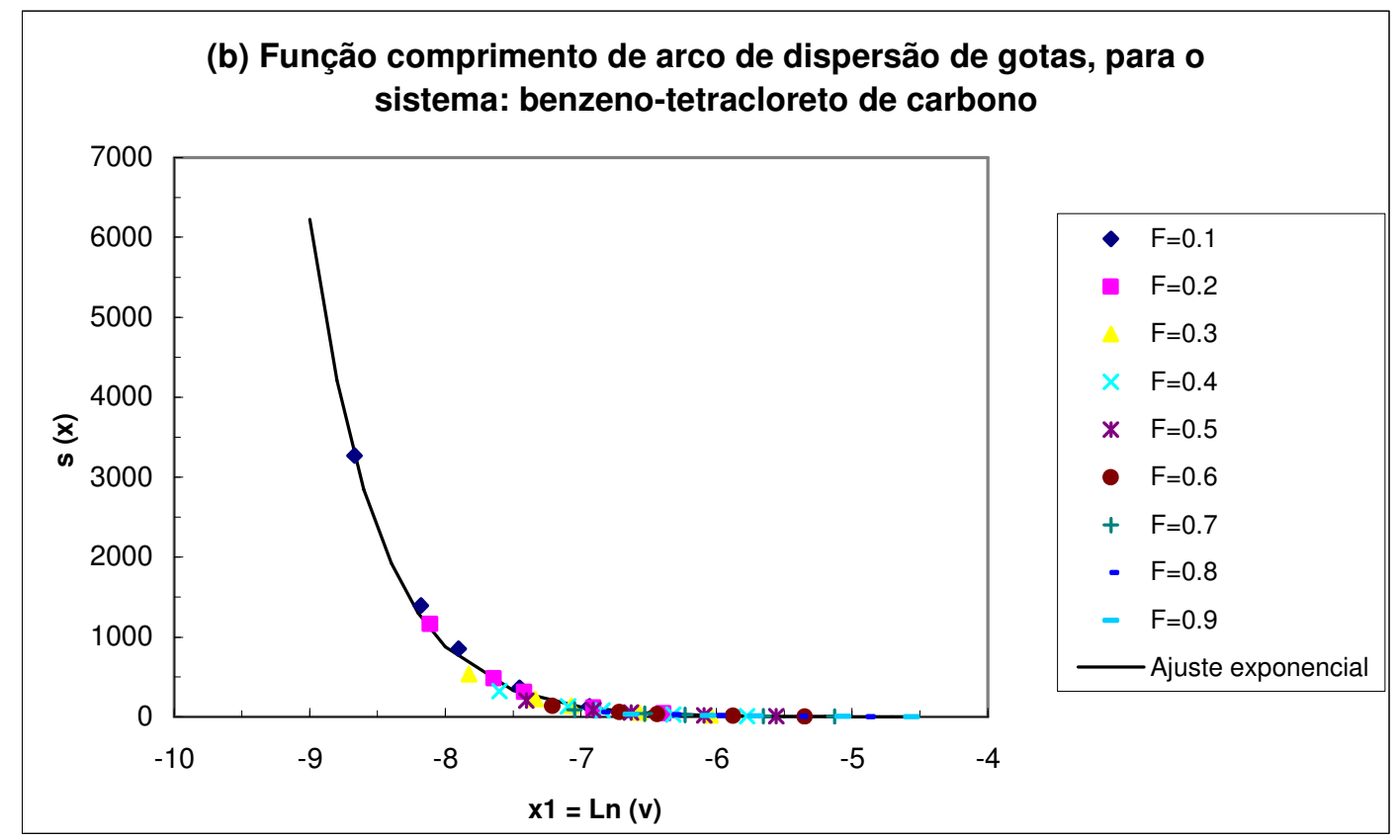

Figura 4.1.4: Exemplo para um caso em que é possível um ajuste exponencial do comprimento de arco: (a) escala logarítmica, e, (b) escala normal, para o sistema: benzeno-tetracloreto de carbono.

Calculando-se, então, a variável de similaridade pela equação (3.4.16), é possível mostrar que todas as distribuições da Figura 4.1.2 quando graficadas em função da variável de similaridade, $\xi$, se superpõem (ver Figura 4.1.5), confirmando que as distribuições são auto-similares e que o procedimento pode ser aplicado.

$\mathrm{Na}$ Figura 4.1.6 está apresentada a função de quebra transacional reportada no trabalho de RAMKRISHNA (2000) e SATHYAGAL et al. (1996). Na Figura 4.1.7 estão apresentadas a função de quebra e a distribuição de partículas filhas obtidas no presente trabalho, para este caso-estudo. Nota-se que o resultado aqui obtido concorda com o resultado reportado na literatura (RAMKRISHNA, 2000), indicando que o procedimento utilizado e os algoritmos preparados funcionam de modo adequado e coerente com o esperado. 


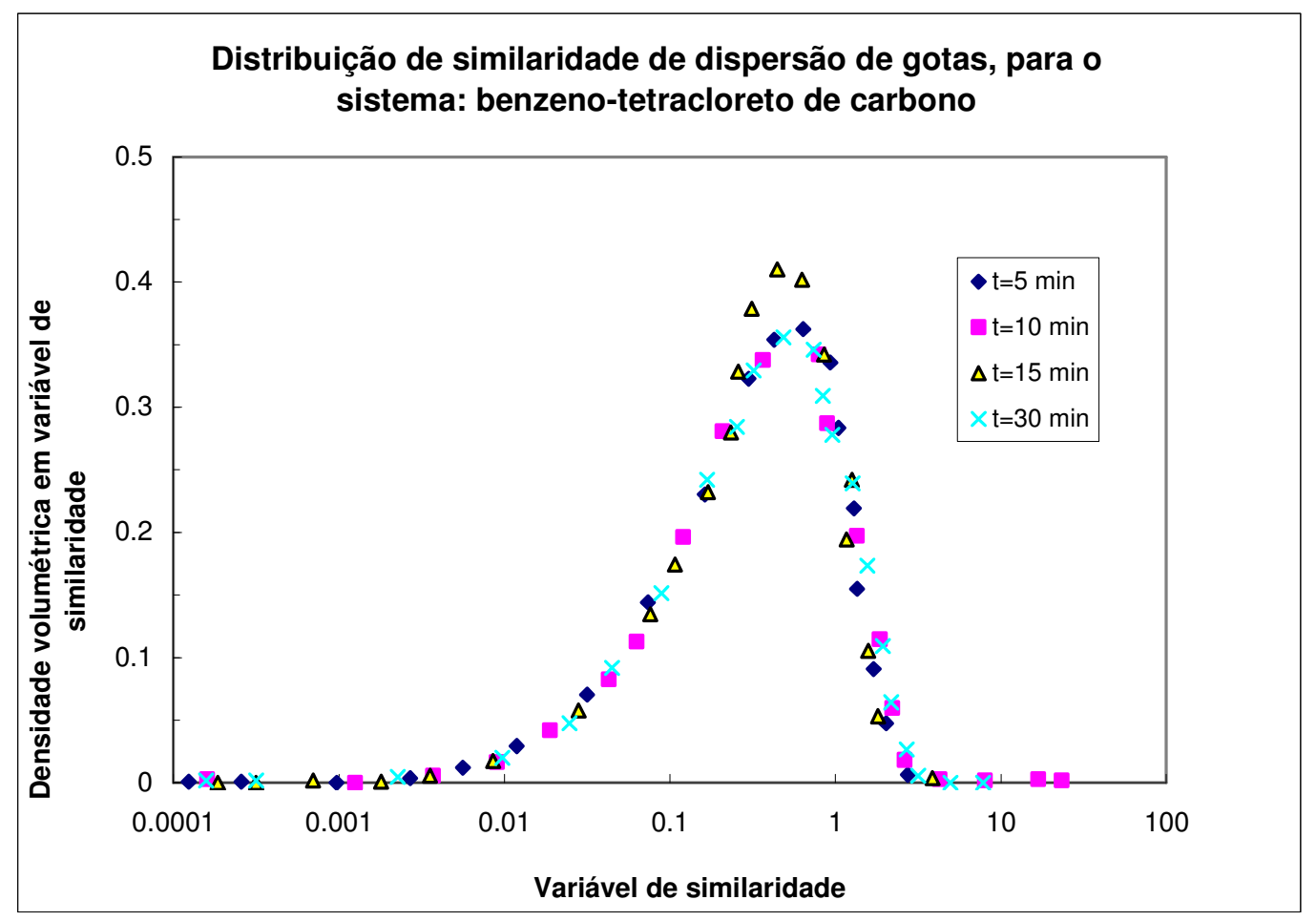

Figura 4.1.5: Sobreposição das distribuições para o caso de dispersão de gotas, para o sistema: benzeno-tetracloreto de carbono, confirmando a auto-similaridade das distribuições.

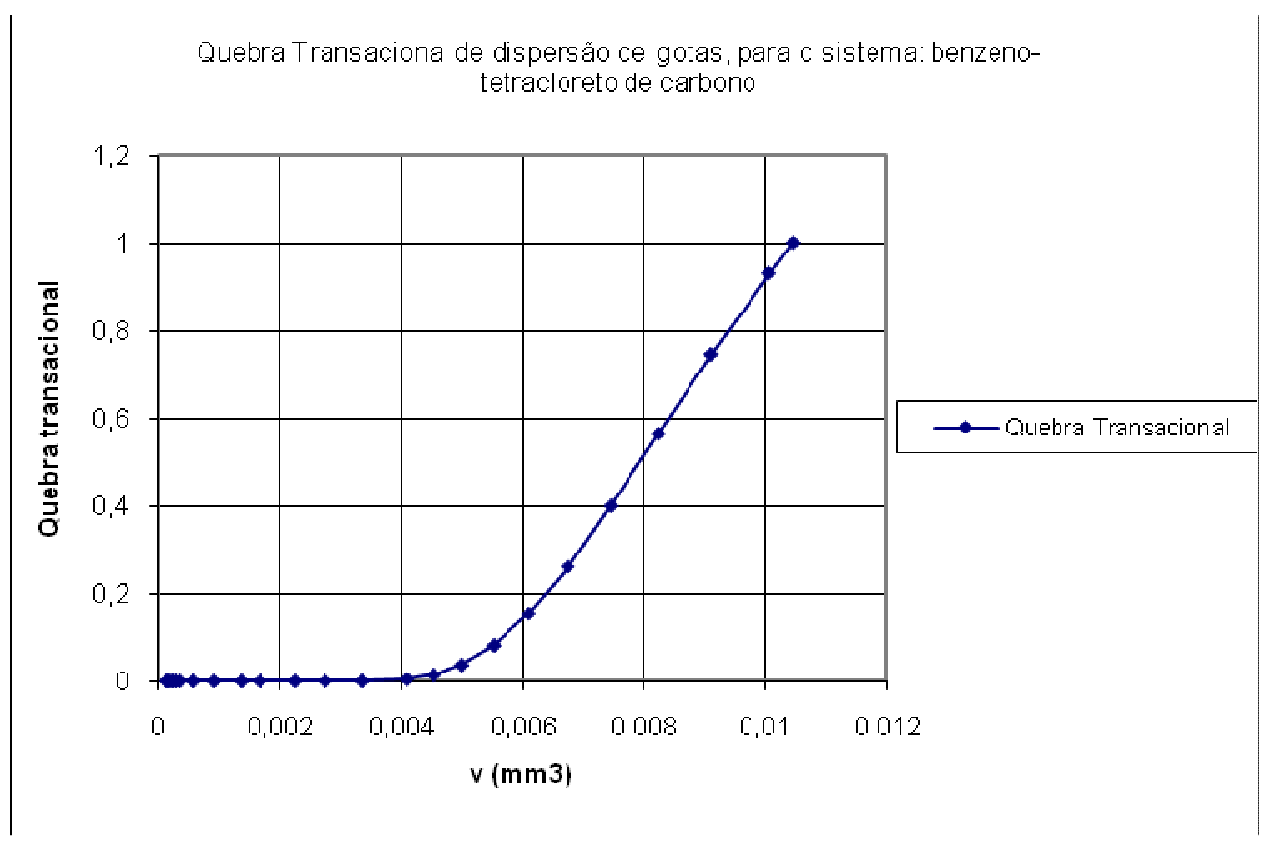


Figura 4.1.6: Função de quebra transacional obtida no trabalho de RAMKRISHNA (2000).

Conforme o resultado que obtivemos, pela figura 4.1.7. pode-se verificar que são coerentes com a literatura. Além disso, RAMKRISHNA e NERE (2005) reexaminaram os dados de SATHYAGAL et al. (1996) e sugeriram que a taxa de quebra estava com um erro, e que a correção seria a multiplicação por um valor de 2,1 . Isto está de acordo com o valor implícito na correlação proposta por NARSIMHAN et al. (1984), para descrever a quebra em sistemas de baixas viscosidades, e, também está de acordo com o resultado obtido no presente trabalho. Simulações do BP mostraram que sem a correção por este fator, a quebra seria insuficiente para deslocar as curvas de distribuição para a região de partículas menores como observado nas distribuições experimentais.

Finalmente, podem-se tomar os resultados do problema inverso (taxa de quebra e distribuição de partículas filhas, figura 4.1.7) e partir da distribuição medida em $\mathrm{t}=2$ min para calcular, usando o problema direto (solução do BP), as demais distribuições e então comparar as distribuições calculadas com as distribuições experimentais. O resultado desta verificação está mostrado na Figura 4.1.8, tanto para as distribuições diferenciais (a) como para as distribuições acumuladas (b). A comparação mostra que apesar de satisfatória do ponto de vista qualitativo, a coincidência quantitativa não é perfeita. 
(a) Taxa de quebra para dispersão de gotas, para o sistema benzenotetracloreto de carbono

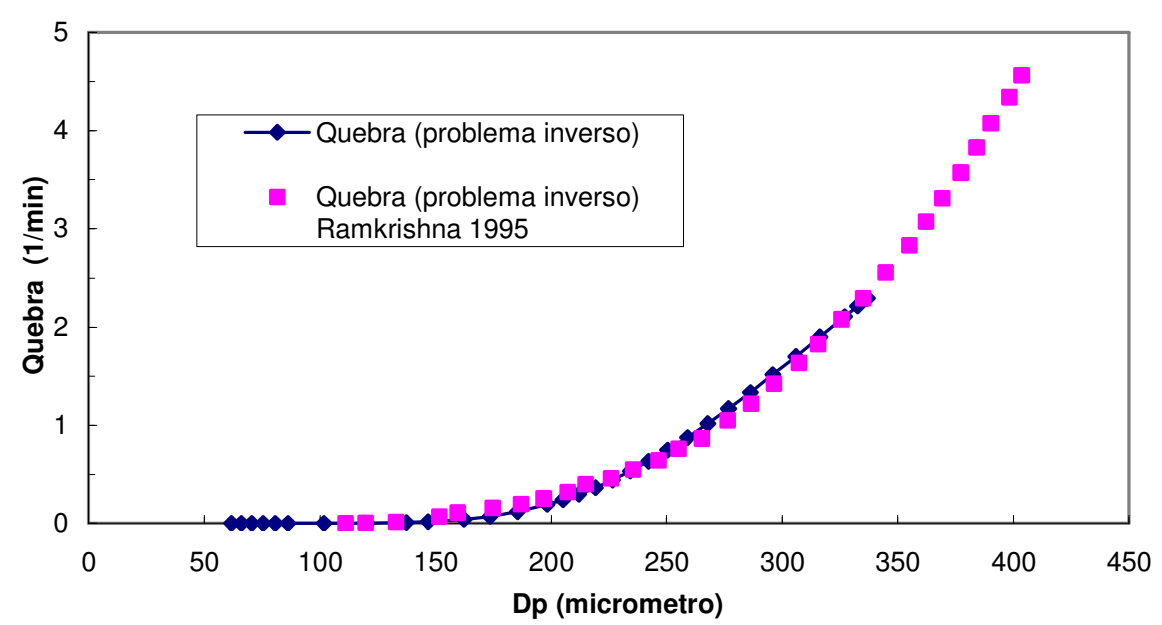

(b) Distribuição de partículas filhas para dispersão de gotas, para o sistema: benzeno-tetracloreto de carbono

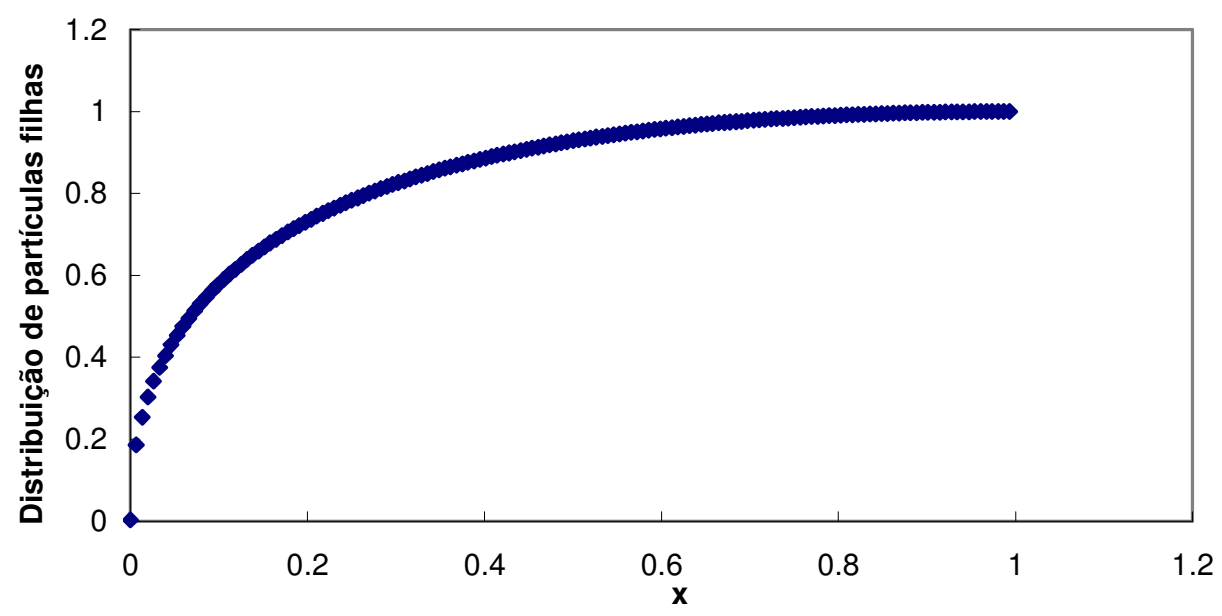

Figura 4.1.7: (a) Comparação entre a taxa de quebra obtida por SATHYAGAL et al. (1995) e a obtida no presente trabalho usando o algoritmo do problema inverso, para o casoestudo 1; (b) Distribuição de partículas filhas obtida no presente trabalho para o casoestudo 1. 

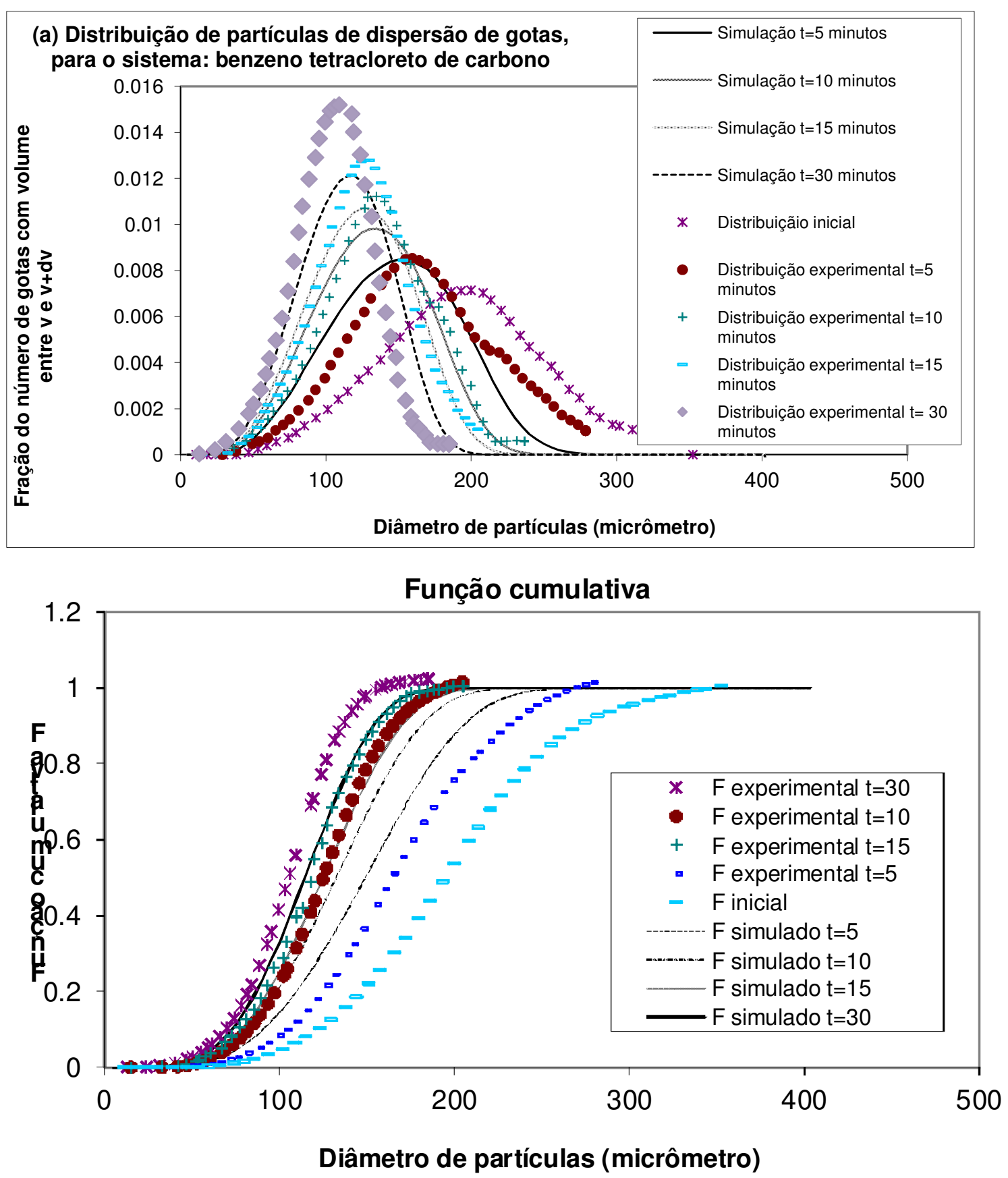

Figura 4.1.8: Comparação entre: os valores experimentais, e, a simulação do problema direto: (a) distribuição de partículas, e, (b) função cumulativa.

Finalmente, um comentário sobre este primeiro caso-estudo: o resultado obtido (função de quebra e distribuição de filhas) só é representativo da quebra nesta situação 
experimental. Caso se aumente a escala do processo, a quebra também irá se tornar maior. Pois a turbulência aumentará segundo uma relação, $\operatorname{Re}_{1}=\operatorname{Re}_{2}\left(D_{2} / D_{1}\right)^{4 / 3}$. Sendo, $D$, o diâmetro do tanque, e, Re o número de Reynolds. É claro que devemos estar atentos também para a agitação para que capturemos corretamente os efeitos de escala na dispersão. Já que muitas vezes observamos que alguns modelos predizem uma taxa de quebra maior que aquelas obtidas neste caso. Portanto, como notado acima, curvas de taxas de quebra para todas as escalas possíveis tendem a convergir caso os tamanhos de partículas aumentem na mesma proporção. Neste caso, isso às vezes pode não ocorre. E, assim, precisamos prestar atenção em cada caso. Para que as taxas de quebra não tenham muita divergência ao mudarmos as escalas.

\subsection{Caso-estudo 2: Quebra radicalar de cadeias lineares de polipropileno.}

A degradação controlada de polipropileno usando peróxidos orgânicos é um processo usado industrialmente para produzir o assim chamado "polipropileno de reologia controlada”. Este processo é usualmente realizado em extrusoras, e peróxido se decompõe, gerando radicais livres que atacam as cadeias de polipropileno e causam reações de quebra, que levam a uma diminuição das massas molares.

Este processo é usualmente acompanhado através de medidas de índice de fluidez ("melt flow index"), cujo valor aumenta à medida em que se diminui a massa molar media do polímero. Estudos mostram que o índice de fluidez da resina aumenta linearmente como a concentração de iniciador quando uma concentração baixa de peróxido é utilizada. Já em altas concentrações, esse índice aumenta apenas até um limite de concentração, e, em seguida começa a diminuir, principalmente devido a perda de eficiência no uso do peróxido. A eficiência de uso do peróxido está relacionada com a eficiência de mistura do mesmo com o polímero.

Este caso-estudo foi selecionado neste trabalho por ser bem conhecido na literatura que a quebra das cadeias neste processo se dá de modo aleatório, já que o radical livre pode atacar as cadeias poliméricas em qualquer posição, sem preferência ou seletividade, para abstrair um átomo de hidrogênio da mesma e em seguida o radical polimérico assim gerado 
sofre quase que imediatamente uma cisão beta, quebrando a molécula original do polímero em duas outras menores. Como as cadeias maiores têm mais hidrogênios, elas estarão proporcionalmente mais sujeitas a sofrer quebra que as cadeias menores, e o resultado líquido deste processo será que as cadeias maiores são quebradas preferencialmente, o que faz diminuir o tamanho médio das cadeias e estreitar a distribuição de tamanhos.

O seguinte esquema reacional pode ser usado para descrever este processo (GIUDICI, 1994a,b):

Decomposição do peróxido

Abstração de H + cisão beta instantânea

Transferência de cadeia + cisão beta

Degradação térmica

Terminação

Terminação com radicais do iniciador

$$
I \stackrel{k_{d}}{\longrightarrow} 2 R_{o}^{\bullet}
$$

$$
R_{o}^{\bullet}+P_{r} \stackrel{k_{1}}{\longrightarrow} R_{o} H+R_{r-s}^{\bullet}+P_{s}
$$$$
R_{n}^{\bullet}+P_{r} \stackrel{k_{2}}{\longrightarrow} P_{n}+R_{r-s}^{\bullet}+P_{s}
$$$$
P_{r} \stackrel{k_{3}}{\longrightarrow} R_{r-s}^{\bullet}+R_{s}^{\bullet}
$$

$$
R_{r}^{\bullet}+R_{s}^{\bullet} \stackrel{k_{4}}{\longrightarrow} P_{r+s}
$$$$
R_{r}^{\bullet}+R_{0}^{\bullet} \stackrel{k_{5}}{\longrightarrow} P_{r}
$$

A partir dos balanços de massa de cada espécie, e usando a hipótese de estado pseudo-estacionário para os radicais livres, chega-se à equação que descreve a variação da distribuição de tamanhos dos polímeros:

$$
\frac{d\left[P_{r}\right]}{d u}=-(r-1)\left[P_{r}\right]+2 \sum_{i=r+1}^{\infty}\left[P_{i}\right]
$$

onde o fator 2 indica que existem duas possibilidades de formar uma cadeia de tamanho $r$ a partir da cisão de uma cadeia de tamanho $i>r$, e $u$ é o grau de cisão (fração das unidades monoméricas que sofreram cisão) é definido por:

$$
\frac{d u}{d t}=k_{1}\left[R_{0}^{\bullet}\right]+k_{2} \sum_{i=1}^{\infty}\left[R_{i}^{\bullet}\right]+k_{3} \cong \frac{f k_{d}[I]}{\sum_{n=1}^{\infty} n\left[P_{n}\right]}=\frac{f k_{d}[I]}{Q_{1}}
$$

onde $Q_{l}$ é o momento de ordem um da distribuição de massas molares $\left[P_{r}\right]$, ou seja é o número total de unidades monoméricas de toda a população de cadeias poliméricas.

Definindo a fração mássica de cadeias de tamanho $j$ por $w(r)=r\left[P_{r}\right] / Q_{1} \quad \mathrm{e}$ considerando $r \gg>1$ e a aproximação por variável contínua, o balanço para as cadeias de tamanho $r$ toma a forma: 


$$
\frac{1}{r} \frac{d w(r, u)}{d u}=-w(r, u)+2 \int_{s}^{\infty} \frac{w(s, u)}{s} d s
$$

\subsubsection{Dados experimentais.}

Os dados experimentais usados neste estudo de caso foram obtidos do trabalho de ROCHA;BALKE;COUTINHO (1994), que reportam dados de distribuição de massas molares para o processo de degradação radicalar de polipropileno com peróxido. Nestes ensaios, o polipropileno foi degradado pela injeção de dois diferentes peróxidos orgânicos (Lupersol 101 e Lupersol 130), durante a extrusão, em duas diferentes rotações (20 e 40 rpm). As variáveis obtidas deste trabalho são as distribuições experimentais de massa molar do polímero.

Experimentalmente ROCHA;BALKE;COUTINHO (1994) utilizaram uma extrusora única, modelo Deltaplast D40:150:24, com uma barreira de 1,5 polegadas de diâmetro, e relação 24:1 L/D, o polipropileno utilizado foi o Pro-Fax 6631, e foi alimentado na entrada da extrusora junto com os iniciadores peróxido, 2,5-dimetil-2,5 bis(tercbutilperoxi)hexano (Lupersol 101), e, 2,5-dimetil-2,5-bis(tercbutilperoxi)-hexino-3 (Lupersol 130), todos foram adicionado à porta de alimentação usando uma bomba tipo seringa marca Sage-355, calibrada previamente. As concentrações utilizadas para ambos os iniciadores foram 0,1 , 0,5 , e, 0,9, em porcentagem mássica.

As reações ocorreram em uma atmosfera inerte, à temperatura de $190^{\circ} \mathrm{C}$. Duas diferentes rotações foram utilizadas 20 e $40 \mathrm{rpm}$. A concentração de peróxido foi variada, de forma aleatória, evitando assim erros sistemáticos. Os produtos já degradados eram coletados de forma a evitar posterior degradação.

As distribuições foram medidas por GCP-SEC (cromatografia de permeação em gel, cromatografia de exclusão de tamanho) Waters modelo $150 \mathrm{C}$ utilizando um detector do tipo refratômetro diferencial. $\mathrm{O}$ cromatógrafo foi operado à temperatura de $145^{\circ} \mathrm{C}$, usando triclorobenzeno como fase móvel na vazão $1 \mathrm{~mL} / \mathrm{min}$.

As distribuições experimentais são apresentadas na Figura 4.2.3. Para cada uma das diferentes curvas, obtidas para diferentes condições de processamento, um valor de u (grau de cisão) foi obtido por ajuste da solução da equação (4.1.3). Com isso, as curvas 
experimentais referem-se a diferentes valores de grau de cisão u, variável independente da equação, que seria equivalente ao tempo na equação de balanço populacional.

\subsubsection{Solução do Problema Inverso.}

Aplicando o algoritmo de problema inverso, inicialmente tomaram-se diversos valores fixos da distribuição acumulada $F(v)$, obtendo-se os valores de $y=\ln (t)$ versus $\mathrm{x}=\ln (\mathrm{v})$ mostrados na Figura 4.2.1(a) e os respectivos comprimentos de arco mostrados na Figura 4.2.1(b).

Na figura 4.2.1 (a) utilizou-se apenas uma interpolação linear ao tentar obter as curvas paralelas para o cálculo do comprimento de arco, desprezando-se os poucos pontos que saiam desta tendência (isso porque verificou-se que o erro aumentaria muito se utilizássemos curvas de polinômios de segundo grau). Observa-se na Figura 4.2.1(b) um adequado alinhamento dos pontos oriundos das diferentes famílias das curvas da Figura 4.2.1(a).

Na Figura 4.2.2 são mostradas as distribuições diferenciais em função da variável de similaridade, mostrando que as distribuições ficaram sobrepostas umas às outras, indicando sua característica de auto-similaridade necessária para a aplicação do algoritmo do problema inverso.

E, com isso, obtivemos uma regressão não linear. 

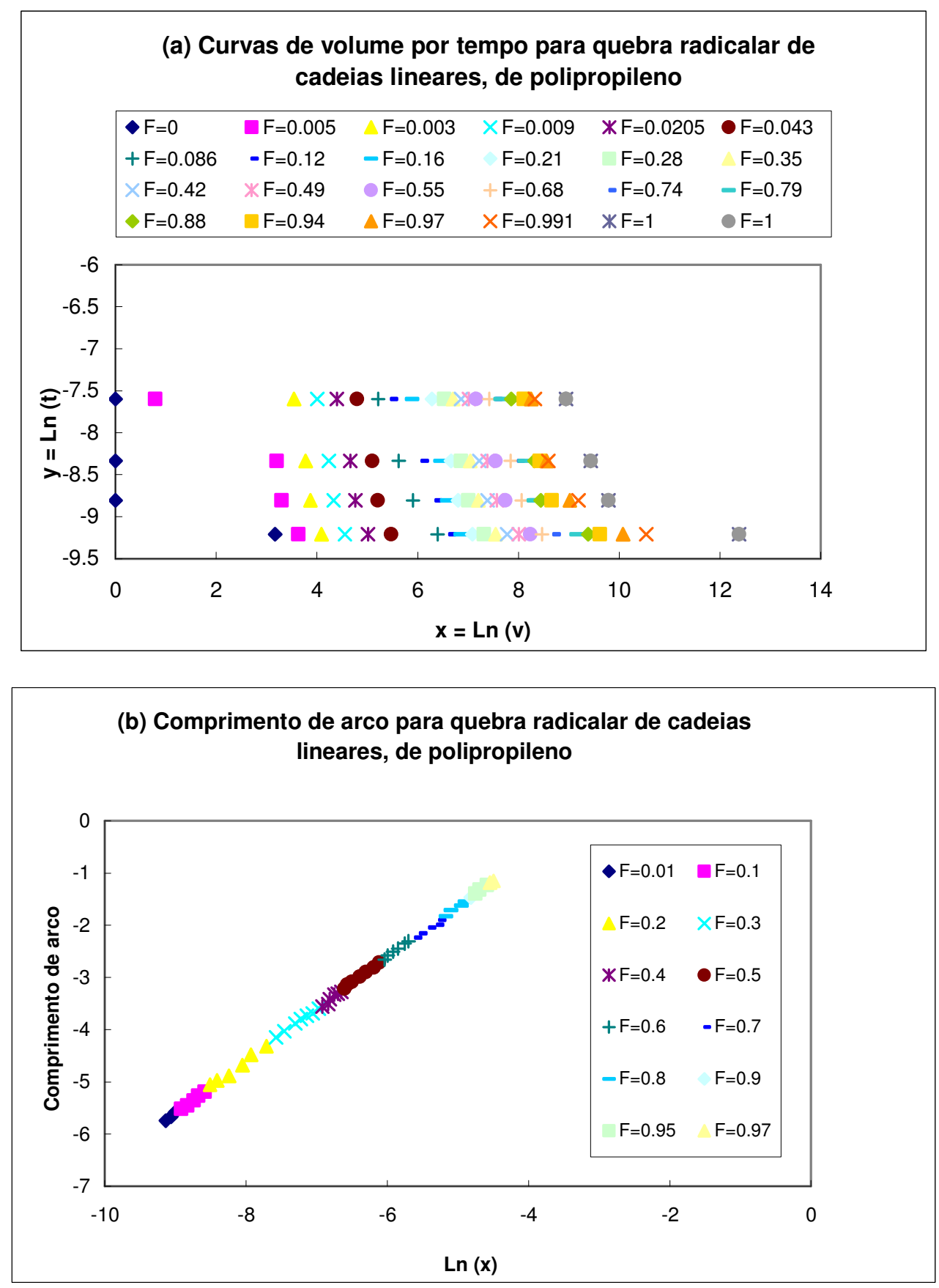

Figura 4.2.1: (a) $\operatorname{Ln}(\mathrm{t})$ por $\ln (\mathrm{v})$ dos dados experimentais, e, (b) Comprimento de arco pelo volume, ambos, calculados com os dados experimentais de (ROCHA;BALKE;COUTINHO,1994) 


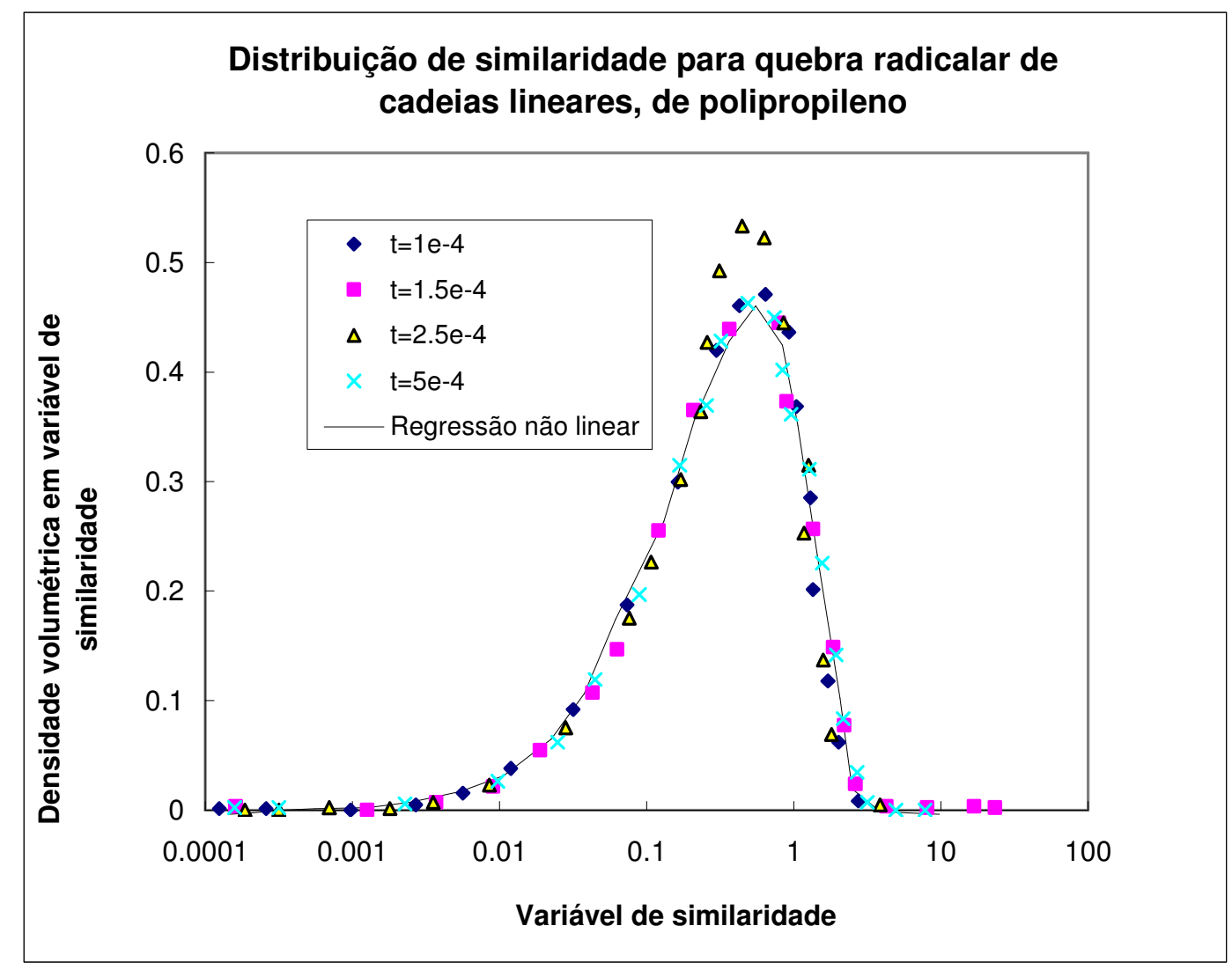

Figura 4.2.2: Sobreposição das curvas de distribuição ao longo do tempo, para a quebra radicalar de cadeias lineares, de polipropileno.

A figura 4.2.3(a) e (b) mostram, respectivamente, as distribuições diferenciais e acumuladas para diferentes instantes de tempo, obtidas a partir do problema inverso (linhas) e sua comparação com as distribuições experimentais (pontos).

No APÊNDICE G é apresentado um procedimento de simulação de Monte Carlo para o processo de cisão e sua comparação com os dados experimentais.

A função de quebra e a distribuição de partículas filhas obtidas pelo algoritmo de otimização de problema inverso são mostradas na Figura 4.2.4. 

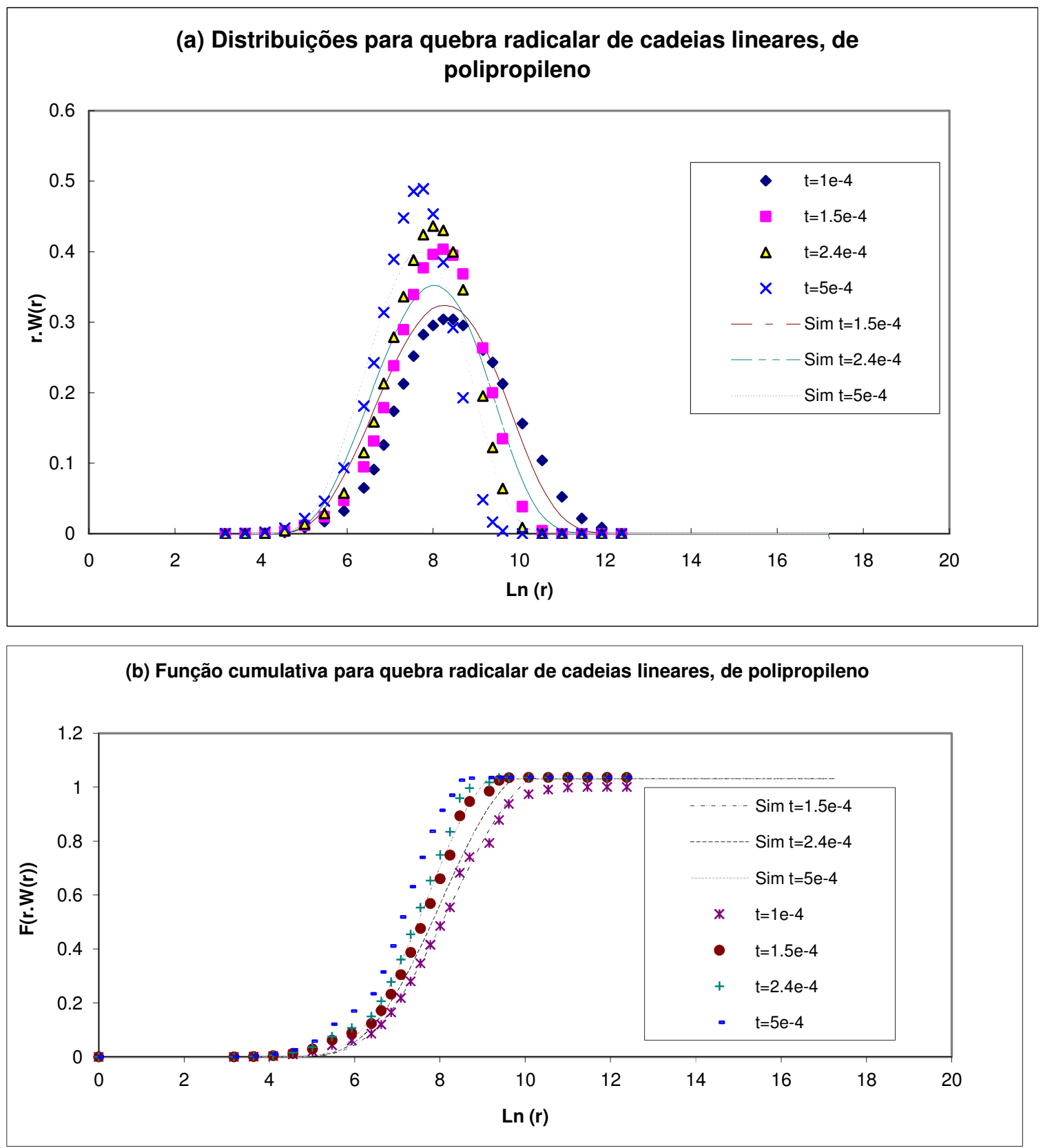

Figura 4.2.3: Comparação dos dados experimentais com as curvas calculadas pelo problema inverso: (a) distribuições diferenciais e (b) funções cumulativas. 
(a) Taxa de quebra para quebra radicalar de cadeias lineares, de polipropileno

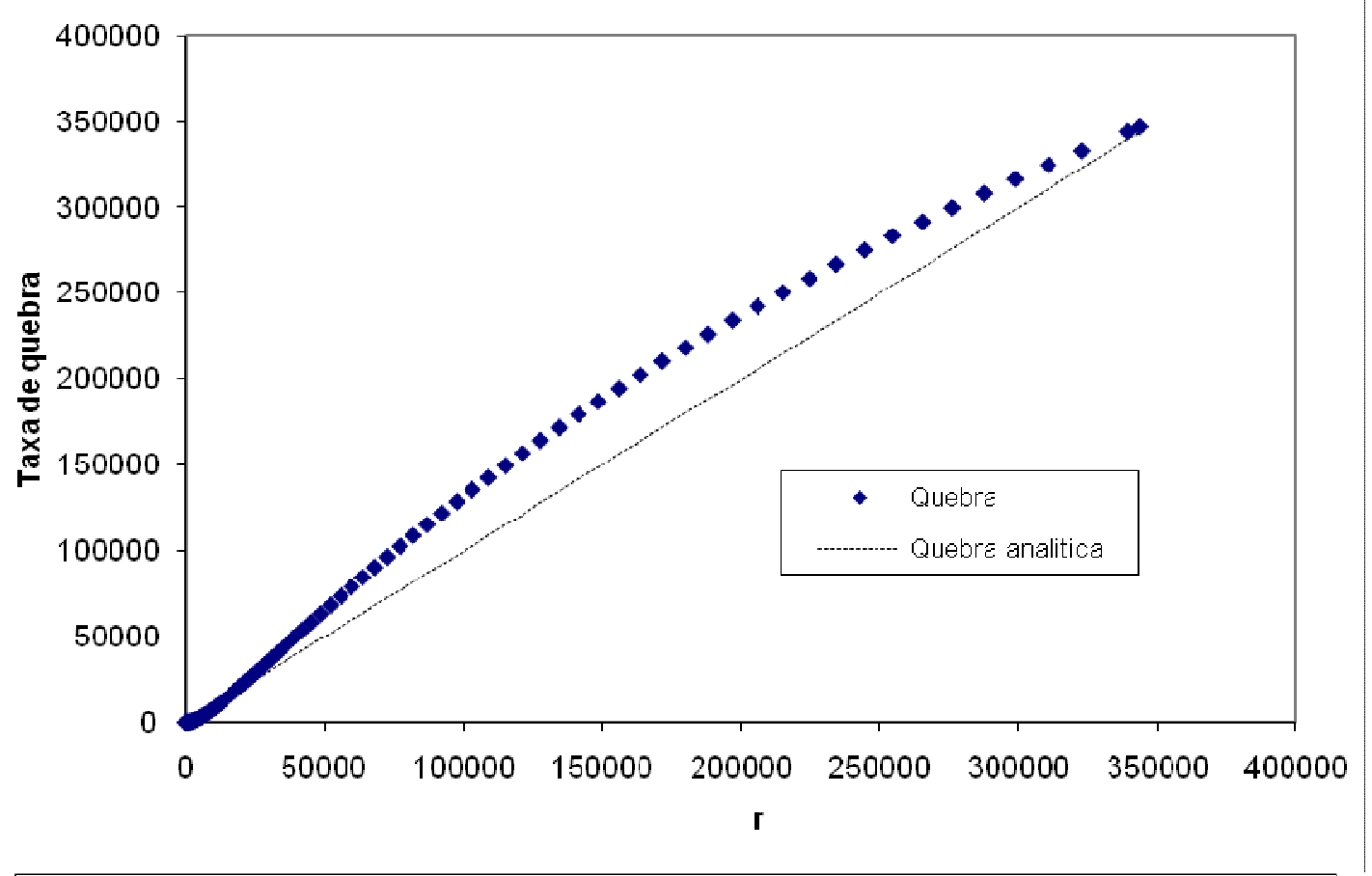

(b) Distribuição de partículas filhas para quebra radicalar de cadeias lineares, de polipropileno

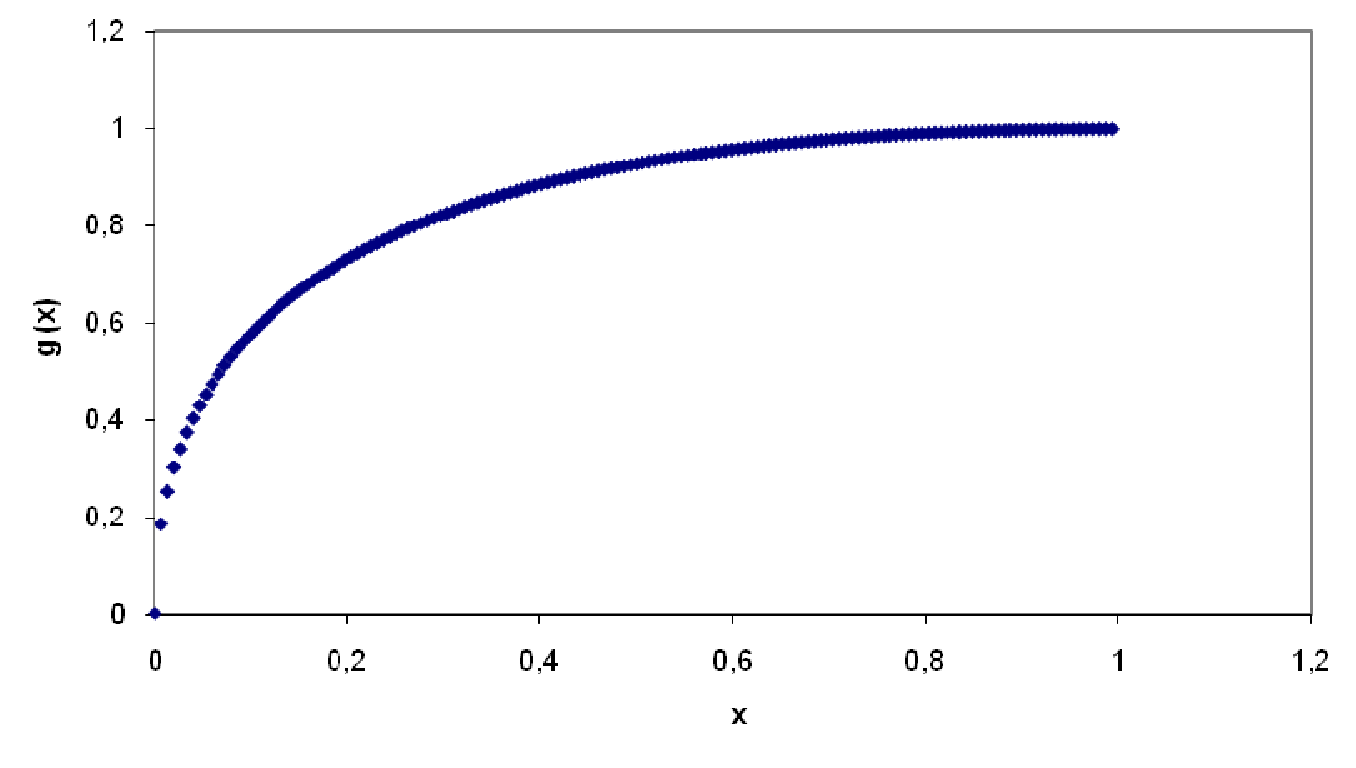

Figura 4.2.4: (a) Funções de quebra, e, (b) distribuição de partículas filhas obtidas pela solução do problema inverso, para a quebra radicalar de cadeias lineares de polipropileno. 
Podemos verificar a coerência entre os resultados obtidos com os esperados. Na figura 4.2.4(a) acrescentou-se uma linha reta que indica o resultado teórico esperado; como o processo de quebra neste caso é aleatório, a taxa de quebra deveria ser proporcional ao comprimento da cadeia (cadeias maiores têm mais chance de sofrer abstração de hidrogênio pelos radicais, portanto têm mais chance de sofrer a cisão). Observa-se que a curva calculada pelo problema inverso não é perfeitamente linear, apresentando um pequeno desvio em relação ao resultado esperado. Isto possivelmente se deve a erros numéricos que são acumulados e propagados no decorrer dos procedimentos de cálculo do algoritmo do problema inverso. Por exemplo, as pequenas diferenças entre as distribuições de similaridade mostradas na Figura 4.2.2, podem ter levado às diferenças observadas nas figuras 4.2.4, uma vez que os resultados simulados com as funções de quebra e distribuição de filhas não reproduziram perfeitamente bem as distribuições experimentais.

Outra comparação possível é combinar a função de quebra e a distribuição de filhas obtidas do algoritmo do problema inverso e comparar com a equação de balanço teórica deste problema:

$$
\frac{d P_{r}}{d t}=-r P_{r}+2 \sum_{s=r+1}^{\infty} P_{s} \quad(\mathrm{r}>>1, \quad \mathrm{r}+1 \approx \mathrm{r})
$$

ou, em termos de variável contínua:

$$
\frac{d w(r, u)}{d t}=-r w(r, u)+2 r \int_{r}^{\infty} \frac{w(s, u)}{s} d s
$$

onde $w(r, u)$ é a fração mássica de polímero de tamanho $\mathrm{r}$ no instante em que o grau de cisão é $u$, dado por:

$$
w(r, u)=\frac{r P_{r}}{\sum_{r=1}^{\infty} r P_{r}}
$$

Portanto, comparando a equação (3.1.14)

$$
\frac{d n(v, t)}{d t}=-\Gamma(v) n(v, t)+\int_{v}^{\infty} \beta\left(v, v^{\prime}\right) v\left(v^{\prime}\right) \Gamma\left(v^{\prime}\right) n\left(v^{\prime}, t\right) d v^{\prime}
$$


com a equação (4.2.2), temos que o resultado esperado para o produto $\beta\left(v, v^{\prime}\right) v(v) \Gamma\left(v^{\prime}\right)=2$ e também que $\Gamma(v)=r=v$. A primeira comparação está mostrada na Figura 4.2.5. Observa-se que há coerência entre a solução do problema inverso e o resultado esperado. A outra comparação está mostrada na Figura 4.2.4(a), novamente mostrando uma razoável, ainda que não perfeita, coerência do resultado obtido pelo problema inverso e o resultado teórico esperado.

De uma maneira geral, pode-se considerar satisfatória a aplicação do algoritmo do problema inverso, produzindo resultados coerentes com os esperados, a despeito dos pequenos desvios observados, que podem ser atribuídos possivelmente a erros acumulados no cálculo do algoritmo do problema inverso.

Esta comparação justifica a escolha deste caso-estudo 2 para o teste do procedimento, uma vez que neste caso existe uma solução teórica que pode ser confrontada diretamente com a solução do problema inverso, permitindo dessa forma avaliar o grau de acuidade do procedimento do problema inverso baseado na auto-similaridade.

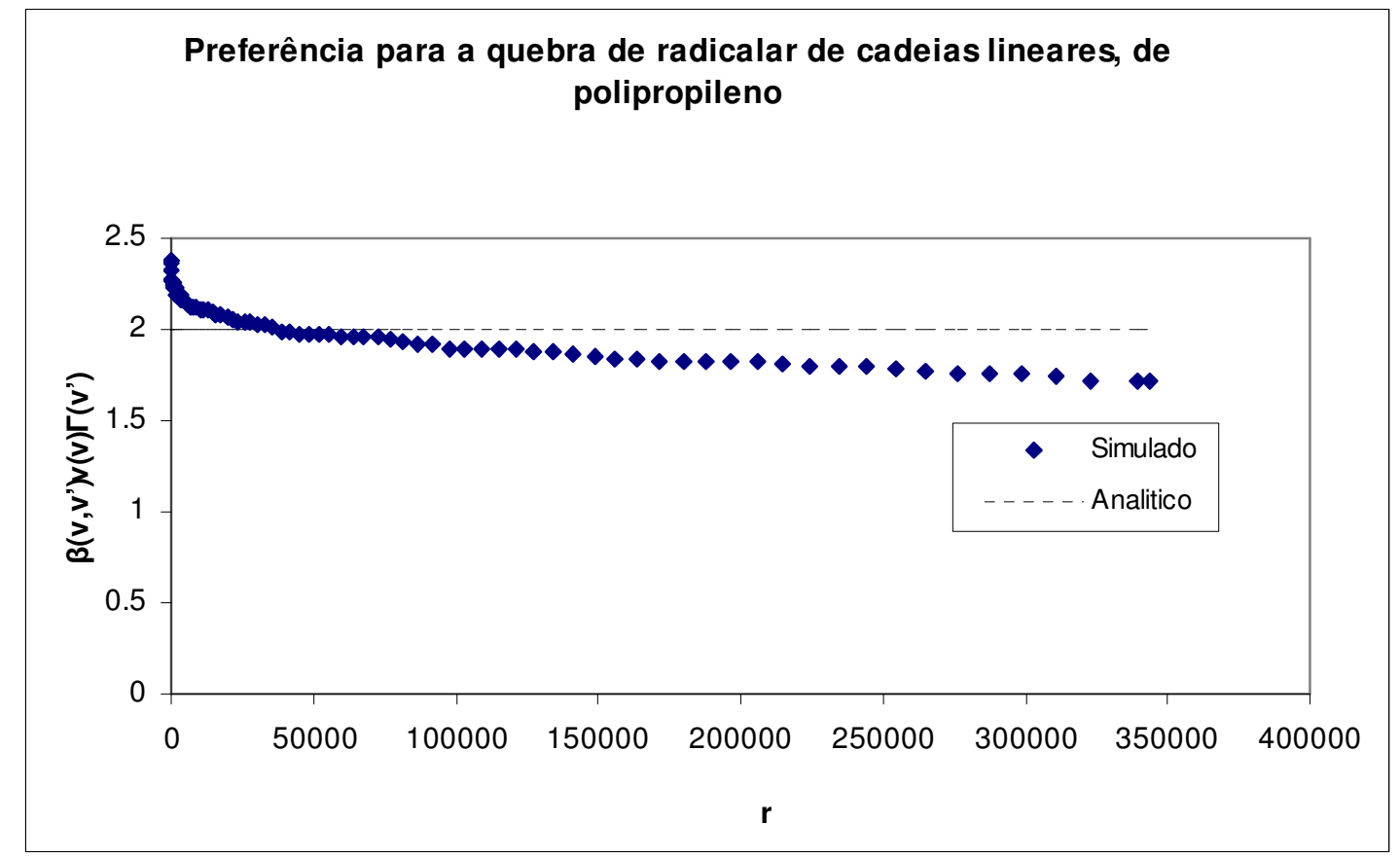

Figura 4.2.5: Valor igual a dois correspondente ao valor, $\mathrm{n}_{\mathrm{i}, \mathrm{k}} \mathrm{b}\left(\mathrm{x}_{\mathrm{k}}\right)=\beta\left(\mathrm{v}, \mathrm{v}^{\prime}\right) v(\mathrm{v}) \Gamma\left(\mathrm{v}^{\prime}\right)=2$, esperado de acordo com a análise das equações de balanço populacional. 


\subsection{Caso-estudo 3: Hidrólise ácida de dextrana.}

Dextranas constituem uma classe de biopolímeros de fórmula empírica $\left(\mathrm{C}_{6} \mathrm{H}_{10} \mathrm{O}_{5}\right)_{\mathrm{n}}$ cujo monômero é o $\alpha$-D-glucaconopiranosil (AQUINO; FRANCO; 2008). È portanto uma poliglucose, que é produzida biologicamente por bactérias do gênero Leuconostoc, com massa molar média $(\mathrm{Mw})$ podendo variar 1.500 Da até vários milhões de daltons, e a sua estrutura dependerá principalmente da espécie bacteriana produtora e do tipo de dextranasacarase presente no meio. As dextranas produzidas pelas cepas mais comuns do Leuconostoc mesenteroides apresentam mais de $90 \%$ de ligações glicosídicas $\alpha(1 \rightarrow 6)$, sendo o restante de suas ligações do tipo $\alpha(1 \rightarrow 4), \alpha(1 \rightarrow 3), \alpha(1 \rightarrow 2)$, as quais são responsáveis pelas ramificações ao longo da cadeia (AQUINO; FRANCO, 2008).

Este caso-estudo refere-se à reação de hidrólise de dextrana em meio ácido, processo que foi estudado experimentalmente por BASEDOW et al. (1978).

\subsubsection{Dados experimentais}

Ensaios experimentais de hidrólise ácida de dextrana foram realizados por BASEDOW et al. (1978) que mediram as distribuições de massas molares da dextrana usando cromatografia de permeação em gel (GPC). Os ensaios de degradação foram realizados em frascos de vidro de $100 \mathrm{~mL}$ fechados e termostatizados a $80 \pm 0,2^{\circ} \mathrm{C}$, com solução aquosa $0,12 \mathrm{~N}$ de ácido sulfúrico. A concentração inicial de dextrana variou de 0,5 a $2 \%$ em massa. A intervalos regulares de tempo, amostras de $10 \mathrm{~mL}$ foram retiradas, misturadas em metanol frio $\left(-30^{\circ} \mathrm{C}\right)$ para a precipitação da dextrana, a qual foi lavada com metanol, e secada sob vácuo até massa constante, e dissolvida em água contendo 0,2\% de nitrato de potássio e analisada por GPC. Neste processo os autores reportam que oligossacarídeos com grau de polimerização menor que 5 não foram precipitados e foram portanto desconsiderados. A figura 4.3.1 ilustra as distribuições experimentais obtidas. 


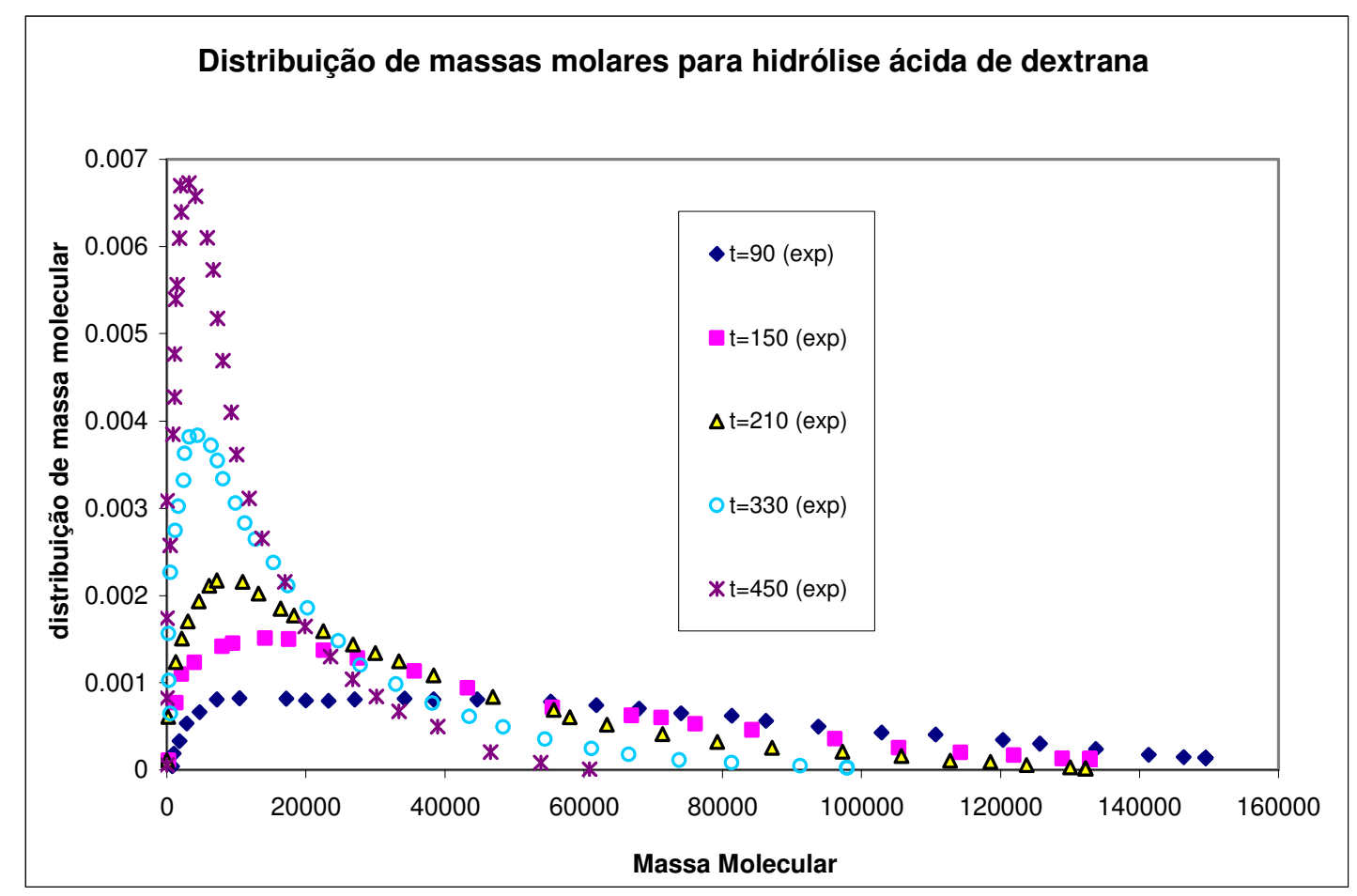

Figura 4.3.1. Distribuições de massa molares experimentais medidas no processo de hidrólise ácida de dextrana (BASEDOW et al., 1978).

\subsubsection{Solução do Problema Inverso.}

A seguir, são apresentadas as curvas e funções calculadas pela metodologia de problema inverso, adotando-se a distribuição medida em $\mathrm{t}=90 \mathrm{~min}$ como sendo a distribuição inicial.

A figura 4.3.2. mostra os valores interpolados na distribuição cumulativa e as curvas de comprimento de arco, colapsadas em uma única reta. A Figura 4.3.3 mostra as diversas distribuições em função da variável de similaridade, mostrando uma superposição não completa, mas aceitável para a aplicação da metodologia.

Na figura 4.3.4 observam-se as funções de taxa de quebra e a distribuição de cadeias filhas obtidas pela aplicação do algoritmo do problema inverso.Na Figura 4.3.5 apresentase a comparação das curvas de distribuição de massas molares experimentais e as curvas calculadas com os parâmetros obtidos do problema inverso. Observa-se uma concordância satisfatória entre as curvas calculadas e as curvas experimentais. 

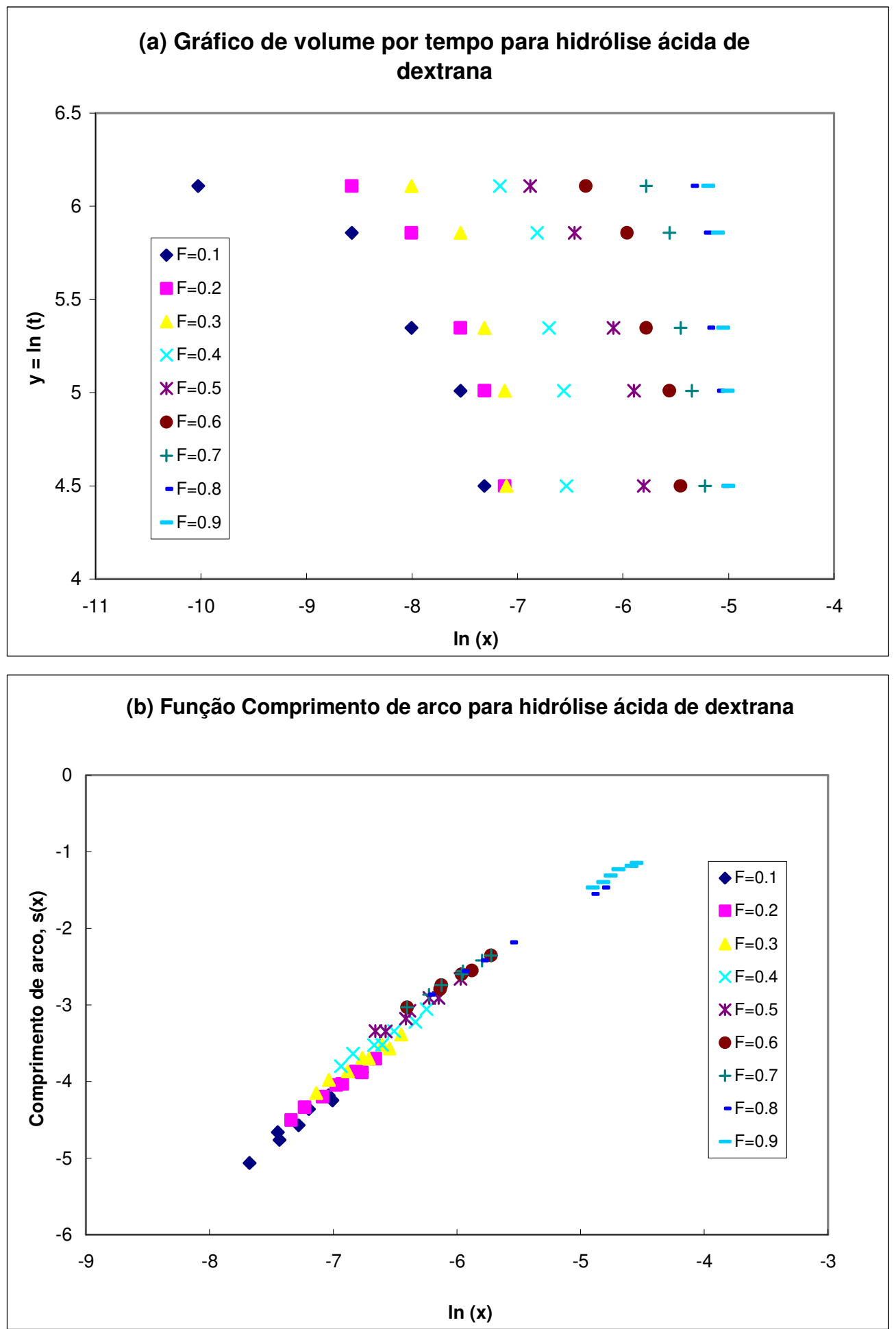

Figura 4.3.2: (a) Curvas de $\ln \mathrm{t}$ versus $\ln \mathrm{x}$ e (b) curvas de comprimento de arco mostrando a similaridade para o caso de hidrólise ácida de dextrana. 


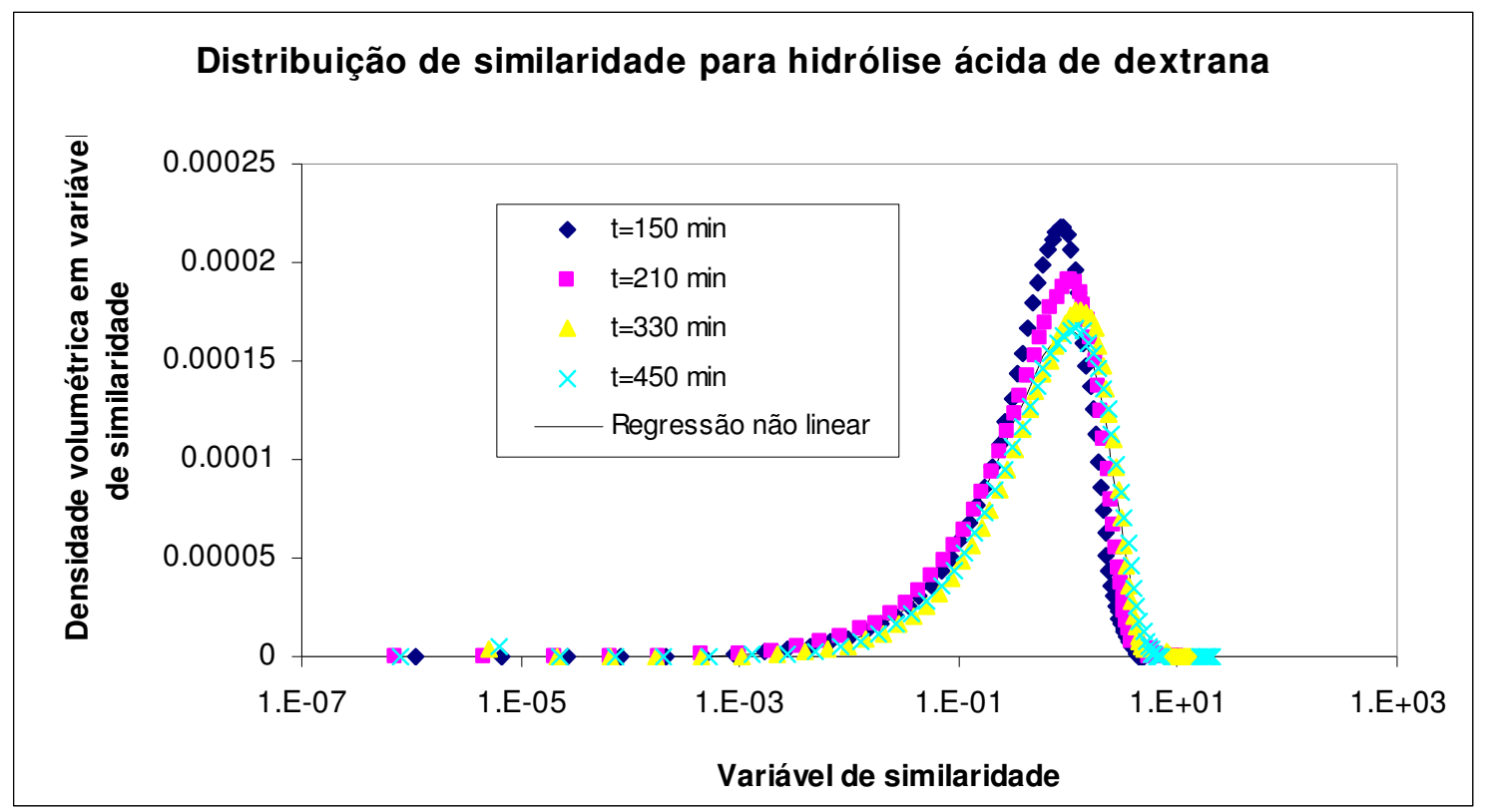

Figura 4.3.3: Teste de distribuição de similaridade das curvas em diferentes tempos, para o caso de hidrólise ácida de dextrana.
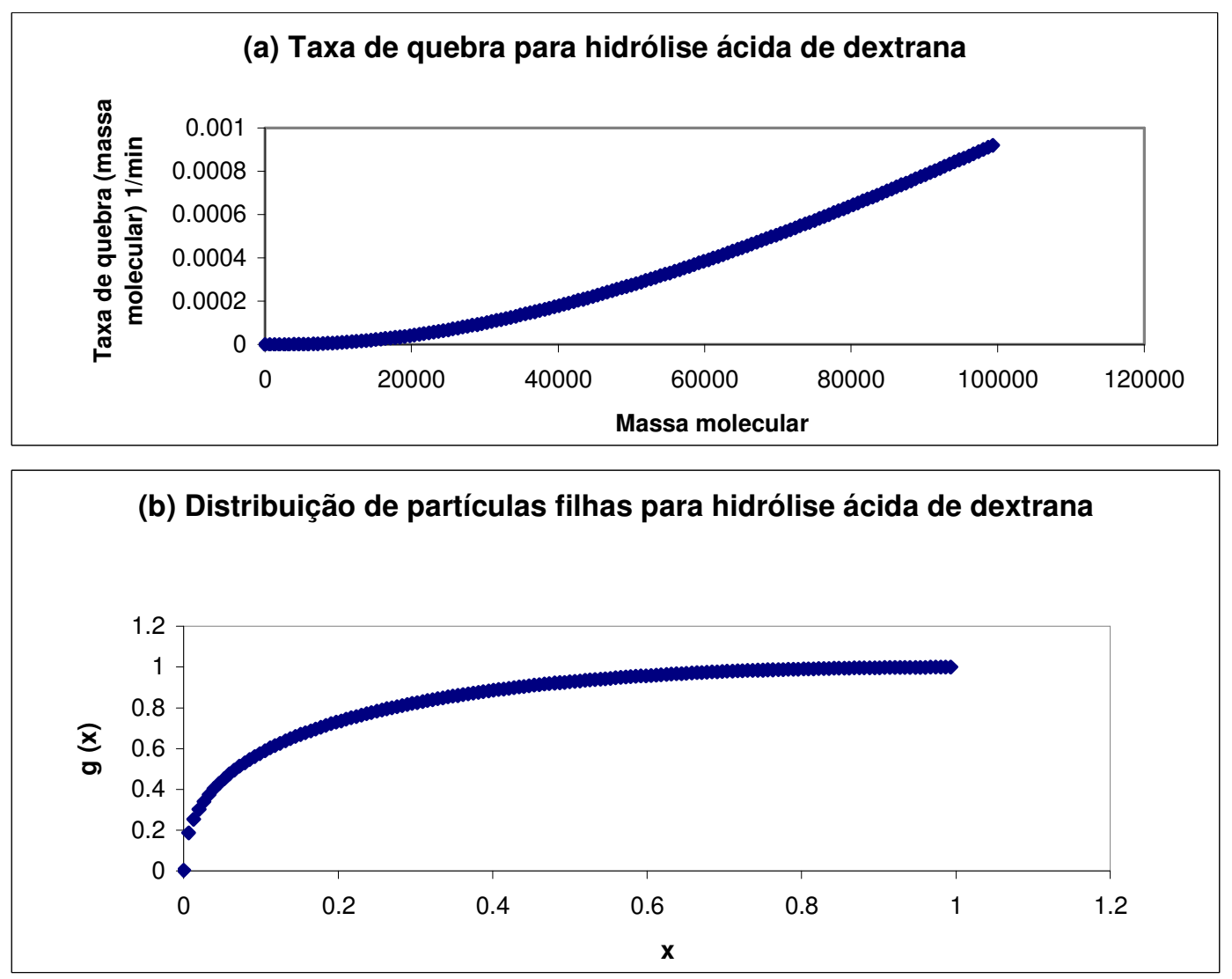

Figura 4.3.4: Resultado do problema inverso para (a) a taxa de quebra e (b) para a distribuição de cadeias filhas para o caso de hidrólise ácida de dextrana. 

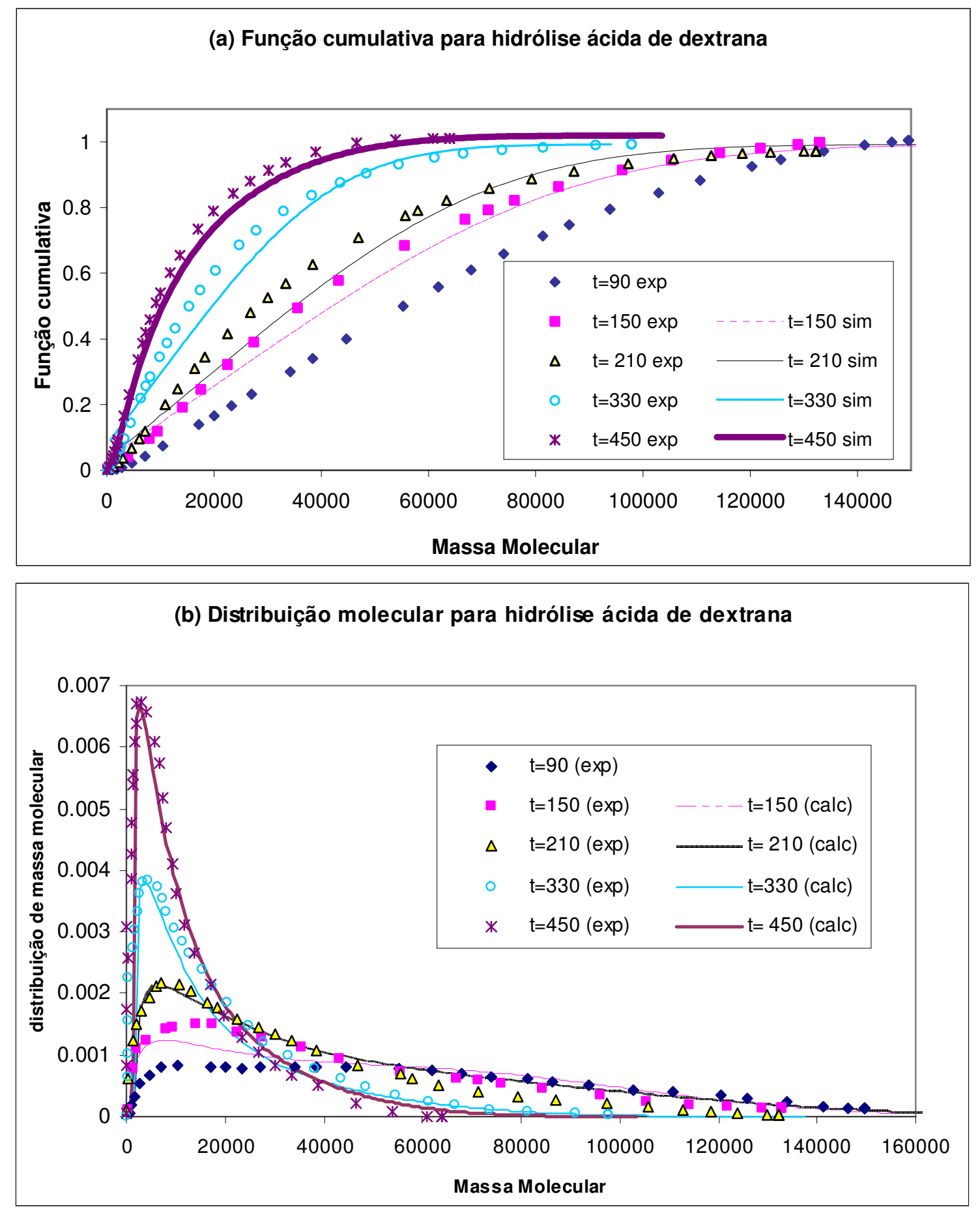

Figura 4.3.5: Distribuições de massas molares diferenciais e cumulativas medidas (símbolos) e calculadas (curvas) para o processo de hidrólise ácida de dextrana. 
O valor correspondente ao fator $\beta\left(\mathrm{v}, \mathrm{v}^{\prime}\right) v(\mathrm{v}) \Gamma\left(\mathrm{v}^{\prime}\right)$ do balanço populacional é apresentado na figura 4.3.6. Nota-se neste caso, que esta função passa por um máximo para massas molares entre 15000 e 20000 , e que o valor desta função se estabiliza e permanece praticamente constante e relativamente baixo para massas molares maiores que 40000. Isto indica que neste processo de degradação por hidrólise ácida, podem existir pontos preferenciais de quebra das cadeias.

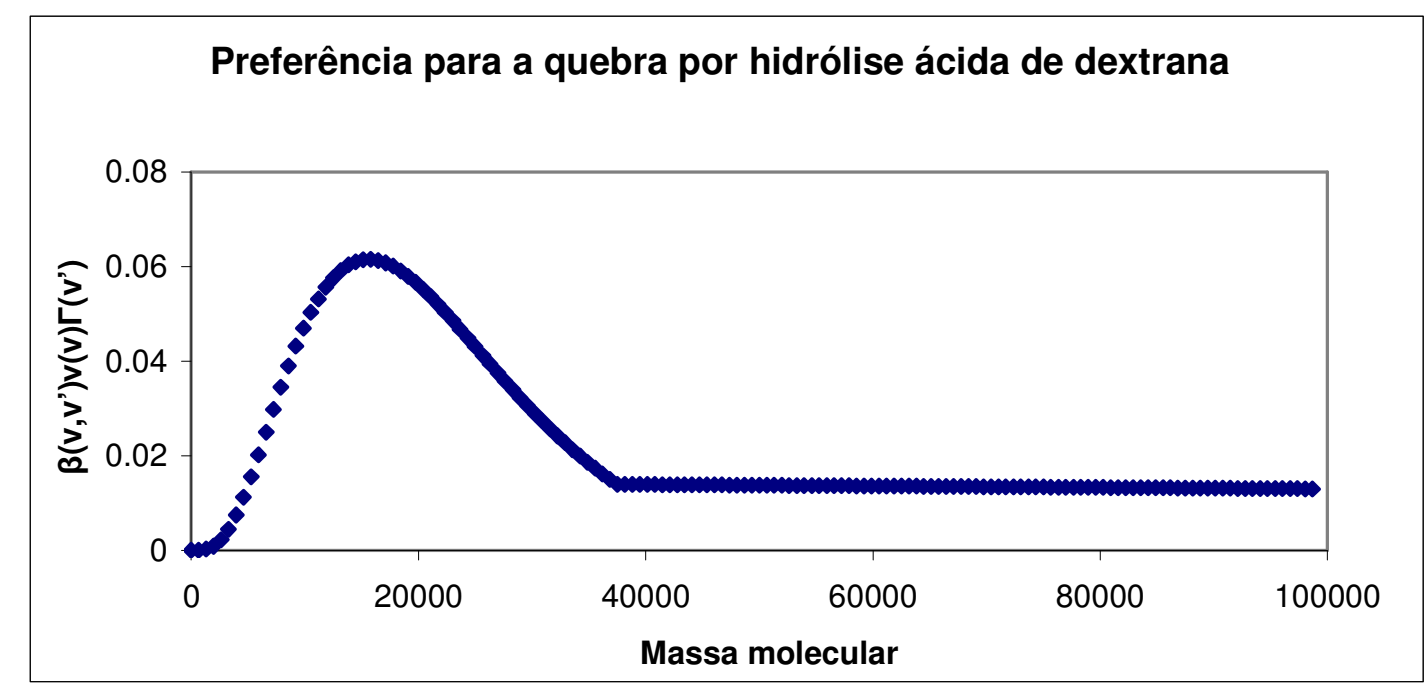

Figura 4.3.6: Gráfico do termo $\beta\left(\mathrm{v}, \mathrm{v}^{\prime}\right) v(\mathrm{v}) \Gamma\left(\mathrm{v}^{\prime}\right)$, do balanço populacional, obtido pelo problema inverso, pelas distribuições de massa molecular, para hidrolise ácida de dextrana.

Ederer et al. (1981) discutem esta possibilidade, indicando que no processo de hidrólise ácida de dextrana, a formação de cadeias menores é favorecida em relação ao caso em que uma degradação randômica é considerada. Aqueles autores indicam também que as taxas ïndividuais" de quebra das diferentes ligações na cadeia da dextrana dependem tanto do grau de polimerização (ou seja, do tamanho da cadeia) e da localização da ligação dentro da cadeia. De fato, no trabalho de Ederer et al. (1981), os autores conseguiram ajustar melhor um modelo de degradação quando consideraram que dentro de uma molécula de polímero, as ligações mais próximas às pontas da cadeia tem maior probabilidade de sofrer uma cisão do que as ligações localizadas mais no centro da cadeia. A razão disso seria, segundo Ederer et al. (1981), que a estrutura das cadeias de dextrana não são lineares, e sim 
ramificadas, e levando em conta a topologia das cadeias ramificadas, resultaria em uma aparente preferência de quebra maior próximo das pontas do que próxima ao centro (ideias similares foram usadas por Giudici e Hamielec (1996) para simular processos de cisão de cadeias ramificadas).

Pela figura 4.3.4(a), pode-se observar que as cadeias menores que $15000 \mathrm{Da}$ tem uma tendência muito pequena para a quebra.

Embora o processo de quebra das cadeias poliméricas de dextrana por hidrólise ácida seja esperado ser randômico (uma vez que o ataque do ácido às ligações é químico, portanto não específico), o fato de ser a dextrana conter cadeias com ramificações torna o processo de quebra dependente da estrutura da cadeia. Basedow et al. (1978) reportam estudos de degradação de dextranas com ultrassom em que, segundo os autores, as cadeias são quebradas preferencialmente no centro da molécula, enquanto que os mesmos autores interpretam seus dados de hidrólise ácida de dextrana de forma inversa, ou seja, com preferência pela quebra das ligações mais próximas das pontas da cadeia.

Outro indício de que a quebra não se dá de modo completamente aleatório na hidrólise ácida de dextrana vem da análise do valor da polidispersidade parâmertros que carateriza a "largura" da distribuição, definido matematicamente por:

$$
P_{D}=\frac{\bar{M}_{w}}{\bar{M}_{n}}=\frac{\int_{0}^{\infty} M \cdot w(M) d M}{\int_{0}^{\infty} w(M) d M} \frac{\int_{0}^{\infty} \frac{w(M)}{M} d M}{\int_{0}^{\infty} w(M) d M}=\int_{0}^{\infty} M \cdot w(M) d M \int_{0}^{\infty} \frac{w(M)}{M} d M
$$

Para uma quebra completamente aleatória, é bem conhecido (TRIACCA et al., 1993; HAMIELEC et al., 1991) que a distribuição final para altos graus de cisão tende a uma distribuição tipo Flory, cujo valor da polidispersidade é 2. Portanto, para processo de quebra aleatória, a polidispersidade tende ao valor de 2. Os dados experimentais reportados por BASEDOW et al. (1978) mostram uma tendência diferente desta, de aumento da polidispersidade com o tempo, conforme mostra a Figura 4.3.7, portanto indicando ser um processo não completamente aleatório. 

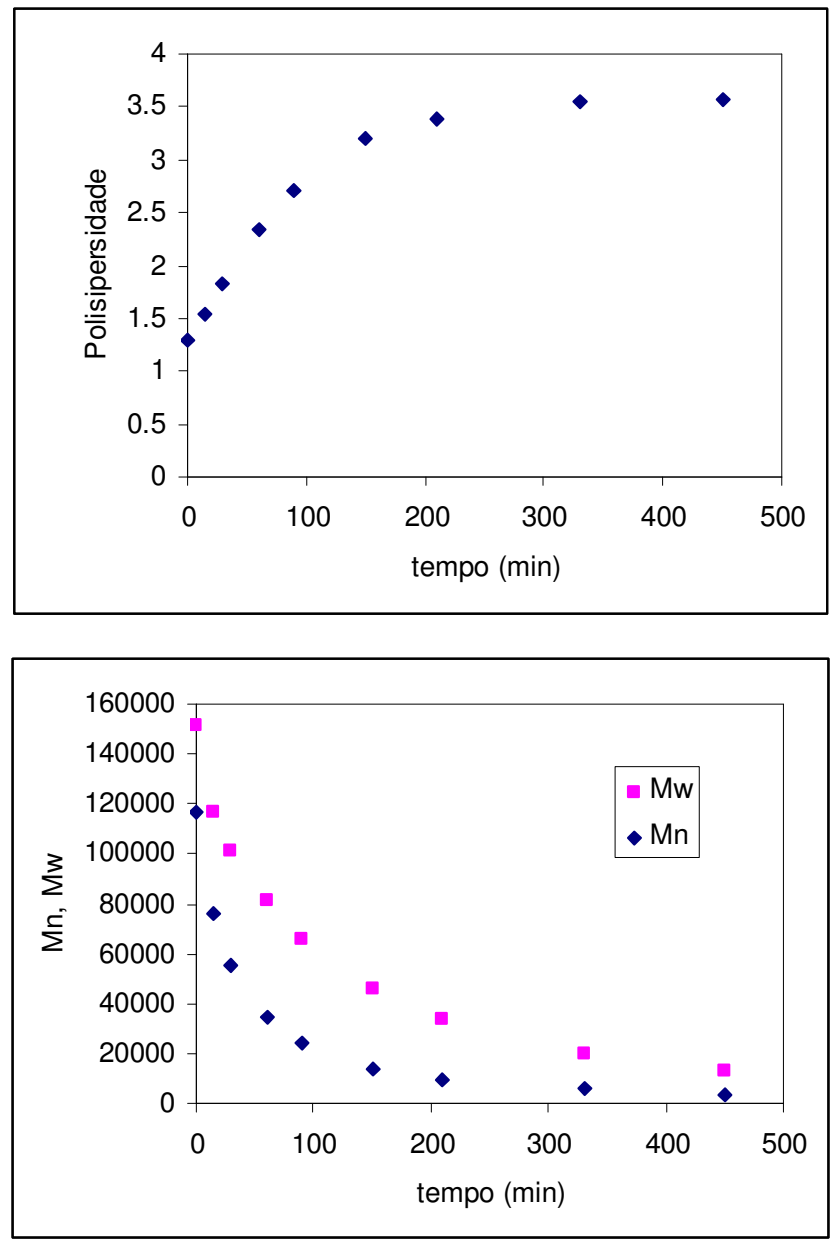

Figura 4.3.7. Evolução dos valores experimentais da polidispersidade (Pd) e das massas molares médias mássica $(\mathrm{Mw})$ e numérica $(\mathrm{Mn})$ para os dados de hidrólise ácida de dextrana (BASEDOW et al., 1978). 


\subsection{Degradação mecânica de poliestireno dissolvido por cisalhamento.}

Neste item, o algoritmo de problema inverso é aplicado ao caso de degradação de poliestireno induzida por cisalhamento mecânico, na presença de um solvente- $\theta$. Solvente- $\theta$ é um solvente no qual o polímero mantém uma conformação de serpentina de "cadeia ideal" com dimensões fixas (diferentemente de um mau solvente no qual a cadeia se contrai, diferentemente de um bom solvente no qual a cadeia se estica). Nesta condição, o potencial químico excedente (ou potencial químico de excesso) entre o polímero e o solvente- $\theta$ é nulo.

BALLAUF; WOLF (1984) estudaram experimentalmente a degradação de poliestireno dissolvido em trans-decalina (que é solvente- $\theta$ para este polímero) em presença de cisalhamento mecânico provocado por um dispositivo tipo Couette (dois cilíndricos concêntricos).

\subsubsection{Dados experimentais.}

Nos experimentos reportados por BALLAUF; WOLF (1984), avaliou-se o efeito da presença ou não de sequestrador de radicais livres ("radical scavengers"), compostos que reagem com os radicais gerados pela cisão homolítica das cadeias. $\mathrm{O}$ polímero que sofre degradação mecânica neste estudo foi o poliestireno. Nele a cisão das cadeias C-C é homolítica, como se espera na degradação mecânica em solventes não polares. Na ausência de sequestradores de radicais, os radicais poliméricos gerados teriam a possibilidade de reagir entre si, e caso isso ocorresse por combinação de radicais, cadeias maiores seriam formadas. Por outro lado, na presença deste sequestradores, a recombinação dos radicais seria evitada. Para isso, foram usados como "radical scavengers" o oxigênio ou o DPPH (2,2-difenil-1-picril-hidrazina).

Um esquema simplificado do aparelho utilizado para esse tipo de degradação é apresentado na figura 4.4.1. Trata-se de um aparelho do tipo Couette. Ele consiste em um termostato e de um rotor. Nele se produzem moderadas taxas de cisalhamento, da ordem de 
$5 \times 10^{3}$ até $10^{4} \mathrm{~s}^{-1}$, que são suficientes para a degradação de poliestireno, quando dissolvido no solvente- $\theta$ que os autores utilizaram, a trans-decalina. $O$ meio é mantido sob uma atmosfera de gás inerte (nitrogênio) para evitar o contato com oxigênio. O rotor tem raio menor de $17,85 \mathrm{~mm}$ e raio maior de $20,10 \mathrm{~mm}$, e comprimento de $60 \mathrm{~mm}$. o estator tem raio menor de $17,5 \mathrm{~mm}$ e raio maior de $20,5 \mathrm{~mm}$. As velocidades de rotação usadas no experimento são tais que o valor do número de Reynolds é da ordem de 10 (portanto a condição de escoamento é laminar) e o número de Taylor é menor que 41,3 (portanto evitase formação de vórtices de Taylor). As diferenças de temperatura causadas pela disspação viscosa (cisalhamento) foram minimizadas pela troca de calor com os cilindros interno e externo, de modo que a maior diferença de temperatura foi estimada ser de $\Delta \mathrm{T}=0,2 \mathrm{~K}(<1$ $\mathrm{K})$.

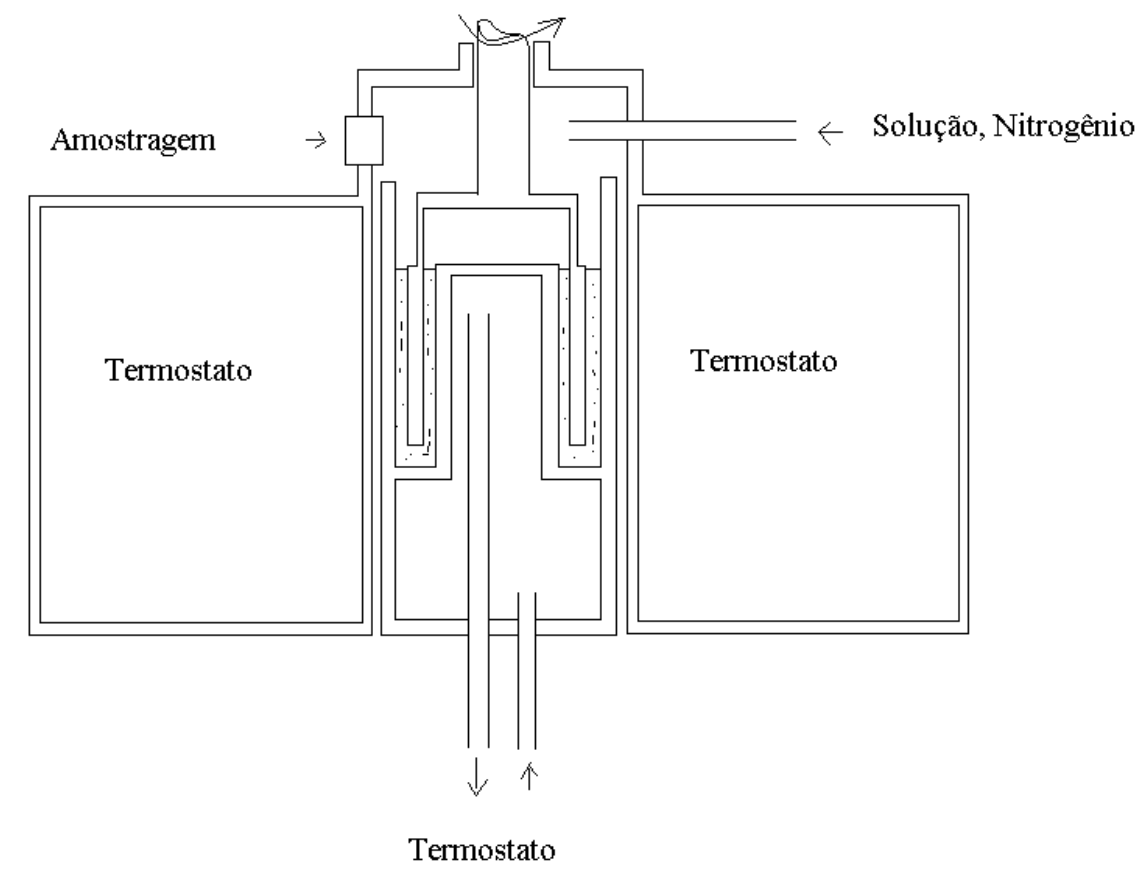

Figura 4.4.1: Esquema do aparelho utilizado por BALLAUF; WOLF (1984) para estudar a degradação de poliestireno por cisalhamento.

Os autores utilizaram poliestireno de peso molecular entre 2600 até 15000 Da e trans-decalina como solvente de 4,9 a $20,0 \%$ em massa. Os reagentes foram tolueno 
(Merck, Darmstadt), sem purificação, trans-decalina (Merck-Schuchardt), que foi purificado antes do uso. Verificou-se por cromatografia gasosa a presença de seu isômero cis com ocorrência em apenas $0,2 \%$ da amostra. DPPH (Fluka) foi utilizado sem prévia purificação. Os dados de solubilidade do oxigênio em trans-decalina não estão disponíveis na literatura, mas foram estimados por BALLAUF; WOFL (1984) a partir de dados de hidrocarbonetos similares, como $0,1 \mathrm{~cm}^{3}$ de $\mathrm{O}_{2} / \mathrm{cm}^{3}$ de solvente a $1 \mathrm{~atm}$, correspondendo portanto à concentração de $4,5 \times 10^{-3} \mathrm{~mol} / \mathrm{L}$. Para fazer comparações adequadas, os autores ajustaram a concentração de DPPH para um mesmo valor, que corresponde a $1,75 \mathrm{mg} / \mathrm{cm}^{3}$, para quando esta molécula, que cria o efeito gaiola, fosse utilizada.

\subsubsection{Solução do Problema Inverso.}

Nas figuras 4.4.2 a 4.4.6 são apresentados os resultados das distribuições finais, e da função cumulativa, as taxas de quebra e a distribuição de partículas filhas, obtidas pela solução do problema inverso, e as curvas paralelas de $\ln (\mathrm{t})$ versus $\ln (\mathrm{t})$, os comprimentos de arcos, e a sobreposição das distribuições após a transformação de similaridade. Neste caso de degradação mecânica, o polímero inicial é poliestireno produzido por polimerização aniônica, e sua distribuição final após 6 horas de aplicação de força mecânica na presença de oxigênio e na presença de DPPH.

Observa-se que as curvas de comprimento de arco (Figura 4.4.3) dos pares de curvas (inicial, $\mathrm{t}=0$, e para $\mathrm{t}=6 \mathrm{~h}$ ) colapsaram para uma única reta, as distrbuições em termos da variável de similaridade apresentam alguma pequena diferença (Figura 4.4.4). As distribuições de partículas filhas e as taxas de quebra obtidas pelo algoritmo do problema inverso, mostradas na Figira 4.4.5, quando substituídas na equação de balanço populacional, não reproduziram satisfatoriamente as curvas de distrbuições de tamanhos de cadeias experimentais (Figura 4.4.6) son o ponto de vista quantitativo. Sob o ponto de vista qualitativo, nota-se alguma semelhança de formato, p.ex. a curva para DPPH apresentando uma característica bimodal com menor grau de quebra e a curva para oxigênio apresentando-se monomodal e com maior grau de quebra. 

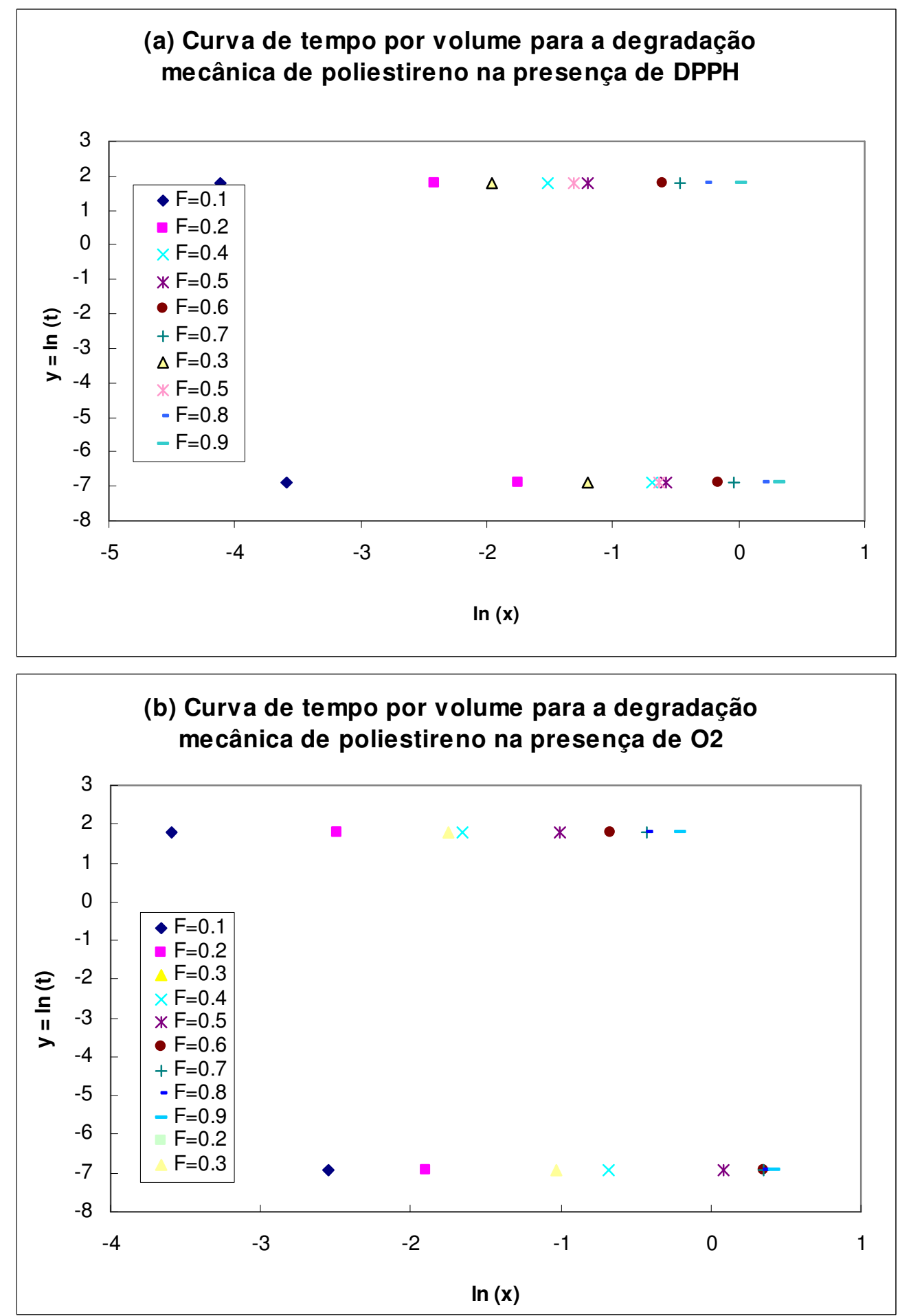

Figura 4.4.2: Curvas de $\ln (\mathrm{t})$ versus $\ln (\mathrm{v})$, para a degradação mecânica de poliestireno em meio com a presença de: (a) DPPH, e, (b) oxigênio. 

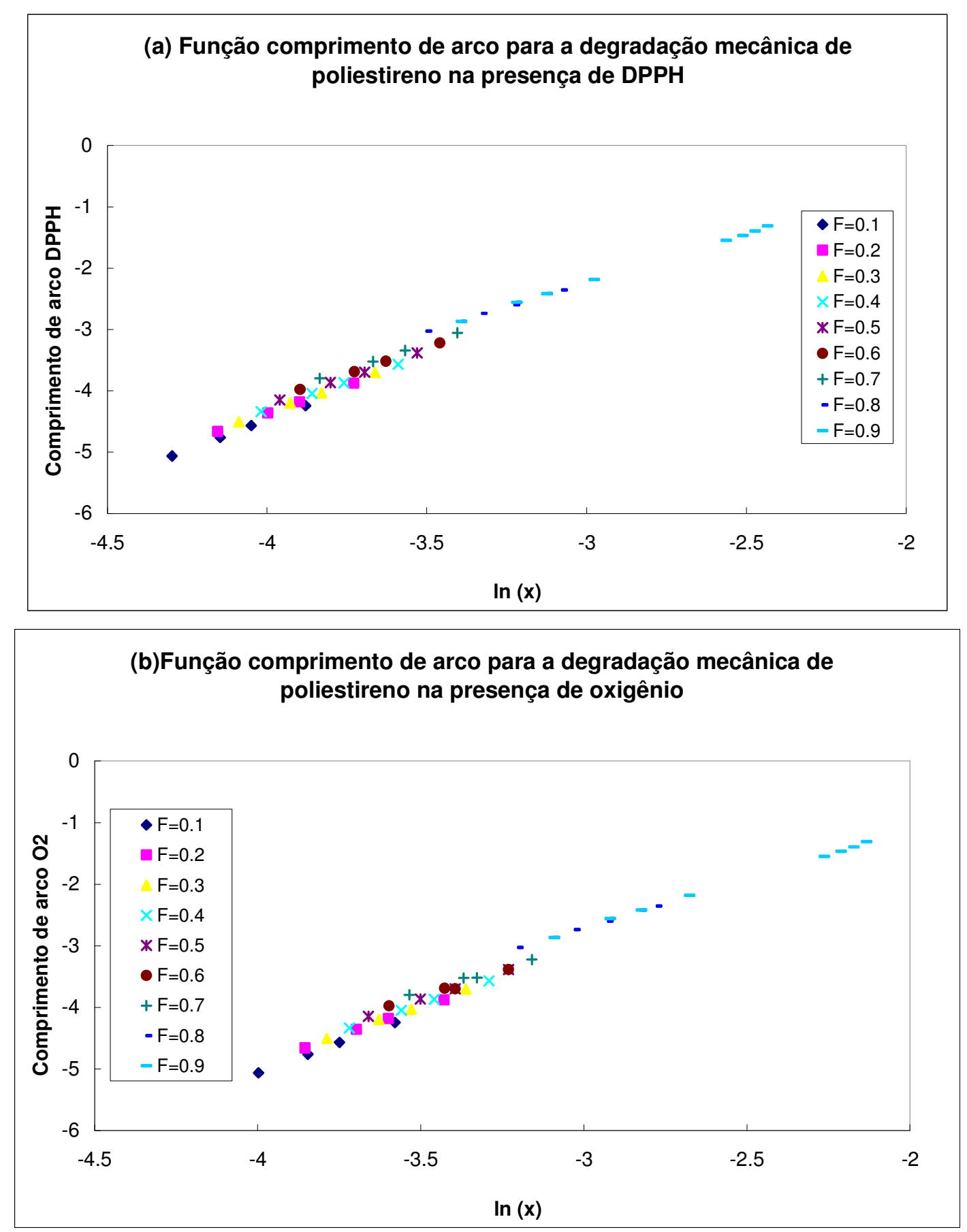

Figura 4.4.3: Comprimento de arco para a degradação mecânica de poliestireno, em meio com a presença de: (a) DPPH e,(b) oxigênio. 

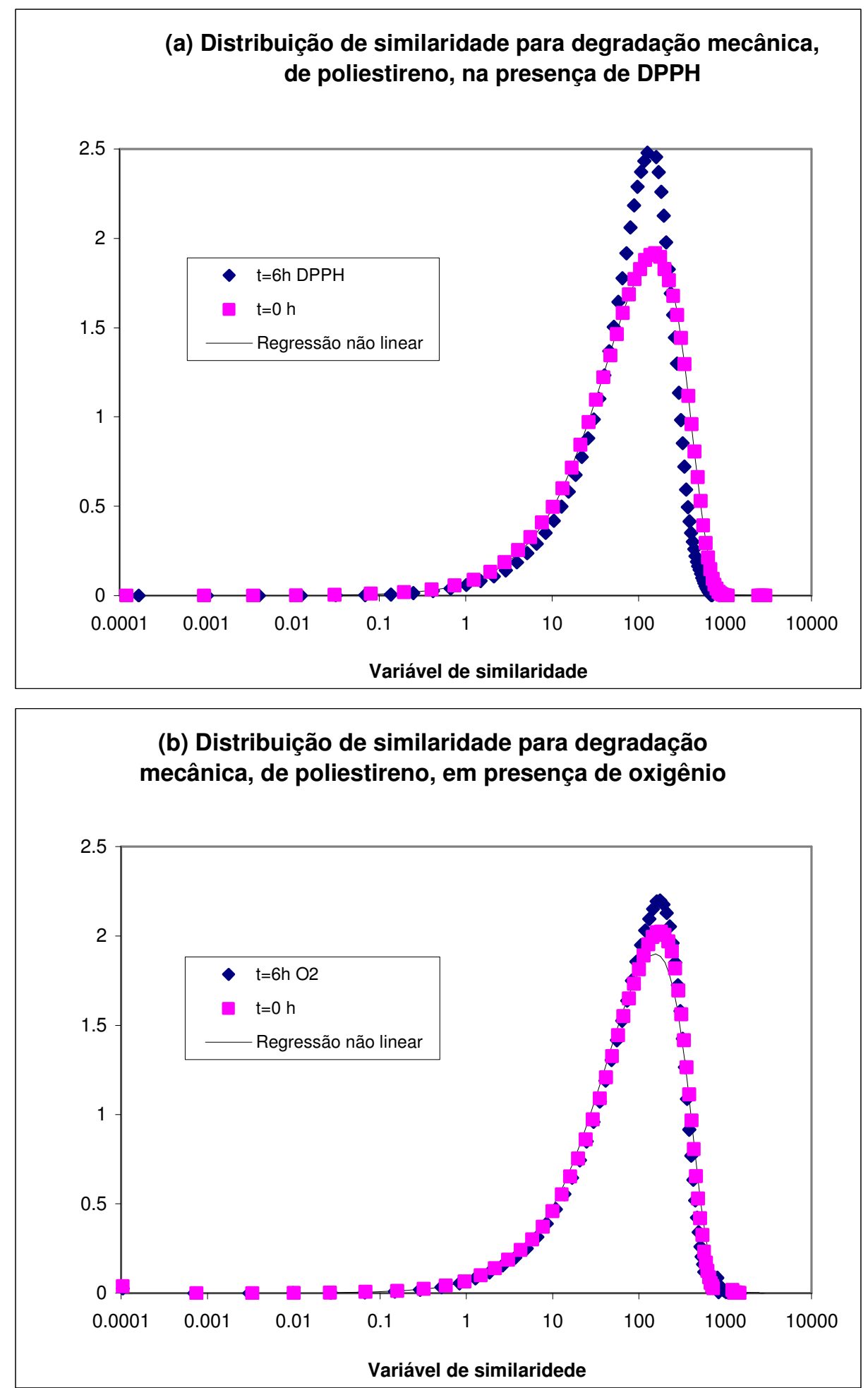

Figura 4.4.4: Distribuição de similaridade para a degradação mecânica de poliestireno em meio com a presença de: (a) DPPH e (b) oxigênio. 


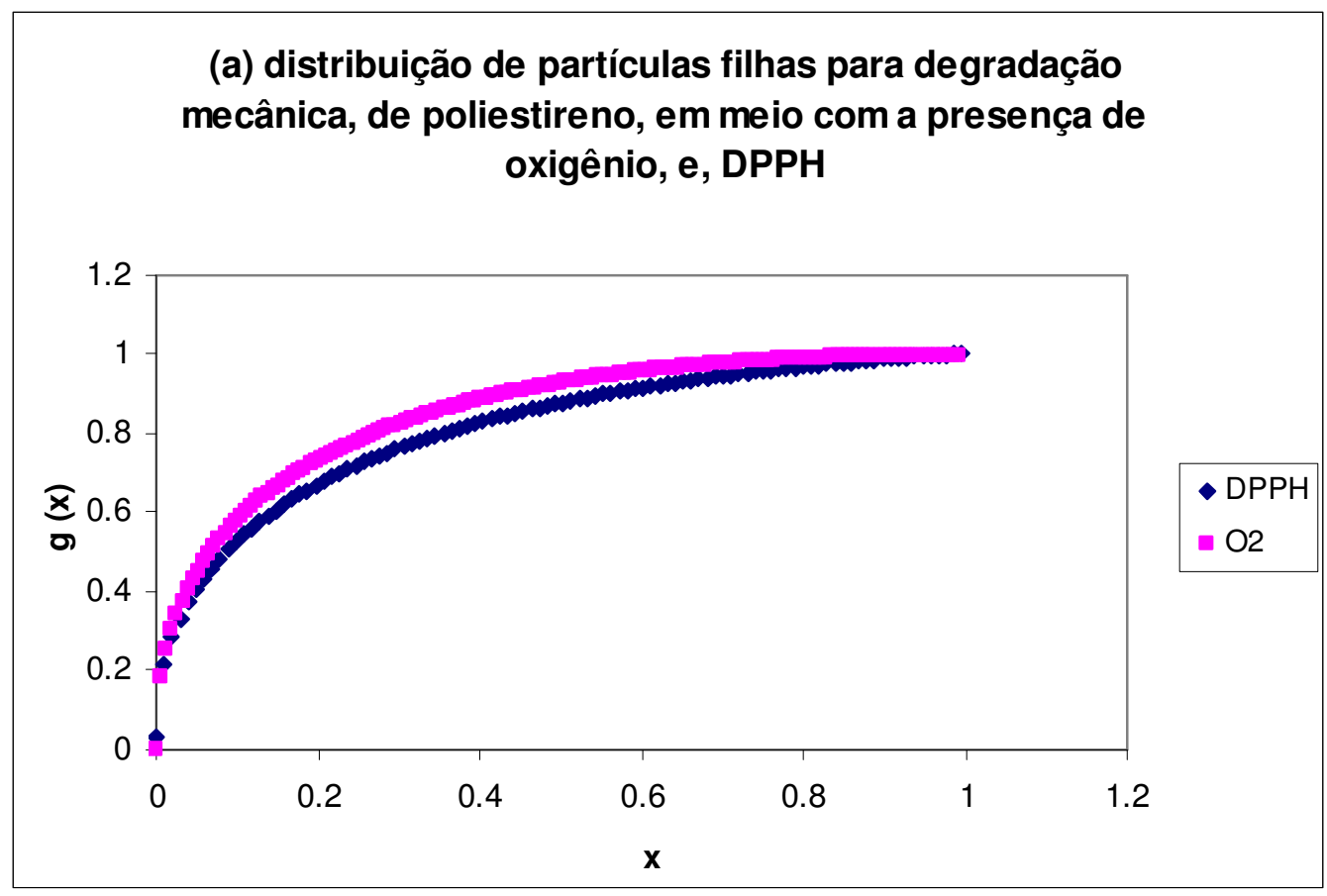

(b) Taxa de quebra para degradação mecânica, de poliestireno, em meio com a presença de oxigênio, e, DPPH

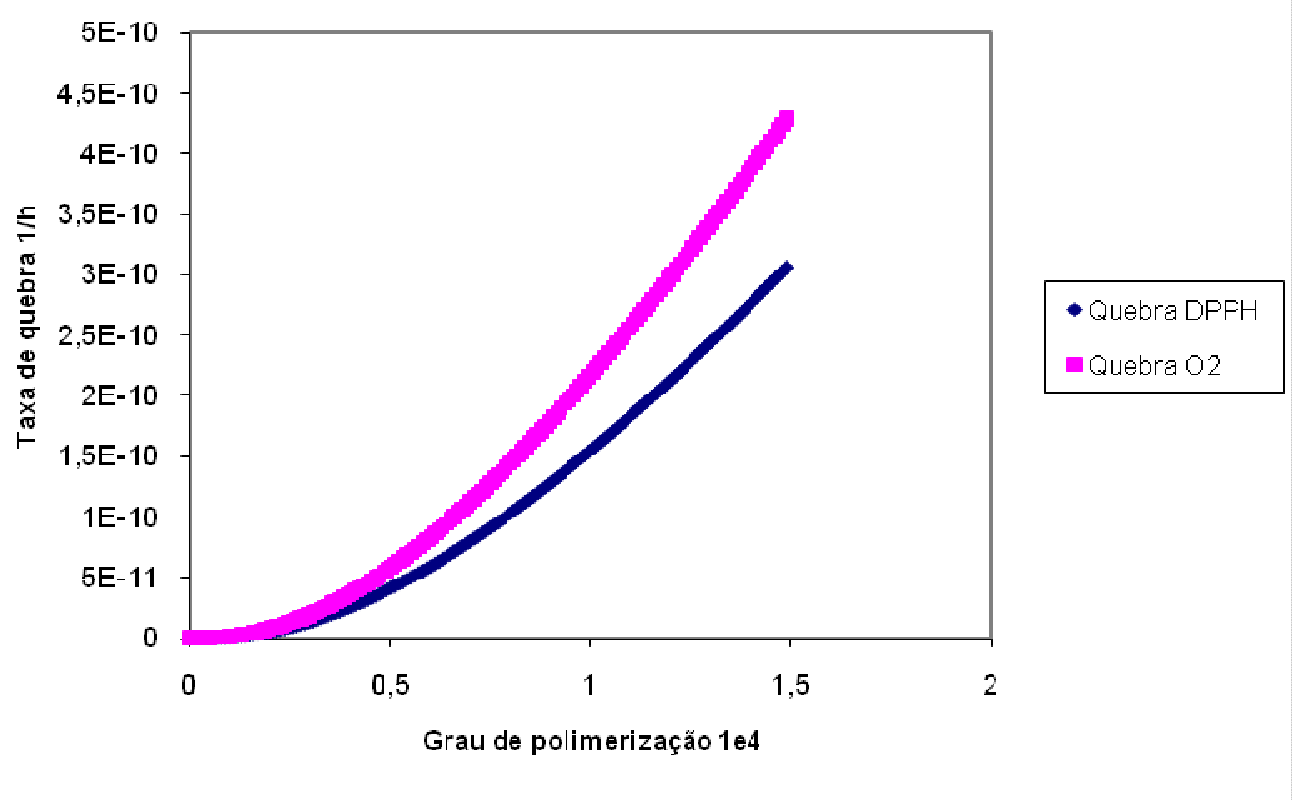

Figura 4.4.5: Distribuições de partículas filhas (a), e, da taxa de quebra (b), nas condições de degradação mecânica de poliestireno em meio com presença de: oxigênio, e, $\mathrm{DPPH}$. 

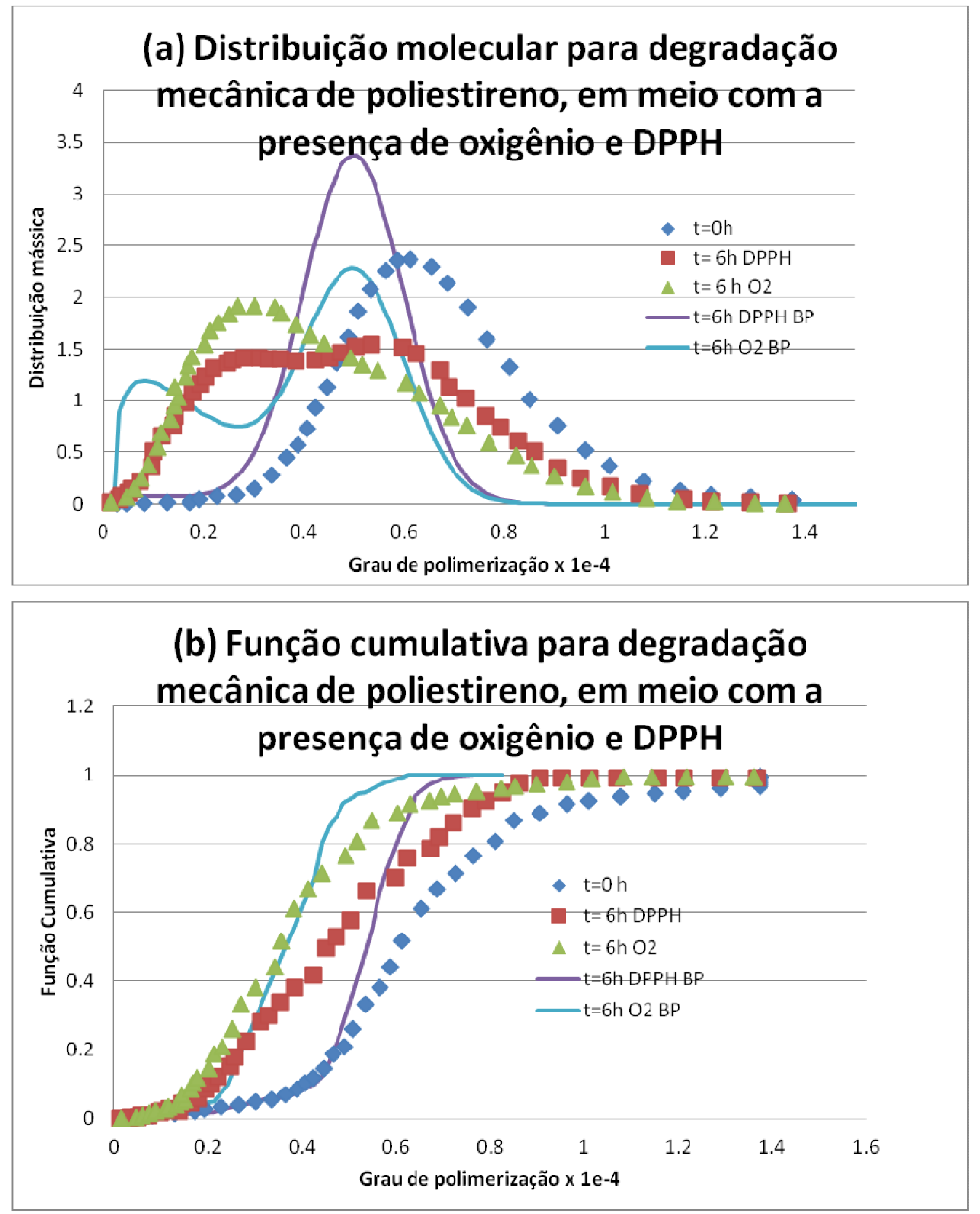

Figura 4.4.6: (a) Distribuições diferencias e (b) funções cumulativas obtidas por meio do problema inverso e medidas experimentalmente, para degradação mecânica de poliestireno, em meio com a presença de DPPH e oxigênio. 
Na figura 4.4.7 apresenta-se o comportamento de $\beta\left(v^{\prime}, v^{\prime}\right) v(v) \Gamma\left(v^{\prime}\right)$, que representa a tendência de preferência de quebra em função do tamanho das cadeias. Nota-se uma relação crescente, indicando que cadeias maiores tem maior tendência de serem quebradas neste sistema. Isto faz sentido, pois em processo de degradação mecânica, as cadeias maiores ficarão mais sujeita às forças mecânicas de cisalhamento presentes no sistema.

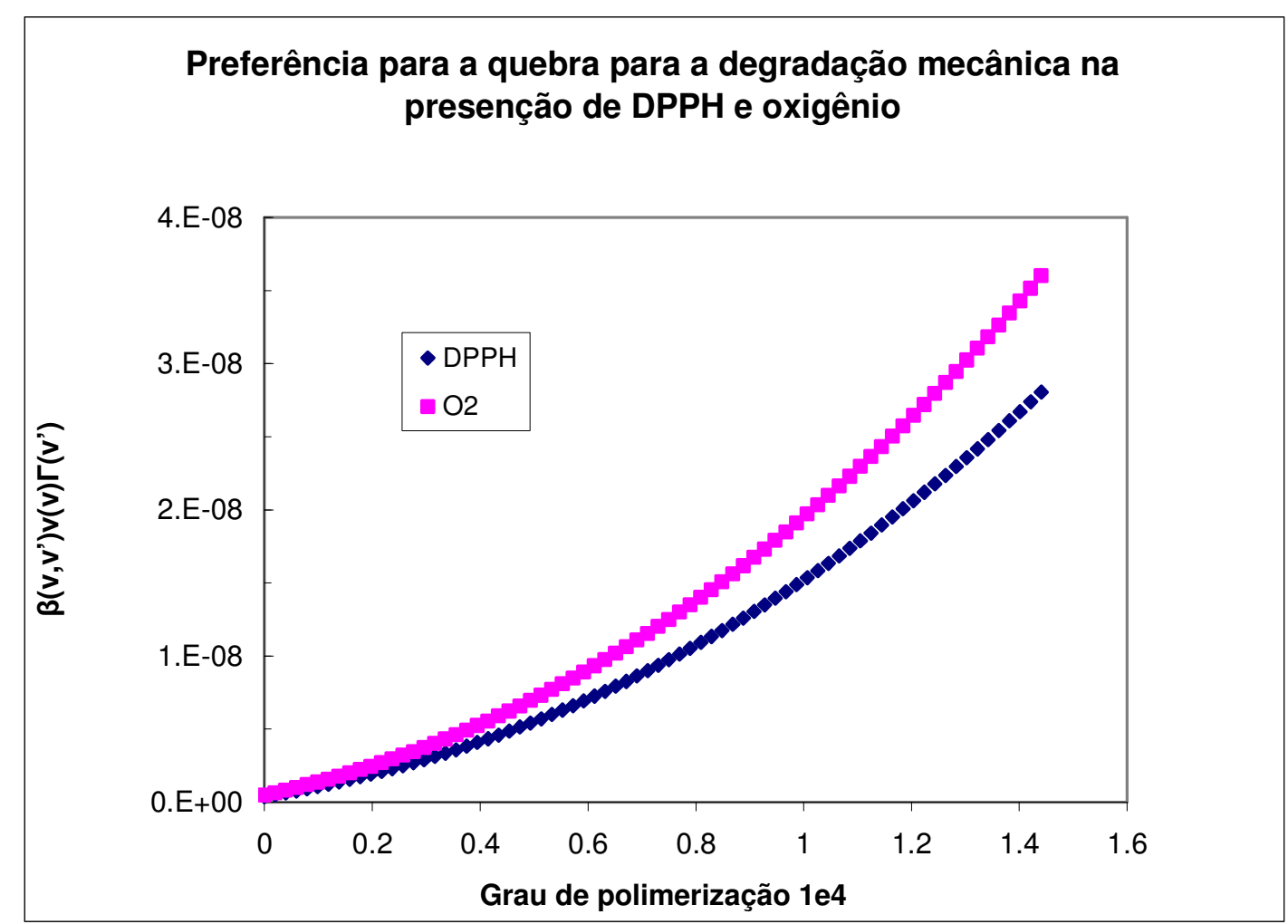

Figura 4.4.7: Valores de $\beta\left(\mathrm{v}, \mathrm{v}^{\prime}\right) v(\mathrm{v}) \Gamma\left(\mathrm{v}^{\prime}\right)$ obtidos pelo problema inverso para a degradação mecânica de poliestireno em meio com a presença de DPPH e oxigênio.

Pela figura 4.4.7 podemos dizer que a degradação mecânica ocorre com maior intensidade para as cadeias maiores, e que a quebra é ligeiramente em maior grau em um meio contendo oxigênio do que em um meio contendo DPPH. A explicação para isso é que existem indícios que, durante a degradação, a quebra por cisalhamento faz gerar radicais que podem ser capturados por oxigênio mais fortemente que o DPPH que é menos polar.

Neste caso em especial é preciso notar os motivos da divergência, ao menos quantitativa, entre o balanço populacional e os valores esperados, na Figura 4.4.6. Deve se 
levar em conta que nesse tipo de degradação mecânica formam-se radicais que podem ser reagir com oxigênio ou com DPPH. Os radicais não capturados por estes sequestradores podem se combinar entre si, criando cadeias maiores ou regenerando as cadeias originais. Esta recombinação de radicais tem analogia com a coalescência, no caso de gotas. Como a formulação do problema inverso aqui utilizado considera apenas a ocorrência de quebra (e não de coalescência) algum desvio pode ocorrer quando ambos os fenômenos estão presentes. Ballauff e Wolf (1984) especularam algumas possíveis explicações para a diferença de comportamento do sistema com DPPH e com oxigênio.

Como a comparação mostrada na Figura 4.4.6 não está satisfatória, foi feita uma tentativa de melhorar o resultado inicialmente obtido pelo algoritmo do problema inverso, fazendo alterações (perturbações) manualmente (isto é, por tentativa e erro) nas funções de taxa de quebra e distribuição de partículas filhas, até que se chegasse a um resultado razoável para as distribuições. Estas novas funções estão apresentadas na Figura 4.4.8. Com estas funções reajustadas sendo substituídas na equação de balanço populacional, as distribuições assim calculadas se apresentam bastante mais próximas às distribuições experimentais, como mostra a Figura 4.4.9, havendo agora claramente uma boa aproximação também quantitativa entre as curvas calculadas e as curvas experimentais. 

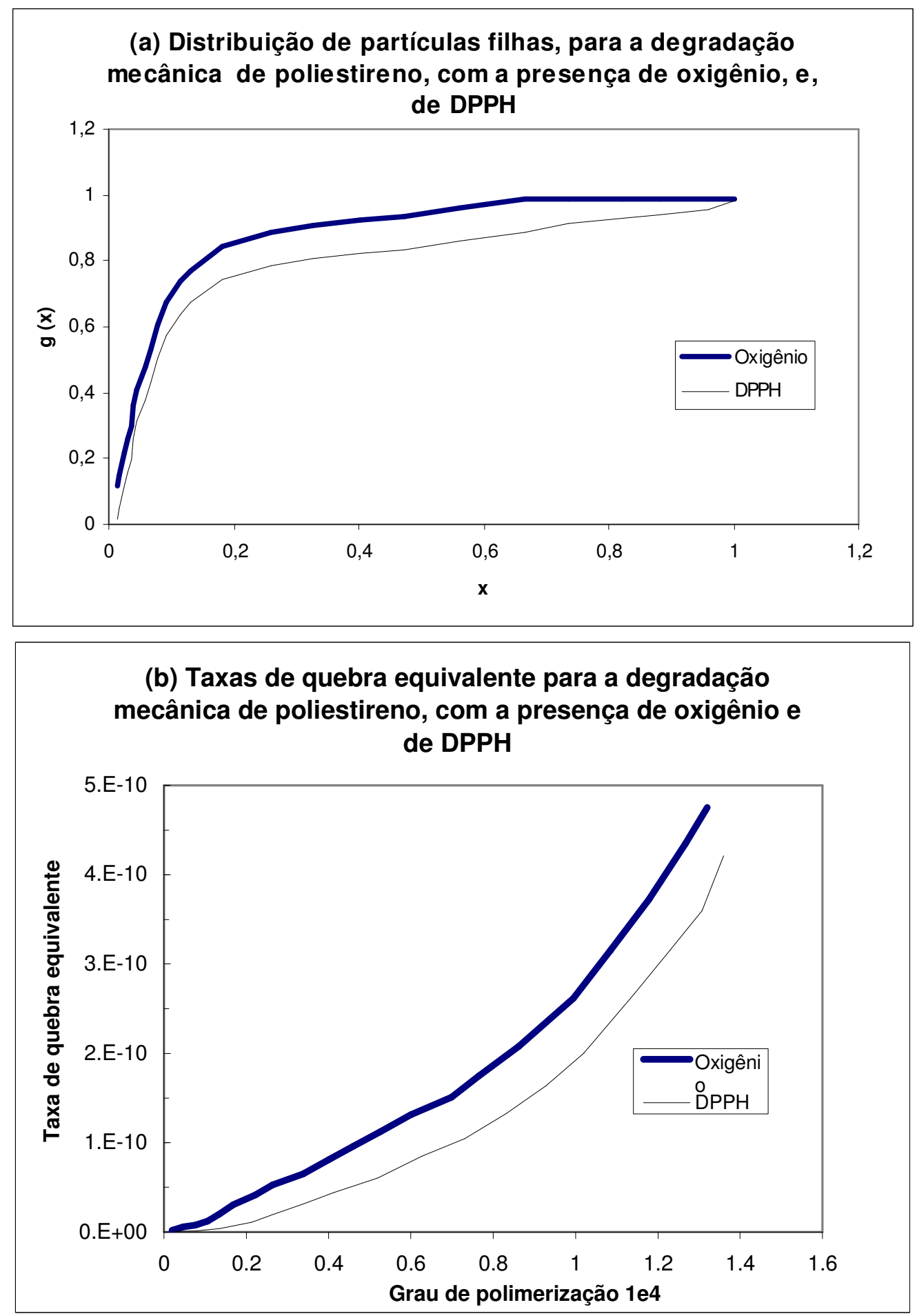

Figura 4.4.8: (a) Distribuição de partículas filhas equivalentes e (b) taxas de quebra equivalentes para a degradação mecânica de poliestireno, na presença de oxigênio e DPPH. 


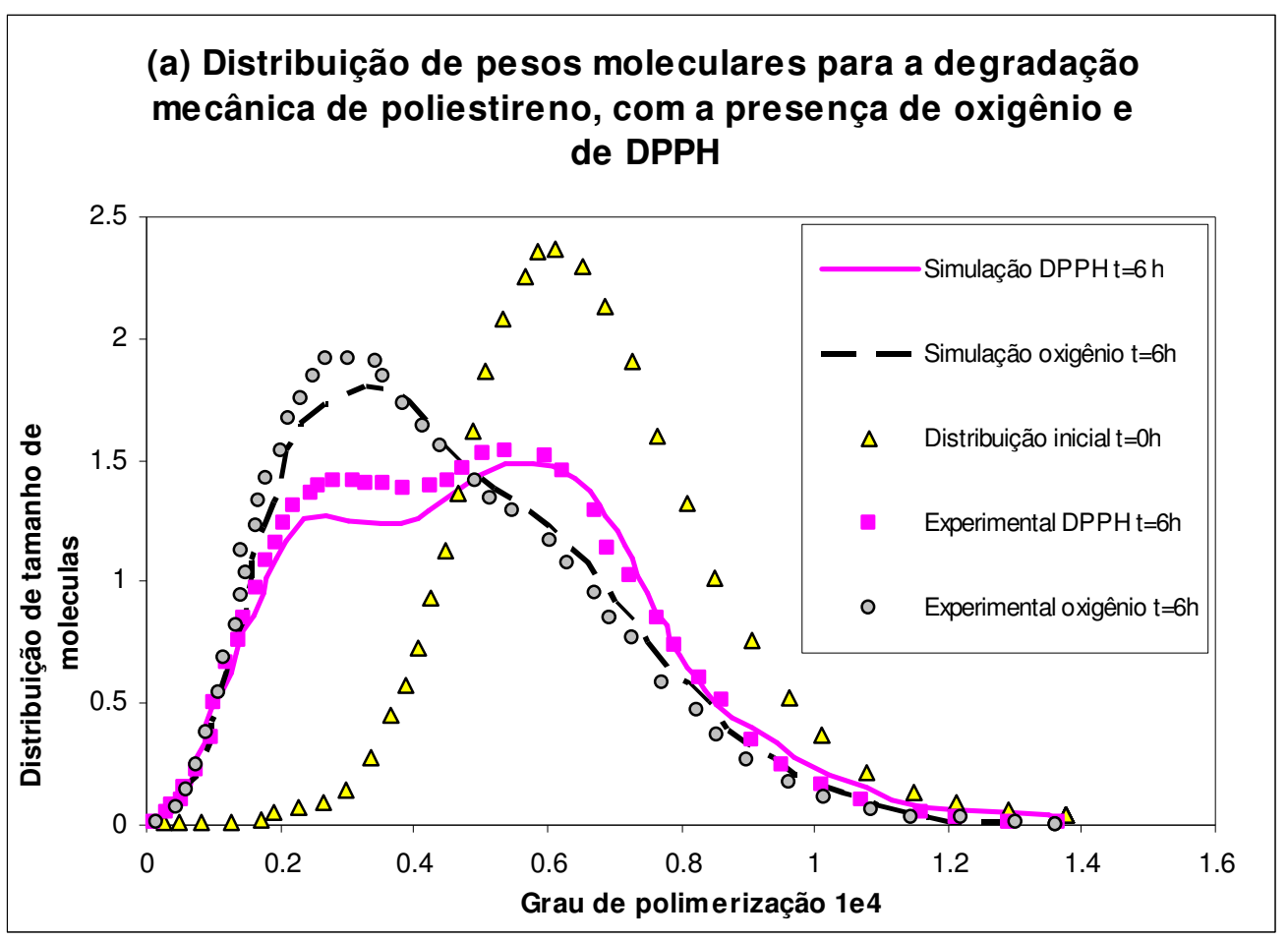

(b) Função cumulativa para a degradação mecânica de poliestireno, com a presença de oxigênio e de DPPH

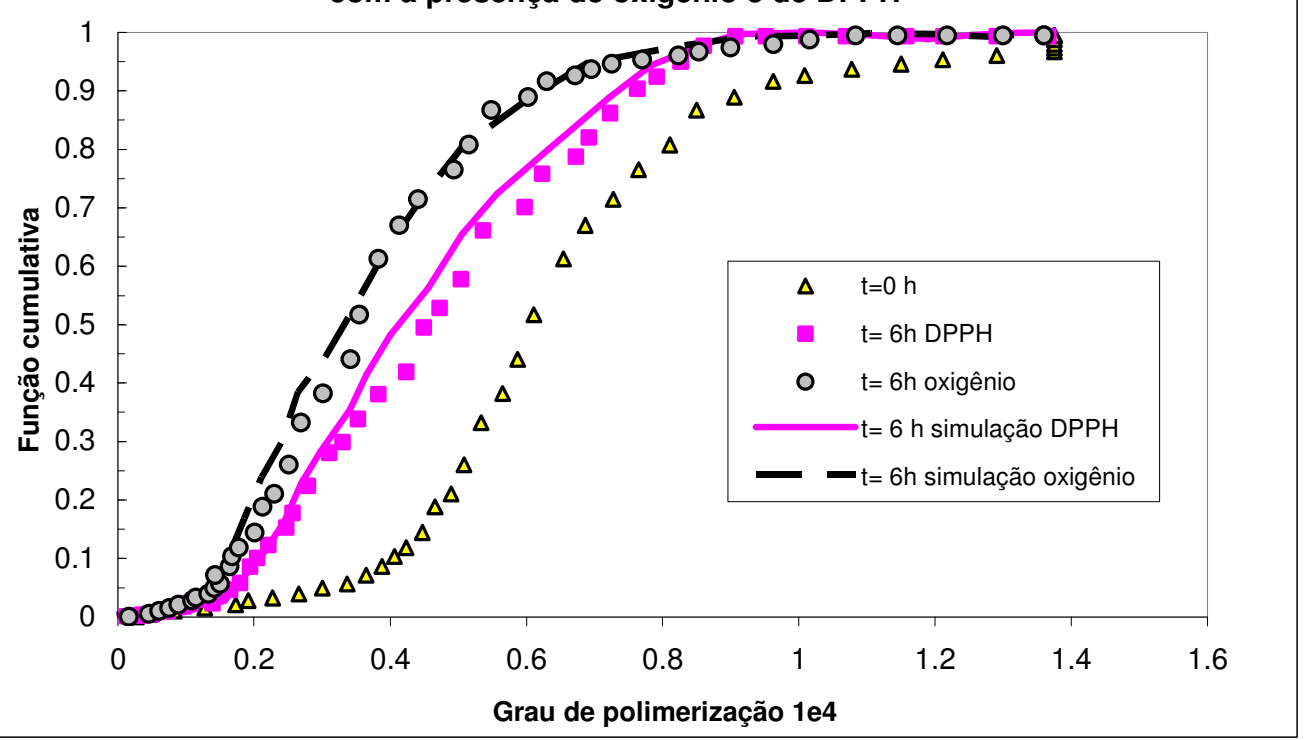

Figura 4.4.9: (a) Distribuições diferenciais de pesos moleculares e (b) distribuições cumulativas para a degradação mecânica de poliestireno, na presença de oxigênio e DPPH, para o caso em que se utiliza uma taxa de quebra e uma distribuição de partículas filhas equivalentes. 
Portanto neste caso, aparentemente o algoritmo do problema inverso como utilizado não se mostrou suficiente para resolver esse tipo de problema. Mas utilizando-se um ajuste manual de funções escolhidas, foi possível obter funções que representam adequadamente e de forma equivalente os fenômenos envolvidos neste processo, conseguindo uma adequada representação das distribuições experimentais.

Com as novas funções de taxa de quebra e de distribuição de partículas filhas equivalentes, a preferência de quebra foi recalculada e está apresentada na Figura 4.4.10.

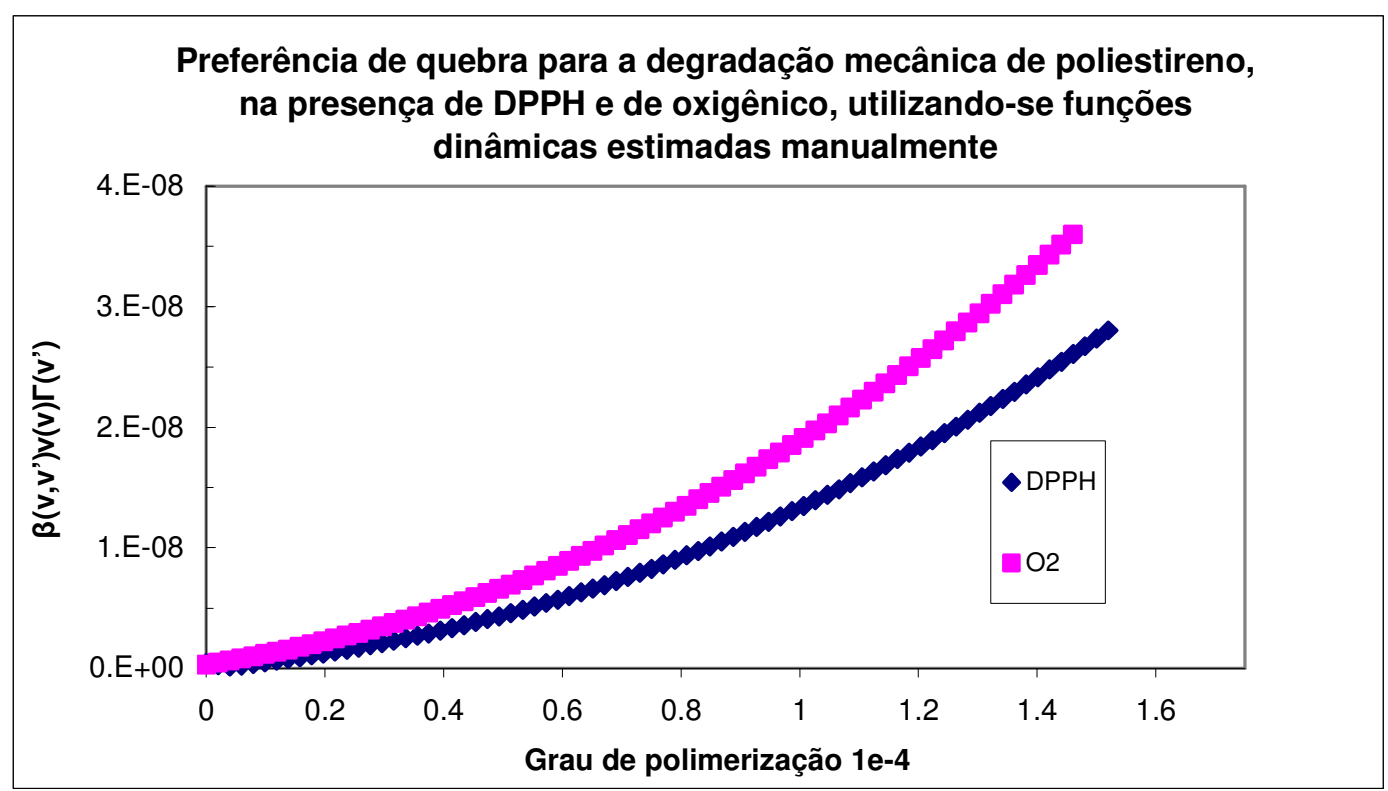

Figura 4.4.10: Preferência de quebra para a degradação mecânica de poliestireno na presença de oxigênio e de DPPH, para o caso em que se utiliza uma taxa de quebra e uma distribuição de partículas filhas equivalentes obtidas com o uso de funções dinâmicas estimadas por tentativa e erro. 


\subsection{Degradação ultrassônica de dextrana.}

O próximo exemplo a ser apresentado é o processo de degradação de polímeros com uso de ultrassom. Sabe-se que a irradiação de ondas de ultrassom em uma solução produz bolhas por cavitação, e a formação e o colapso dessas bolhas pode ser usado para a degradação de polímeros em solução.

Esse tipo de degradação já foi bastante estudado por determinados autores como por exemplo, por BASEDOW; EBERT $(1975,1977)$ e BASEDOW; EBERT; EDERER (1979, 1981), para a degradação de dextrana, por GLYNN; VAN DER HOFF; REILLY (1972) para a degradação de poliestireno, por KODA et al. (1994) para a degradação de polímeros solúveis em água poli(óxido de etileno), poli(vinilpirrolidona e pululana, e por WU et al. (1977) e por MADRAS e KARMORE (2001) para a degradação de poly(metacrilato de metila).

O exemplo relatado neste item refere-se à degradação ultrassônica do polímero dextrana, que é utilizado no processo de fabricação de celulose, com os dados experimentais reportados por EDERER; BASEDOW; EBERT (1981).

\subsubsection{Dados experimentais}

Os dados experimentais que usaremos neste exemplo foram tirados do trabalho de EDERER; BASEDOW; EBERT (1981). Estes autores estudaram a degradação ultrassônica do polímero dextrana em uma mistura de dextrana em água com $10 \%$ em massa de $\mathrm{MgSO}_{4}$. A potência aplicada de ultrassom foi de $24 \mathrm{~W} / \mathrm{cm}^{2}$, usando um oscilador de ultrassom mergulhado no recipiente, como ilustrado na Figura 4.5.1.

Para a degradação ultrassônica de polímeros, uma possível explicação de seu funcionamento é o de que bolhas de cavitação se formam inicialmente, dentro do líquido. Durante a fase de colapso, uma alta não homogeneidade de escoamento e ondas de choque são geradas. Os altos gradientes de velocidade tencionam os polímeros e moléculas, com a força máxima exercida ao redor dos polímeros, forçando que o principal ponto de ataque seja o centro dos polímeros pelas ondas de choque. A Figura 4.5.2 ilustra este modelo de funcionamento. 
A ação mecânica do ultrassom é sempre acompanhada de efeitos térmicos. O calor gerado pelo colapso das bolhas de cavitação pode ser muito intenso, requerendo o uso de um sistema de resfriamento para compensar o aquecimento gerado pelo ultrassom e mantendo a temperatura global do sistema constante.

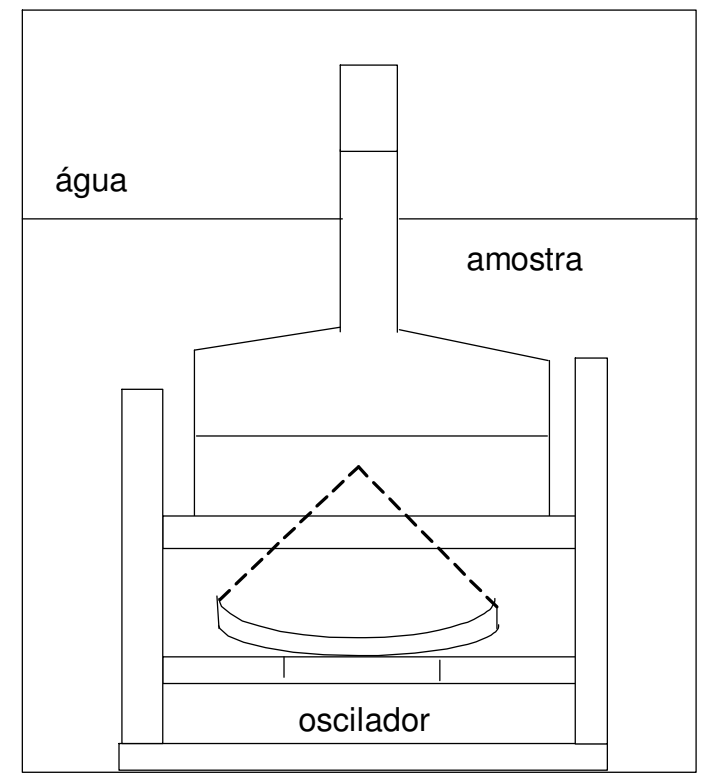

Figura 4.5.1: Sistema de irradiação de ultra-som (EDERER et al., 1981).

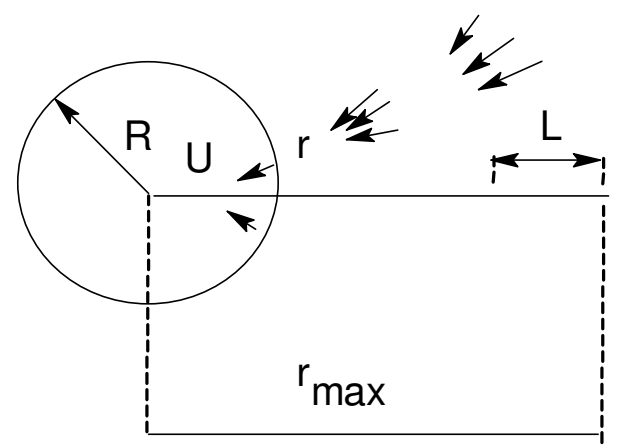

Figura 4.5.2: Modelo de degradação ultrassônica de polímeros. $\mathrm{R}$ = raio da bolha de cavitação, $U$ = velocidade do colapso da bolha na superfície, $r$ = distância do polímero até a bolha de cavitação, $\mathrm{L}=$ tamanho da molécula de polímero. (EDERER et al., 1981). 


\subsubsection{Solução do Problema Inverso.}

Apresentam-se nas figuras 4.5.3 a 4.5.6, a curva de comprimento de arco, as curvas paralelas $\ln (\mathrm{t})$ versus $\ln (\mathrm{v})$, as distribuições sobrepostas após a transformação de similaridade, e as taxas de quebra e a distribuição de partículas filhas obtidas pela regressão.
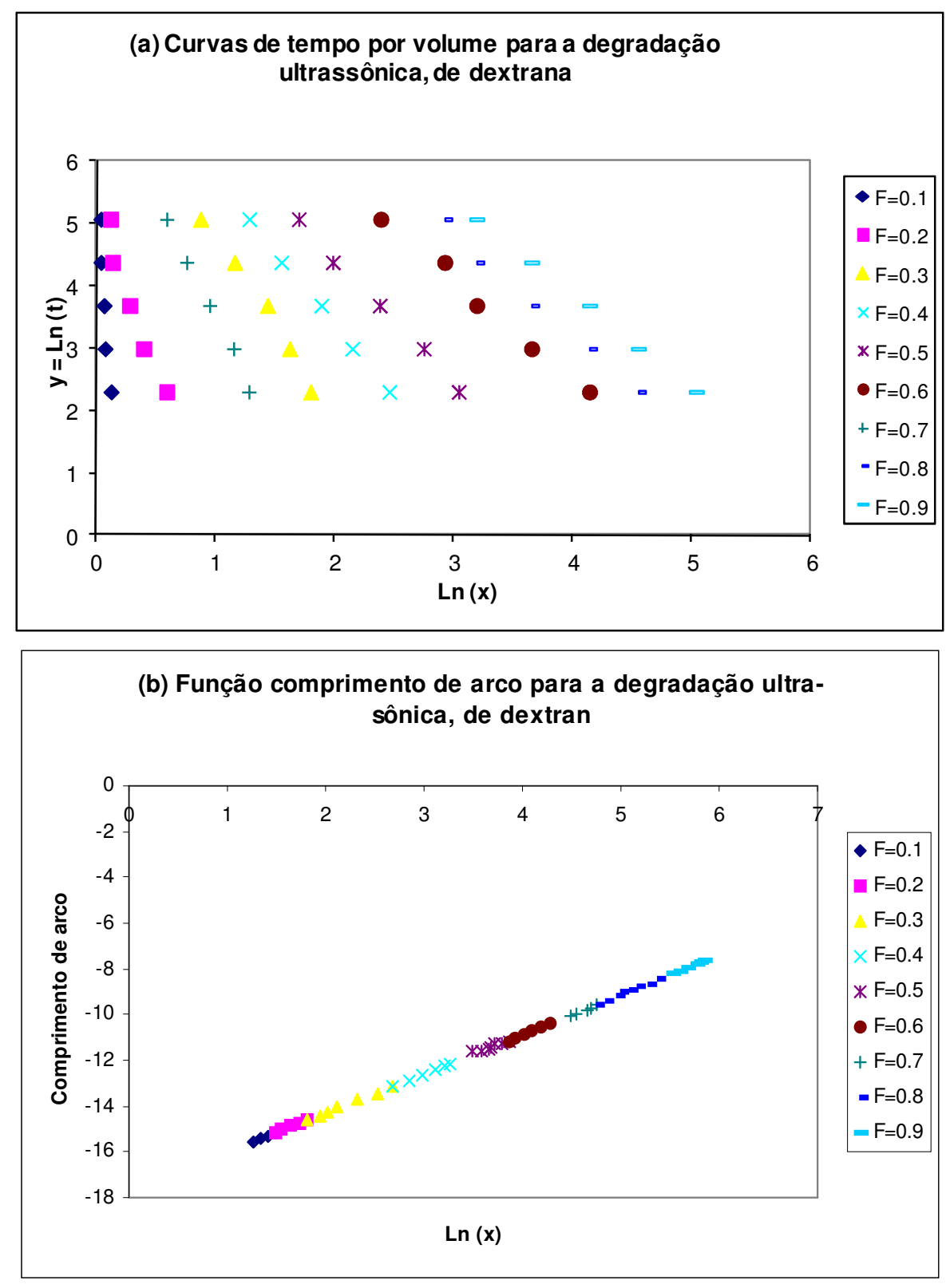

Figura 4.5.3: (a) Curvas de $\ln (\mathrm{t})$ versus $\ln (\mathrm{v})$ e (b) curvas de comprimento de arco para o caso de degradação ultrassônica de dextrana. 


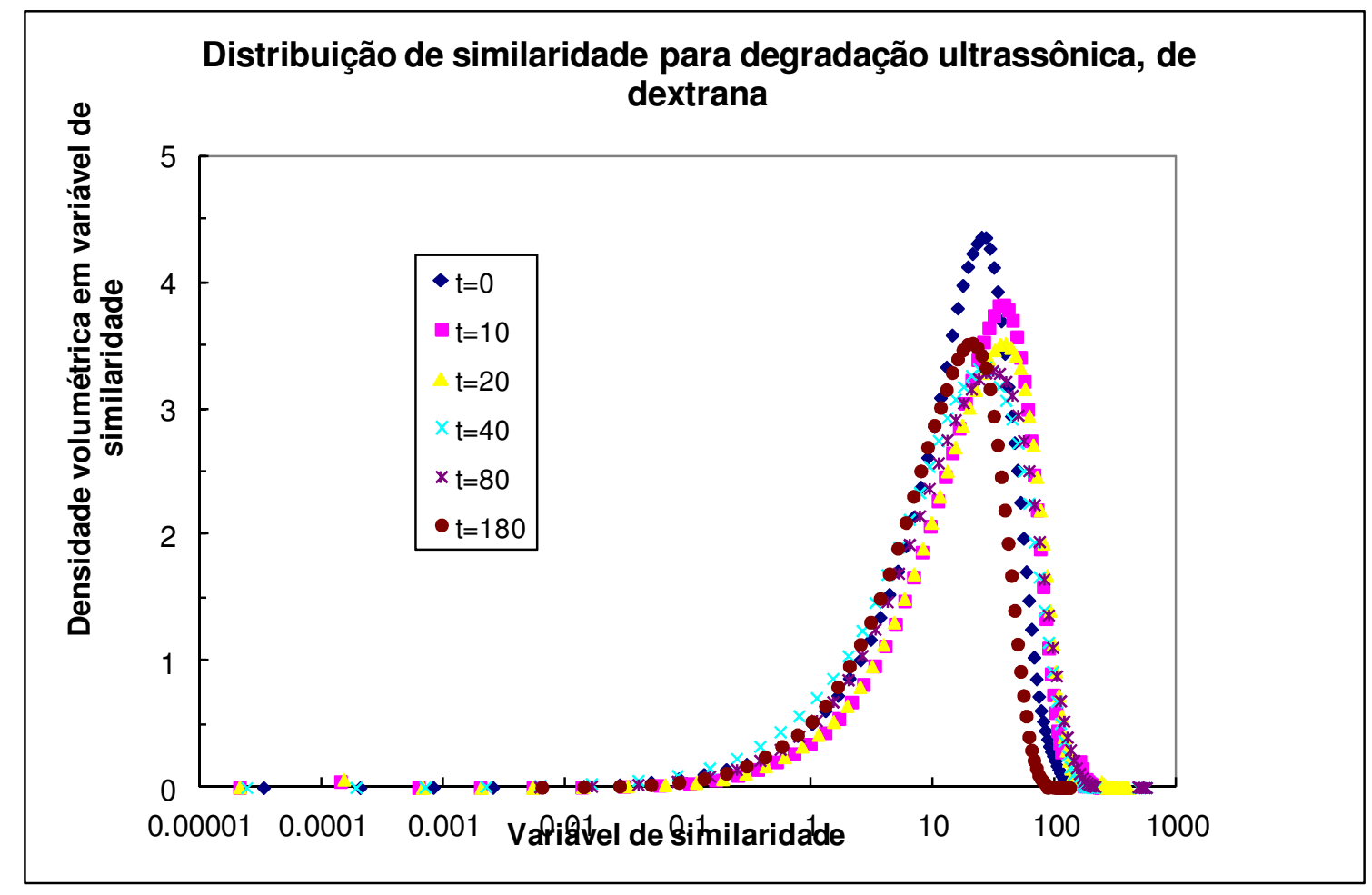

Figura 4.5.4: Sobreposição das curvas experimentais, obtidas pela transformação de similaridade, para a degradação ultra-sônica de dextrana.

Nota-se, na Figura 4.5.5, que os valores de taxa de quebra em função da massa molar do polímero obtidos pelo problema inverso, concordam muito bem com os valores "experimentais" reportados no trabalho de EDERER et al. (1981). As taxas específicas de quebra são maiores para as cadeias maiores. EDERER et al. (1981) reportam, entretanto, que existiria um valor mínimo de massa molar abaixo do qual as moléculas não sofreriam quebra; esta conclusão foi obtida porque eles ajustaram uma equação de reta aos pontos de taxa de quebra versus massa molar, e extrapolaram esta reta para valores baixos de massa molar. A curva obtida do problema inverso não é uma reta, e diminui a inclinação para valores pequenos de massa molar, até atingir a origem $(0,0)$. Em termos práticos, para cadeias com massa molar abaixo de $10.000 \mathrm{~g} / \mathrm{mol}$, a taxa de quebra é praticamente nula, corroborando a afirmação de EDERER et al. (1981). 

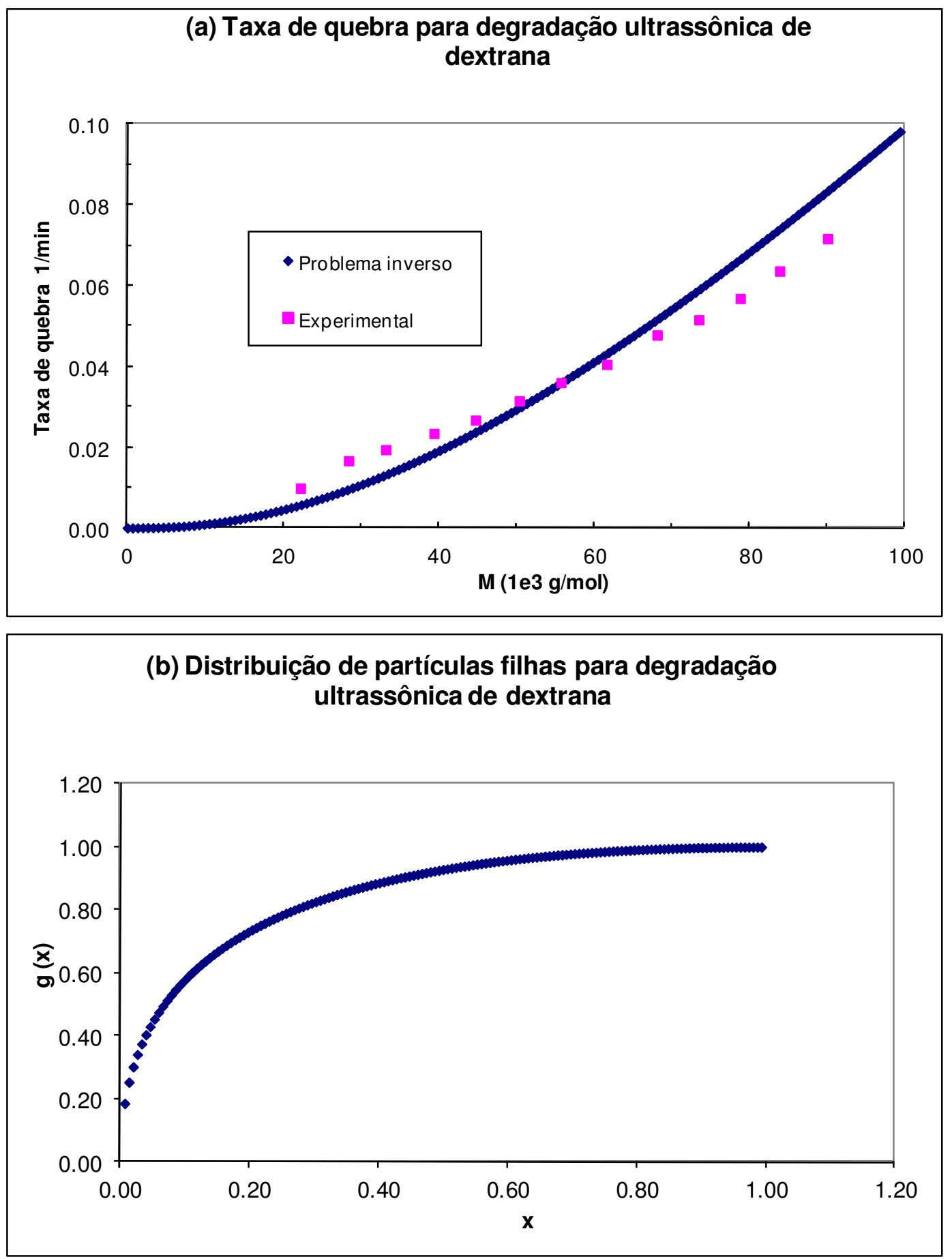

Figura 4.5.5: Taxas de quebra (a) e distribuição de partículas filhas (b) obtidas para o caso de degradação ultra-sônica de dextrana. 

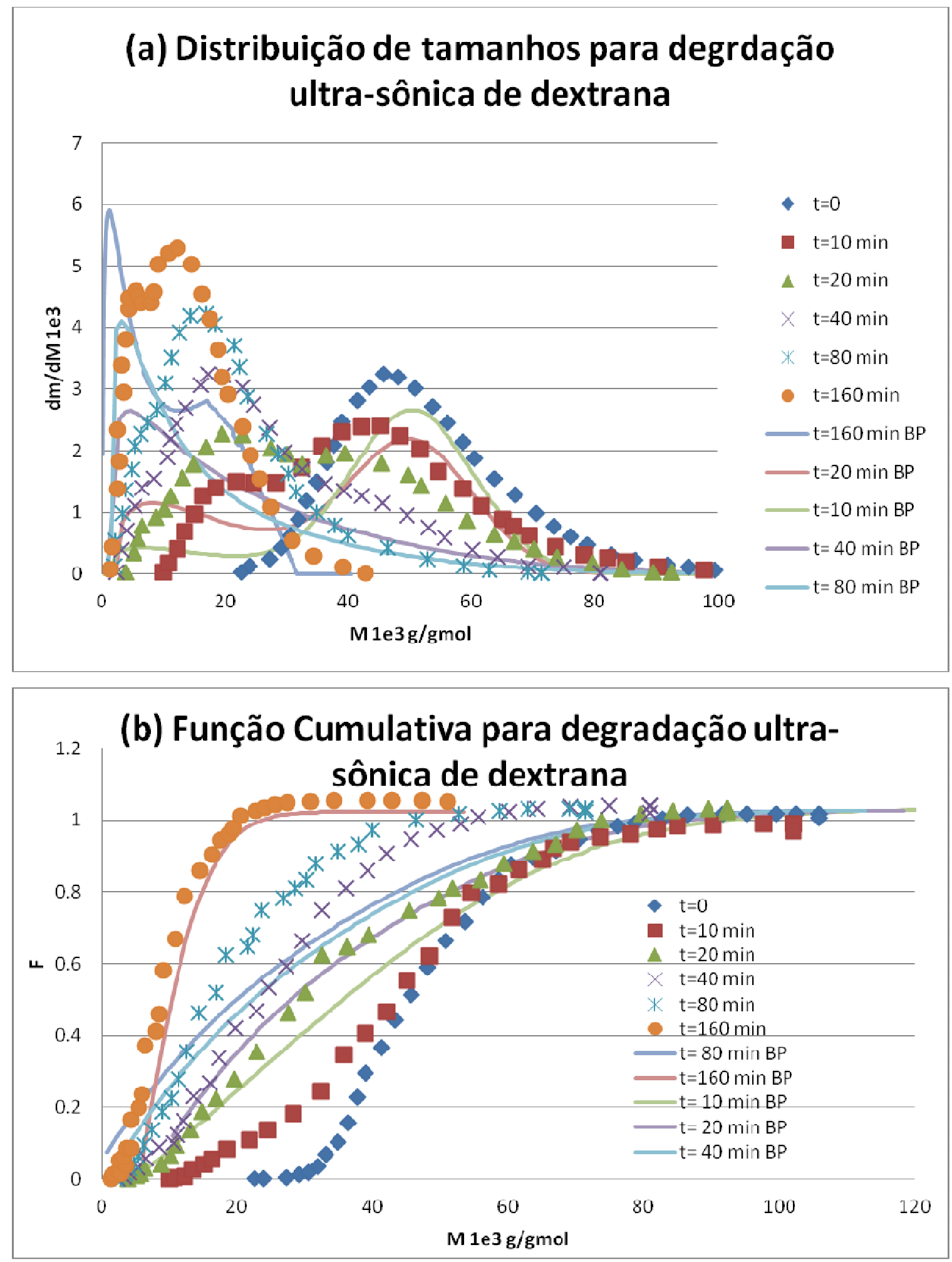

Figura 4.5.6: (a) Distribuições de partículas ao longo do tempo de irradiação, e, (b) funções cumulativas, para o caso de degradação ultra-sônica de dextrana. 
O que podemos perceber pela taxa de quebra é que o problema inverso acaba subestimando a quebra em pequenas partículas. Por isso as distribuições apresentam médias um pouco menores que as obtidas experimentalmente. $\mathrm{O}$ que acontece na realidade é que cadeias muito pequenas simplesmente não quebram. Mas o problema inverso dá valores baixos para a quebra de cadeias menores não extinguindo completamente a quebra nessas situações.

Na figura 4.5.7 é apresentada a função $\beta\left(v^{\prime}, v^{\prime}\right) v(v) \Gamma\left(v^{\prime}\right)$ que se encontra em um dos termos dentro da formulação do balanço populacional. Experimentalmente, nós deveríamos encontrar, como em outros casos na literatura, que a quebra é geralmente centrada em um tamanho da molécula. Mas não zerada ao longo dela e nem aleatória, mas sim seguindo uma função de distribuição como uma gaussiana ao longo da cadeia, como é apresentado coerentemente pelo modelo de GLYNN; VAN DER HOFF; REILLY (1972). Quando esses autores modelaram a quebra ultra-sônica, eles não utilizaram o balanço populacional na mesma forma aqui empregada, mas uma técnica diferente. Na modelagem deles utilizou-se, que a média no número de moléculas de grau de polimerização $\mathrm{GP}_{\mathrm{i}}$, resultante da quebra no tempo $t+1$ podia ser avaliada de dois modos: Primeiro pela diferença entre os produtos do número total de moléculas, e, a fração de moléculas com $\mathrm{GP}_{\mathrm{i}}$, depois da quebra no tempo $\mathrm{t}$, e, depois do tempo $t+1$. Segundo, a soma dos produtos da probabilidade de se escolher a molécula a ser quebrada e a probabilidade de produzir uma molécula com $\mathrm{GP}_{\mathrm{i}}$, menos a probabilidade de se escolher uma molécula de $\mathrm{GP}_{\mathrm{i}}$, para ser quebrada. Igualando esses dois termos esses autores conseguiram uma equação para a média dos incrementos. E, com isso também puderam calcular as distribuições de partículas, e, compará-las com os experimentos.

Podemos, a princípio, pela figura 4.5.7 dizer que a quebra ultra-sônica favorece cadeias pequenas já que as grandes amortecem essa quebra. No geral, embora possamos reconhecer que a solução obtida pelo problema inverso não foi a melhor possível. Podemos utilizar exclusivamente a taxa de quebra experimental da figura 4.5.5 (a), e, com ela adicionarmos um ajuste à distribuição de partículas filhas. No caso obtivemos a função da figura 4.5.8.Portanto com a taxa de quebra experimental, isto é, utilizando-se os valores experimentais interpolados linearmente, e zerando-se a taxa de quebra para valores menores 
que o valor limite, em que não existe mais quebra de moléculas menores pela energia do ultra-som. E, com a distribuição de partículas filhas escolhida manualmente da figura 4.5.8, conseguimos melhorar significativamente a solução do problema inverso. Podemos verificar as distribuições de pesos moleculares são muito mais próximas do esperado com erros muito menores, como nos indica a figura 4.5.9.

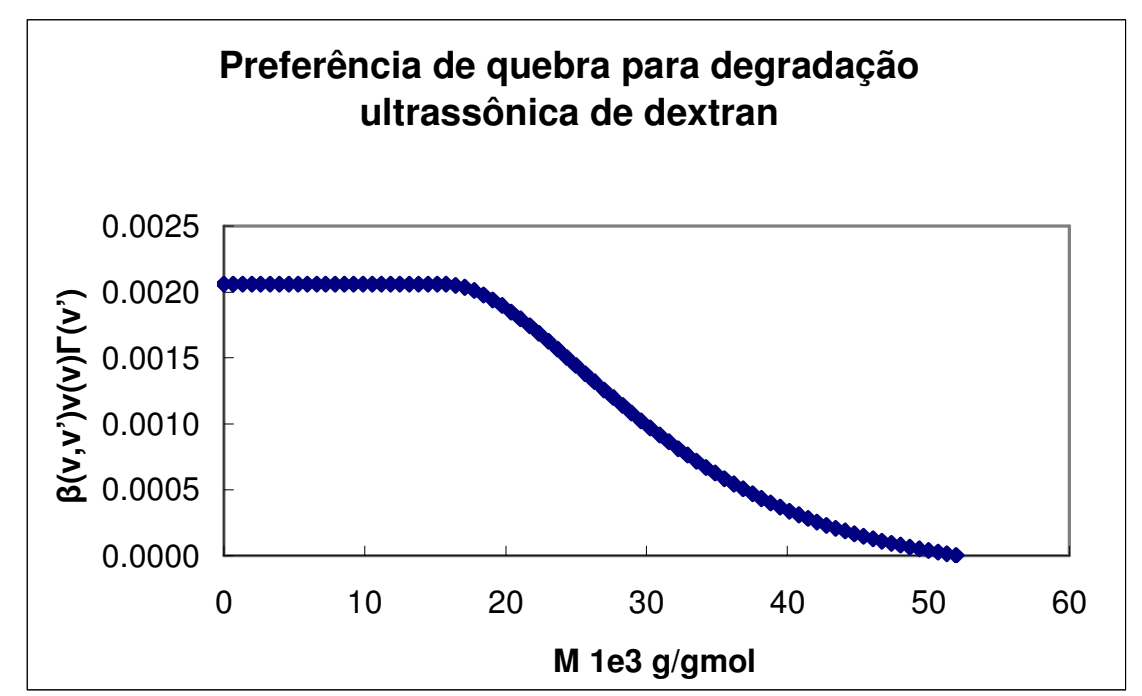

Figura 4.5.7: Gráfico de, $\beta\left(v, v^{\prime}\right) v(v) \Gamma\left(v^{\prime}\right)$, que corresponde a um termo existente no cálculo do balanço populacional obtido após solução do problema inverso, para a degradação ultra-sônica de dextrana.

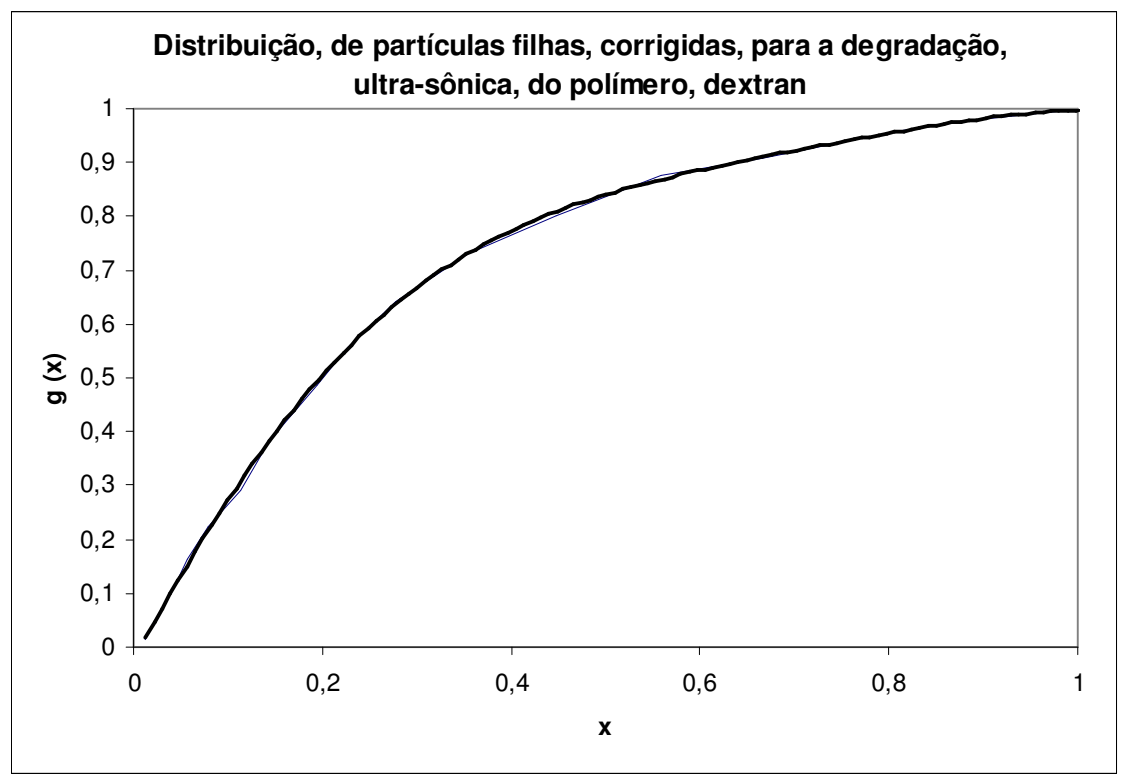


Figura 4.5.8: Distribuição de partículas filhas ajustada manualmente, para a degradação ultrassônica de dextrana.
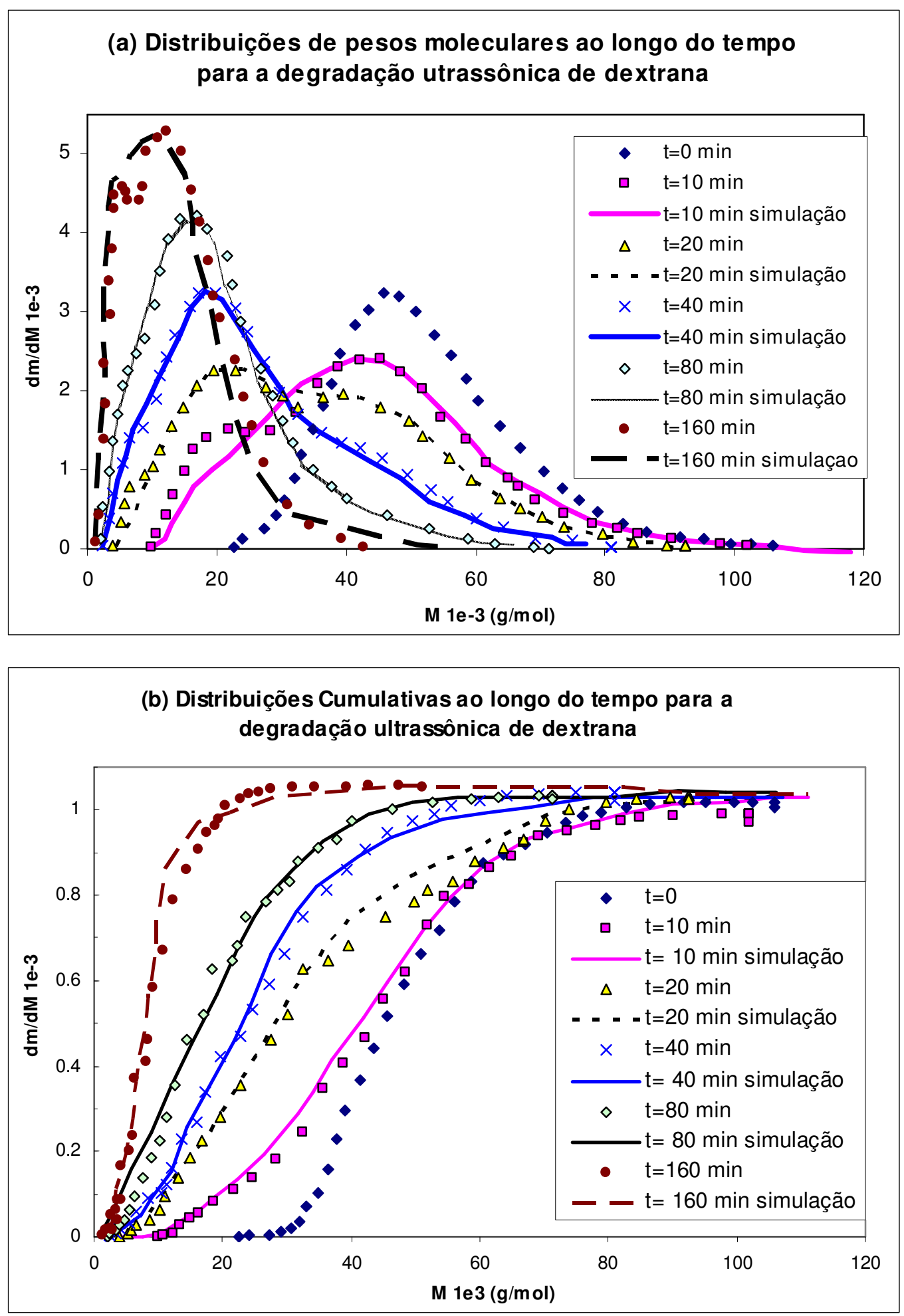
Figura 4.5.9: (a) Distribuição de pesos moleculares, e, (b) funções cumulativas, após ajuste manual da distribuição de partículas filhas, e, com o uso da taxa de quebra experimental.

A Figura 4.5.10 apresenta a curva de preferência de quebra, mostrando que, neste caso, as cadeias menores, na faixa de 5.000 a 10.000 Da são formadas preferencialmente na quebra.

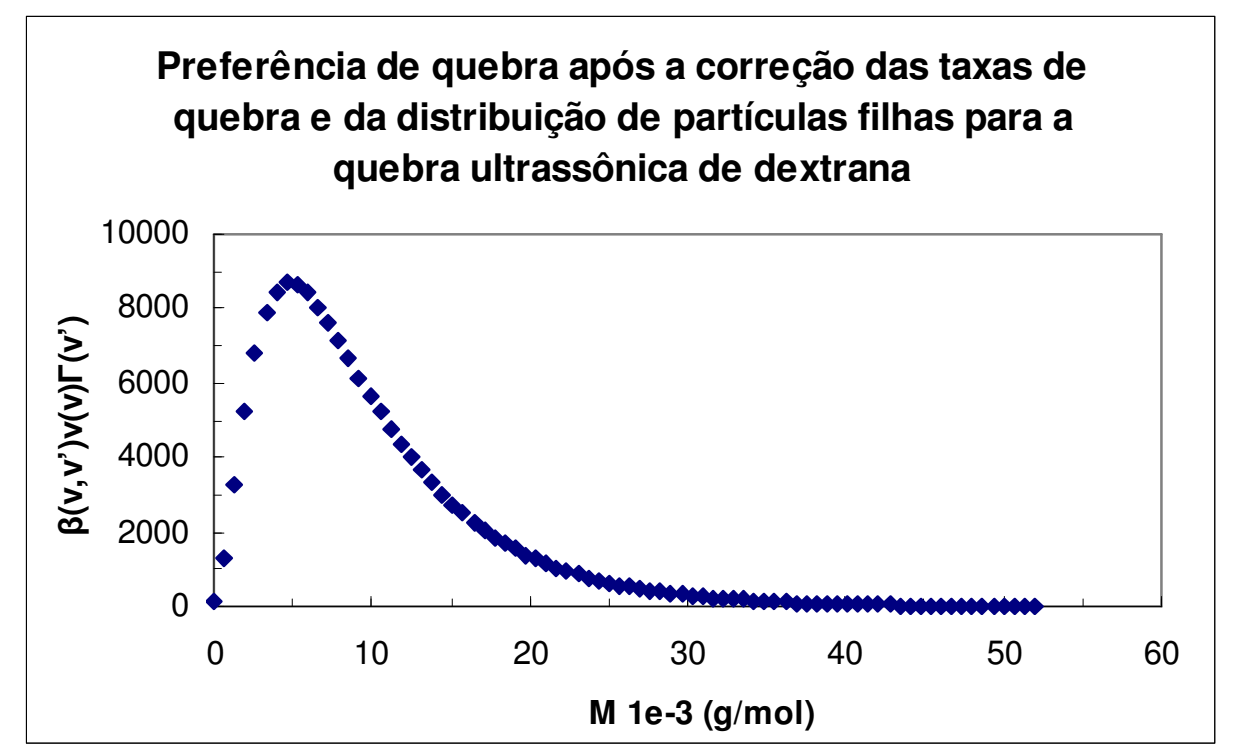

Figura 4.4.10: Preferência de quebra esperada quantitativamente, de acordo com estudos experimentais, para a degradação mecânica de poliestireno, na presença de oxigênio, e, DPPH, para o caso em que se utiliza uma taxa de quebra e uma distribuição de partículas filhas equivalentes.

Uma interpretação física da degradação ultrassônica seria que ocorreria colapso e ondas de choque e o polímero sofreria estiramento e a força máxima ocorreria no centro da molécula e este seria o mais provável ponto de ataque pelas ondas de choque.

Existem muitos estudos a respeito da degradação ultrassônica. Porém não existe uma concordância entre a teoria a ser aplicada ao processo, nem uma evidência experimental geral que indique que teoria deveria ser a melhor. Experimentalmente, observa-se que a taxa de desaparecimento de um polímero com um dado grau de polimerização, GP, é de primeira ordem aparente. Porém a ordem de reação é 
verdadeiramente mais complexa, e a degradação é uma função da concentração de polímeros e do tamanho de cadeia das moléculas que sofrem degradação.

Este último aspecto é de muito interesse. Normalmente admite-se na literatura que para um dado sistema existe um tamanho mínimo de cadeia e, este tamanho seria, por exemplo, $\mathrm{GP}_{\min }$. Abaixo desse valor nenhuma degradação ocorreria. Acima desse valor, muitas taxas já foram propostas. SCHIMID (1939) apud SMITH; TEMPLE (1968) propuseram uma função linear da taxa de polimerização como: (Taxa de degradação $)_{\mathrm{i}}=$ Const $3\left(\mathrm{GP}_{\mathrm{i}}-\mathrm{GP}_{\min }\right)$, onde Const3 é uma constante dessa taxa. JELLINEK; WHITE (1951) apud SMITH; TEMPLE (1968) propuseram um modelo, um pouco, mais complexo. Este modelo foi simplificado na época, para propósitos computacionais como: (Taxa de degradação $)_{i}=$ Const $4\left(\mathrm{GP}_{\mathrm{i}}-1\right)$, onde Const4 é uma constante. Argumentando a partir das considerações a respeito das energias das ondas de choque produzidas durante o processo de cavitação, GOOBERMAN; LAMB (1960) apud SMITH; TEMPLE (1968) derivaram uma proporcionalidade da (Taxa de degradação) $)_{\mathrm{i}} \operatorname{com} \mathrm{DP}_{\mathrm{i}} \exp (2,8)$. OVENALL; HASTING; ALLEN (1958) apud SMITH; TEMPLE (1968) consideraram também a distribuição de produtos vindos da fragmentação de moléculas. No modelo de Jellinek, todas as ligações das moléculas maiores que $\mathrm{GP}_{\min }$ são igualmente aptas à quebra. OVENALL; HASTING; ALLEN (1958) apud SMITH; TEMPLE (1968) assumiram que as ligações de unidades de $\mathrm{GP}_{\min } / 2$ não quebrariam no final de cada comprimento de cadeia, enquanto uma probabilidade igual existiria para a quebra em torno do segmento central. GOOBERMAN; LAMB (1960) apud SMITH; TEMPLE (1968) determinaram a distribuição de material para uma amostra de poliestireno degradado usando uma técnica turbidiométrica e concluíram que a ruptura, provavelmente, ocorre no centro da molécula.

Em nossa análise detalhada das mudanças, nas distribuições de pesos moleculares, para a degradação ultra-sônica para dextrana, como também visto em muitos dados da literatura, é evidente que o processo em questão dificilmente pode ser entendido como uma quebra aleatória.

Existe também uma controvérsia na literatura sobre o alargamento ou o achatamento da distribuição. Mas acredita-se que isso não é realmente uma grande controvérsia. Claramente se alguém começa com uma fração monodispersa e quebra ligações, a distribuição se alargará. Em geral, se alguém trabalha com uma distribuição polidispersa, 
ou seja, um polímero com distribuição larga de massas molares, as cadeias de alto peso molecular degradarão mais rapidamente e veremos o efeito do estreitamento da distribuição. Aparentemente, pelos resultados da literatura alguns autores relatam um estreitamento, enquanto outros relatam um alargamento da distribuição, e outros um estreitamento seguido de um alargamento (WU; SHETH; JOHNSON, 1977) O tempo de irradiação de ultra-som nesse estudo foi suficientemente longo para que, ao final do experimento, tivéssemos os pesos e as distribuições moleculares sempre iguais independentemente das distribuições iniciais utilizadas. A taxa de degradação parece sempre diminuir com o tempo, mas parece, também, que sempre existe um pouco de degradação acontecendo mesmo ao final do tempo dos experimentos.

\subsection{Degradação ultrassônica de guar.}

Outro exemplo foi estudado de degradação ultrassônica de polímero, com base nos dados apresentados no trabalho de TAYAL; KHAN (2000). Estes autores estudaram experimentalmente a degradação de guar galactomanana por ultrassom em solução aquosa a $1 \%\left(\mathrm{~m} / \mathrm{v}\right.$ ) a $25^{\circ} \mathrm{C}$, usando um sonicador (XL 2020 Heat-Systems Ultrasonics) por até 30 minutos. Amostras com diferentes tempos de irradiação foram analisadas por GPC. As distribuições experimentais de massas molares medidas estão apresentadas na Figura 4.6.1.

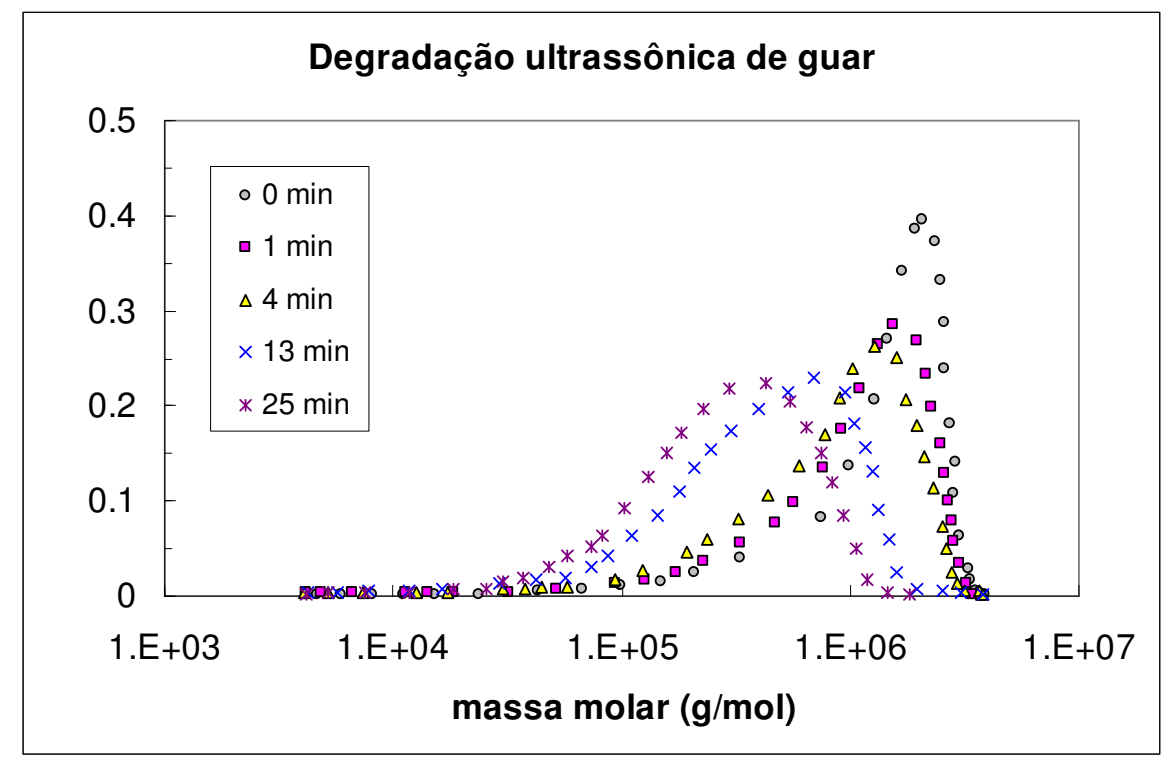


Figura 4.6.1. Distribuições de massa molar experimentais de guar galactomanana degradadas por ultrassom (TAYAL; KAHN, 2000).

Na Figura 4.6.2 são apresentadas as curvas de $\ln (\mathrm{t})$ versus $\ln (\mathrm{x})$, as curvas de comprimento de arco e as curvas de distribuição de similaridade. Nota-se que os pontos estão razoavelmente alinhados na curva de comprimento de arco, e uma também satisfatória superposição (embora não perfeita) das diferentes distribuições em termos da variável de similaridade.
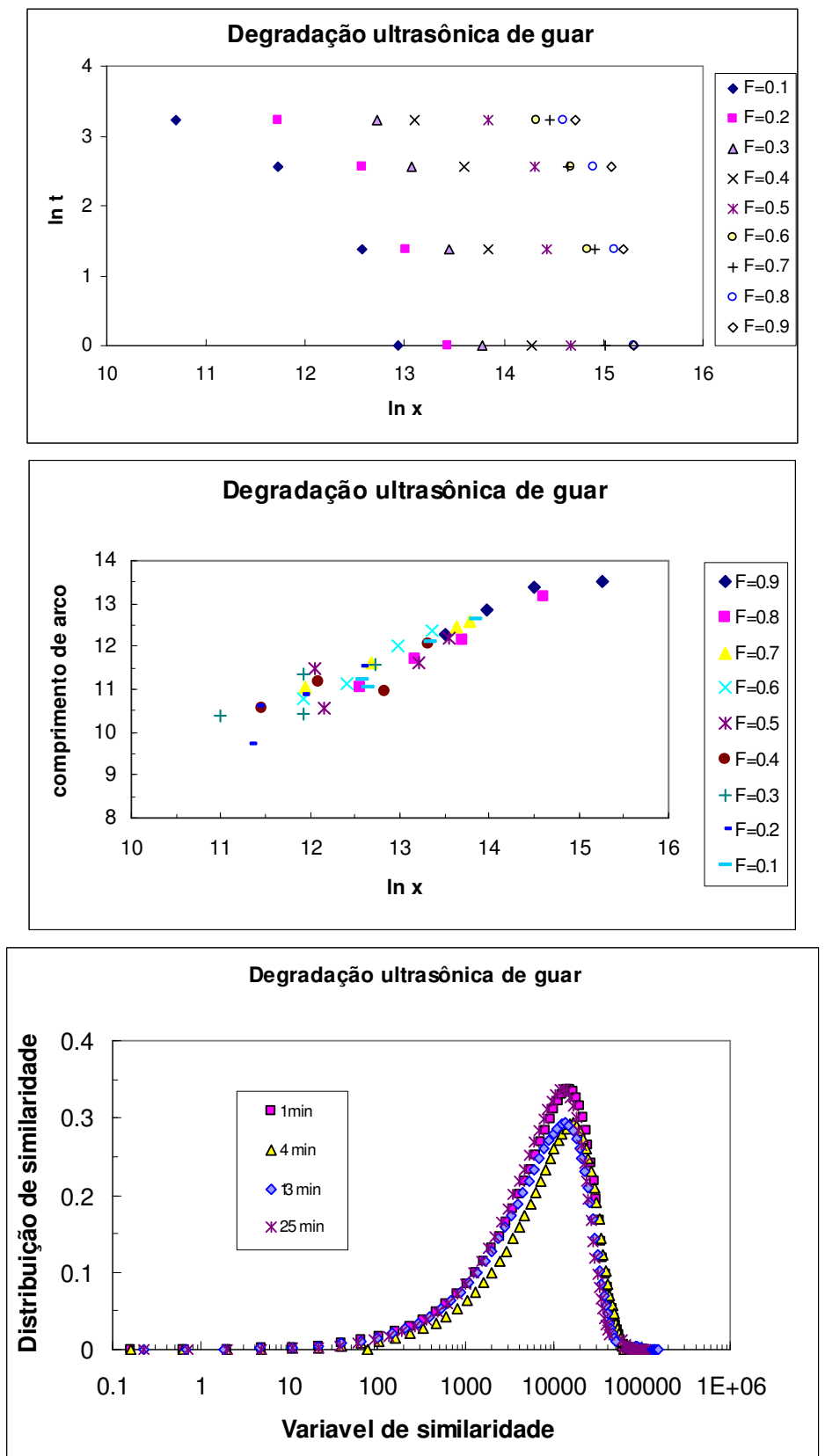
Figura 4.6.2. Curvas de (a) $\ln (\mathrm{t})$ versus $\ln (\mathrm{x})$, (b) comprimento de arco e (c) distribuição de similaridade para a degradação ultrassônica de guar.

Na figura 4.6.3 apresentam-se as curvas de taxa de quebra e de distribuição de filhas. O formato é similar ao encontrado nos casos anteriores já analisados. Na figura 4.6.4 apresenta-se a comparação entre as curvas de distribuição diferencial e acumulada de massa molares experimentais e calculadas pelo balanço populacional usando as taxas de quebra e distribuição de filhas obtidas pelo problema inverso. Nota-se, neste caso, um bom ajuste das curvas calculadas em relação às curvas experimentais.
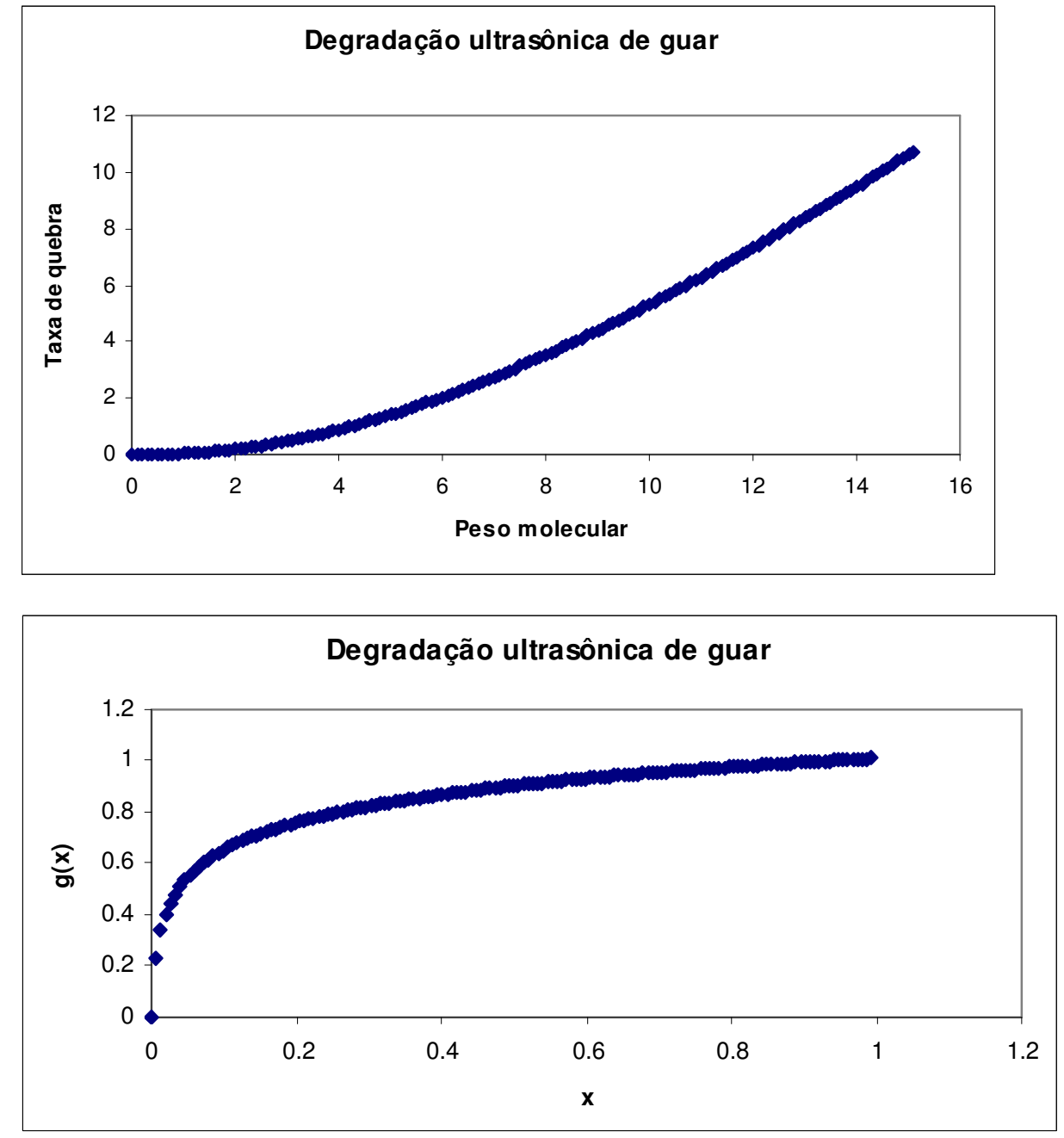

Figura 4.6.3. Taxa de quebra e distribuição de partículas filhas resultante do problema inverso para degradação ultrassônica de guar. 

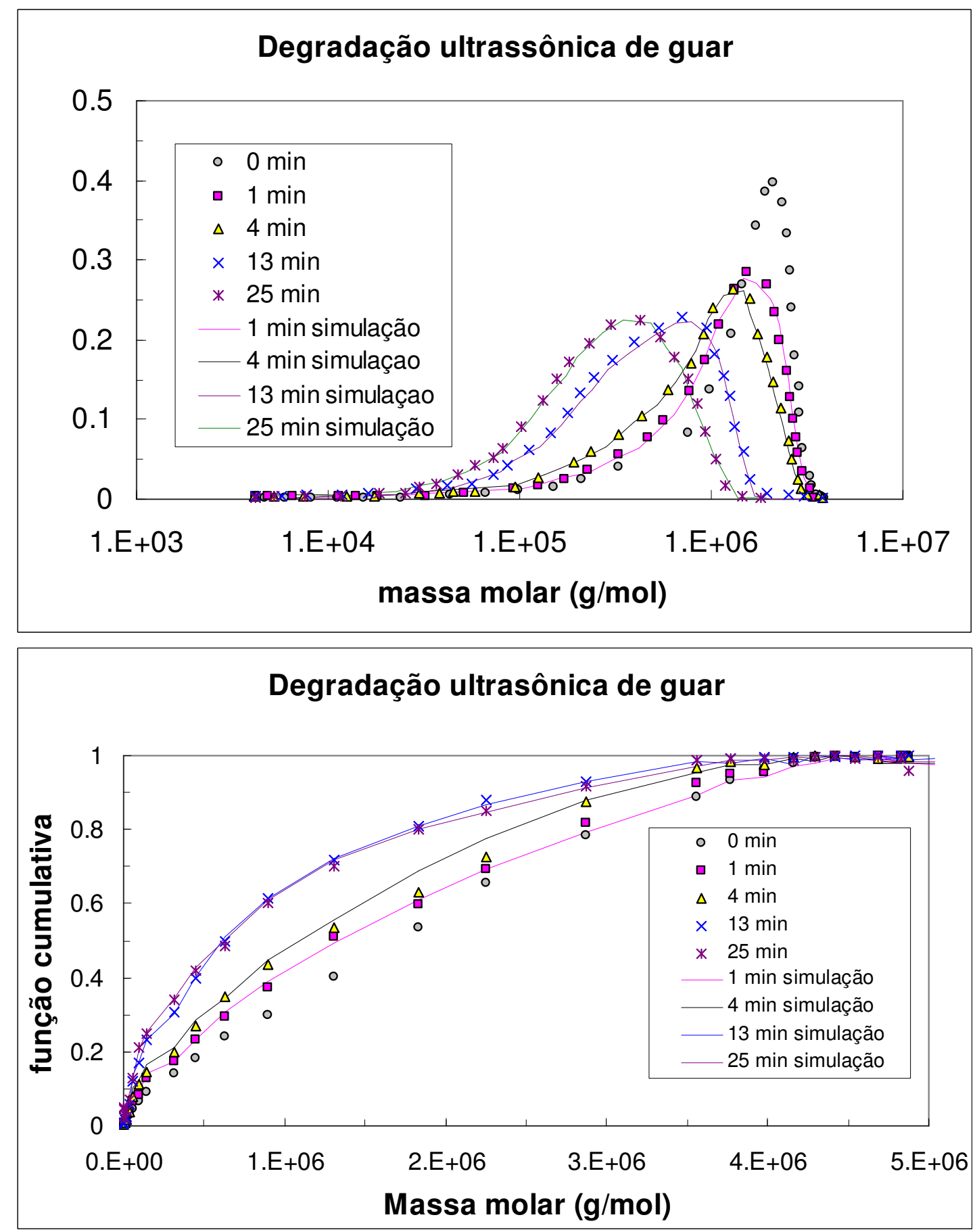

Figura 4.6.4. Distribuições de massa molar experimentais (pontos) e calculadas (curvas) para a degradação ultrassônica de guar. (a) Distribuição diferencial. (b) Distribuição acumulada ou cumulativa. 
A partir das curvas de taxa de quebra e distribuição de filhas obtidas do problema inverso, a curva de preferência de quebra pode ser calculada e está apresentada na Figura 4.6.5. Nota-se que o gráfico de preferência de quebra tem um aspecto de valor constante a partir de um certo valor de massa molar. TAYAL; KHAN (2000) observaram que as curvas experimentais foram bem representadas por um modelo de quebra aleatória, em relação aos casos de quebra Gaussiana e quebra central.

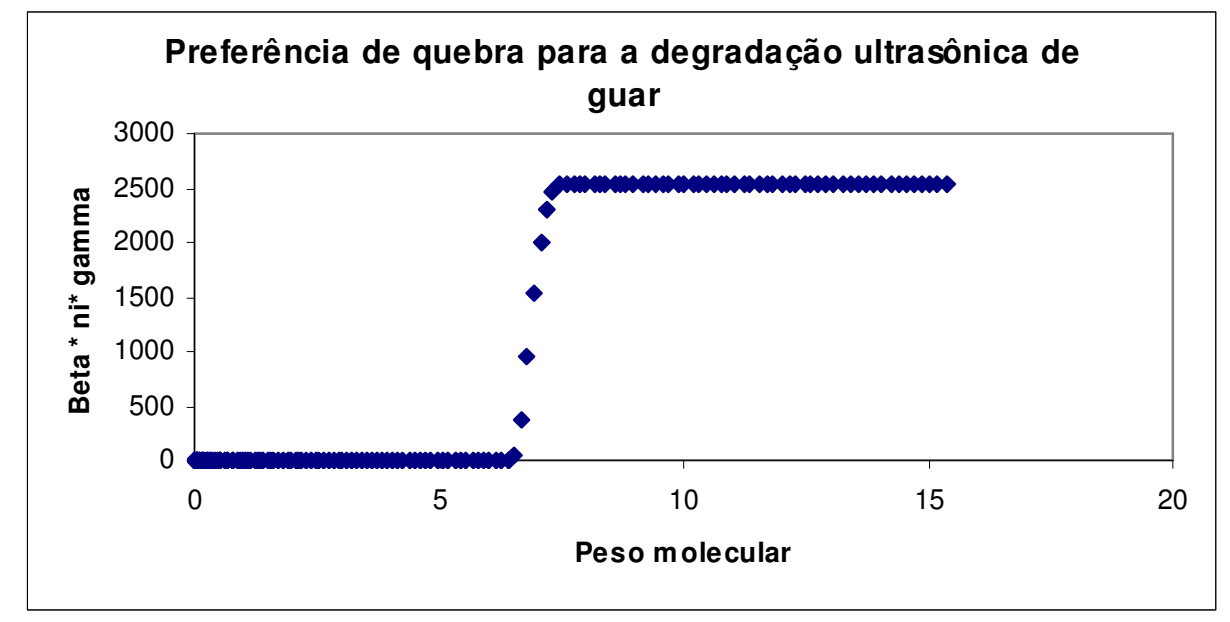

Figura 4.6.5. Preferência de quebra para degradação ultrassônica de guar.

\subsection{Degradação por hidrólise ácida de guar.}

Outro exemplo de degradação de guar também estudado por TAYAL; KHAN (2000) foi o caso de degradação enzimática. Estes autores estudaram experimentalmente a degradação de guar galactomanana em solução aquosa a $1 \%(\mathrm{~m} / \mathrm{v})$ a $25^{\circ} \mathrm{C}$, usando enzima endo- $\beta$-mananase (de Aspergillus niger) obtida comercialmente da Megazyme Corp. (Ireland). Amostras com diferentes tempos de processo foram analisadas por GPC. As distribuições experimentais de massas molares medidas estão apresentadas na Figura 4.7.1.

A partir destas curvas, utilizou-se a metodologia do problema inverso, obtendo-se as curvas de $\ln (\mathrm{t})$ versus $\ln (\mathrm{x})$, comprimento de arco e distribuição de similaridade, mostradas na Figura 4.7.2, que mostram a existência de similaridade entre as distribuições 
experimentais, e as curvas de taxa de quebra e distribuição de filhas mostradas na Figura 4.7.3.

Estes resultados do problema inverso (taxa de quebra e distribuição de filhas) foi substituído no balanço populacional e resolvido, obtendo-se as curvas de distribuição de massa molar calculadas, as quais são comparadas com as experimentais na Figura 4.7.4. Nota-se que as curvas calculadas com os parâmetros obtidos do problema inverso conseguem reproduzir adequadamente as curvas experimentais.

Finalmente, na Figura 4.7.5. está apresentada a curva de preferência de quebra. TAYAL; KHAN (2000) reportam que no caso da hidrólise enzimática de guar, eles não conseguiram reproduzir os dados experimentais satisfatoriamente com nenhum dos modelos de quebra que eles testaram, a saber, nem o modelo de distribuição aleatória, nem o modelo de quebra Gaussiana, e nem o modelo de quebra central.

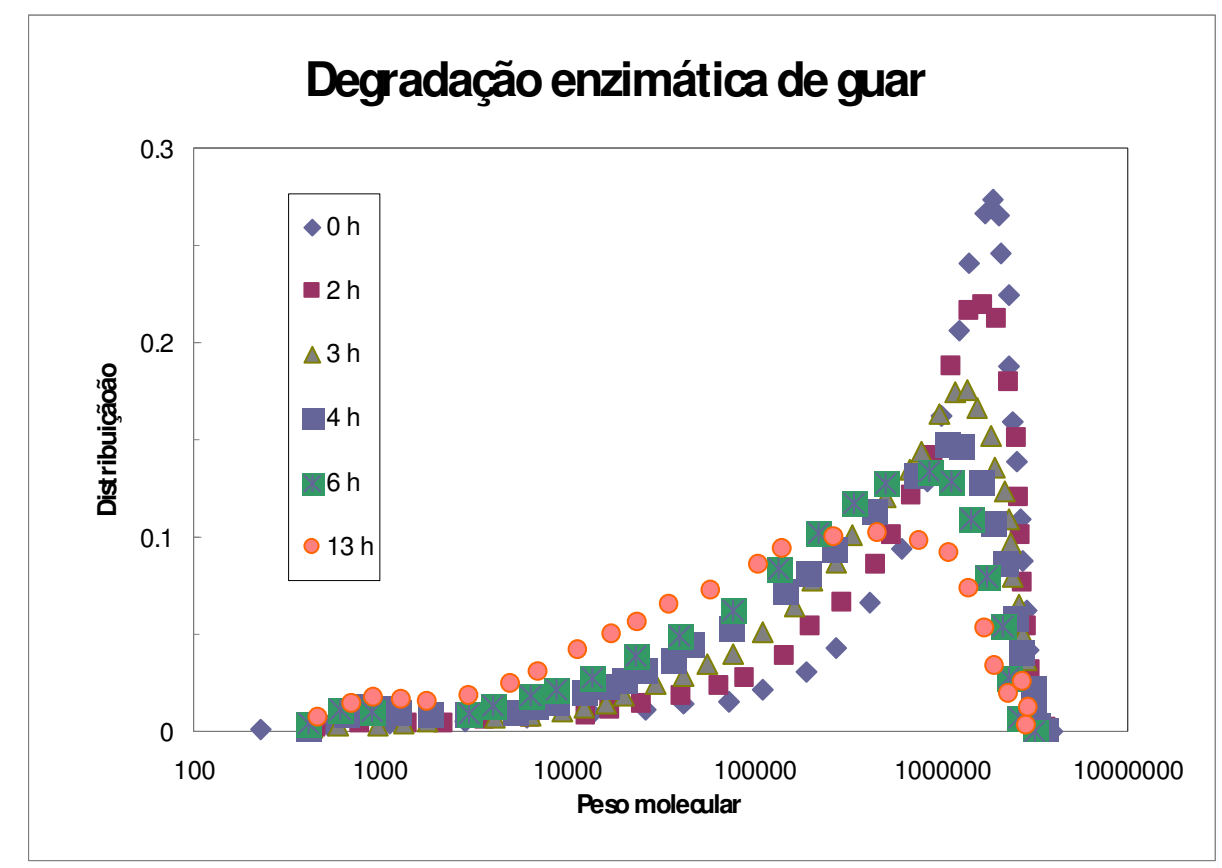

Figura 4.7.1. Distribuições de massa molar experimentais de guar galactomanana degradadas enzimaticamente (TAYAL; KAHN, 2000). 

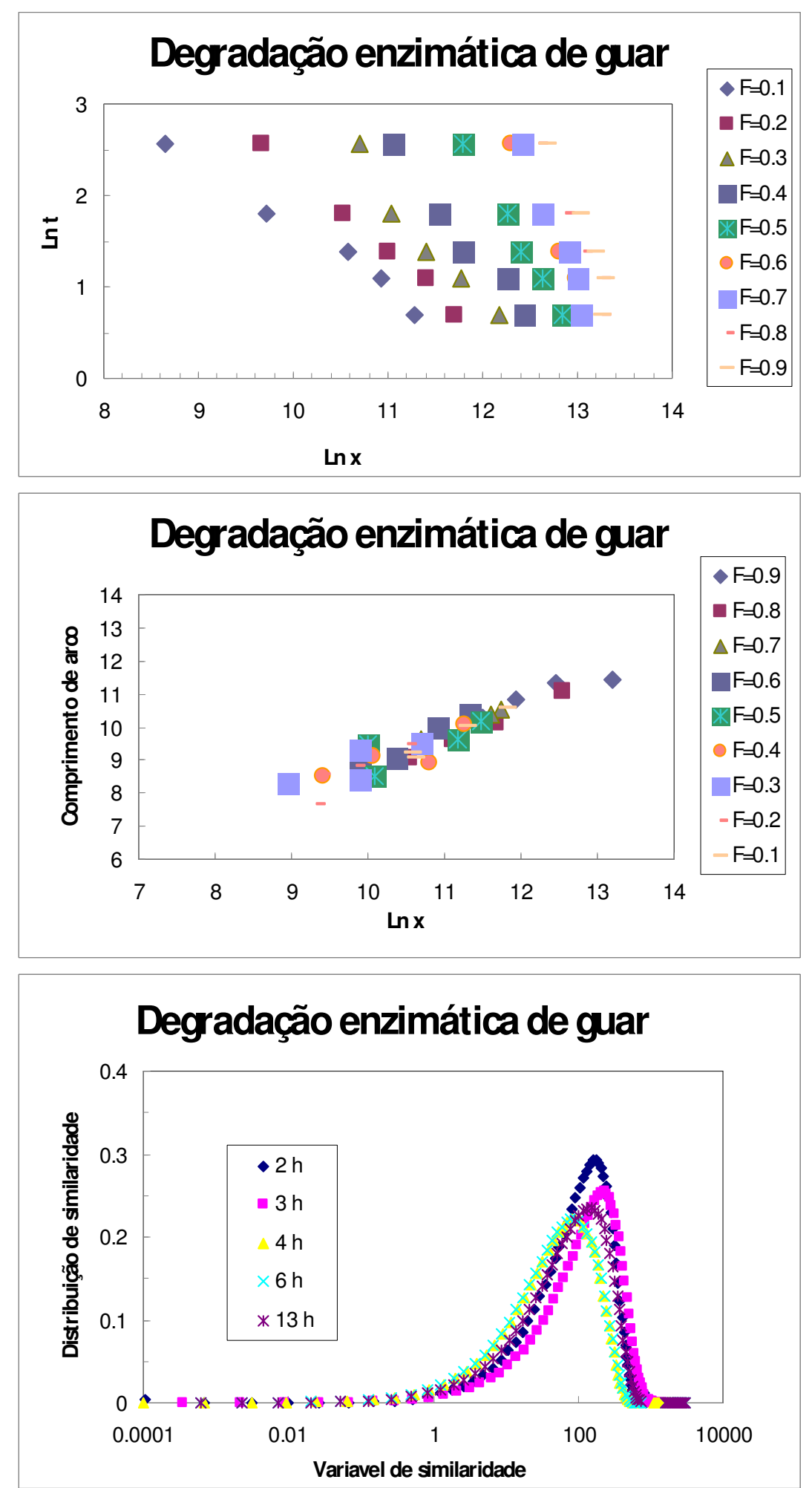

Figura 4.7.2. Curvas de (a) $\ln (\mathrm{t})$ versus $\ln (\mathrm{x})$, (b) comprimento de arco e (c) distribuição de similaridade para a degradação enzimática de guar. 

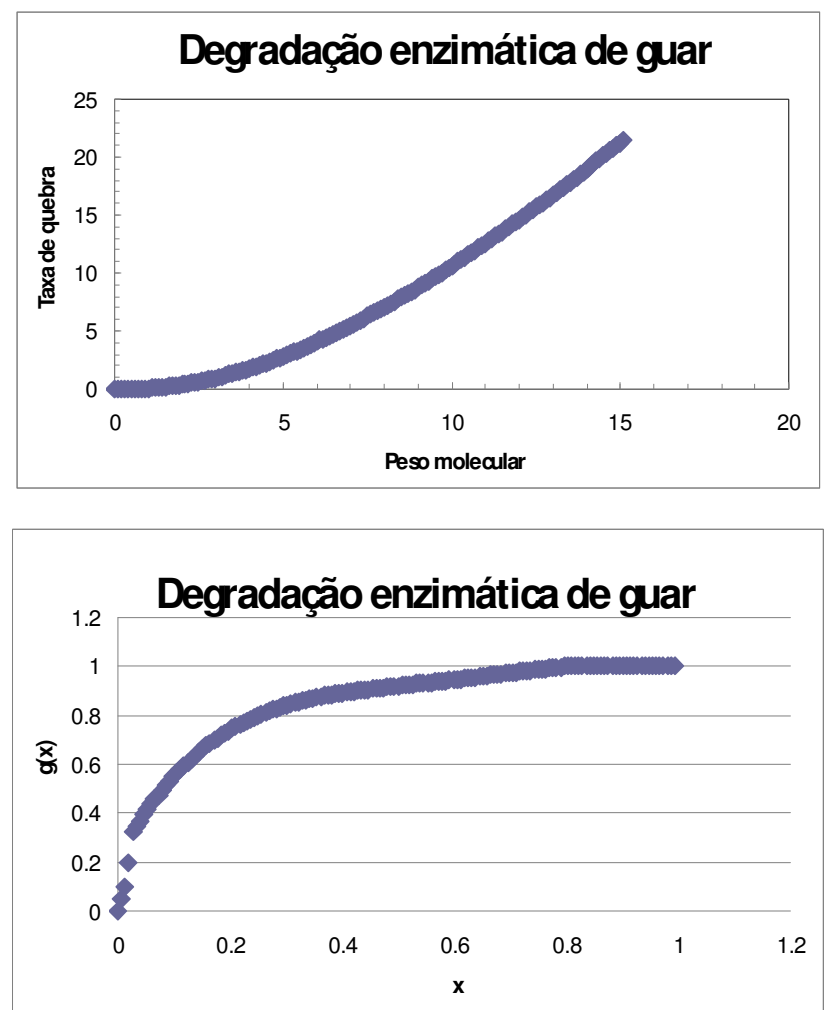

Figura 4.7.3. Taxa de quebra e distribuição de partículas filhas resultante do problema inverso para degradação enzimática de guar.

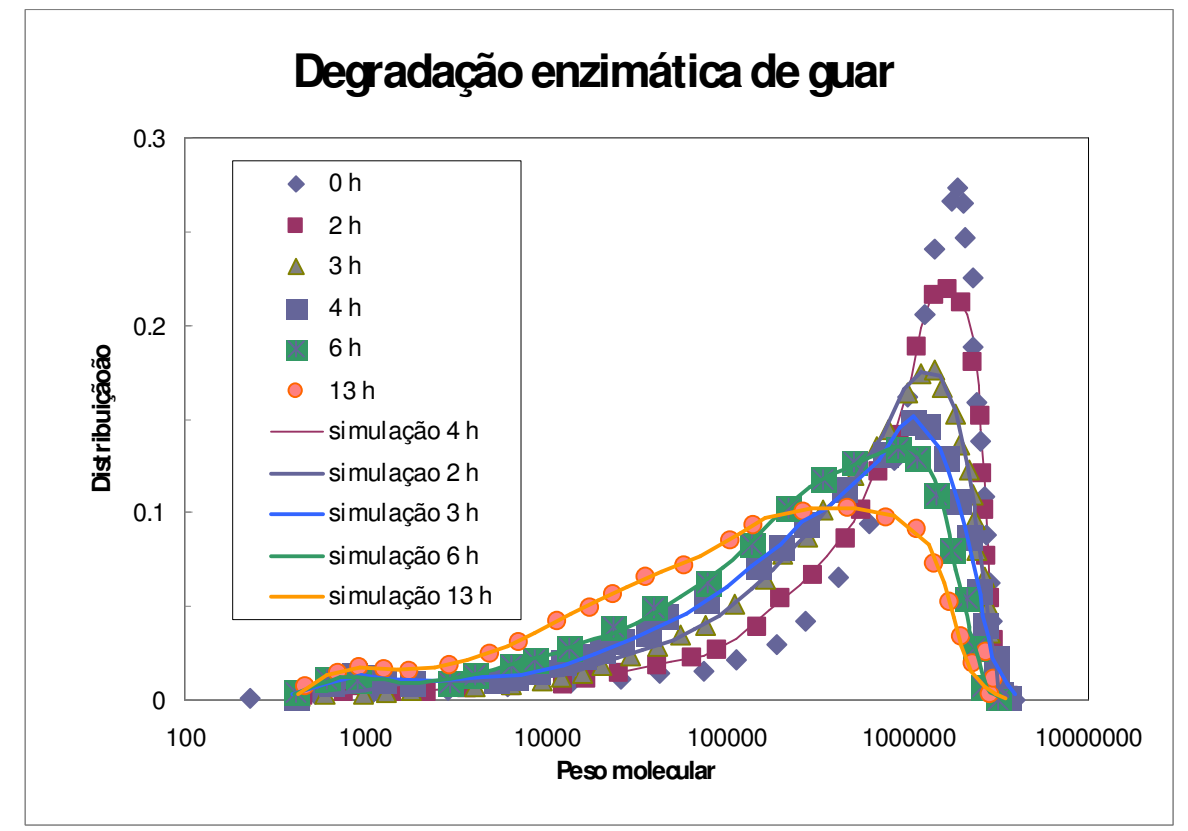

Figura 4.6.4. Distribuições de massa molar experimentais (pontos) e calculadas (curvas) para a degradação enzimática de guar. 


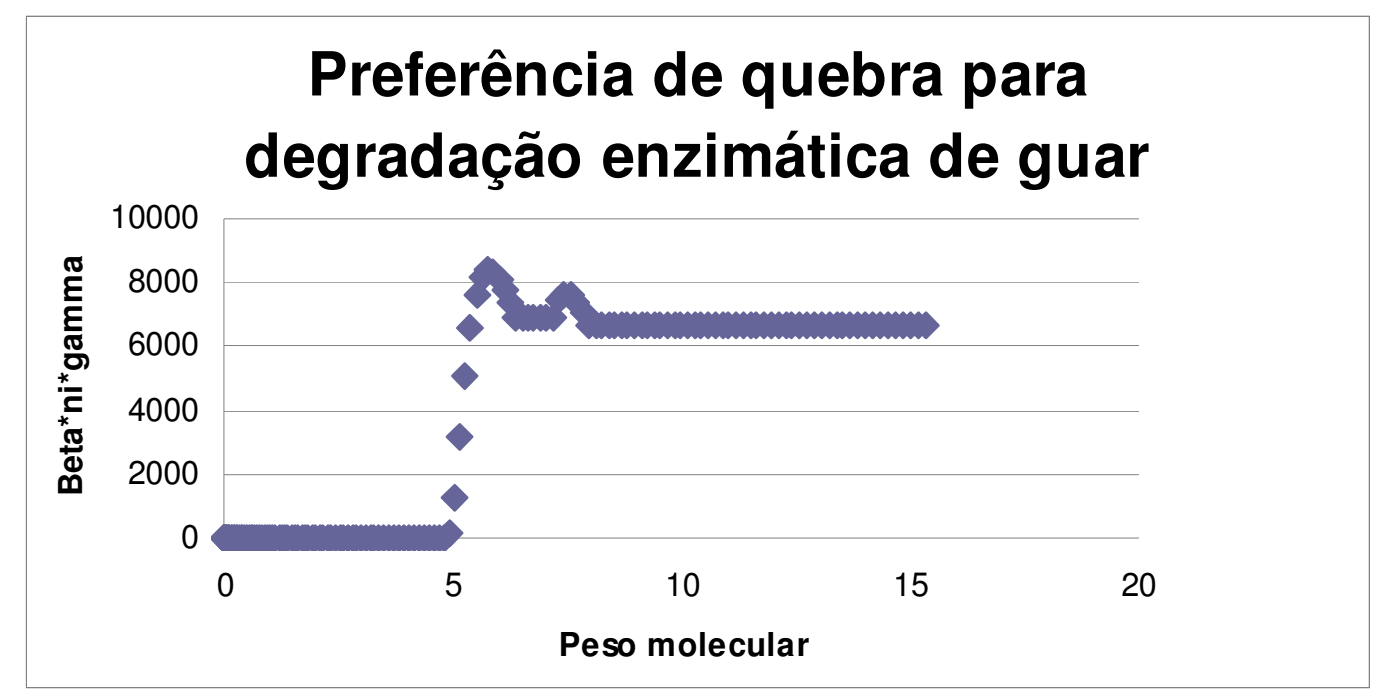

Figura 4.7.5. Preferência de quebra para degradação ultrassônica de guar.

\subsection{Procedimento alternativo para o modelo de degradação de polímeros.}

Podemos detalhar o estudo da degradação de polímeros com o seguinte modelo apresentado por GLINN, VAN DER HOFF; REILLY (1972). Sendo, $\mathrm{ff}_{\mathrm{nn}}(\mathrm{t}, \mathrm{xx})$, a fração numérica de moléculas de grau de polimerização $\mathrm{GP}_{\mathrm{xx}}$, após $\mathrm{t}$ quebras, e $\mathrm{pp}(\mathrm{xx})$ o fator de peso que descreve a relação entre a probabilidade de quebra e o grau de polimerização GP das moléculas de polímero. $\mathrm{AA}(\mathrm{t}) \mathrm{pp}(\mathrm{xx}) \mathrm{ff}_{\mathrm{nn}}(\mathrm{t}, \mathrm{xx})$ é a probabilidade de escolhermos uma molécula de $\mathrm{GP}_{\mathrm{xx}}$ para romper depois de $\mathrm{t}$ eventos de quebra. Por conveniência, isso será representado por $\mathrm{PP}(\mathrm{t}, \mathrm{xx})$. $\mathrm{AA}(\mathrm{t})$ é o fator de normalização que aparece pelo fato de $\mathrm{PP}(\mathrm{xx}, \mathrm{t})$ ser uma probabilidade e portanto a equação (4.5.1)

$\sum_{x x=1}^{\infty} P P(x x, t)=1$

$\mathrm{QQ}(\mathrm{yy}, \mathrm{xx})$ é a probabilidade de uma molécula de $\mathrm{GP}_{\mathrm{yy}}$ produzir, na quebra, um fragmento de $\mathrm{GP}_{\mathrm{xx}}$. Pelo fato de $\mathrm{QQ}(\mathrm{yy}, \mathrm{xx})$ ser uma probabilidade, também: 


$$
\sum_{x x=1}^{\infty} Q Q(y y, x x)=1
$$

NN é o número inicial de moléculas. O total de moléculas após t eventos de quebra seria então $\mathrm{NN}+\mathrm{t}$.

A derivação de uma equação modelo é como se segue: A média no incremento do número de moléculas de $\mathrm{GP}_{\mathrm{xx}}$ resultantes após $\mathrm{t}+1$ quebras pode ser avaliada de duas formas. Primeiro, pela diferença entre os produtos do total de números de moléculas e a fração de número para $\mathrm{GP}_{\mathrm{xx}}$, após $\mathrm{t}$ quebras e após $\mathrm{t}+1$ quebras. E em segundo, pela soma dos produtos da probabilidade de se escolher a molécula para ser quebrada e a probabilidade dela produzir uma molécula de $\mathrm{GP}_{\mathrm{xx}}$, menos a probabilidade de escolhermos uma molécula de $\mathrm{GP}_{\mathrm{xx}}$ para ser quebrada. Equacionando essas duas expressões para um incremento médio teremos:

$$
(N N+t+1) f f_{n}(t+1, x x)-(N N+t) f f_{n}(t, x x)=2\left\{\sum_{u u=x x+1}^{\infty} P P(t, u u) Q Q(u u, x x)\right\}-P P(t, x x)
$$

O limite superior $\infty$ é colocado na soma para indicarmos que existe um termo para cada GP até o máximo presente. Para GP maiores que aqueles de qualquer molécula presente, $\mathrm{PP}(\mathrm{t}, \mathrm{uu})$ será zero e, portanto, não existirá o termo correspondente na soma. Para a simplicidade das equações de modelo, elas foram escritas para homopolímeros lineares e uma distribuição Q simétrica em relação ao ponto médio das cadeias de moléculas. Essa simetria nos leva ao fator 2 do lado direito da equação (4.5.3), isso porque fragmentos de tamanho xx são produzidos com a mesma probabilidade de ruptura nas unidades xx para cada ponta da molécula polimérica. Se essa simetria não estivesse presente, o modelo poderia ser facilmente modificado. Em geral, equações podem ser desenvolvidas usando esse modelo para polímeros com diferentes composições químicas e arquiteturas.

Com a equação (4.5.3), ffnn(t+1,xx) pode ser calculado a partir de $\mathrm{ff}(\mathrm{t}, \mathrm{xx})$ para todos os possíveis valores de $\mathrm{xx}$. Então a distribuição numérica $\mathrm{ff}_{\mathrm{nn}}(\mathrm{t}, \mathrm{xx})$ pode ser construída, para qualquer valor de t, pela distribuição de pesos moleculares iniciais, $\mathrm{ff}_{\mathrm{nn}}(0, \mathrm{xx})$, por uma repetição da aplicação dos esquemas de cálculos acima para cada valor da integral de 0 até t. Deve-se ter em mente que entre os cálculos de passos consecutivos, o valor de $\mathrm{AA}(\mathrm{t})$, deve ser determinado para que a equação (4.5.1) seja satisfeita. 
Esse modelo permite a inclusão do conceito de que abaixo de determinados tamanhos de moléculas não ocorrerá quebra. Este conceito de um mínimo tamanho degradável de polímero foi feito repetidamente na literatura, e pode ser incorporado pela imposição da condição, de que $\mathrm{PP}(\mathrm{t}, \mathrm{xx})=0$ para todo $\mathrm{xx}$ menor que o grau de polimerização mínimo degradável. O fator de normalização AA(t) é então calculado, por meio, de $\sum_{x x=G P}^{\infty} P P(t, x x)=1$.

Por causa da generalidade desse modelo, qualquer combinação pode ser considerada da probabilidade de escolha de uma molécula para a ruptura $(\operatorname{PP}(t, x x))$ e a distribuição de probabilidade da localidade da quebra ao longo da cadeia (QQ(yy,xx)). A seguinte distribuição de probabilidade para $\mathrm{PP}(\mathrm{t}, \mathrm{xx})$ e $\mathrm{QQ}(\mathrm{yy}, \mathrm{xx})$ são mencionadas.

As distribuições PP podem, em geral ser as seguintes:

Para $1 \leq \mathrm{xx} \leq \mathrm{GP}: \mathrm{PP}(\mathrm{t}, \mathrm{xx})=0$

Para $\mathrm{xx} \geq \mathrm{GP}$ :

(1) $P P(t, x x)=A A(t) f f_{n n}(t, x x)$

A probabilidade de escolhermos uma molécula para a ruptura é proporcional à fração numérica.

(2)PP(t,xx)=AA(t)MMM $\mathrm{Mff}_{\mathrm{nn}}(\mathrm{t}, \mathrm{xx})$

A probabilidade de escolhermos uma molécula

é proporcional à fração mássica, isto é, aleatória no espaço. $\mathrm{MMM}_{0}$, é o peso molecular de uma unidade repetida.

(3) $\mathrm{PP}(\mathrm{t}, \mathrm{xx})=\mathrm{AA}(\mathrm{t})\left(\mathrm{MMM}_{0} \mathrm{xx}\right)^{\mathrm{ss}} \mathrm{ff}_{\mathrm{nn}}(\mathrm{t}, \mathrm{xx}) \quad$ A probabilidade de escolher uma molécula para a ruptura é proporcional ao peso molecular da potência ss. Se ss=0 isso se reduz ao caso 1 , e se $\mathrm{ss}=1$ isso se reduz ao caso 2

As distribuições QQ podem, em geral, ser as seguintes:

(a) $Q Q(y y, x x)=1 /(y y-1)$

(b) $Q Q(y y, x x)=1$ para $x x=y y / 2$ e
Distribuição aleatória de pontos de quebra, isto é, igual probabilidade de ruptura ao longo da cadeia polimérica. Isso será chamado de quebra aleatória.

Quebra de moléculas ocorre apenas no 


\begin{abstract}
$\mathrm{QQ}(\mathrm{yy}, \mathrm{xx})=0$ para qualquer outro $\mathrm{xx}$ centro da molécula. Isto se chama quebra centrada

(c) $\mathrm{QQ}(\mathrm{yy}, \mathrm{xx})=1 / \sigma(2 \pi)^{1 / 2} \exp \left(-(\mathrm{x}-\mathrm{y} / 2)^{2} / 2 \sigma^{2}\right) \mathrm{A}$ probabilidade de ruptura das localizações segue uma distribuição Gaussiana com determinada média e desvio padrão. Com desvio padrão de $\sigma=$ rryy. Se $\sigma$ é largo ( $r>10)$ esse caso é igual ao caso (a), e, se $\sigma$ é pequeno $(\mathrm{rr}<0,0005)$, ele fica igual ao caso (b). Isso é chamado de quebra Gaussiana centrada.
\end{abstract}

A quebra aleatória pode ser escrita de uma forma mais simples, para ser implementada, em um algoritmo de computador. A equação (4.5.3), quando aplicada ao caso de quebra aleatória de moléculas poliméricas $[\mathrm{QQ}(\mathrm{yy}, \mathrm{xx})=1 /(\mathrm{yy}-1)]$, e pode ser simplificada da seguinte maneira. Para $1 \leq \mathrm{xx} \leq \mathrm{nn}$, o lado direito da equação (4.5.3) se torna:

$\mathrm{xx}=1 \quad 2[\mathrm{P}(\mathrm{t}, 2)(1 / 1)+\mathrm{P}(\mathrm{t}, 3)(1 / 2)+\mathrm{P}(\mathrm{t}, 4)(1 / 3)+\ldots+\mathrm{P}(\mathrm{t}, \mathrm{nn})(1 / \mathrm{nn}-1)]-\mathrm{P}(\mathrm{t}, 1)$

$\mathrm{xx}=2 \quad 2[\mathrm{P}(\mathrm{t}, 3)(1 / 2)+\mathrm{P}(\mathrm{t}, 4)(1 / 3)+\ldots+\mathrm{P}(\mathrm{t}, \mathrm{nn})(1 / \mathrm{nn}-1)]-\mathrm{P}(\mathrm{t}, 2)$

$\mathrm{xx}=3 \quad 2[\mathrm{P}(\mathrm{t}, 4)(1 / 3)+\ldots .+\mathrm{P}(\mathrm{t}, \mathrm{nn})(1 / \mathrm{nn}-1)]-\mathrm{P}(\mathrm{t}, 3)$

$\cdots$

$\mathrm{xx}=\mathrm{nn}-1 \quad 2[\mathrm{P}(\mathrm{t}, \mathrm{nn})(2 / \mathrm{nn}-1)]-\mathrm{P}(\mathrm{t}, \mathrm{nn}-1)$

$\mathrm{xx}=\mathrm{nn} \quad-\mathrm{P}(\mathrm{t}, \mathrm{nn})$

A combinação da simplificação acima com a parte esquerda da equação (4.5.3), para $\mathrm{o} x \mathrm{x}$ aplicado, nos permite $\mathrm{n}$ equações, cada uma pode ser resolvida para $\mathrm{ff}_{\mathrm{n}}(\mathrm{t}+1, \mathrm{xx})$. Esse vetor de equações é particularmente adequado para cálculos computacionais.

A quebra centrada, também, pode ser escrita de uma forma mais simples para implementação computacional. Por causa da quebra ser permitida apenas em intervalos de $\mathrm{GP}_{\mathrm{rr}}$, é necessário definirmos o que é principal na quebra centrada quando GP/GP $\mathrm{rr}_{\mathrm{rr}}$ é difícil. Neste caso a quebra centrada será tomada pelo meio para que uma molécula com grau de polimerização GP de $(2 \mathrm{uu}+1) \mathrm{GP}_{\mathrm{rr}}$, quebre formando fragmentos de tamanho uuGP $\mathrm{rr}_{\mathrm{rr}}$, e, 
(uu+1)GP $\mathrm{rr}_{\mathrm{rr}}$. Portanto, o numero de moléculas de tamanho uuGP $\mathrm{rr}_{\mathrm{rr}}$, para qualquer $\mathrm{u}$, é aumentada por um da quebra de moléculas de tamanho (2uu+1)GP $\mathrm{Gr}_{\mathrm{rr}}$, e, (2uu-1)GP $\mathrm{Gr}_{\mathrm{rr}}$, e, é aumentada por duas moléculas provenientes da quebra de moléculas de tamanhos, $2 \mathrm{uuGP}_{\mathrm{rr}}$. $\mathrm{E}$, portanto, seguindo que $\mathrm{Q}(\mathrm{yy}, \mathrm{uu})=1 / 2$ quando $\mathrm{y}=2 \mathrm{uu}-1$ ou $\mathrm{yy}=2 \mathrm{uu}+1 ; \mathrm{Q}(\mathrm{yy}, \mathrm{uu})=1$ para $\mathrm{yy}=2 \mathrm{uu} ; \mathrm{e} \mathrm{Q}(\mathrm{yy}, \mathrm{uu})=0$ para todos os outros valores de $\mathrm{yy}$.

Para $1 \leq \mathrm{xx} \leq \mathrm{nn}$, o lado direito da equação (4.5.3) se torna

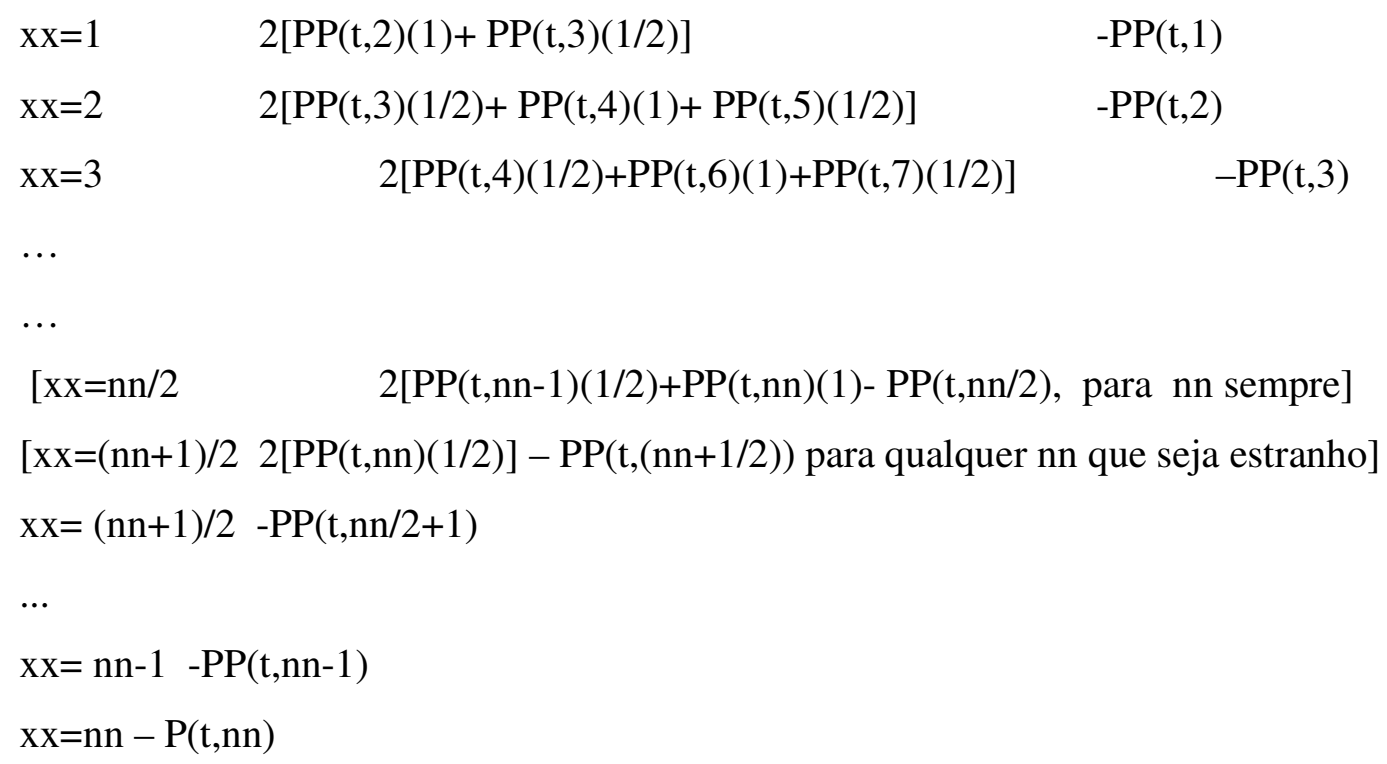

A distribuição numérica $\mathrm{ff}_{\mathrm{nn}}(\mathrm{t}+1, \mathrm{xx})$ é então calculada da mesma maneira que demonstrada para a quebra aleatória. Maiores detalhes desse equacionamento proposto para o funcionamento da degradação ultra-sônica estão expostos no trabalho de GLYNN; VAN DE HOFF; REILLY (1972).

\subsection{Procedimento alternativo para o problema inverso.}

Uma outra abordagem que podemos utilizar para verificar a validade dos cálculos é representar a taxa de quebra $\Gamma(\mathrm{M})$ e a distribuição de partículas filhas $\mathrm{g}(\mathrm{x})$ por funções discretizadas, quebrando o domínio em pedaços e considerando o valor destas funções constante em cada intervalo. Matematicamente, isto seria uma aproximação "piecewise" constante em cada intervalo, ou um histograma, como ilustrado na figura 4.6.1: Nesta abordagem alternativa, o problema inverso seria tratado como uma problema de 
minimização entre as distribuições experimentais e as distribuições calculadas pelo balanço populacional (problema direto), sendo as variáveis de otimização os valores discretizados das funções de quebra e distribuição de filhas. Na figura 4.6.2 apresenta-se pictoricamente o esquema deste procedimento alternativo para o problema inverso.

Taxa de quebra

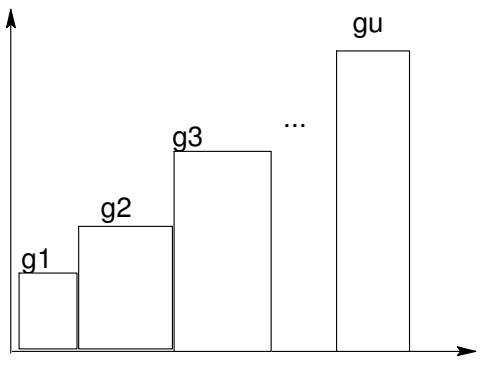

Distribuição de partículas

filhas

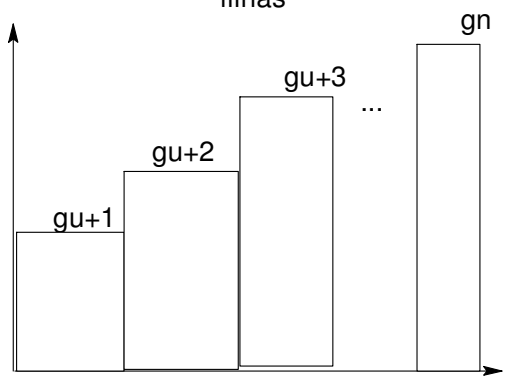

v

Figura 4.6.1: Representação da taxa de quebra, e, da distribuição de partículas filhas por apenas um número de classes escolhido.

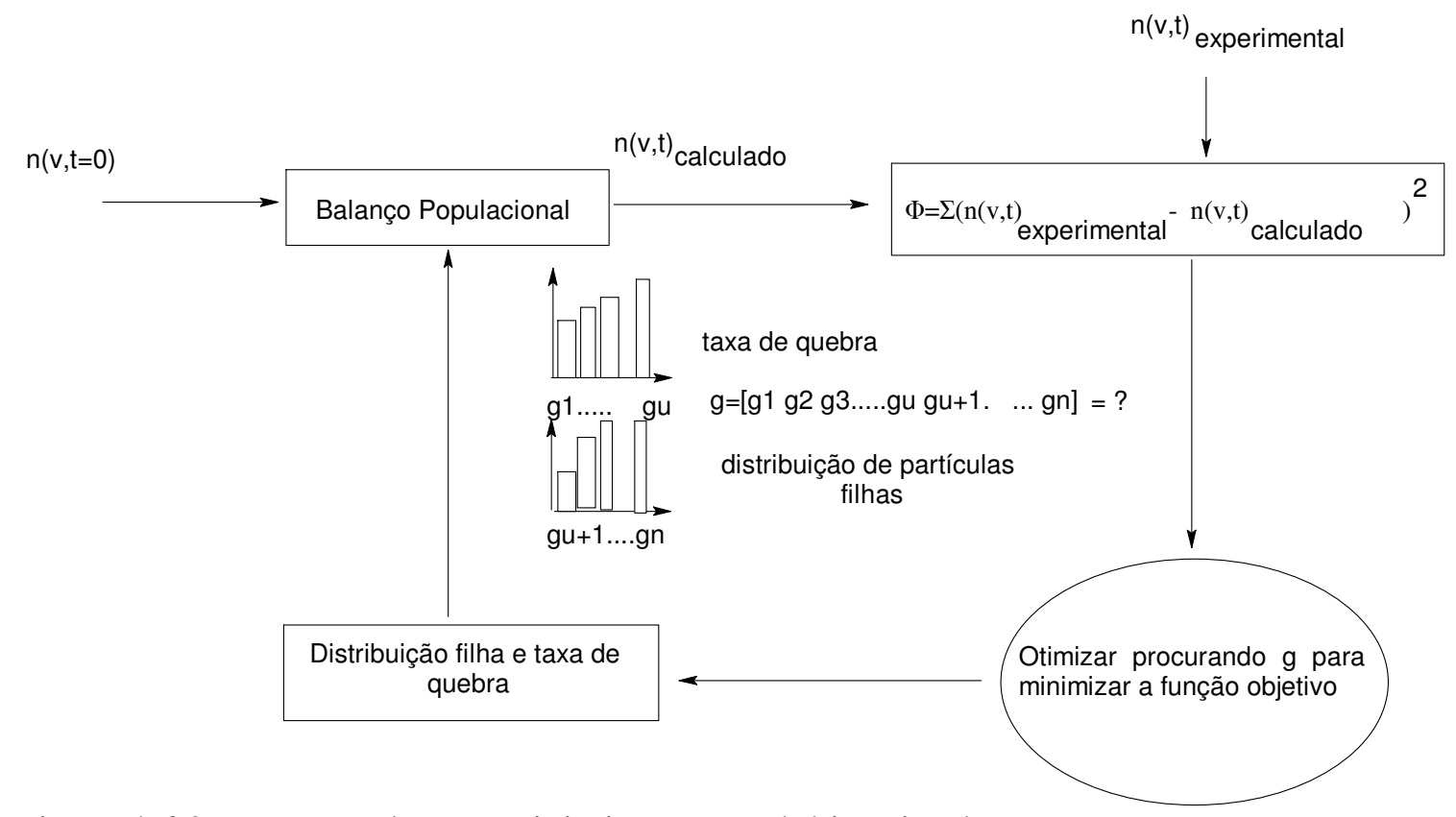

Figura 4.6.2: Esquema de uma minimização quadrática simples.

Em resumo, o que a figura 4.6.2 nos apresenta é uma otimização em que devemos minimizar a função objetivo

$\min \Phi=\sum\left(n(v, t)_{\text {calculado }}-n(v, t)_{\exp \text { erimental }}\right)^{2}$ 
ou seja, maximizar a concordância entre os valores da distribuição calculados e os experimentais,. O vetor de variáveis de otimização (cujos valores serão variados para buscar a minimização de (4.6.1)) é formado pelos valores "piecewise"das funções discretizadas em classes:

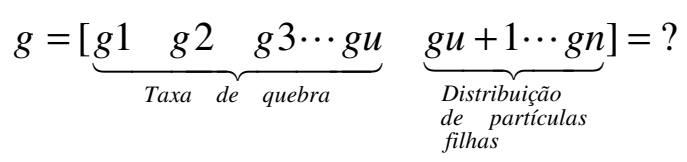

O método de otimização utilizado foi a mimização quadrática do scilab, a função lsqlsolve.

A partir dessa minimização recalculamos as taxas de quebra e distribuições filhas para os casos de degradação ultrassônica e de degradação mecânica e apresentamos nas figuras 4.6 .3 e 4.6.4.

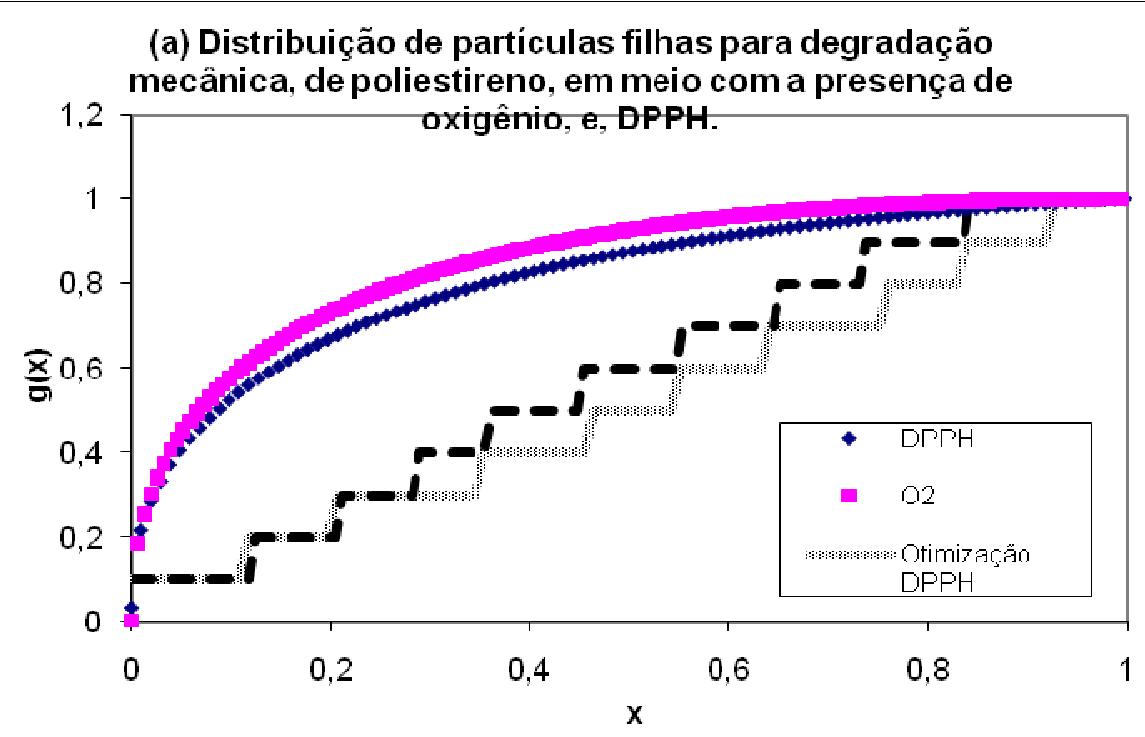


(b) Taxa de quebra para degradação mecânica de poliestireno em meio com a presença de oxigênio, e, DPPH

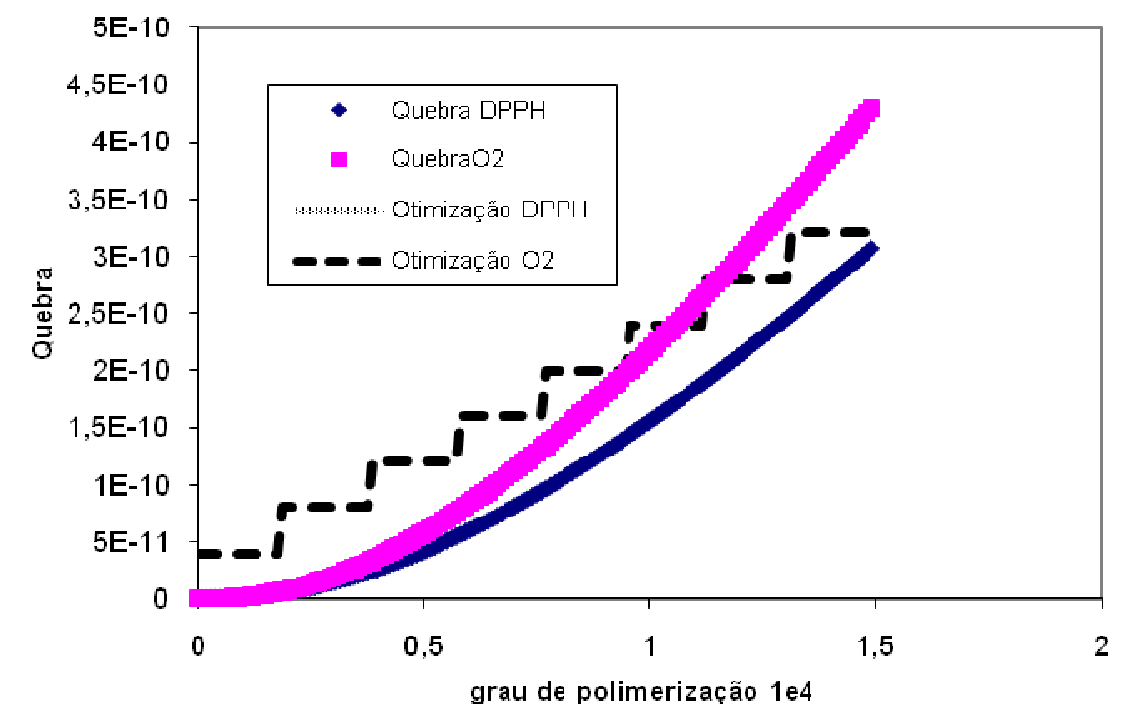

Figura 4.6.3: Cálculo por meio de otimização das (a) distribuições de partículas filhas e (b) taxas de quebra, para degradação mecânica de poliestireno em meio com a presença de oxigênio e de DPPH. 

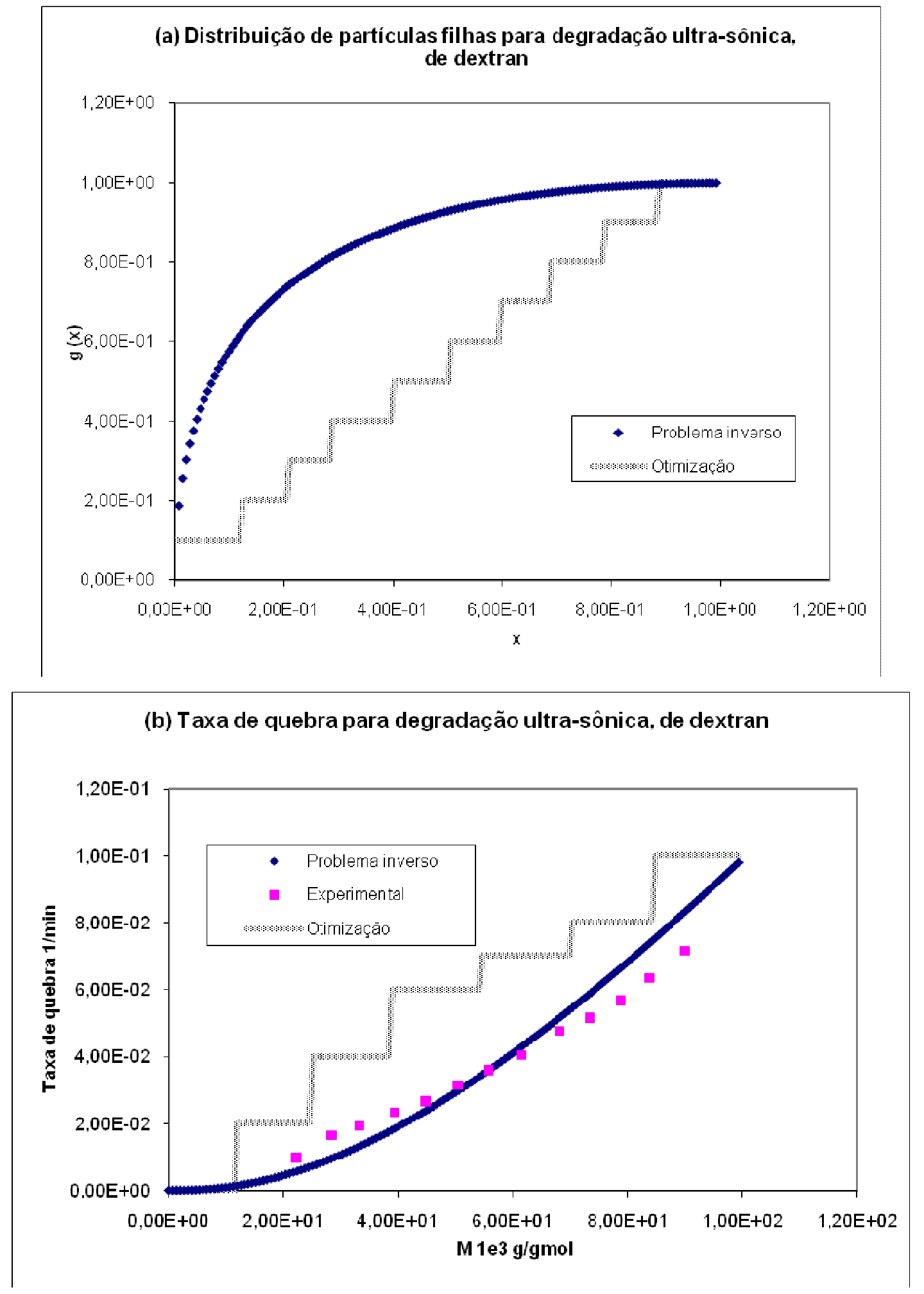

Figura 4.6.4: Cálculo por meio de otimização da (a) distribuição de partículas filhas e (b) da taxa de quebra para degradação ultrassônica de dextrana. 
Podemos observar das figuras 4.6.3 e 4.6.4, que a otimização segue de maneira similar o formato funcional das taxas e das distribuições de partículas filhas obtidas anteriormente pelo algoritmo do problema inverso.

As distribuições obtidas com estes novos parâmetros ficaram diferentes das anteriormente obtidas porém, são próximas aos valores das distribuições calculadas pelo problema inverso neste trabalho, como podemos ver pela figura 4.6.5.
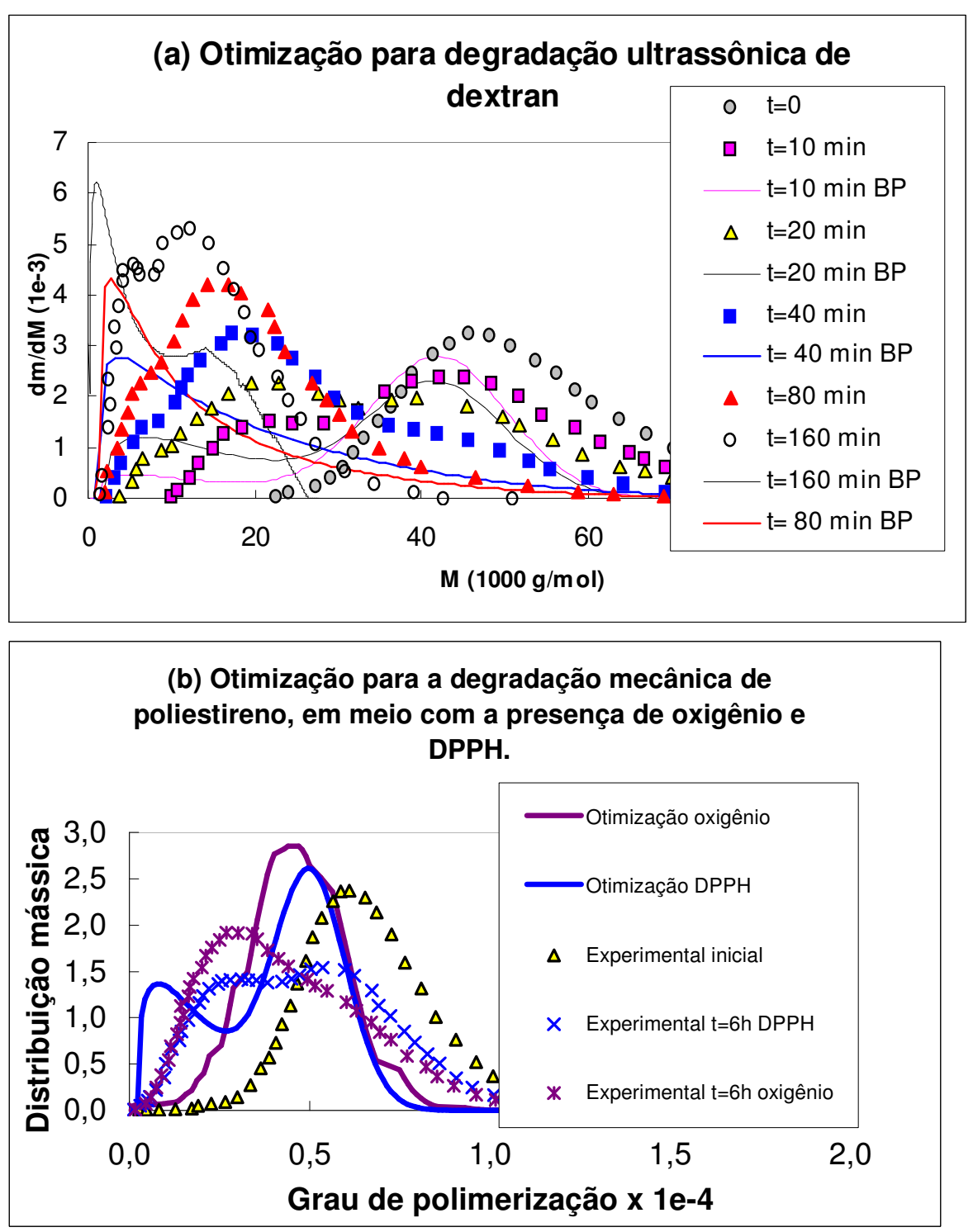

Figura 4.6.5: Distribuições obtidas pela otimização para: (a) quebra ultra-sônica de dextrana, e, para (b) degradação mecânica de poliestireno, em meio com a presença de DPPH, e, oxigênio. 

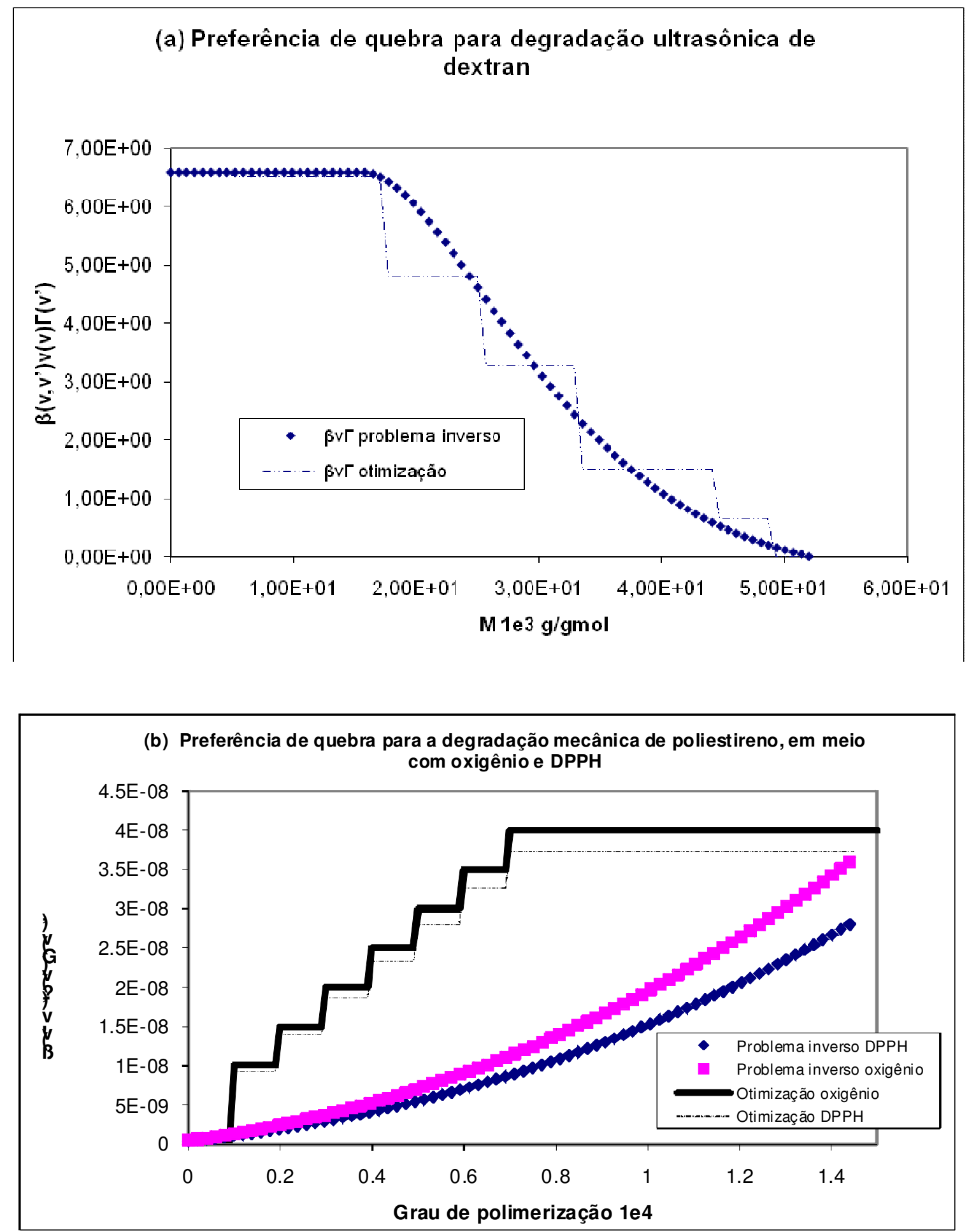

Figura 4.6.6: (a) resultados da preferência de quebra para a otimização na degradação ultrassônica de dextrana, e (b) na degradação mecânica de poliestireno, em meio com oxigênio e DPPH. 
Comparando as duas formas de quebra estudadas neste item, por degradação mecânica (cisalhamento) e por ultrassom, podemos notar que o formato das curvas de preferência de quebra difere bastante do ponto de vista qualitativo. No caso da degradação ultrassônica, a função de preferência é decrescente com o tamanho da cadeia, e no caso da degradação mecânica por cisalhamento a função de preferência de quebra é crescente (cadeias maiores quebram mais facilmente).

Com relação à preferência de quebra, calculada, podemos notar que pela figura 4.6.6 (a), a quebra preferencial para degradação de ultrassônica de dextrana é muito semelhante à calculada pelo problema inverso. Na degradação mecânica de poliestireno, na figura 4.6.6 (b), vemos que a preferência de quebra é a mesma, porém com mais intensidade nas partículas maiores para a simulação de otimização do que para a solução do problema inverso. 


\section{CONCLUSÕES.}

A aplicação da metodologia do problema inverso de balanço populacional, desenvolvido originalmente na literatura para sistemas de quebra de gotas em emulsões líquido-líquido (distribuição de tamanhos de gotas), foi aplicado no presente trabalho para diferentes sistemas de degradação de polímeros (distribuição de tamanhos de cadeias, ou distribuição de massas molares).

Pela análise dos resultados obtidos no trabalho, podemos tirar determinadas conclusões.

O problema inverso permite obter soluções para os casos em que as curvas de quebra são suaves e crescentes, curvas com "concavidade para cima", isto é, com derivada segunda positiva. Isso se encaixa na maioria dos casos. Porém existem situações limites em que para determinado tamanho de moléculas há uma descontinuidade, não ocorrendo quebra para moléculas menores que um dado limite, como foi o caso da degradação ultrassônica de dextrana. Mas mesmo neste caso a curva de taxa de quebra obtida pelo problema inverso representou bem, quantitativamente, o comportamento descrito na literatura.

A combinação adequada dos resultados de taxa de quebra e de distribuição de filhas permite calcular uma função que descreve a preferência de quebra ao longo do comprimento da cadeia polimérica ou em função do seu tamanho. No caso da degradação radicalar de cadeias lineares de polipropileno, o resultado obtido concordou muito bem com o comportamento mecanistico bem conhecido da literatura de que esta quebra se dá aleatóriamente (randomicamente) em qualquer posição da molécula, já que o ataque do radical livre que provoca a quebra não é seletivo.

No caso da hidrólise ácida de dextrana, o resultado aponta para uma quebra mais frequente nas regiões das "pontas" da cadeia do que no "meio" das moléculas poliméricas. A interpretação deste resultado passa pela consideração da presença de ramificações neste polímero, em conjunto do um ataque aleatório, como seria esperado pela química deste processo de degradação.

Também verificamos convergência entre o problema inverso e o Monte Carlo. Esta é uma abordagem probabilística não parametrizada para um caso em que as cadeias são lineares, e existe predominância de quebra. 
Verificamos que, para degradação ultrassônica de dextrana, a quebra é preferencial em cadeias menores, visto que, em cadeias maiores ocorre dissipação da energia ao longo da cadeia. Ao contrário da degradação mecânica (por cisalhamento), em que a quebra de cadeias maiores é favorecida.

Alguns dados preliminares de distribuições de peso molecular do polímero durante o processo de degradação devem ser obtidos para se obter as taxas cinéticas de quebra e, a partir deste resultado, calcular o seu comportamento ao longo do tempo. O intuito é com dados experimentalmente obtidos fazer uma espécie de regressão para encontrar as constantes ideais para representar esse processo cinético, e verificar que sejam consistentes com os mecanismos de degradação envolvidos. As funções cinéticas relacionadas ao polímero, obtidas deste problema inverso, devem estar relacionadas com os mecanismos físico-químicos envolvidos nessa reação. Assim, a metodologia aqui estudada é útil para se interpretar e inferir os possíveis mecanismos envolvidos no processo de degradação. Por exemplo a regressão mostrou que a quebra das cadeias pode apresentar uma tendência não específica (aleatória), ou então uma preferência para determinados locais específicos da molécula, como as suas bordas ou o centro.

Foi verificada, em maiores detalhes, a validade das taxas parametrizadas. Em algumas situações observou-se, como por exemplo na degradação ultrassônica de dextrana e na degradação mecânica de poliestireno, os resultados não aparentavam ser coerentes. Para esses casos foi possível um pequeno ajuste adicional das funções dinâmicas (via ajuste manual, tentativa e erro), através do qual se conseguiu obter resultados mais coerentes e mais próximos dos dados experimentais. Em muitos estudos, como o realizado por COOPER et al. (2010), já se sabe que às vezes um ajuste manual combinado com uma ajuda computacional pode nos resultar em soluções muito melhores e coerentes, como foi analisado neste trabalho.

Por fim, verificou-se que a degradação foi adequadamente modelada por meio da teoria envolvendo o balanço populacional de quebra para os casos estudados.

Em geral a metodologia aqui estudada é potencialmente aplicável para uma ampla gama de problemas de sistemas particulados (fragmentação, moagem, formação de aerossóis por explosão,etc.) e de sistemas poliméricos além dos aqui estudados. 
Para trabalhos futuros recomenda-se utilizar uma abordagem mais abrangente que admita uma cinética de segunda ordem na fragmentação, como a proposta por BRAUMANN; MAN; KRAFT (2010), o que permitiria estudar sistemas mais complexos, não apenas com quebra de partículas, e sim com a inclusão de outros fenômenos. 


\section{REFERÊNCIAS BIBLIOGRÁFICAS}

Andersson R., Andersson B., Modeling the breakup of fluid particles in turbulent flows, A.I.Ch.E. Journal, 52, 2031-2038 (2006).

Aquino, F.W.B., Franco, D.W., Dextranas em açúcares do estado de São Paulo, Química Nova, 31(5), 1034-1037 (2008).

Austin L. G., A review: Introduction to the mathematical description of grinding as a rate process, Powder Technology, 5, 1-17 (1971).

Attarakih M. M., Bart H. J., Faqir N. M., Solution of the droplet breakage equation for interacting liquid-liquid dispersion: A conservative discretization approach, Chemical Engineering Science., 59, 2247-2565 (2004).

Ballauf M., Wolf B.A., Degradation of chain molecules. II - Thermodynamically induced shear degradation of dissolved polystyrene, Macromolecules, 17, 209-216 (1984).

Baltensperger U., Aerosols in clearer focus, Science, 329(5998), 1474-1475 (2010).

Basedow A. M., Ebert K. H., Ultrasonic degradation of polymers in solution, Advances in Polymer Science, 22, 83-148, (1977).

Basedow A. M., Ebert K. H., Ederer H. J., Kinetic studies on the acid hydrolysis of dextrana., Macromolecules, 11, 774-781 (1978).

Basedow A. M., Ebert K. H., Zum Mechanismus des Abbaus von Polymeren in Lösung durch Ultraschall., Die Makromolekulare Chemie, 176, 745-757 (1975).

Bass L., Theorie der Mahlvorgänge., Z. Angew. Maths. Phys., 5, 283-292 (1954).

Braumann A., Man P. L.W., Kraft M., Statistical approximation of the inverse problem in multivariate population balance modeling, Ind. Eng. Chem. Res., 49, 428-438 (2010).

Becher P., Encyclopedia of emulsion technology., Volume 1, Marcel Dekker., New York., N.Y., (1983).

Bennett J. G., Brown R. L., Crone H. G., Broken coal - II, Journal of The Institute of Fuel, 111-128 (1941). 
Bennett J. G., Broken Coal., Journal of The Institute of Fuel., 10, 34, (1936).

Berthiaux H., Varinot C., Dodds J., Approximate calculation of breakage parameters from batch grinding tests, Chemical Engineering Science, 51(19), 4509-4516 (1996).

Berthiaux H., Dodds J., A new estimation technique for the determination of breakage and selection parameters in batch grinding, Powder Technology, 94, 173-190, (1997).

Bilgili E., On the Consequence of non-first-order breakage kinetics in comminution processes: absence of self-similar size spectra, Particles and Particles System Characterization, 24, 12-17 (2007).

Bockhorn H., Hornung A., Hornung U., Schwaller D., Kinetic Study on thermal degradation of polypropylene and polyethylene., Journal of Analytical and Applied Pyrolysis, 48, 93-109 (1999).

Bove S., Solberg T., Hjertager B. H., A novel Algorithm for solving population balances equations: The parallel parent and daughter classes. Derivation analysis and testing, Chem. Eng. Sci., 60, 1449-1464 (2005).

Brown D. L., Glatz C. L., Aggregate breakage in protein precipitation, Chem. Eng. Sci., 42, 1831-1839 (1987).

Canu P., Prediction of multimodal distribution in breakage processes, Ind. Eng. Chem. Res., 44, 2649-2655 (2006).

Chakraborty J., Kumar S., A new framework for solution of multidimensional population balance equations., Chemical Engineering Science, 62(15), 4112-4125 (2007).

Chatzi E. G., Gavrielides A. D., Kiparissides C., Generalized model for prediction of the steady state drop size distribution in batch stirred vessels, Industrial Engineering Chemistry Research, 28, 1704-1711 (1989).

Chen Z., Pruss J., Warnecke H. J., A population balance model for disperse systems: Drop size distribution in emulsion, Chemical Engineering Science., 53, 1059-1066 (1998).

Claude J., Ubbink J., Thermal degradation of carbohydrate polymers in amorphous states: A physical study including colorimetry, Food Chemistry., 96, 402-410 (2006). 
Cooper S., Khatib F., Treuille A., Barbero J., Lee J., Beenem M., Leaver-Fay A., Baker D., Popovic Z., Predicting protein structures with a multiplayer online game, Nature: Letter, Volume 466, 5, 756-760 (2010).

Coulaloglou C. A., Tavlarides L. L., Description of interaction processes in agitated liquidliquid dispersions, Chem. Eng. Sci., 32, 1289 - 1297, (1977).

Cullum J., Numerical differentiation and regularization, S. I. A. M. J. Numer. Anal. 8, 254 (1971).

Cutter L. A., Flow and turbulence in a stirred tank, A.I.Ch.E. Journal., 12, 34 (1966).

Delichatsios M. A., Model for the breakup rate of spherical drops in isotopic turbulent flows, Phys. Fluids, 18, 622 (1975).

Delichatsios M. A., Probstein R. R., The effect of coalescence on the average drop size in liquid-liquid dispersions, Ind. Chem. Fundam., 15, 134 (1976).

Delves L. M., Mohamed J. L., Computational Methods for integral equations, Cambridge University Press, London (1987).

Diemer R. B., Olson J. H., A moment methodology for coagulation and breakage problems: Part III - Generalized daughter distribution functions, Chemical Engineering Science., 57, 4187-4198 (2002).

Dudukovik M. P., Larachi F., Mills P. L., Multiphase reactors - Revisited, Chemical Engineering Science, 54, 1975-1995 (1999).

Eastwood C. D., Armi L., Lasheras C. A., The breakup of immiscible fluids in turbulent flows., Journal of Fluid Mechanics, 502, 309-333 (2004)

Ebert H. K., Ederer H. J., Basedow A. M., Effects of Long-Chain Branches on the Degradation Kinetics of Polymers. Angewandte Chemie International Edition in English, 18, 321-322 (1979).

Ederer H. J., Basedow A. M., Ebert K. H., Modeling of polymer degradation reactions, IN Modeling of Chemical Reaction Systems (Proceedings of an International Workshop, Heidelberg, Germany, September 1-5, 1980), Eds. K.H.Ebert, P. Hdeuflhard, W. Jager, Springer-Verlag, Berlin, Germany, pp. 189- 215 (1981) 
Epstein B., Logarithmic-normal distribution in breakage of solids, Ind. Eng. Chem., 40, 2289 (1948).

Filippov A. F., On the distribution of the sizes of particles which undergo splitting., Theory Prob. Applic., 6 , 275-294 (1961).

Flagan R. C., Friedlander S. K., Combustion - A review. Recent development in aerosol science. D. T. Shaw, ed. Wiley. New York, 25-29 (1978).

Floury J., Belletre J., Legrand J., Desrumax A., Analysis of a new type of high pressure homogenizer: A study of the flow pattern. Chemical Engineering Science, 59(4), 843-853 (2004a).

Flory J., Legrand J., Desrumax A. Analysis of new type of high pressure homogenizer. Part B: Study of the droplet break-up and recoalescence phenomena, Chemical Engineering Science, 59, 6, 1285-1294 (2004b).

Fuchs N. A., Mechanics of aerosols., Pergamon., New York. (1964).

Fukusawa T., Adachi Y., Effect of flock structure on the rate o Brownian coagulation, Journal of Colloid and Interface Science, 304, 115-118 (2006).

Friedlander S. K., Wang C. S., High speed beams of small particles, J. Coil. Interface Sci., 24, 170, (1967).

Friedlander S. K., Smoke. Dust and Haze: Fundamentals of Aerosol Behavior, Wiley., New York. (1977).

Gaudin A. M., Meloy T. P., Model and a comminution distribution equation for repeated fraction, Trans. Am. Inst. Min. Engrs., 223, 401 (1962).

Gelbard F., MAEROS user manual., doc. no. NUREG/CR - 1931, SAND80 - 0822., Sandia National Laboratory., Albuquerque., New Mex. (1982).

Giudici, R.; Hamielec, A.E., A simulation study on random scission of branched chains". Polymer Reaction Engineering, 4(1), 73-101 (1996).

Gelbard F., Peterson T. W., Extensions of generalized method for simulating multicomponent particle dynamics: Applications to fragmenting particles., Submetido ao: Chemical Engineering Science, (1985). 
Glynn P. A. R., Van der hoff B. M. E., Reilly P. M., A general model for prediction of molecular weight distributions of degraded polymers, development and comparisons with ultrasonic degradation experiments., J. Macromol. Sci.- Chem., A6, 8, pp. 1653-1664, (1972).Goncarskii A. V., Jagola A. G., Uniform approximation of monotonic solutions of noncorrect problems., Soviet Mathematics Doklady, 3, 981-983 (1962).

Hagesaether L., Jakobsen H. A., Svendsen H. F., Modeling of the dispersed-phase size distribution in bubble columns., Industrial Engineering Chemistry Research, 41, 2560-2570 (2002).

Hamielec, A. E.; Gloor, P. E.; Zhu, S., Kinetics of, free radical modification of polyolefins in extruders - chain scission, crosslinking and grafting. Can. J. Chem. Eng. 69, 611-618 (1991).

Henson M. A., Malone F. M., Bhatia R. S., Raikar N. B., Self-similar population balance modeling for turbulently prepared batch emulsions: Sensitivity to measurement errors, Chemical Engineering Science, 61, $7421-7435$ (2006).

Hesketh R. P., Etchells A. W., Russell T. W. F., Bubble breakage in pipeline flow., Chemical Engineering Science, 46, 1-9 (1991).

Hoyer D. I., Batch grinding simulation - population balance models and self-similar size distributions, Minerals Engineering, 8(11), 1275-1284 (1995).

Ivanov V. K., On linear problems which are not well-posed, Soviet Mathematics Doklady, 10, 155-157 (1969).

Kapur P. C., A similarity solution to an integro-differential equation describing batch grinding, Chemical Engineering Science, 25, 899 (1970).

Kapur P. C., Self-Preserving spectra of comminuted particles, Chemical Engineering Science., 27, 425 (1972).

Karthikeyan S., Sijbesma P. R., Ultrasound can be used to control molecular processes as delicate as rotation around a single carbon-carbon bond, Nature Chemistry, 2, 436437 (2010). 
Kerstein A. R., Niksa S., Fragmentation during char conversion: Predictions and measurements, $20^{\text {th }}$ Int. Symposium on Combustion, Ann Arbor, Michigan, Aug. 12-17. (1985).

Kerstein A. R., Prediction of the critical porosity for char fragmentation during combustion or gasification, Int. Conf. on Coal Science, Pittsburg, Aug. (1983).

Koda S., Mori H., Matsumoto K., Nomura H., Ultrasonic degradation of water-soluble polymers., Polymer., 35(1), 30-33 (1994).

Konno M., Aoki M., Saito S., Scale effect on breakup process in liquid-liquid agitated tanks, J. Chem. Eng. Japan, 16, 312-319 (1983).

Kostoglou M., Karabelas A. J., A contribution towards predicting the evolution of droplet size distribution in flowing dilute liquid-liquid dispersions, Chemical Engineering Science, 56, 4283-4292 (2001).

Kostoglou M., Karabelas A. J., On the self-similar solution of fragmentation equation: Numerical evaluation with implications for the inverse problem, Journal of Colloid and Interface Science, 284, 571-581 (2005).

Kostoglou M., Karabelas A. J., Toward unified framework for the derivation of breakage of functions based on the statistical theory of turbulence, Chemical Engineering Science, 60(23), 6584-6595 (2005).

Kotoulas C., Kiparissides C., A generalized population balance model for the prediction of particle size distribution in suspension polymerization reactors. Chemical Engineering Science. 61, 332-346,(2006).

Kumar S., Ramkrishna D., On the solution of the population balance equations by discretization - I. A fixed pivot technique. Chemical Engineering Science. 51, 1311-1332 (1996).

Lasheras J. C., Eastwood C., Martinez-Bazan C., Montanes J. L., A review of statistical models for the break-up of an immiscible fluid immersed into a fully developed turbulent flow, International Journal of Multiphase Flow, 28, 247-278 (2002). 
Luo G. S., Li H. B., Tang S. J., Wang J. D., Drop breakage in a coalescence-dispersion pulsed-sieve plate extraction column, Chemical Engineering Journal, 102, 185-191 (2004).

Luo H., Svendsen H. F., A theoretical model for drop for bubble breakup in turbulent dispersions, A.I.Ch.E. Journal, 42, 1225 (1996).

Lushnikov A. A., Evolution of coagulation system, J. Colloid Interface Sci., 45, 549 (1973).

MacLoughlin P. F., O’Rourke M. A., A study of drop breakage in lean dispersions using the inverse-problem method, Chemical Engineering Science., 65(1), 3681-3694 (2010).

Madden A. J., McCoy, B. J., Drop size in stirred liquid-liquid system via encapsulation, Chem. Eng. Sci., 24, 416, (1969).

Madras G., Smith J. M., McCoy J. B., Effect of tetralin on the degradation of polymer in solution, Ind Eng. Chem Res., 34(12), 4222-4228 (1995).

Madras G., McCoy B. J., Numerical and similarity solutions for reversible population balance equations with size-dependent rates, Journal of Colloid and Interface Science., 246, 356-365, (2002).

Madras, G., Karmore, V. , Continuous distribution kinetics for ultrasonic degradation of poly(methyl methacrylate), Polymer International, 50, 683-687 (2001).

Malmsten M., Surfactants and polymers in drug delivery, Marcel Dekker., Inc. New York., (2002)

Marti-Mestres G., Nielloud F., Emulsions in health care applications - an overview., Journal of dispersion science and technology., 23(1-3), 419-439 (2002).

Martinez-Bazan C., Montanes J. L., Laceras J. C., On the breakup of an air bubble injected into a fully developed turbulent flow. Part I. Breakup frequency, Journal of fluid Mechanics., 401, 157-182 (1999a). 
Martinez-Bazan C., Montanes J. L., Laceras J. C., On the breakup of an air bubble injected into a fully developed turbulent flow. Part II. Size PDF of the resulting daughter bubbles, Journal of fluid Mechanics, 401, 183-207 (1999b).

Massimo P., Alessandro C., Giacomo C., A novel simulation model for stem cells differentiation, Journal of Biotechnology, 130, 171-182, (2007).

McCoy J. B., Madras G., Effect of hydrogen donors on polymer degradation, Catalysis Today, 40, 321-332 (1998).

Sterling J. W., Walline K. S., McCoy B. J Experimental study of polystyrene thermolysis to moderate conversion., Polymer Degradation and Stability, 73(1), 75-82 (2001).

Muralidhar R., Ramkrishna D., Inverse problems of agglomeration kinetics: II binary clustering from self - preserving spectra, J. Coil. Interface Sci., 131, 503 (1989).

Nambiar D. K. R., Kumar R., Das T. R., Gandhi K. S., A new model for the breakage frequency of drops in turbulent stirred dispersions, Chemical Engineering Science, 47, 2989-3002 (1992).

Nambiar D. K. R., Kumar R., Das T. R., Gandhi K. S., A two zone model of breakage frequency of drops in stirred dispersions, Chemical Engineering Science, 49, 21942198 (1994).

Narsimham G., Ramkrishna D., Gupta J. P., A model for transitional breakage probability of droplets in agitated lean liquid-liquid dispersions, Chemical Engineering Science, 34, 257-265 (1979).

Nielloud F., Marti-Mestres G., Pharmaceutical emulsions and suspensions, Marcel Dekker, Inc., New York., NY. (2000).

Nopens I., Beheydt D., Vanrolleghem P. A., Comparison and pitfalls of different discretized solution for population balance models: A simulation study, Chemical Engineering Science, 29, 367-377 (2005).

Patruno L. E., Dorao C. A., Svendsen H. F., Jakobsen H. A., Analysis of breakage kernels for population balance modeling, Chemical Engineering Science, 64, 501-508 (2009). 
Peterson T. W., Scotto M. V., Sarofim A. F., Comparison of comminution data to analytical solutions of the fragmentation equation, Powder Technology, 45(1), 87-93 (1985).

Peterson T. W., Similarity solutions for the population balance equation describing particle fragmentation, Aerosol Sci. Technol., 5, 93 (1986).

Qamar S., Warnecke G., Numerical solution of population balance equations for nucleation, growth and aggregation processes, Computers and Chemical Engineering, 31, 15761589 (2007).

Rao V. B., Datta A., Analysis of nonlinear batch grinding in stirred media mills using selfsimilarity solution, Powder Technology, 169, 41-48 (2006).

Ramkrishna D., Amundson N. R., Linear operator methods in chemical engineering, Prentice-Hall, Englewood Cliffs, New Jersey (1985).

Ramkrishna D., Drop-breakage in agitated liquid-liquid dispersions, Chemical Engineering Science, 29, 987-992 (1974).

Ramkrishna D., Mahoney A. W., Population balance modeling. Promise for the future, Chemical Engineering Science, 57, 595-606 (2002).

Ramkrishna D., Narsimham G., Gupta, P. J., Analysis of Drop Size Distribution in Lean Liquid-Liquid Dispersions, A.I.Ch.E. Journal, 26(6), 991-999 (1980).

Ramkrishna D., Narsimham G., Nejfelt G. N., Breakage Functions for Droplets in Agitated Liquid-Liquid Dispersions, A.I.Ch.E. Journal, 30(3), 457-467 (1984).

Ramkrishna D., Narsimham G., Sathyagal A. N., Droplet breakage in stirred dispersions breakage functions from experimental drop size distributions, Chemical Engineering Science., 51(9), 1377-1391 (1996).

Ramkrishna D., Narsimham G., Sathyagal A. N., Solutions of inverse problems in population balances. II - Particle breakup, Chemical Engineering Science, 19(4), 437-451 (1995).

Ramkrishna D., Nere N. K., Evolution of drop size distribution in fully developed turbulent pipe flow of a liquid-liquid dispersion by breakage, Ind. Eng. Chem. Res., 44, $1187-$ 1193 (2005). 
Ramkrishna D., Population balances theory and applications to particulate systems in engineering, Academic Press. (2000).

Ramkrishna D., Shah B. H., A population balance model for mass transfer in lean liquidliquid dispersions, Chemical Engineering Science, 28, 389-399 (1973).

Ramkrishna D., Wright H., Solutions of inverse problems in population balances I Agregation Kinetics, Chemical Engineering Science, 16(12), 1019-1038 (1992).

Reid K. J., A solution to the batch grinding equation, Chemical Engineering Science., 20, 953-963 (1965).

Ribeiro L. M., Regueiras P. F. R., Guimarães M. M. L., Madureira C. M. N., Cruz-Pinto J. J. C., The dynamics behavior of liquid-liquid agitated dispersions - I. The hydrodynamics, Computers and Chemical Engineering, 19, 333-343 (1995).

Rocha M. C. G., Coutinho F. M. B., Balke S. T., Controlled degradation of polypropylene, I, $2^{\circ}$ SIAP, $4^{\circ}$ SLAP, $6^{\circ}$ IMC, $783-785$ (1994).

Ross S. L., Measurements and models of the dispersed phase mixing process, $\mathrm{Ph}$. D. Thesis, University of Michigan, Ann Arbor., (1971).

Ruiz M. C., Padilla R., Analysis of breakage function for liquid-liquid dispersions, Hydrometallurgy, 72, 245-258 (2004).

Rumscheidt F. D., Mason S. G., Break-up of stationary liquid threads, J. Colloid Sci., 17, 260-269 (1962).

Sathyagal A. N., Ramkrishna D., Narsimham G., Solution of the inverse problems in population balances II: Particle break-up, Computers \& Chemical Engineering, 19(4), 437-451 (1995).

Sedlatschek K., Bass L., Contribution to the theory of milling processes, Powder Metall. Bull., 6, 148-153 (1953).

Silverman B. W., Density estimation for statistics and data analysis, London, Chapman \& Hall (1986). 
Smith W. B., Temple H. W., Polymer studies by gel permeation chromatography. IV. The degradation of polystyrene by ultrasonics and by benzoyl peroxide, J. Phys. Chem. 72(13), 4613-4619 (1968).

Soon S., Harbidge J., Tichener-Hooker N., Shamlou P., Prediction of drop breakage in a ultra high velocity jet homogenizer, Journal of Chemical Engineering of Japan, 34(5), 640-646 (2001).

Staggs J. E. J., Population Balance Models for the thermal degradation of PMMA, Polymer, 48(13), 3868-3876 (2007)

Staggs J. E. J., A continuous model for vaporization of linear polymers by random scission and recombination, Fire Safety Journal., 610-627 (2005).

Stone H. A., Leal L. G., Relaxation and breakup of an initially extended drop in an otherwise quiescent fluid, J. Fluid. Mech., 198, 399-427 (1989).

Sundback C. A., Beer J. M., Sarofim A. F., Fragmentation behavior of single coal particles in fluidized bed., $20^{\text {th }}$ Int. Symposium on Combustion, Ann Arbor, Michigan, Aug. 12-17 (1984).

Swift D. L., Friedlander S. K., The coagulation of hydrosols by Brownian motion and laminar shear flow, J. Colloid Sci., 19(7), 621-647 (1964).

Teymour F., Campbell J. D., Analysis of the Dynamics of Gelation in Polymerization Reactors Using the Numerical Fractionation Technique, Macromolecules, 27(9), 2460-2469 (1994).

Tikhonov A. N., Arsenin V. Y., Solutions of ill-posed problems, V. H. Winston and Sons, Washington (1977).

Tjahjadi M., Stone H. A., Ottino J. M., Satellite and sub-satellite formation in capillary breakup, J. Fluid Mech., 243, 297-317 (1992).

Tobin T. G., Experimental measurement of drop coalescence frequencies in turbulent liquid-liquid dispersions, M. S. Thesis, Purdue University, W. Lafayette (1989). 
Tobita H., Simultaneous long-chain branching and random scission: I. Monte Carlo simulation. Part B: Polymer Physics, Journal of Polymer Science, 39, 391-403 (2001).

Tobita H., Simulation model for the modification of polymers via crosslinking and degradation, Polymer, 36(13), 2585-2596 (1995).

Tobita H., Molecular weight distribution of living radical polymers II. Monte Carlo Simulation, Macromolecular Theory and Simulations, 15, 23-31 (2006).

Triacca, V. J.; Gloor, P. E.; Zhu, . S. ; Hrymak, A. N., Hamielec, A. E., Free radical degradation of polypropylene: Random chain scission, Polym. Eng. Sci. 33(8), 445454 (1993).

Tsouris C., Tavlarides L. L., Breakage and coalescence models for drops in turbulent dispersions, A.I.Ch.E. Journal, 40, 395-406 (1994).

Valentas K., Amundson N. R., Breakage and coalescence in dispersed phase systems, Industrial Engineering Chemistry Fundamentals, 5, 533-542 (1966).

Valentas K., Bilous O., Amundson N. R., Analysis of breakage in dispersed phase systems, Ind. Eng. Chem. Fundam., 5, 271 (1966).

Van Dongen P. G. J., Ernest M. H. J., Upper critical dimension in irreversible aggregation, Stat. Phys., 50, 295 (1988).

Vassileva N. D., Van Den Ende D., Mugele F., Mellema J., Fragmentation and erosion of two-dimensional aggregates is shear flow, Langmuir, 23, 2352-2361 (2007).

Vikhansy A., Kraft M., Simon M., Schmiddt S., Bart H. J., Droplets population balance in a rotation disc contactor: An inverse problem approach, A.I.Ch.E. Journal, 52(4), 1441-1450 (2005).

Wahba G., Practical approximate solutions to linear operator equations when the data are noisy, S. I. A. M. J. Numer. Anal., 14, 651-667 (1977).

Walstra P., Principles of emulsion formation, Chemical Engineering Science, 48(2), 333349 (1993). 
Wright H., Muralidhar R., Tobin T., Ramkrishna D., Inverse problems of aggregation processes, J. Stat. Phys., 61(3-4), 843 (1990).

Williams M. C., Meloy T. P., Tarshan M., Assessment of numerical solution approaches to the inverse problem for grinding systems: Dynamic population balance model problems, Powder Technology, 78, 257- 261 (1994).

Williams M. C., Meloy T. P., Population balance models and self-similar size distributions, Minerals Engineering, 10(2), 189-198 (1997).

Wu C. B., Sheth P. J., Johson J. F., Ultrasonic degradation of poly (methyl methacrylate), Polymer, 18(8), 822-824 (1977). Yang J., A distribution approach for polymer crystallization and phase separation, $\mathrm{Ph}$ D. Thesis, Louisiana State University (2006).

Zhang S., Jin J., Computational of special functions, Wiley-Inter Science, New York (1996).

Ziff R. M., Ernest M. H., Hendriks E. M., Dynamic scaling in the kinetics of clustering, Phys. Rev. Lett. 54, 1396-1399 (1985)

Ziff R. M., McGrady E. D., Meakin P., On the viability of Smoluchowski's equation for cluster-cluster aggregation kinetics, J. Chem. Phys., 82, 5269 (1985).

Ziff R. M., McGrady E. D., Shattering transition in fragmentation, Physical Review Letters, 58, 892-895 (1987).

Ziff R. M., New solutions to the fragmentation equation, J. Phys., A Math. Gen. 24, 28212828 (1991). 


\section{APÊNDICE A: ADIMENSIONALIZAÇÃO DA DISTRIBUÇÃO DE PARTÍCULAS.}

A quebra, ou, fragmentação pode ser descrita geralmente pela seguinte equação parcial diferencial integral:

$\frac{d \hat{n}(\widehat{v}, \widehat{t})}{d \widehat{t}}=-\widehat{\Gamma}(\widehat{v}) \widehat{n}(\widehat{v}, \widehat{t})+\int_{v}^{\infty} \widehat{\beta}\left(\widehat{v}, \widehat{v}^{\prime}\right) \widehat{v}\left(\widehat{v}^{\prime}\right) \widehat{\Gamma}\left(\widehat{v}^{\prime}\right) \widehat{n}\left(\widehat{v}^{\prime}, \widehat{t}\right) d \widehat{v}^{\prime}$

Onde $\widehat{t}$ é tempo, $\widehat{v}$ é tamanho de partícula, $\widehat{n}(\widehat{v}, \widehat{t})$ é número de densidade da partícula, $\widehat{\Gamma}(\widehat{v})$ é a taxa de quebra, e $\widehat{\beta}\left(\widehat{v}, \widehat{v}^{\prime}\right) \widehat{v}\left(\widehat{v}^{\prime}\right)$ é a probabilidade de distribuição de partículas de volume $\widehat{v}$ resultantes da quebra de partículas de volume $\widehat{v}^{\prime}$, e $\widehat{n}_{0}=\widehat{n}(\widehat{v}, 0)$ a distribuição inicial. O volume total de concentração, o número total de concentração e o tamanho médio da distribuição inicial serão.

$$
\begin{aligned}
& \widehat{V}_{T}=\int_{0}^{\infty} v \widehat{n}_{0}(v) d v \\
& \widehat{N}_{0}=\int_{0}^{\infty} \widehat{n}_{0}(v) d v \\
& \widehat{u}_{0}=\frac{\widehat{V}_{T}}{\widehat{N}_{T}}
\end{aligned}
$$

As funções e variáveis já definidas acima podem ser adimensionalizadas como:

$$
\begin{aligned}
& v=\frac{\widehat{v}}{\widehat{u}_{0}}, \quad v^{\prime}=\frac{\widehat{v}^{\prime}}{\widehat{u}_{0}}, \quad t=\widehat{\Gamma}\left(\widehat{u}_{0}\right) \widehat{t} \\
& n(v, t)=\frac{u_{0} \widehat{n}(\widehat{v}, \widehat{t})}{\widehat{N}_{0}}, \quad \Gamma(v)=\frac{\widehat{\Gamma}(\widehat{v})}{\widehat{\Gamma}\left(\widehat{u}_{0}\right)} \\
& \beta\left(v, v^{\prime}\right) v\left(v^{\prime}\right)=\frac{\widehat{\beta}\left(\widehat{v}, \widehat{v}^{\prime}\right) \widehat{v}\left(\widehat{v}^{\prime}\right)}{\widehat{u}_{0}}
\end{aligned}
$$

Reescreveremos a equação (A.1) como:

$$
\frac{d n(v, t)}{d t}=-\Gamma(v) n(v, t)+\int_{v}^{\infty} \beta\left(v, v^{\prime}\right) v\left(v^{\prime}\right) \Gamma\left(v^{\prime}\right) n\left(v^{\prime}, t\right) d v^{\prime}
$$

A expressão (A.6) é o balanço de quebra na forma não dimensionalizada ou adimensional. 


\section{APÊNDICE B: COMPORTAMENTO ASSINTÓTICO DA DISTRIBUIÇÃO DE PARTÍCULAS FILHAS.}

A equação da distribuição de similaridade pode ser reescrita da seguinte forma:

$$
\xi^{\prime}(\xi)=\gamma \int_{x}^{\infty} g\left(\frac{\xi}{\xi^{\prime}}\right) \xi^{\prime} f^{\prime}\left(\xi^{\prime}\right) d \xi^{\prime}
$$

Vamos trocar $\xi \mathrm{f}^{\prime}(\xi)$ por $\phi(\xi)$.

Em todos os dados experimentais, nós observamos que o comportamento da distribuição de similaridade para pequenos $\xi$ pode ser descrito por:

$\phi(\xi)=c \xi^{n}$

Onde c é uma constante. Nós estamos interessados em determinar o comportamento de $\mathrm{g}(\mathrm{x})$ para $\mathrm{x}<<1$, dado esse comportamento de $\phi(\xi)$ para pequenos $\xi$.

Deixaremos $\xi$ pertencer a região onde a equação (B.2) é viável, e definimos $\xi_{\mathrm{m}}$, de forma que:

$$
\xi_{m}(1-h)<\xi<\xi_{m} \quad, \quad h<<1
$$

A equação (B.1) pode ser escrita como:

$$
\phi(\xi)=\gamma \int_{\xi}^{\xi_{m}} g\left(\frac{\xi}{\xi^{\prime}}\right) \phi\left(\xi^{\prime}\right) d \xi^{\prime}+\gamma \int_{\xi_{m}}^{\infty} g\left(\frac{\xi}{\xi^{\prime}}\right) \phi\left(\xi^{\prime}\right) d \xi^{\prime}
$$

Para o primeiro termo do lado direito da equação (B.4), nós podemos expandir a função $\mathrm{g}(\mathrm{x})$ em uma série de Taylor em torno de $\mathrm{x}=1$ como:

$$
g(x)=1-g^{\prime}(1)(1-x)+\frac{g^{\prime \prime}(1)}{2}(1-x)^{2}+\cdots
$$

Desde que estamos lidando com valores pequenos de $\xi_{\text {e }} \xi_{\mathrm{m}}$, a equação (B.2) pode ser substituída no lado esquerdo e o primeiro termo do lado direito da equação (B.4). Essa equação pode então ser reescrita como:

$$
c \xi^{\mu}=c \gamma\left[\int_{\xi}^{\xi_{m}} \xi^{\prime \mu} d \xi^{\prime}-g^{\prime}(1) \int_{\xi}^{\xi_{m}}\left(1-\frac{\xi}{\xi^{\prime}}\right) \xi^{\prime \mu} d \xi^{\prime}+\frac{g^{\prime \prime}(1)}{2} \int_{\xi}^{\xi_{m}}\left(1-\frac{\xi}{\xi^{\prime}}\right)^{2} \xi^{\prime \mu} d \xi^{\prime}\right]+\cdots+\gamma \int_{\xi_{m}}^{\xi} g\left(\frac{\xi}{\xi^{\prime}}\right) \phi\left(\xi^{\prime}\right) d \xi^{\prime} \text { (B.6) }
$$

Essa equação pode ser diferenciada para que obtenhamos:

$$
c \mu \xi^{\mu-1}=-c \gamma\left[\xi^{m}-g^{\prime}(1) \int_{\xi}^{\xi_{m}} \xi^{\prime \mu-1} d \xi^{\prime}+g^{\prime \prime}(1) \int_{\xi}^{\xi_{m}}\left(1-\frac{\xi}{\xi^{\prime}}\right) \xi^{\prime \mu-1} d \xi^{\prime}\right]+\cdots+\gamma \int_{\xi_{m}}^{\infty} g^{\prime}\left(\frac{\xi}{\xi^{\prime}}\right) \frac{\phi\left(\xi^{\prime}\right)}{\xi^{\prime}} d \xi^{\prime} \text { (B.7) }
$$

Resolvendo as integrais indicadas teremos: 
$c \mu \xi^{\mu-1}=-c \gamma \xi^{m}\left[1-g^{\prime}(1)(h+\ldots)+g^{\prime \prime}(1)\left(\frac{h^{2}}{2}+\ldots\right)+\ldots\right]+\gamma \int_{\xi_{m}}^{\infty} g^{\prime}\left(\frac{\xi}{\xi^{\prime}}\right) \frac{\phi\left(\xi^{\prime}\right)}{\xi^{\prime}} d \xi^{\prime}$

Esta expressão (B.8) pode ser reescrita como:

$c \xi^{\mu-1}\{\mu+\gamma \xi[1+O(h)]\}=\gamma \int_{\xi_{m}}^{\xi} g^{\prime}\left(\frac{\xi}{\xi^{\prime}}\right) \frac{\phi\left(\xi^{\prime}\right)}{\xi^{\prime}} d \xi^{\prime}$

Utilizando $\xi=\xi_{\mathrm{m}}[1+\mathrm{O}(\mathrm{h})]$, nós podemos reescrever a expressão acima (B.9) como:

$c \xi^{\mu}+O(h)=\gamma \int_{\xi_{m}}^{\infty} g\left(\frac{\xi}{\xi^{\prime}}\right) \phi\left(\xi^{\prime}\right) d \xi^{\prime}$

Substituindo $\xi^{\mu}$ da equação (B.10) na equação (B.9) teremos:

$\gamma \int_{\xi_{m}}^{\infty} g\left(\frac{\xi}{\xi^{\prime}}\right) \phi\left(\xi^{\prime}\right) d \xi^{\prime}+O(h)=\gamma \frac{\xi}{\mu+\gamma \xi_{m}} \int_{\xi_{m}}^{\infty} g^{\prime}\left(\frac{\xi}{\xi^{\prime}}\right) \frac{\phi\left(\xi^{\prime}\right)}{\xi^{\prime}} d \xi^{\prime}$

Então, o comportamento percebido de $\mathrm{g}(\mathrm{x})$ pode ser determinado por:

$\gamma \int_{\xi_{m}}^{\infty}\left[\frac{1}{\xi^{\prime}} g^{\prime}\left(\frac{\xi}{\xi^{\prime}}\right)-\frac{\mu+\gamma \xi_{m}}{\xi} g\left(\frac{\xi}{\xi^{\prime}}\right)\right\rfloor \phi\left(\xi^{\prime}\right) d \xi^{\prime}=0$

Desde que a equação (B.12) foi dita que para todo $\xi$ do qual a equação (B.2) é válida, o integrando deve ser da mesma forma zero. Então:

$\frac{1}{\xi^{\prime}} g^{\prime}\left(\frac{\xi}{\xi^{\prime}}\right)-\frac{\mu+\gamma \xi_{m}}{\xi} g\left(\frac{\xi}{\xi^{\prime}}\right)=0$

Essa equação (B.13) pode ser resolvida de forma que obtenhamos o resultado:

$g(x)=c_{1} x^{\mu+\gamma_{m}^{*}}$

Desde que $\xi_{\mathrm{m}}$ é normalmente pequeno, pela seguinte escolha de $\xi_{\mathrm{m}}<<\mu / \gamma$, nós encontramos que o comportamento provável de $\mathrm{g}(\mathrm{x})$ é da seguinte forma: $g(x)=c_{1} x^{\mu}$

Experimentalmente os valores de $\mu$ que são encontrados do comportamento da distribuição de similaridade para baixos $\xi$ tem sido na faixa de $0.2-0.8$ e os valores de $\gamma$ tem sido da ordem de 1 . Desde que pequeno $\xi$, o comportamento da distribuição de similaridade

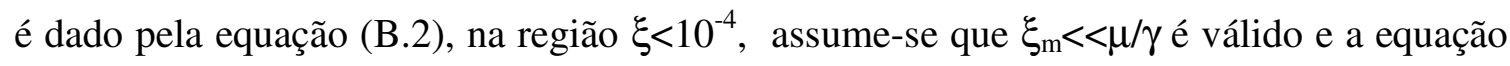
(B.15) portanto nos dá o provável comportamento da distribuição de partículas filhas.

Expressões analíticas da distribuição de similaridade podem ser determinadas da solução da equação (B.1) para duas formas particulares da função $g(x)$. Em ambos os casos, 
nós encontramos que a relação determinada pela análise acima entre o comportamento da distribuição de similaridade para valores pequenos de $\xi$ e o comportamento provável de $\mathrm{g}(\mathrm{x})$ e como apresentado.

Se $\mathrm{g}(\mathrm{x})=\mathrm{x}^{\mu}$, a equação (B.1) pode ser escrita como:

$$
\frac{\phi(\xi)}{\xi^{\mu}}=\gamma \int_{\xi}^{\infty} \frac{\phi\left(\xi^{\prime}\right)}{\xi^{\prime \mu}} d \xi^{\prime}
$$

Essa equação (B.16) pode ser resolvida com o intuito de obtermos:

$$
\phi(\xi)=c_{2} \xi^{\mu} \exp (-\gamma \xi)
$$

A constante $c_{2}$ pode ser determinada pela condição de normalização:

$$
\int_{0}^{\infty} \frac{\phi(\xi)}{\xi} d \xi
$$

Finalmente, nós temos:

$$
\phi(\xi)=\frac{\gamma^{\mu}}{\operatorname{Gamma}(\mu)} \xi^{\mu} \exp (-\gamma \zeta)
$$

Onde Gamma se refere a função gamma que generaliza para qualquer número a função fatorial para números reais. Então neste caso, para valores pequenos de $\xi$ nós encontramos que $\phi(\xi) \cong \xi^{\mu}$.

Outra solução analítica pode ser obtida de para $g(x)=a x^{\beta}+(1-a) x^{\delta}$. $(Z I F F, 1991)$ resolveu a equação de similaridade (B.1) para esta forma de $\mathrm{g}(\mathrm{x})$. Seguindo sua solução podemos obter neste caso:

$\phi(\xi)=\frac{\operatorname{Gamma}[(1-a) \beta+a \delta]}{\Gamma(\beta) \operatorname{Gamma}(\boldsymbol{\delta})} \gamma^{\beta} \xi^{\beta} \exp (-\gamma \xi) U[(1-a)(\beta-\delta), \beta-\delta+1, \gamma \xi]$

Onde U se refere a função de confluência hiper geométrica. Quando $\beta<\delta$, a equação (B.20) nos mostra que $\phi(\xi)=\xi^{\beta}$ para valores pequenos de $\xi$. 


\section{APÊNDICE C: SOLUÇÃO ANALÍTICA PARA BALANÇO \\ POPULACIONAL.}

Se escrevermos a equação fundamental para quebra da seguinte forma:

$\frac{\partial^{2} F(v, t)}{\partial v \partial t}=-\Gamma(v) \frac{\partial F(v, t)}{\partial t}+\int_{v}^{v_{\max }} \frac{\partial B\left(v, v^{\prime}\right)}{\partial v} \Gamma(v) \frac{\partial F\left(v^{\prime}, t\right)}{\partial v} d v^{\prime}$

Nesta equação $F(v, t)$ nos fornece a fração mássica de material menor que o volume $\mathrm{v}$ depois de inicialmente receber uma alimentação com a distribuição $\mathrm{F}(\mathrm{v}, 0)$ e tamanho máximo $\mathrm{v}_{\max }$, em determinado tempo $\mathrm{t}$, e $\mathrm{B}\left(\mathrm{v}, \mathrm{v}^{\prime}\right)$ é a quebra resultante da fração de material menor que o volume $\mathrm{v}$ obtida da quebra primária de material de tamanho v'. A quebra primária se refere a condição em que os produtos de qualquer evento com quebra não resulta em nenhuma fratura posterior. $\mathrm{O}$ último termo $\Gamma(\mathrm{v})$, é a taxa fracional de quebra de material de tamanho $\mathrm{v}$ e tem sido chamada por estudos anteriores como ambas a função de probabilidade ou função de seleção.

Desde que $n(v, t)=\partial F(v, t) / \partial v, d v$ nos dá a fração de material na faixa entre $v$ e $v+d v$, e a taxa fracionada de quebra seria, caso seja assumida uma taxa de quebra independente do tempo e que implicitamente define uma reação de primeira ordem.

$-\frac{d n(v, t)}{n(v, t) d t}=\Gamma(v)$

Por integração:

$n(v, t)=n(v, 0) \exp (-\Gamma(v) t)$

A equação (C.1) é uma equação integral diferencial e resulta no balanço de massa do material fracionado $\mathrm{n}(\mathrm{v}, \mathrm{t})$ no tamanho diferencial $\mathrm{v}$ até v+dv. A equação diz que taxa na rede de produção de material de qualquer tamanho $\mathrm{v}$ se igual a taxa de produção dos tamanhos resultantes da quebra de todo o material inicialmente maior que $\mathrm{v}$ menos a rede de quebra de material de tamanho v.

A equação (C.1) não tem solução analítica simples mas sob determinadas condições pode se degenerar para uma equação com solução conhecida. Se considerarmos que o maior tamanho de qualquer alimentação ou o inicio com alimentação de um único tamanho apenas, o decaimento da maior partícula é dado pela equação (C.2).Um segundo caso de degeneração é quando as taxas $\Gamma(\mathrm{v})$ ou $\partial \mathrm{B}\left(\mathrm{v}, \mathrm{v}^{\prime}\right) / \partial \mathrm{v}$ iguais a zero resultando em acúmulo zero fazendo a distribuição final permanecer igual a inicial, mas um caso mais interessante 
analiticamente de existência de solução analítica ocorre quando as taxas $\Gamma(\mathrm{v}), \partial \mathrm{B}\left(\mathrm{v}, \mathrm{v}^{\prime}\right) / \partial \mathrm{v}$, são iguais a um valor constante C como na seguinte equação (C.4):

$$
\Gamma(v)=C v \quad e \quad B\left(v, v^{\prime}\right)=\frac{v}{v^{\prime}}
$$

Nessas condições a equação se degenera para a seguinte (C.5)

$\frac{\partial^{2} F(v, t)}{\partial v \partial t}=-K v \frac{\partial F(v, t)}{\partial t}+K \int_{v}^{v_{0}} \frac{\partial F\left(v^{\prime}, t\right)}{\partial v} d v^{\prime}$

Essa equação resulta na seguinte solução (GAUDIN;MELOY,1962):

$$
\varepsilon(v, t)=\varepsilon(v, 0) \exp (-C v t)
$$

Onde $\varepsilon(v, t)$ é a fração de material maior que o tamanho v num instante $t$, isto é, $\varepsilon(\mathrm{v}, \mathrm{t})=1-\mathrm{F}(\mathrm{v}, \mathrm{t})$. A comparação das equações (C.6) e (C.3) nos mostram que sob determinadas condições especiais da equação (C.4) a massa de material acima do tamanho $\mathrm{v}$ cai como se fosse todas exatamente do tamanho $\mathrm{v}$. 


\section{APÊNDICE D: SOLUÇÃO ANALÍTICA COM VARIAVÉIS DE SIMILARIDADE PARA BALANÇO POPULACIONAL.}

A equação de um balanço populacional de quebra é a seguinte:

$\frac{d n(v, t)}{d t}=-\Gamma(v) n(v, t)+\int_{v}^{\infty} \beta\left(v, v^{\prime}\right) v\left(v^{\prime}\right) \Gamma\left(v^{\prime}\right) n\left(v^{\prime}, t\right) d v^{\prime}$

A mesma equação para os momentos é a seguinte:

$\frac{d M_{w}(t)}{d t}=\int_{0}^{\infty} \Gamma\left(v^{\prime}\right) v^{\prime w} n\left(v^{\prime}, t\right)\left[\int_{0}^{v}\left(\frac{v}{v^{\prime}}\right)^{w} \beta\left(v^{\prime}, v\right) d v-1\right] d v^{\prime}, \quad M_{w}(t)=\int_{0}^{\infty} v^{w} n(v, t) d v$

Vamos admitir as seguintes quebra homogêneas

$\Gamma(v)=A v^{b}$

$\beta\left(v, v^{\prime}\right) v(v)=\varphi\left(v / v^{\prime}\right) / v^{\prime}$

Ao usarmos (D.3) e (D.4) em (D.1) e (D.2), acharemos as seguintes expressões para o balanço e para os momentos, note que (D.5) é o balanço para uma quebra que segue a lei de potências:

$\frac{d n}{d t}+A v^{b} n(v, t)=A \int_{v}^{\infty} v^{\prime b-1} \varphi\left(v / v^{\prime}\right) n\left(v^{\prime}, t\right) d v^{\prime}$

$\frac{d M_{w}(t)}{d t}=A\left(\vartheta_{i}-1\right) N_{w+b}(t), \quad \vartheta_{w}=\int_{0}^{1} v^{w} \varphi(v) d v=\int_{0}^{v^{\prime}}\left(\frac{v}{v^{\prime}}\right)^{w-1} \frac{\varphi\left(v / v^{\prime}\right)}{v} d v$

Só poderemos obter a solução analítica de (D.5) se assumirmos a seguinte

transformação de similaridade:

$n(v, t)=h_{1}(t) \tau(t) ; \eta=h_{2}(t) v$

Aplicando essa transformação na definição de $M_{0}(t)$ e $M_{1}$ nos retorna:

$h_{1}(t)=M_{0}^{2}(t) / M_{1}$

$h_{2}(t)=M_{0}(t) / M_{1}$

Para todos os momentos em seqüência a transformação (D.10) resulta:

$M_{w}(t)=M_{0}(t)\left(\frac{M_{1}}{M_{0}(t)}\right)^{w} K_{w}$

Onde:

$K_{w}=\int_{0}^{\infty} \eta^{w} \tau(\eta) d \eta$ 
As definições de $\mathrm{M}_{0}(\mathrm{t})$ e $\mathrm{M}_{1}$ requerem que $\mathrm{K}_{0}=\mathrm{K}_{1}=1$. Usando (D.10) em (D.6) e resolvendo:

$M_{0}(t)=\left[M_{0}^{b}(0)+A b\left(\vartheta_{0}-1\right) M_{0}^{b} K_{b} t\right]^{\frac{1}{b}}$

E com isso conseguimos:

$M_{w}(t)=K_{w} M_{1}^{w}\left[M_{0}^{b}(0)+A b\left(\vartheta_{0}-1\right) M_{0}^{b} K_{b} t\right]^{1-w}$

Esse resultado nos provê a dinâmica dos momentos da distribuição ao decorrer da fragmentação, e vemos claramente a dependência da quebra pelos momentos mesmo que aparentemente os momentos possam parecer independentes da quebra, a dependência de $\beta\left(v . v^{\prime}\right) v\left(v^{\prime}\right)$ aparece em ambos $\varphi_{0}$ e $K_{w}$ em suas forma integrais, e aplicando (D.7) em (D.5) obteremos:

$\frac{1}{M_{0}} \frac{d M_{0}(t)}{d t}\left[\eta \frac{d \tau}{d \eta}+2 \tau\right]=A\left(\frac{M_{1}}{M_{0}}\right)^{b}\left[\int_{\eta}^{\infty} \widehat{\eta}^{b-1} \varphi(\eta / \widehat{\eta}) \tau(\widehat{\eta}) d \hat{\eta}-\eta^{b} \varphi(\eta)\right]$

Mas de (D.10) e de (D.2):

$\frac{1}{M_{0}} \frac{d M_{0}(t)}{d t}=A\left(\vartheta_{0}-1\right) K_{b}\left(M_{1} / M_{0}\right)^{b}$

E portanto (D.13) se torna:

$\left(\vartheta_{0}-1\right) K_{b}\left[\eta \frac{d \tau}{d \eta}+2 \tau\right]=\int_{\eta}^{\infty} \widehat{\eta}^{b-1} \varphi(\hat{\eta}) d \hat{\eta}-\eta^{b} \varphi(\eta)$

Essa é uma equação ordinária diferencial integral e linear em $\tau$. Portanto uma transformação de similaridade é possível. Vamos tentar provar que a solução de (D.16) existe, e , em geral um procedimento numérico é necessário, vendo-se que o cálculo requer um procedimento interativo devido a dependência de $\tau(\eta)$ e $K_{b}$

Agora se propormos que a distribuição de quebra seja da forma (D.4), mas especificamente descrita como (D.17):

$\beta\left(v, v^{\prime}\right) \nu(v)=\frac{\gamma}{v^{\prime}}\left(v / v^{\prime}\right)^{\gamma-2}$

Dessa forma haverá uma solução analítica da equação para essa classe de funções, inicialmente notemos que essa forma de quebra satisfaz o balanço de massa, que a quebra 
seja maior que zero e que partículas menores não quebra resultando em partículas maiores, ou seja, as restrições físicas e fenomenológicas do sistema:

$$
\begin{aligned}
& \beta\left(v, v^{\prime}\right) v(v) \geq 0 \\
& \beta\left(v, v^{\prime}\right) v(v)=0 \quad \text { para } \quad v>v^{\prime} \\
& \int_{0}^{v} v \beta\left(v, v^{\prime}\right) v(v) d v=v^{\prime}
\end{aligned}
$$

A equação (D.18) restringe a distribuição a valores que não sejam negativos, (D.19) nos diz que partículas maiores não podem ser formadas pela quebra de partículas menores e (D.20) é o balanço de massa restrito para partículas de densidade constante.

Podemos deduzir facilmente que quando pensamos na forma geral $\beta\left(v, v^{\prime}\right) v\left(v^{\prime}\right)=v^{\text {,expoente }} \varphi\left(v^{\prime} / v^{\prime}\right)$ a equação que supomos inicialmente a (D.4), é a única que além de seguir essa forma geral satisfaz (D.20).

Outra conseqüência do balanço de massa é que para o caso w=1, (D.20) requer que $\varphi_{1}=1$, e portanto $M_{1}$ é constante. É também interessante notar que para o caso de quebra independente do tamanho $(b=0)$, uma solução fechada para todas as equações dos momentos pode ser obtida.

Note que (D.17), que é a expressão com a qual vamos trabalhar, satisfaz (D.18)(D.20) para todo $\gamma>0$, mas vamos restringir ainda mais (D.17) para os casos em que $>1$ embora (D.17) admita quebras no domino1 $\geq \gamma$, note que nesse caso a previsão é de um infinito número de quebras mas, é preciso ter em mente que isso não é nenhum sinal de uma transformação de similaridade inadequada ou que não seja possível mas que é uma conseqüência de uma taxa de quebra mal definida e esse é o motivo pelo qual uma transformação de similaridade feita baseada no número de partículas em geral é difícil de se implementar, por enquanto podemos notar que nós estamos adicionando portanto muitas restrições para as funções $\Gamma(\mathrm{v})$, como por exemplo o fato de seguir a lei de potências, e para $\beta\left(\mathrm{v}, \mathrm{v}^{\prime}\right) \mathrm{v}\left(\mathrm{v}^{\prime}\right)$, com por exemplo (D.18)-(D.20), mas essas são restrições medianas se considerarmos a generalidade dos resultados que serão obtidos em seguida.

Seguindo com o raciocínio com todas essas restrições simplificaremos e necessariamente obteremos:

$$
\vartheta_{i}=\frac{\gamma}{\gamma-1}
$$


E aplicando (D.21) em (D.16):

$\eta \frac{d \tau}{d \eta}+\left(2+\frac{\gamma-1}{K_{b}} \eta^{b}\right) \tau=\frac{\gamma(\gamma-1)}{K_{b}} \eta^{\gamma-2} \int_{\eta}^{\infty} \hat{\eta}^{b-\gamma+1} \tau(\widehat{\eta}) d \hat{\eta}$

Acharemos a seguinte solução:

$$
\tau(\eta)=\frac{b \operatorname{Gamma}(\gamma / b)}{\left[\operatorname{Gamma}\left(\frac{\gamma-1}{b}\right)\right]^{2}}\left[\frac{\operatorname{Gamma}(\gamma / b)}{\operatorname{Gamma}\left(\frac{\gamma-1}{b}\right)} \eta\right]^{\gamma} \exp \left[-\left(\frac{\operatorname{Gamma}(\gamma / b)}{\operatorname{Gamma}\left(\frac{\gamma-1}{b}\right)} \eta\right)^{b}\right]
$$

Porém lembramos que essa solução analítica é válida apenas quando b $>0$ e $>1$.

Para $\beta\left(v, v^{\prime}\right) v\left(v^{\prime}\right)$ dado pela equação (D.17) a equação para os momentos (D.13) se reduz após algumas simplificações:

$$
\frac{M_{w}(\varpi)}{M_{w}(0)}=\left[1+\left[\frac{\operatorname{Gamma}\left(\frac{\gamma-1}{b}\right)}{\operatorname{Gamma}\left(\frac{\gamma}{b}\right)}\right]^{b}\right]^{(1-w) / b}
$$

Onde $\varpi$ é um tempo adimensional dado por:

$$
\varpi=A\left(\frac{M_{1}}{M_{0}(0)}\right)^{b} t
$$

Aqui claramente, $\varpi$ representa um tempo característico expresso em termos dos número de eventos de quebra que ocorreram.

Podemos notar algumas características interessantes do problema proposto neste apêndice, o primeiro é que a distribuição de quebra quando for independente de $\mathrm{v}(\gamma=2)$ $\tau(\eta)$ adquire um valor assintoticamente que não é zero a medida que $\eta \rightarrow 0$. Esse valor é:

$$
\lim _{\eta \rightarrow 0} \tau(\eta)=\frac{b \operatorname{Gamma}(2 / b)}{[\operatorname{Gamma}(1 / b)]^{2}} ; \quad \text { para } \quad \gamma=2
$$

Veja que esse resultado pode pare ser fisicamente fora da realidade, ele é esperado para o caso de "uniformidade" na distribuição de partículas durante a quebra. Portanto, $\tau(\eta=0) \neq 0$ não implica que exista uma probabilidade finita de existirem partículas de tamanho zero, desde que a probabilidade seja dada pelo produto $\tau(\eta) \mathrm{d} \eta$.

Para valores pequenos de $\eta, \tau(\eta)$ chega a uma forma limite de: 
$\tau(\eta)=C_{1} \eta^{\gamma-2}$

Onde:

$C_{1}=b\left[\frac{\operatorname{Gamma}(\gamma / b)}{\operatorname{Gamma}\left(\frac{\gamma-1}{b}\right)}\right]^{\gamma-1} \frac{1}{\operatorname{Gamma}\left(\frac{\gamma-1}{b}\right)}$

Portanto a tangente de $\log (\tau(\eta))$ contra $\log (\eta)$ alcança um valor constante, $\gamma-2$, independentemente da taxa de quebra, se extrapolarmos ao ponto $\eta=1$ acharemos $C_{1}$, do qual uma taxa de quebra pode ser encontrada.

Finalmente, a medida que a taxa de quebra e sua dependência com o tamanho de partículas aumenta, o resultado é que a função de distribuição $\tau(\eta)$ diminuí. Esse resultado é esperado, pois devido a tendência de que uma partícula uma vez quebrada tenha uma chance menor de ser quebrada novamente. Essa diminuição de $\tau(\eta)$ também pode ser observada para a mesma taxa de quebra e apenas aumentando-se $\gamma$ na função de distribuição de quebra. De novo aumentando-se $\gamma$ nós reduziremos a tendência das partículas quebrarem e formarem partículas muito pequenas, e portanto a tendência é de as partículas não permanecerem em uma determinada distribuição inicial e sim migrarem para uma distribuição e estacionarem nela. Esse comportamento para quebra de partículas a medida que o espectro de partículas diminuí é semelhante a diversos dados experimentais observados.

Soluções analíticas para (D.16) para $\beta\left(\mathrm{v}, \mathrm{v}^{\prime}\right) \mathrm{v}\left(\mathrm{v}^{\prime}\right)$ dadas por (D.17) nos demonstram que soluções de similaridade para (D.16) existem para certas formas de funções quebra. É provável que uma solução de similaridade exista para uma faixa muito mais ampla de classes de taxas de distribuições de quebra, e talvez em alguns casos esse tipo de solução só seja possível numericamente. Variando $\beta\left(\mathrm{v}, \mathrm{v}^{\prime}\right) v\left(\mathrm{v}^{\prime}\right)$ e $\varphi\left(\mathrm{v} / \mathrm{v}^{\prime}\right)$ atinge (D.16) apenas se modificarmos as taxas dentro das integrais. Devemos sempre nos lembra que $\varphi\left(v / v^{\prime}\right)$ é por definição uma taxa bem comportada (isto é, que segue as restrições D.18- D.20).

Portanto para o caso especifico $\varphi\left(\mathrm{v}^{\prime} / \mathrm{v}^{\prime}\right)=\gamma\left(\mathrm{v}^{\prime} \mathrm{v}^{\prime}\right)^{\gamma-2}$, temos uma solução analítica completa incluindo aspectos como o comportamento assintótico.Esses resultados são potencialmente aplicáveis a uma faixa ampla de problemas de fragmentação de partículas, 
incluindo combustão de pó pulverizado, formação de aerossóis por explosão, agregação de partículas e cinéticas de cristalização.

Uma outra função que poderíamos usar seria (D.26), que segue o mesmo padrão da (D.17):

$$
\beta\left(v, v^{\prime}\right) v(v)=\frac{1}{v^{\prime}}\left[a 1 \gamma\left(\frac{v}{v^{\prime}}\right)^{\gamma-1}+(1-a 1) a 2\left(\frac{v}{v^{\prime}}\right)^{a 2-1}\right]
$$

Onde a1 e a2 são constantes, o que se pode fazer é aproximar as soluções analíticas conhecidas que temos da equação (D.16) portanto teríamos.

$$
\tau_{\text {médio }}(\eta)=a 1 \tau_{1}(\eta)+(1-a 1) \tau_{2}(\eta)
$$

Onde $\tau_{1}$ e $\tau_{2}$ seria as soluções conhecidas para a $1=1$ e $a 1=0$.

$\mathrm{O}$ modelo usado no fornece que a concentração numérica varia com $\mathrm{t}^{1 / \mathrm{b}}$, e os momentos da distribuição $\mathrm{M}_{\mathrm{w}}(\mathrm{t})$ variam todos assintóticamente com a taxa proporcional $\mathrm{t}^{(1-}$ w)/b a dependência dos momentos com a taxa de quebra $\beta\left(v, v^{\prime}\right) v\left(v^{\prime}\right)$ entra apenas na constante de proporcionalidade com respeito ao tempo, para a taxa de quebra escolhida ,$\tau(\eta)$ chega a um valor constante assintóticamente dependente da taxa de quebra assim que $\eta \rightarrow 0$, para valores suficientes pequenos de $\eta, \tau(\eta)$ chega a uma forma limitante $\tau(\eta) \cong C_{1} \eta^{\gamma-}$ ${ }^{2}$, , o alargamento da distribuição $\tau(\eta)$ decresce com ambos tanto o aumento de b na taxa de quebra quanto com o decréscimo de $\gamma$ na função de distribuição de quebra, e que podemos obter uma média de soluções já conhecidas.

Podemos também definir a fração mássica como (D.28):

$$
F M(v)=\int_{0}^{v} \frac{m(v, t) d v}{M_{0}}=\int_{0}^{v} \tau(\eta) d \eta
$$

Nesse caso m é a concentração mássica e assim teríamos de acordo com a equação (D.23):

$$
F M(\eta)=\gamma_{c}\left(\frac{\gamma}{b},\left[\frac{\operatorname{Gamma}\left(\frac{\gamma+1}{b}\right)}{\operatorname{Gamma}\left(\frac{\gamma}{b}\right)} \eta\right]^{b}\right)
$$

Uma consequiência da equação (D.29) é que para o caso especial $\gamma / \mathrm{b}=1$ : 


$$
F M(\eta)=\gamma_{c}\left(1,\left[\operatorname{Gamma}\left(1+\frac{1}{b}\right) \eta\right]^{b}\right)
$$

Ou de outra forma

$$
F M(\eta)=1-\exp \left(-\left[\operatorname{Gamma}\left(1+\frac{1}{b}\right) \eta\right]^{b}\right)
$$

Esse modelo nos fornece uma base para analisarmos melhor todo o corpo da literatura de dados experimentais, e são úteis para a interpretação desses dados, pois mesmo com essa abordagem restritiva é possível se coletar alguns princípios gerais de sistemas particulados. 


\section{APÊNDICE E: COMENTÁRIOS SOBRE AS FUNÇÕES DE QUEBRA FORMULADAS DE MANEIRA ESTRITAMENTE TEÓRICAS.}

A primeira tentativa de se criar uma expressão para a função de quebra foi a proposta por (BENNET,1936), ele iniciou usando estatística de Poisson e propôs o seguinte:

$$
R\left(\xi_{x}\right)=N_{x} \exp \left(-\xi_{x} / \bar{\xi}_{x}\right)
$$

Onde $\mathrm{R}\left(\xi_{\mathrm{x}}\right)$ é o número provável de fragmentos cujo tamanho é maior que $\xi_{\mathrm{x}}, \bar{\xi}_{\mathrm{x}}$ é a média dos fragmentos definidos por $\mathrm{L}_{\mathrm{x}} / \mathrm{N}_{\mathrm{x}}, \mathrm{L}_{\mathrm{x}}$ sendo o tamanho original da partícula, $\mathrm{N}_{\mathrm{x}}$ sendo o número de fragmentos em que $\mathrm{L}_{\mathrm{x}}$ é quebrado $\left(\mathrm{N}_{\mathrm{x}}\right.$ é assumido ser um número grande). De forma similar para o peso e a largura:

$$
\begin{aligned}
& R\left(\xi_{y}\right)=N_{y} \exp \left(-\xi_{y} / \bar{\xi}_{y}\right) \\
& R\left(\xi_{z}\right)=N_{z} \exp \left(-\xi_{z} / \bar{\xi}_{z}\right)
\end{aligned}
$$

O número total de fragmentos é:

$$
N_{T}=N_{x} N_{y} N_{z}
$$

Argumentou-se então que o volume total de partículas tendo-se um volume excedente $\xi_{\mathrm{x}} \xi_{\mathrm{y}} \xi_{\mathrm{z}}$ é:

$$
\begin{aligned}
& V\left(\xi_{u}\right)=\beta N_{x} N_{y} N_{z} \\
& \iiint \exp \left[-\left(\frac{\xi_{x}}{\bar{\xi}_{x}}+\frac{\xi_{y}}{\bar{\xi}_{y}}+\frac{\xi_{z x}}{\bar{\xi}_{z}}\right)\right] d \xi_{x} d \xi_{y} d \xi_{z}
\end{aligned}
$$

Onde $\beta$ é uma constante volumétrica que depende da forma da partícula. Então, se a partícula tem um volume original de $\mathrm{V}_{0}$ :

$$
V_{0}=N_{T} \bar{\xi}_{x} \bar{\xi}_{y} \bar{\xi}_{z}
$$

E assim a fração por volume de fragmentos maiores que o volume $\mathrm{V}$, digamos $\mathrm{R}$, é:

$$
R=V_{0} \exp \left[-\xi_{u} / \bar{\xi}_{u}\right]
$$

Onde $\xi$ e $\bar{\xi}$ são definidos por:

$$
-\xi_{u} / \bar{\xi}_{u}=\frac{\bar{\xi}_{x} \bar{\xi}_{y} \xi_{z}+\bar{\xi}_{x} \xi_{y} \bar{\xi}_{z}+\xi_{x} \bar{\xi}_{y} \bar{\xi}_{z}}{\bar{\xi}_{x} \bar{\xi}_{y} \bar{\xi}_{z}}
$$

Sem contarmos a validade do modelo físico, a equação (E.5) contem um erro matemático que invalida (E.8). O procedimento correto seria: 
Aceitando-se (E.1), o número de fragmentos de tamanho $\xi_{\mathrm{x}}$ até $\xi_{\mathrm{x}}+\mathrm{d} \xi_{\mathrm{x}}$ é $d R\left(\xi_{x}\right)=-N_{x}\left[d\left(\exp \left[-\xi_{x} / \bar{\xi}_{x}\right]\right) / d \xi_{x}\right] d \xi_{x}$

A fração por número tendo o tamanho $\xi_{\mathrm{x}}$ até $\xi_{\mathrm{x}}+\mathrm{d} \bar{\xi}_{x}$, peso $\xi_{\mathrm{y}}$ até $\xi_{\mathrm{y}}+\mathrm{d} \bar{\xi}_{y}$, e comprimento $\xi_{\mathrm{z}}$ até $\xi_{\mathrm{z}}+\mathrm{d} \bar{\xi}_{z}$, é:

$d R / N_{T}=\left(1 / \bar{\xi}_{x} \bar{\xi}_{y} \bar{\xi}_{z}\right) \exp \left[-\left(\frac{\xi_{x}}{\bar{\xi}_{x}}+\frac{\xi_{y}}{\bar{\xi}_{y}}+\frac{\xi_{z}}{\bar{\xi}_{z}}\right)\right] d \xi_{x} d \xi_{y} d \xi_{z}$

O volume de uma dessas partículas é $\beta \bar{\xi}_{x} \bar{\xi}_{y} \bar{\xi}_{z}$, portanto o volume de um número dR de partículas é:

$$
d V=N_{T} \beta\left(\xi_{x} \xi_{y} \xi_{z} / \bar{\xi}_{x} \bar{\xi}_{y} \bar{\xi}_{z}\right) \exp \left[-\left(\frac{\xi_{x}}{\bar{\xi}_{x}}+\frac{\xi_{y}}{\bar{\xi}_{y}}+\frac{\xi_{z}}{\bar{\xi}_{z}}\right)\right] d \xi_{x} d \xi_{y} d \xi_{z}
$$

$\mathrm{O}$ volume total de partículas com volume maior que $\mathrm{V}$ é:

$$
\int_{V}^{V_{0}} d V=V\left(\xi_{u}\right)=N_{T} \beta \iiint\left(\xi_{x} \xi_{y} \xi_{z} / \bar{\xi}_{x} \bar{\xi}_{y} \bar{\xi}_{z}\right) \exp \left[-\left(\frac{\xi_{x}}{\bar{\xi}_{x}}+\frac{\xi_{y}}{\bar{\xi}_{y}}+\frac{\xi_{z}}{\bar{\xi}_{z}}\right)\right] d \xi_{x} d \xi_{y} d \xi_{z}
$$

Este é claramente diferente de (E.5)

O erro na dedução de (E.5) pode ser visualizado mais claramente se considerarmos o caso simples em que para uma fibra bem longa quebrando de forma aleatória ao longo de seu comprimento em $\mathrm{N}_{\mathrm{T}}$ fragmentos. Aplicando a estatística de Poisson, a probabilidade do comprimento $\xi+\mathrm{d} \xi$ ocorrer entre sucessivas posições de fraturas é $\mathrm{P}\left(\xi_{\mathrm{u}}\right)=\left(1 / \xi_{\mathrm{u}}\right) \exp [-$ $\left.\xi_{\mathrm{u}} / \bar{\xi}_{u}\right] \mathrm{d} \xi$. Desde que um número maior de partículas é assumido, o número fracional acima para o tamanho $\xi_{\mathrm{u}}$ é:

$$
R\left(\xi_{u}\right) / N_{T}=\int_{\xi_{u}}^{L_{0}}\left(1 / \xi_{u}\right) \exp \left[-\left(\xi_{u} / \bar{\xi}_{u}\right)\right] d \xi_{u}=\exp \left[\xi_{u} / \bar{\xi}_{u}\right]
$$

Desde que $\mathrm{L} / \xi_{\mathrm{u}}=\mathrm{N}_{\mathrm{T}}$, que é grande. Esta é a equação (E.1). A soma dos comprimentos dos fragmentos acima do tamanho $\xi_{\mathrm{u}}$ é:

$$
=\int_{\xi_{u}}^{L} \xi_{u} d R\left(\xi_{u}\right)=N_{T} \int_{\xi_{u}}^{L} \xi_{u}\left(-1 / \xi_{u}\right) \exp \left[-\left(\xi_{u} / \bar{\xi}_{u}\right)\right] d \xi_{u}
$$

Esta é a forma unidimensional da equação (E.12), mas não é a redução a uma única dimensão da equação (E.5). A integração nos dá, desde que L/ $\xi_{\mathrm{u}}$ seja grande, "a soma dos 
comprimentos acima de zero" $=\mathrm{N}_{\mathrm{T}} \xi_{\mathrm{u}}$. Este é o esperado resultado lógico por que $\xi_{\mathrm{u}}$ é definido por $\mathrm{L} / \mathrm{N}_{\mathrm{T}}$.

Em muitas, outras, deduções iniciais das primeiras taxas de quebra, erros parecidos foram cometidos, por exemplo, fornecida por (GAUDIN;MELLOY,1962):

$$
N /(n+1)=1-\left(1-\xi_{u} / L\right)^{n}
$$

Onde $\mathrm{N}$ é o número cumulativo de fragmentos menores que o tamanho $\xi_{\mathrm{u}}$, e n é o número de fragmentos resultando em $n+1$ fragmentos. Está é uma forma mais geral de (E.1), outra seria:

$$
M=1-\left(1-\xi_{u} / L\right)^{n}\left(1+n \xi_{u} / L\right)
$$

Onde M é a fração cumulativa de volume (ou peso). Esta equação está correta e é a forma integrada unidimensional das equações (E.12) e (E.14), desde que $\xi_{\mathrm{u}}=\mathrm{L} / \mathrm{n}$, por definição e $\exp \left[-\left(\xi_{\mathrm{u}} / \bar{\xi}_{u}\right)\right]=\left(1-\xi_{\mathrm{u}} / \mathrm{L}\right)^{\mathrm{L} / \xi_{\mathrm{u}}}$, onde $\xi_{\mathrm{u}} / \mathrm{L}$ é pequeno. Portanto a equação que também é fornecida por (GAUDIN;MELOY,1962):

$$
M=1-\left(1-\xi_{u} / L\right)^{n}
$$

É também incorreta.

Baseado nessas deduções incorretas (BROWN;GLATZ,1941), assumiram que a função de quebra para um sistema de pó era:

$$
\beta\left(v, v^{\prime}\right)=\frac{1-\exp (-v)}{1-\exp \left(-v^{\prime} / m\right)}, \quad \text { para } 0<v<v^{\prime} / m
$$

Onde $\mathrm{m}$ é uma constante para um determinado sistema $\mathrm{m} \geq 1$, ela assume que todo o produto tem tamanho menor que $\mathrm{v}^{\prime} / \mathrm{m}$, visto que $\beta\left(\mathrm{v}^{\prime} / \mathrm{m}, \mathrm{v}^{\prime}\right)=1$.

É claro que nos anos que se passaram notáveis adições foram realizadas nesse aspecto com uma variedade de abordagens, mas todas dependes de constantes em geral parametrizadas como a constante $m$ que notamos em (E.18)

Note que embora a tentativa foi de se chegar a um modelo fenomenológico, ele foi feito usando-se um modelo de estatística aleatória, ou seja, praticamente a forma estatística e a fenomenológica parecem convergir para um mesmo modelo. 


\section{APÊNDICE F: PROBLEMAS MAL CONDICIONADOS EM BALANÇO POPULACIONAL.}

Toda solução de um balanço populacional segue originariamente a seguinte sequiência da figura F.1:

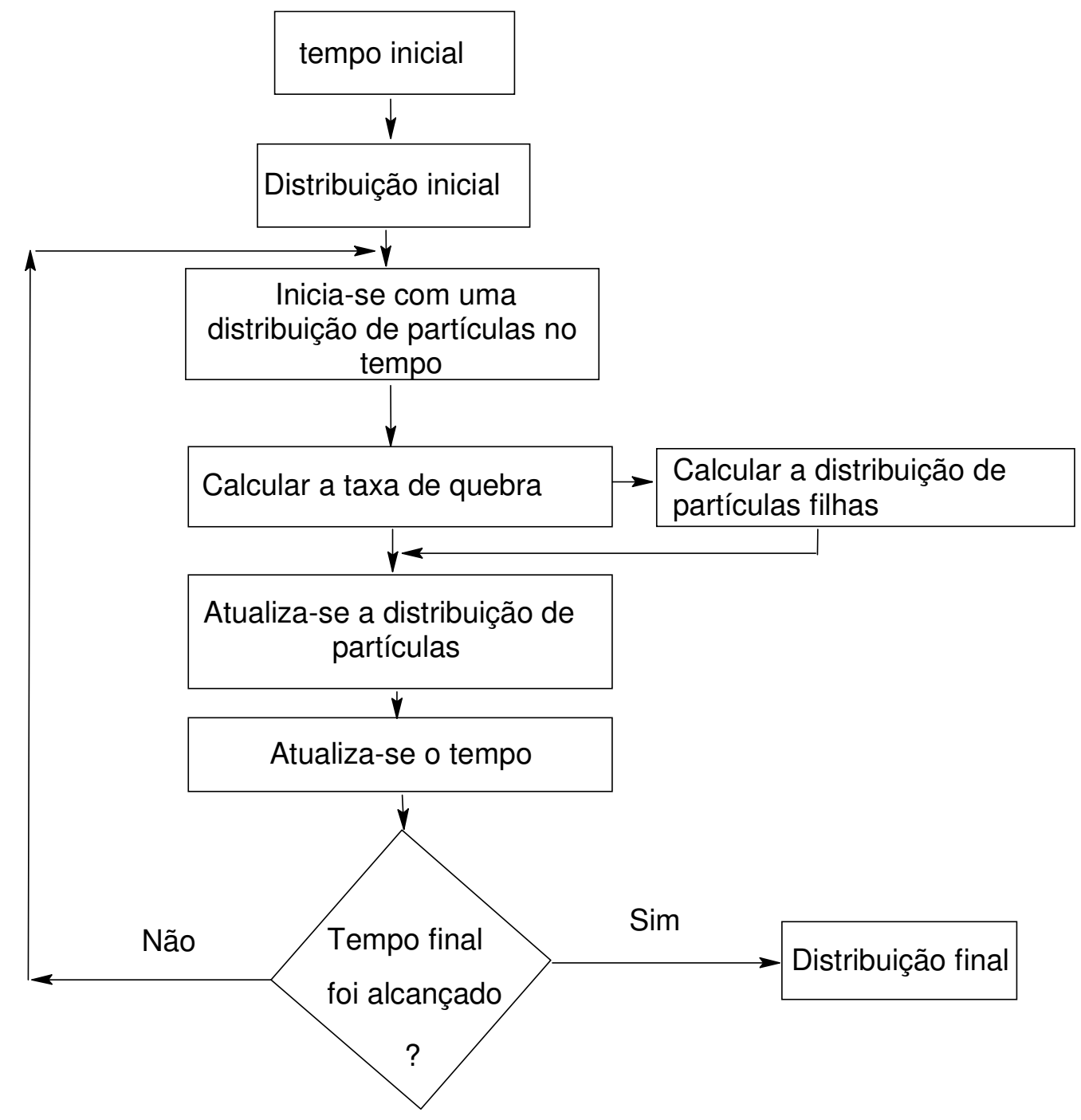

Figura F.1: Seqüência de solução geral de um balanço populacional.

Pela figura F.1 podemos verificar que basicamente os resultados finais dependem das taxas e da distribuição inicial. Portanto partindo disso podemos variar esses dois, fatores, afim, de alcançarmos, alguma, conclusão. Veja, que estamos mantendo a distribuição de partículas filhas, sempre igual, àquela apresentada na equação (3.3.1). 
Este apêndice tem como fim apresentar o problema de mal condicionamento na resolução do problema inverso de um balanço populacional, para tanto vamos utilizar as seguintes taxas de quebra apresentadas pela figura F.2:

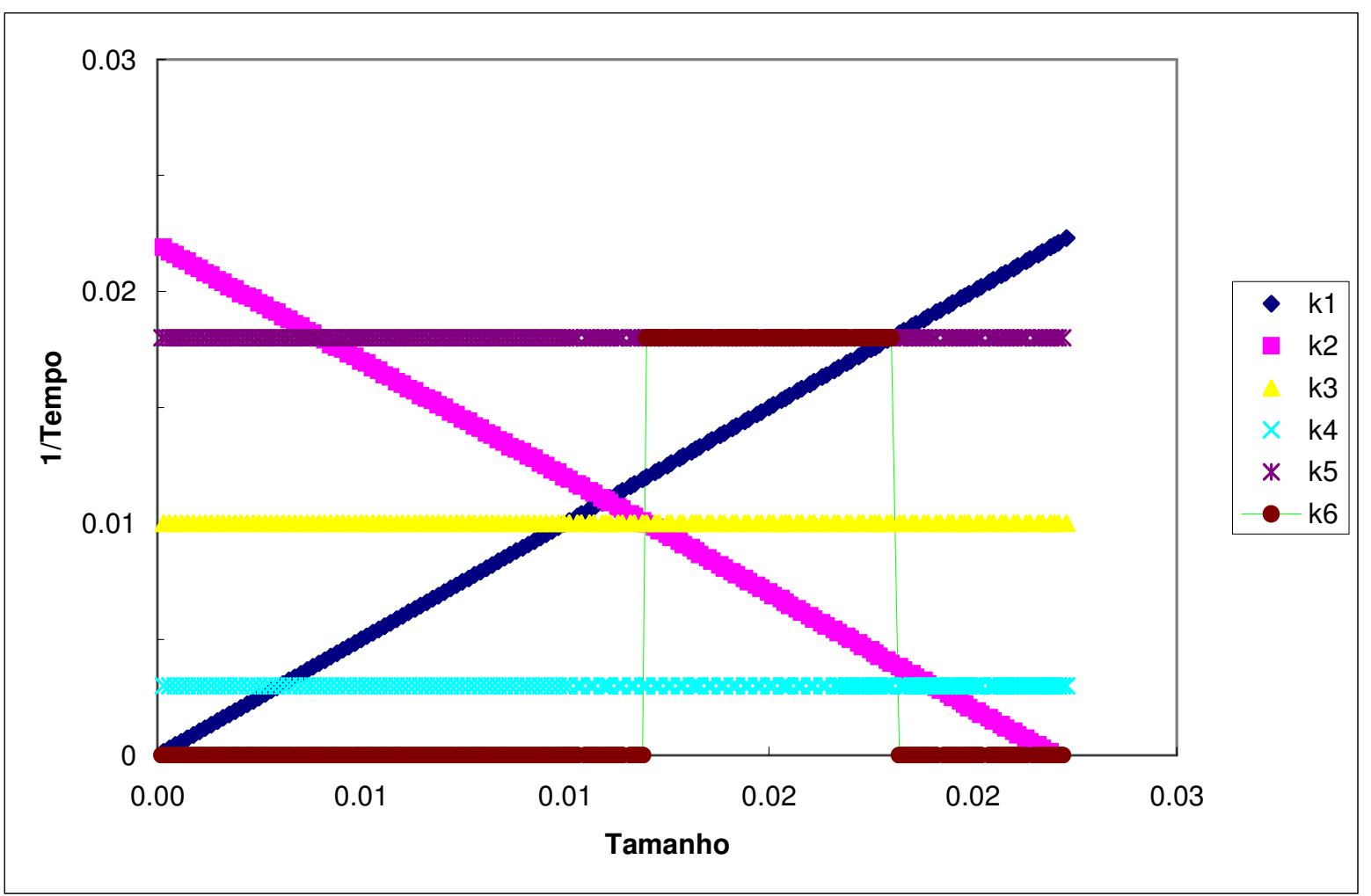

Figura F.2: Taxas de quebra utilizadas em um balanço populacional em que a média irá variar

Após utilizarmos essas taxas e resolvermos o balanço populacional notaremos claramente o mal condicionamento do problema como será explicado sucintamente a seguir, no caso a resolução do balanço populacional para diferentes taxas e média e a seguinte figura F.3: 


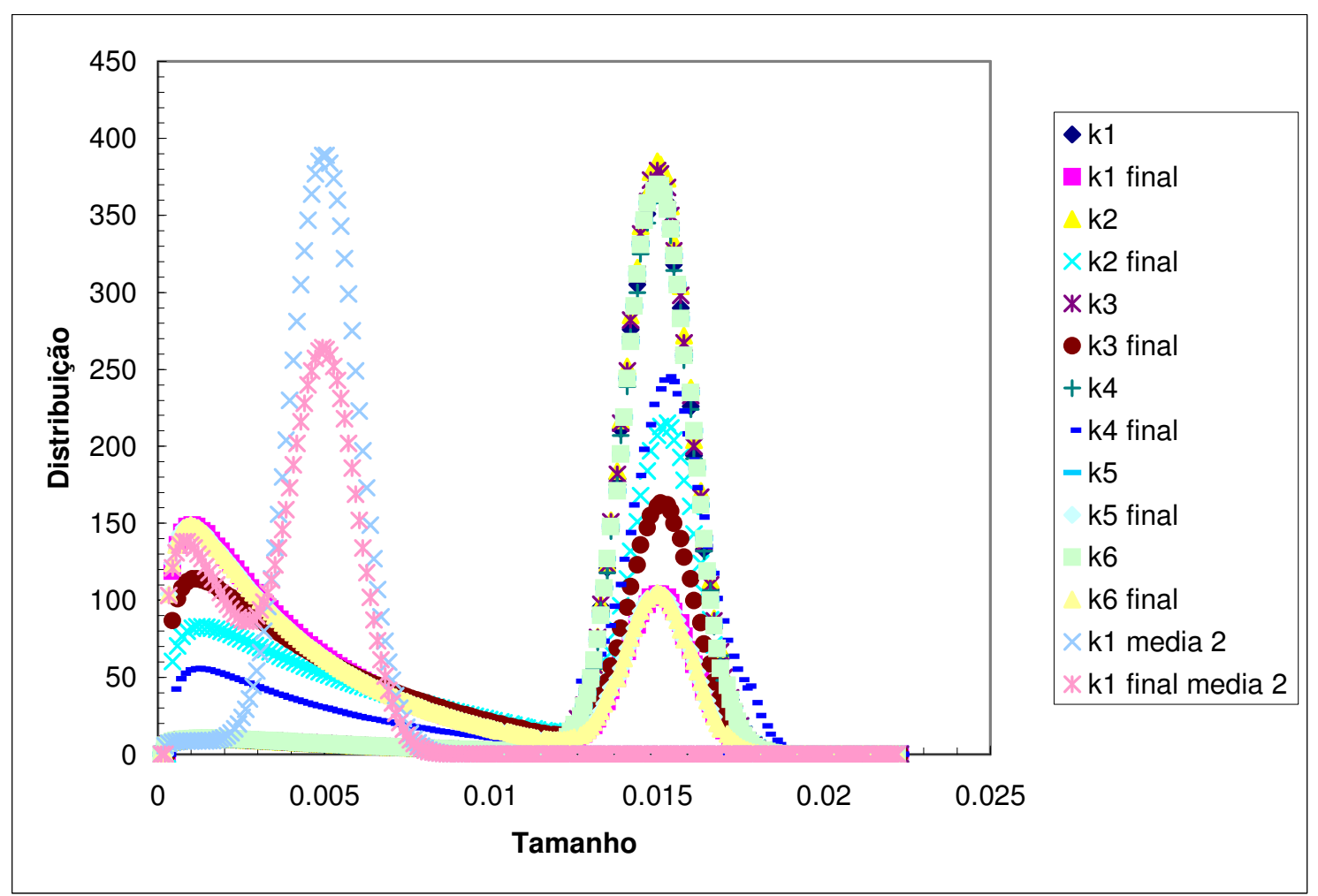

Figura F.3: Resolução do balanço populacional para diferentes taxas de quebra e médias como condições iniciais

Agora é fácil notar pela figura F.3 e tirarmos as seguintes conclusões, para as taxas de quebra k1, k5 e k6 obtemos curvas muito próximas, da mesma forma pra as taxas $\mathrm{k} 4 \mathrm{e}$ k2 as curvas também são muito próximas, isso evidencia que para diferentes taxas em muitos casos muito diferentes a solução do balanço populacional muitas vezes é semelhante, o que é comumente chamado de mal condicionamento da solução.

Portanto através dessas soluções geradas em simulação podemos concluir que o mal condicionamento do problema de balanço populacional pode existir dependendo muito fortemente das taxas de quebra com a qual estamos trabalhando tanto experimentalmente como em simulações e também das condições iniciais que escolhemos experimentalmente ou em simulações podendo ou não gerar no caso do problema inverso uma solução diferente da qual desejamos pois as taxas encontradas estatisticamente como as fenomenológicas que desejamos podem ser semelhantes ou dependendo do caso serem diferentes, mas sempre encontrando-se um perfil de distribuição igual ao que notamos experimentalmente no caso esse é o critério para a solução do problema inverso. 
Vamos notar agora a seguinte figura F.4 com outras taxas de quebra:

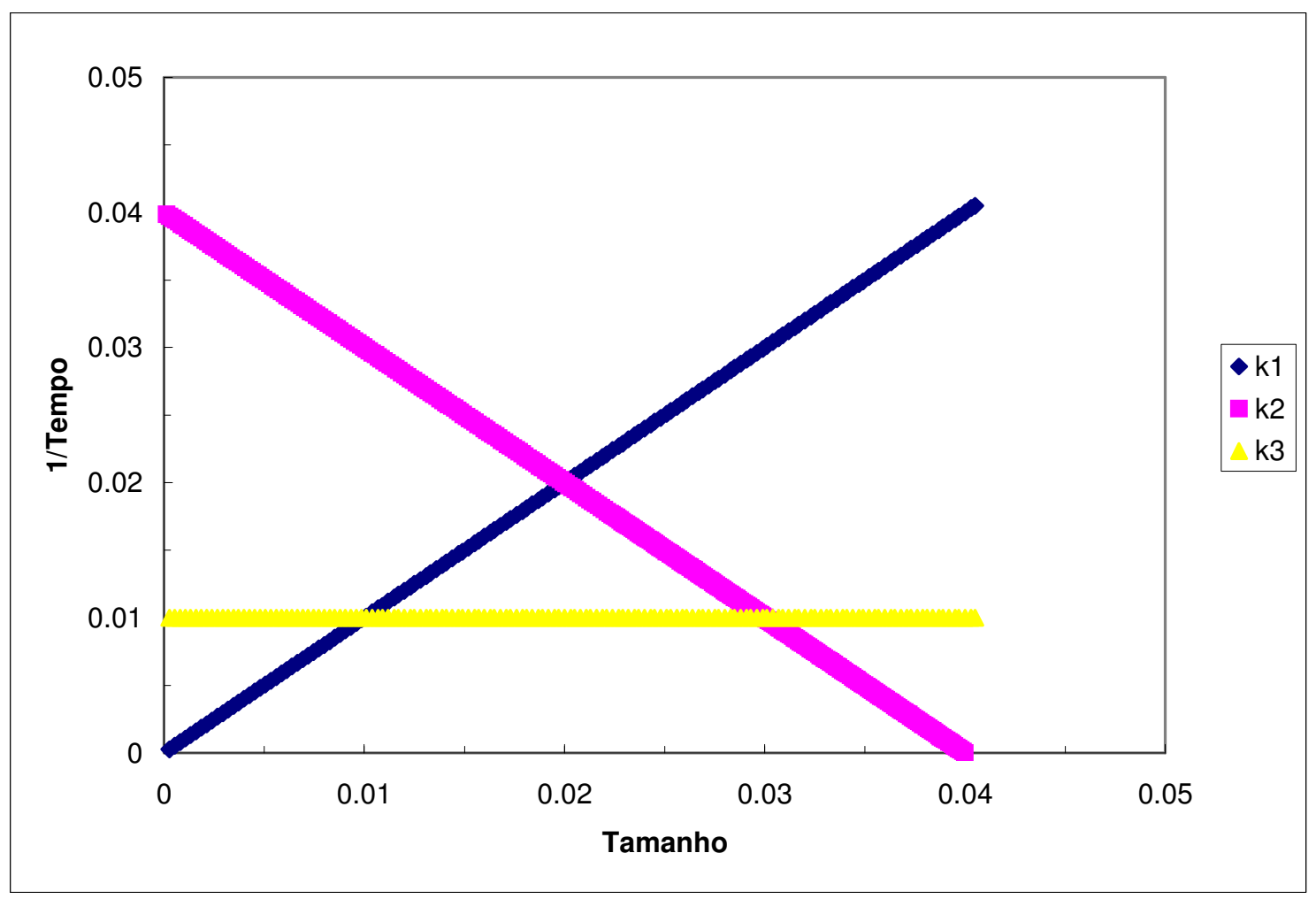

Figura F.4: Taxas de quebra para um balanço populacional, em que a distribuição é larga

Nelas notaremos claramente pela figura F.5, uma solução, de um balanço populacional, para uma distribuição inicial larga: 


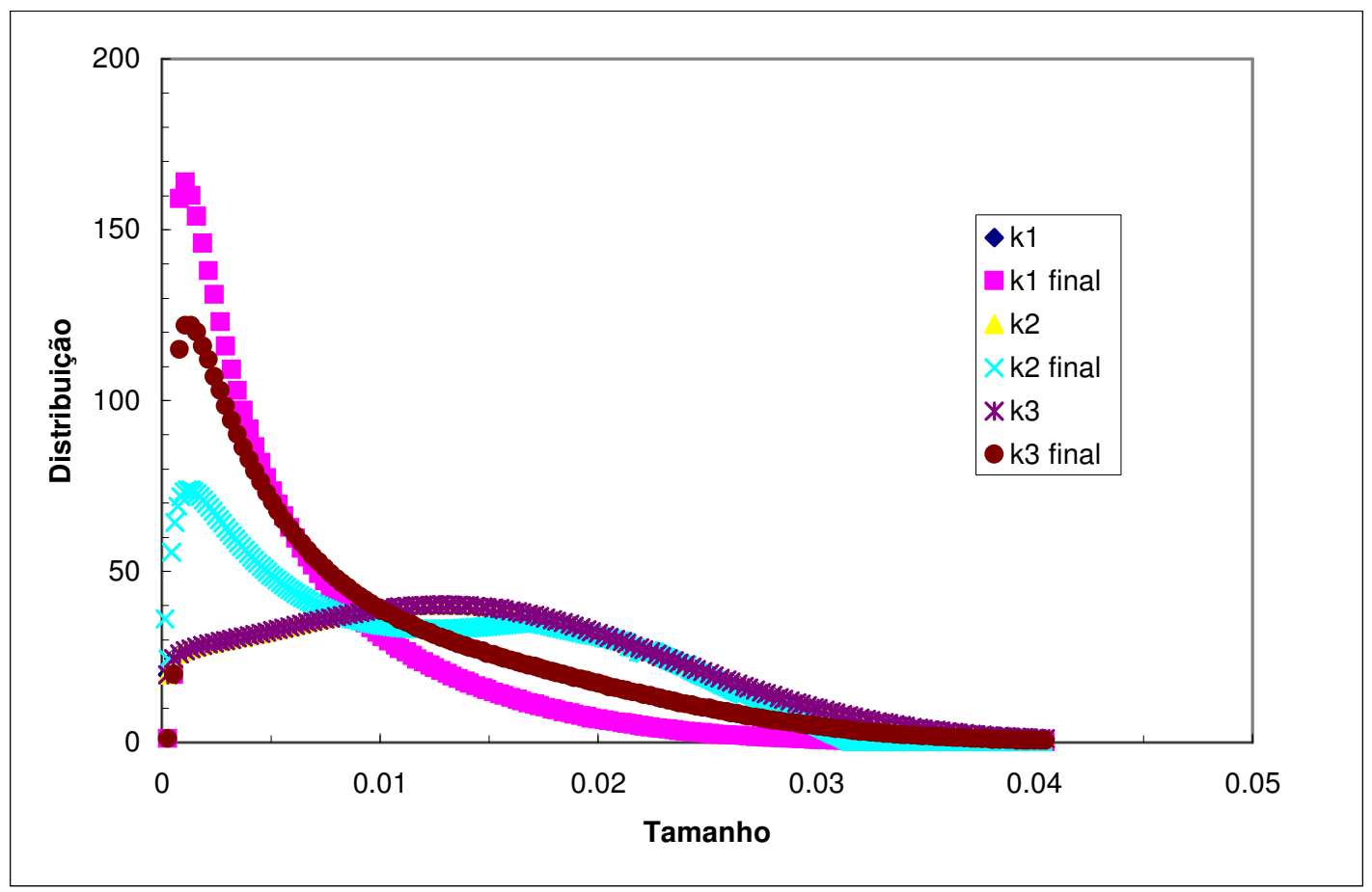

Figura F.5: Distribuições finais diferentes com distribuição inicial larga.

É fácil notar pela figura F.5, que quando utilizamos uma distribuição inicial larga o mal condicionamento da solução do balanço populacional e conseqüentemente do problema inverso, não ocorre pelo menos de forma tão visível, podendo ser claro que para diferentes taxas teremos nesse caso diferentes distribuições finais, diferente do que ocorreu na figura F.2.

Note que logicamente se caso escolhermos então uma distribuição inicial em uma região em que todas as taxas apresentam valores semelhantes e teríamos a mesma solução para a distribuição final, vamos então escolher as seguintes taxas de quebra da figura F.6. 


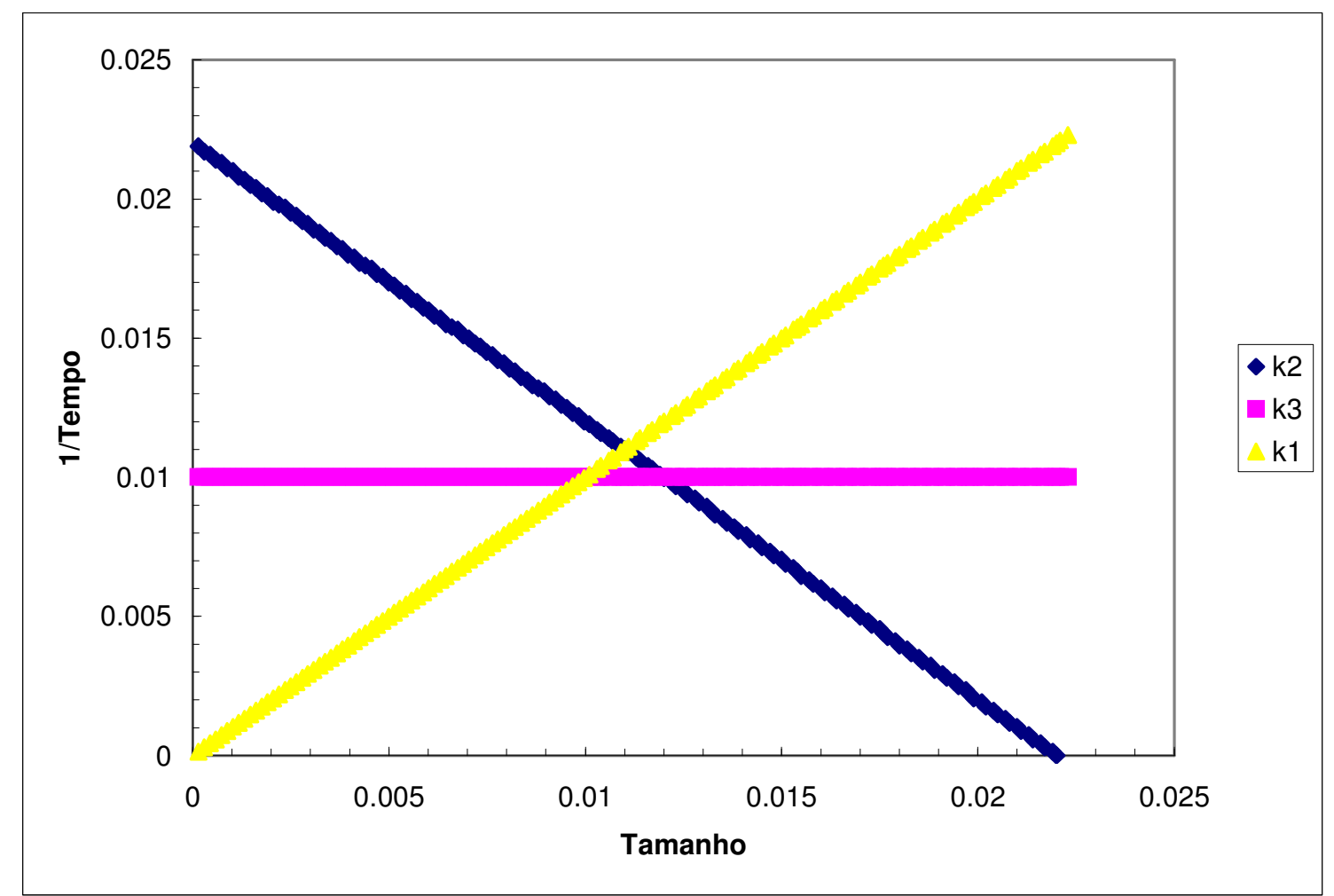

Figura F.6: Taxas de quebra para solução de balanço populacional com média em que as taxas apresentam valores semelhantes.

Notamos, portanto agora a seguir o resultado para a distribuição em uma média de 0.001 pela figura F.7 a seguir: 


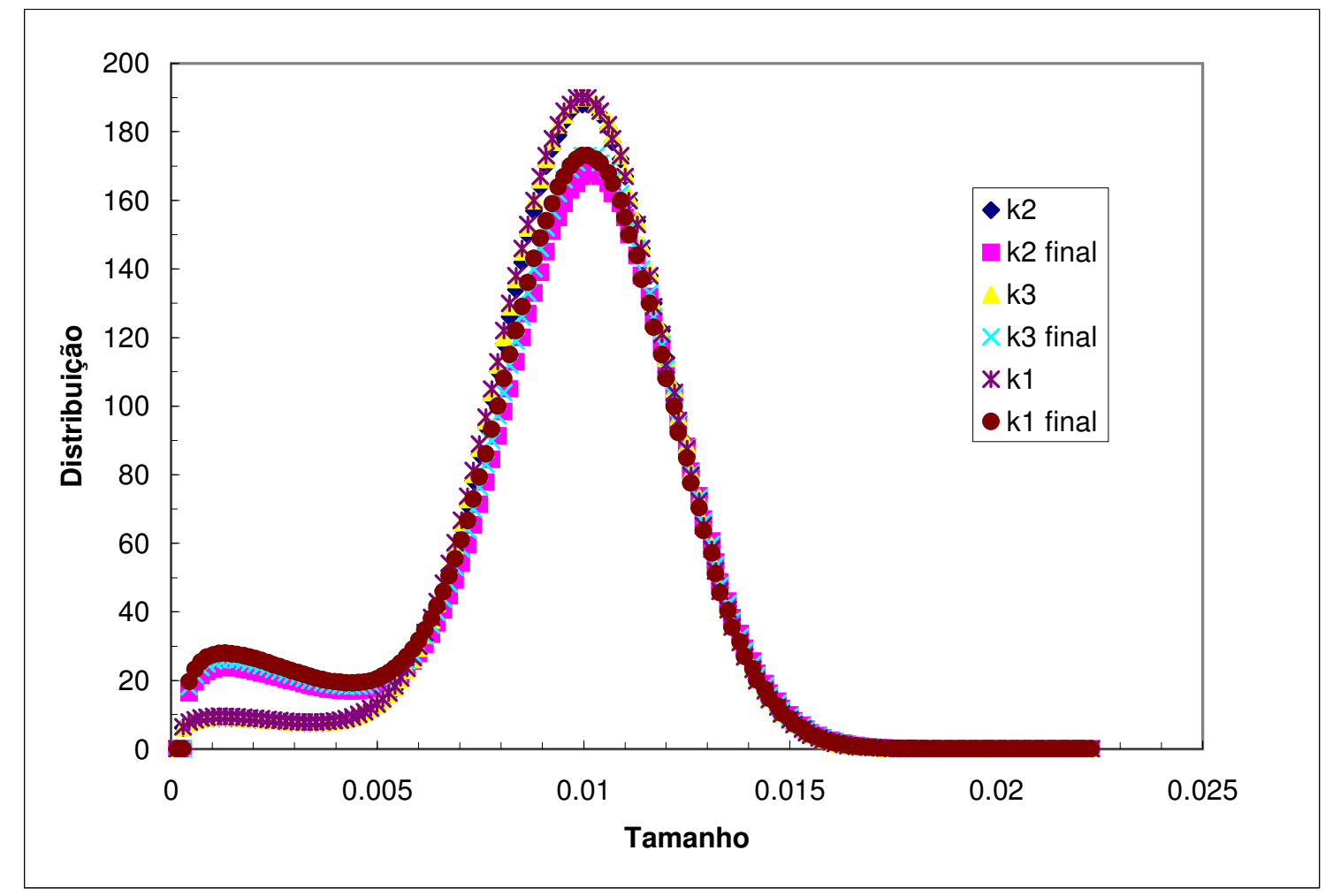

Figura F.7: Distribuições finais próximas com taxas de quebra diferentes.

Visualizamos, portanto pela figura F.7 que a distinção entre os casos não é possível pois nessa situação todas as distribuições finais são iguais e também os valores para as taxas de quebra também são próximas, nesse caso poderíamos obter uma relação estatística das taxas de quebra para determinado fenômeno, mas uma taxas fenomenológica seria mais difícil devido ao mal condicionamento do problema inverso. 


\section{APÊNDICE G: SIMULAÇÃO DE MONTE CARLO (MC).}

A relação entre o Balanço populacional e a simulação de Monte Carlo (MC) é exemplificada pelo seguinte diagrama da figura G.1 abaixo, nele nota-se que por uma lado o balanço populacional supõe uma relação entre as partículas pela equação geral de BP, algo desnecessário no método de (MC) ,mas que muitas vezes pode-se chegar nos mesmos resultados com as duas abordagens.

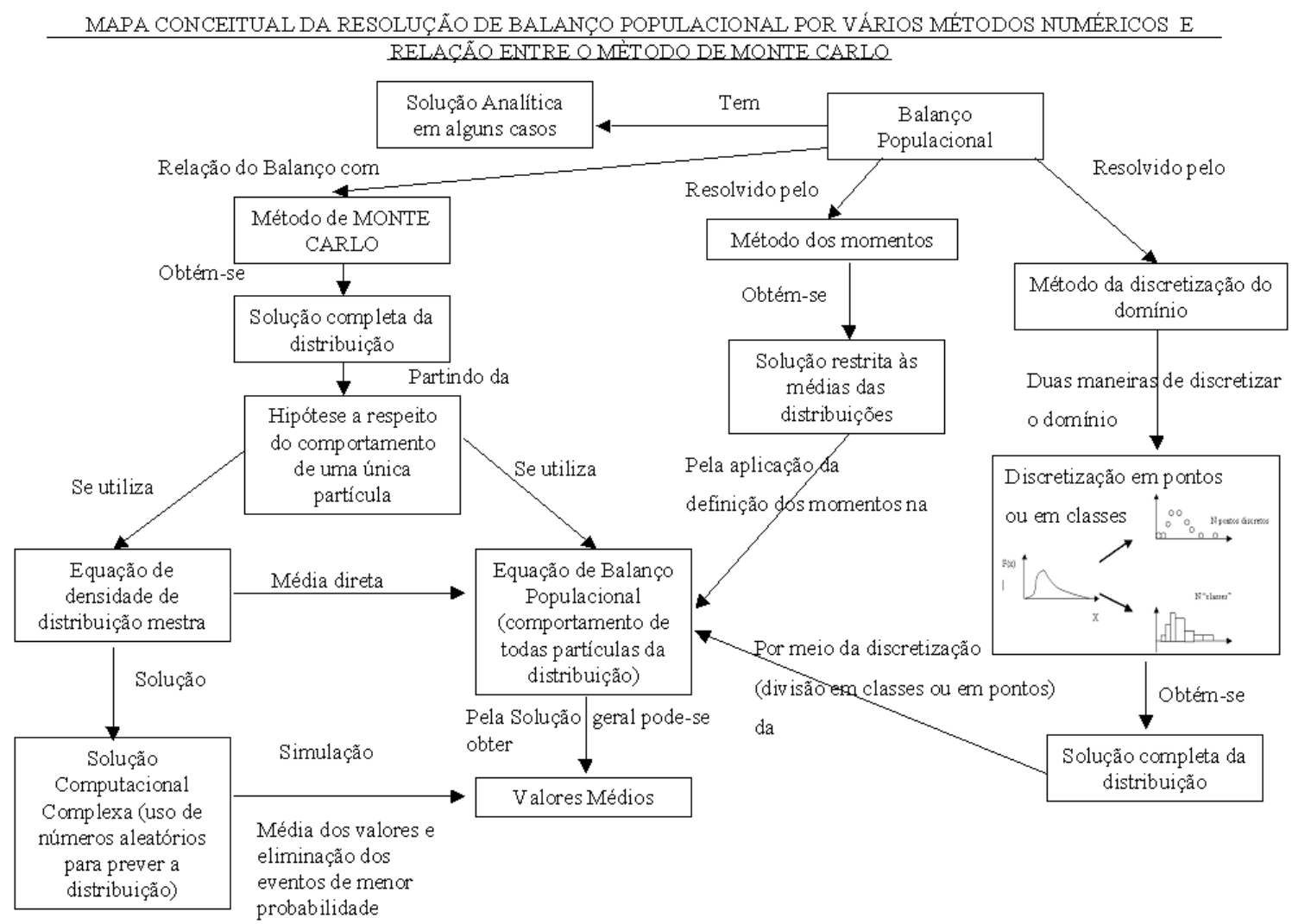

Figura G.1: Relação entre o Método de Monte Carlo e alguns métodos para sistemas particulados

O método de simulação de Monte Carlo (MC) é uma técnica versátil em que as equações diferenciais não são necessárias. O método pode ser aplicado necessitando-se apenas de que as probabilidades de cada evento envolvido no sistema possam ser definidas explicitamente (TOBITA,2006).

Em polímeros, o método se utilizada da determinação de propriedades e cinéticas de uma partícula elementar pequena, embora seja possível é dificultoso extrapolar seu uso para prever a existência de efeito gel quanto todo o reator se transforma em uma única molécula 
de polímero, visto que as simulações são inicialmente feitas em micro regiões do reator (TOBITA,1994).

Desenvolvimentos recentes de diversas técnicas analíticas para quebra de cadeias longas e pequenas são promissoras para o entendimento da arquitetura molecular de polímeros não lineares. Além dessas técnicas de caracterização um modelo matemático apropriado é requerido para um ajuste fino de controle dos produtos poliméricos, esses fatores dependentes dos mecanismos de reação e dos processos químicos usados. Geralmente a estrutura ramificada ainda não foi conectada de forma satisfatória com as operações com reatores usadas na síntese de polímeros.

Muitas reações elementares estão envolvidas na polimerização por radicais livres, e parece razoável considerar que as reações de transferência nos levam a ambos quebra de cadeias longas e cisão de cadeias como apresentado na figura G.2. 


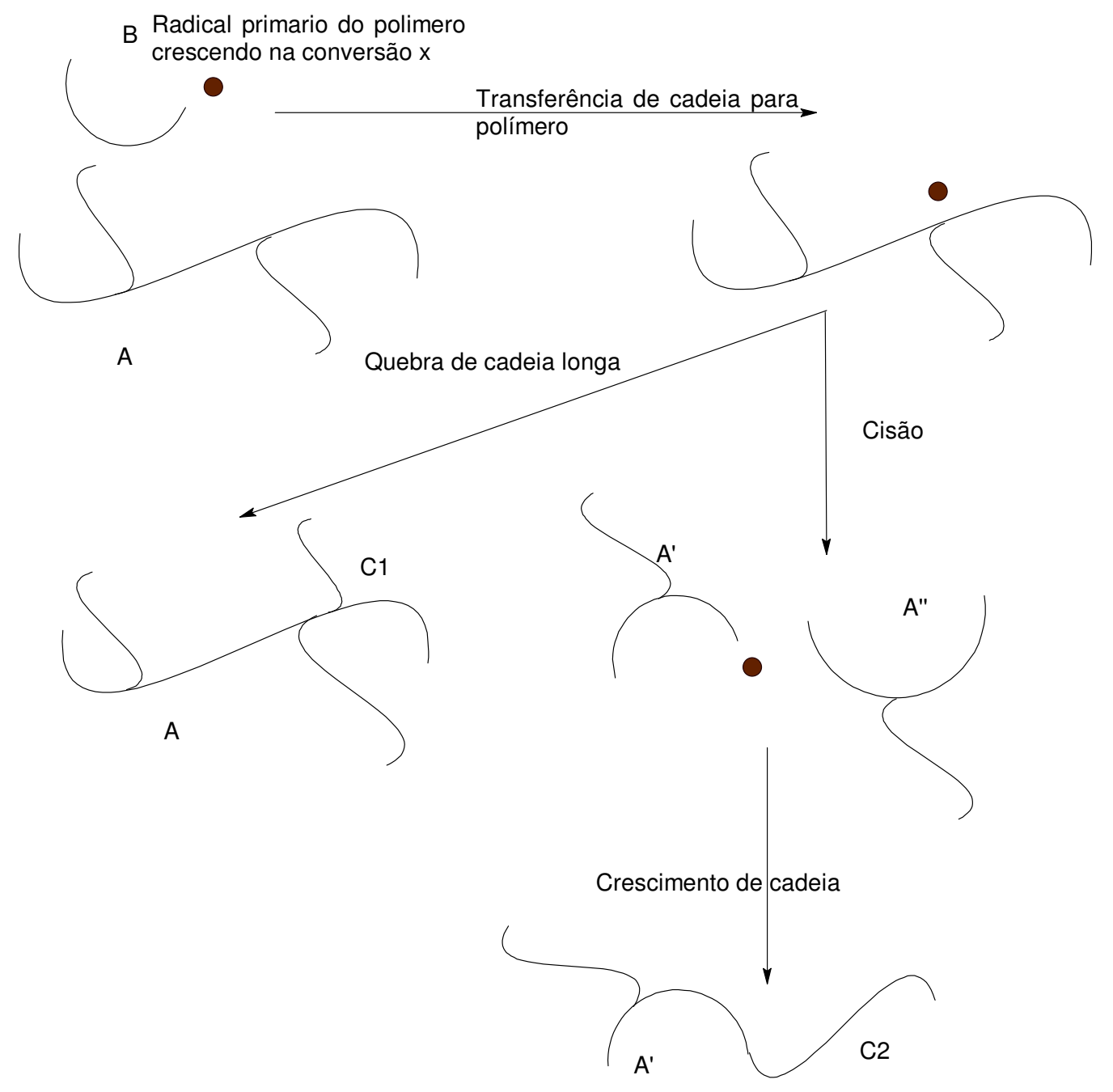

Figura G.2: Processo de transferência de cadeia para polímero, levando a uma quebra de cadeia longa e a uma cisão de cadeia.FONTE: (TOBITA,2000)

A cadeia primária A é formada na conversão, $x=\theta$, e em $x=\psi(\theta<\psi)$, uma cadeia de radical de polímeros primários tira o hidrogênio de $\mathrm{A}$ e um centro de radical é transferido para a cadeia $\mathrm{A}$. Se esse radical interno propaga uma cadeia longa $\mathrm{C}_{1}$ é formado na cadeia A. Por outro lado, o radical interno pode causar reação de cisão para formar uma cadeia primária $\mathrm{A}^{\prime}$ com um radical terminal que cresce adicionando monômeros para formar um segmento de cadeia $\mathrm{C}_{2}$. Note que a cadeia primária $\mathrm{A}$ " poderia ser um radical de polímero terminal ao invés de $\mathrm{A}^{\prime}$ com probabilidade igual. Porque as cadeias primárias (ou mais especificamente os segmentos dentro das cadeias como $A^{\prime}$ e $C_{2}$ ) formado no estágios mais 
iniciais da polimerização são sujeitos às reações de transferência para longos períodos de tempo, a probabilidade que uma unidade monomérica grude em uma cadeia polimérica tenha uma quebra de cadeia longa (densidade de quebra) ou um ponto de cisão (densidade de cisão) é maior que aquelas formadas nos estágios iniciais de polimerização. Pelo sistema sem reações de cisão, a densidade de quebra esperada das cadeias de radicais primários que são formadas em um patamar de conversão foi formulado para diversos tipos de reator.

Quando ambas a cisão e a quebra ocorrem como na figura 2, a cisão aleatória de moléculas poliméricas quebradas deve ser considerada. A predição dos produtos de cisão provenientes de polímeros quebrados não é uma tarefa fácil. Por exemplo, considere o número de possíveis pontos de cisão para obter uma molécula polimérica cujo grau de polimerização (GP) é 12 tendo duas quebras pela cisão de uma molécula polimérica cuja GP é 14 tendo duas quebras, como mostrada na figura G.3.

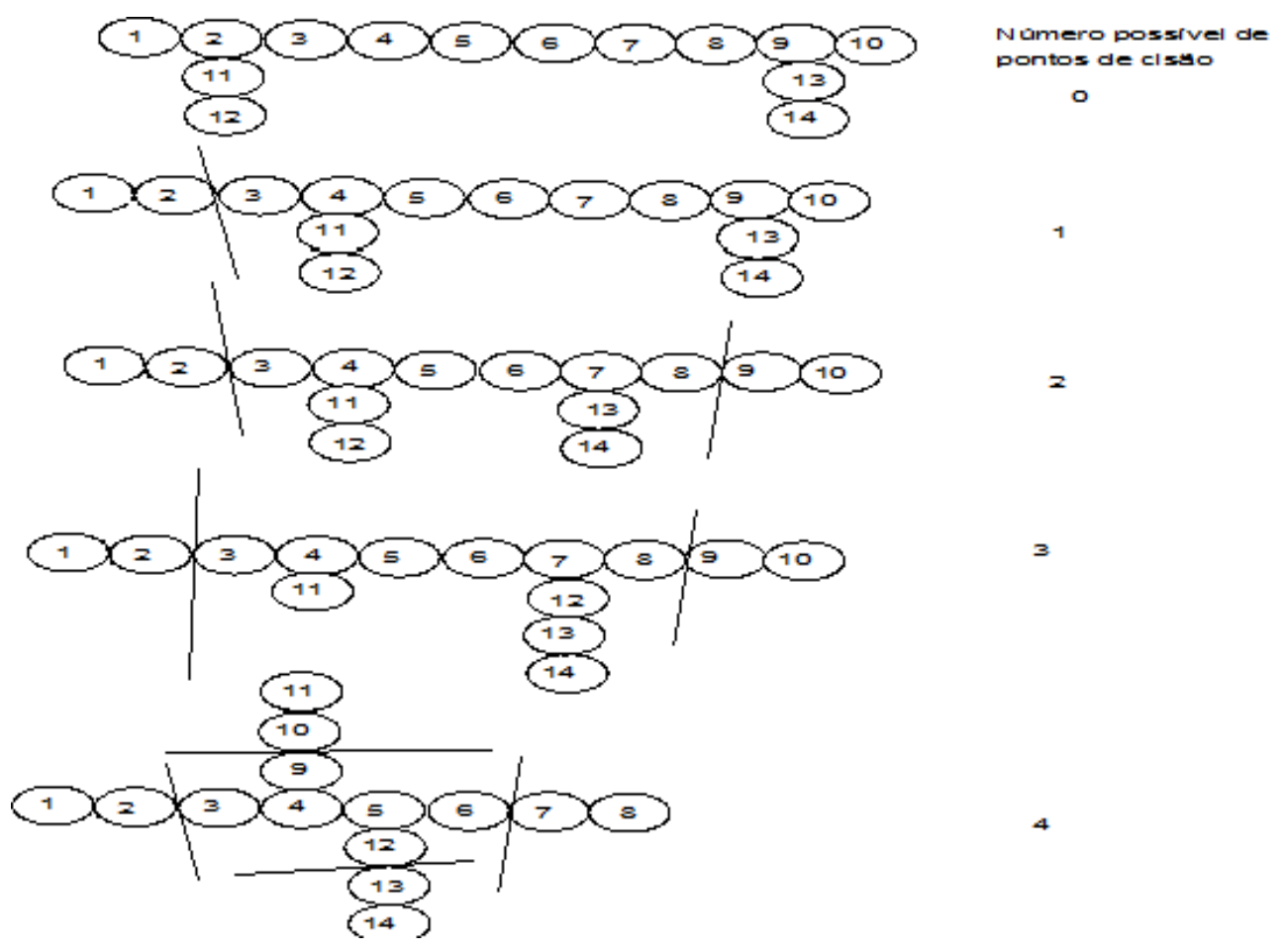

Figura G.3: Número de possíveis pontos de cisão obtidos, de um polímero, cujo GP é 12.

Tendo 2 quebras. Ocorridas pela quebra, de uma molécula polimérica, cujo GP é 14 . $\mathrm{E}$, tendo dois possíveis pontos de quebra. O número de possíveis pontos de cisão muda de 0 para 4 dependendo da estrutura do polímero. FONTE: (TOBITA,2000) 
Nesse exemplo o número possível de pontos de cisão muda de 0 para 4, dependendo das quebras ocorridas na estrutura original de polímero. Como o GP de moléculas poliméricas quebradas aumenta, o número de diferentes arquiteturas moleculares aumenta exponencialmente, e portanto, o problema de cisão aleatória de moléculas poliméricas quebradas não pode ser resolvida rigorosamente pelas equações diferenciais usuais de balanço populacional.

No caso de cisão aleatória de moléculas poliméricas com ligação cruzada (formadas pelo modelo de argola livre), os processo de ligação cruzada e cisão de cadeias são mutáveis internamente, e o problema pode ser resolvido artificialmente considerando os fragmentos da cadeia primária. Por outro lado, para polímeros quebrados, os processos não são mutáveis internamente e a cisão de cadeias de polímeros quebrados deve ser considerada diretamente. A degradação de moléculas poliméricas quebradas pode ser resolvida pela probabilidade de amostragem de números aleatórios e uma simulação de Monte Carlo (MC). Por causa da amostragem aleatória foi usada para resolver a quebra de cadeia longa para a formação de polímeros, tudo que se deve fazer e combinar as teorias da quebra de cadeia longa e de cisão aleatória de quebra de polímeros e levar em conta o crescimento de cadeia dos radicais terminais criados pela reação de cisão.

Assim temos uma amostragem aleatória que é usada para desenvolver uma simulação de MC que leve em conta a polimerização por radicais livres e que envolve simultaneamente a quebra de cadeias longas e a cisão. $\mathrm{O}$ número e tamanho médio de moléculas, e a distribuição de tamanhos moleculares completa, a determinação do ponto de gel, é possível fazer uma comparação experimental ou analítica, e também é possível construir um polímero bi ou tridimensional do sistema.

Terminações por desproporcionamento e cisão aleatória podem produzir polímeros com terminais que podem ser polimerizados nas duas fronteiras, mas as reações desses tipos de polímeros não serão consideradas. Também não serão consideras as reações em que o radical do polímero ataca seu próprio terminal formando cadeias pequenas em geral. Isto será feito pois em geral essas reações não alteram significativamente o a distribuição de peso molecular das partículas e tem um efeito muito pequeno na alteração das propriedades viscoelásticas. 
As reações elementares consideradas são, a iniciação $\mathrm{R}_{\mathrm{I}}$ taxa em [mol/ $\left.\mathrm{L} \mathrm{s}\right]$, propagação $R_{P}$, transferência de cadeia para moléculas pequenas como solvente, monômero, e agentes de transferência de cadeia $\mathrm{R}_{\mathrm{f}}$, terminação por desproporcionamento $\mathrm{R}_{\mathrm{td}}$, por combinação $\mathrm{R}_{\mathrm{tc}}$, e reações de transferência de cadeia para polímero que leva a uma quebra de cadeias longas $R_{b}$, e também a cisão de cadeias $R_{s}$.

Assumimos também que a hipótese do estado estacionário (G.1) e que todas as taxas e constantes cinéticas são independentes do comprimento de cadeia (G.2), estas são em geral hipóteses comuns adotadas na polimerização por radicais livres.

$$
\begin{aligned}
& R_{b}=k_{b}\left[R^{\bullet}\right] Q_{1} \quad, \quad Q_{1}=\sum_{r=1}^{\infty} r\left[P_{r}\right] \\
& R_{s}=k_{s}\left[R^{\bullet}\right] Q_{1}
\end{aligned}
$$

Onde $\left[\mathrm{P}_{\mathrm{r}}\right]$ é a concentração de polímero com grau de polimerização $\mathrm{r}$, com essas equações a probabilidade que um radical interno formado por reação de transferência de polímero leva a um ramificação de cadeia longa ou a uma cisão de cadeia e elas são mantidas constantes durante a reação.Note que isso é um simplificação das expressões para taxa.

A probabilidade que um radical polimérico começa a crescer de um centro de radical interno criado pela reação de transferência para polímero é dado por:

$$
P_{\lambda}=\frac{R_{b}}{R_{I}+R_{f}+R_{s}+R_{b}}=\frac{R_{b}}{R_{t c}+R_{t d}+R_{f}+R_{s}+R_{b}}=\frac{\lambda}{\tau+\beta+\sigma+\lambda}
$$

Onde $\tau=\left(R_{t d}+R_{f}\right) / R_{p}, \beta=R_{t c} / R_{p}, \sigma=R_{s} / R_{p}, \lambda=R_{b} / R_{p}$, perceba que os valores de Onde, $, \sigma, \lambda$, mudam com o tempo de reação, significando que todas as probabilidades apresentadas vão se alterar durante o curso da polimerização. Por outro lado por causa das cadeias primárias na polimerização por radicais livres poderem ser considerada como formadas instantaneamente (em um intervalo de tempo muito curto), as probabilidade são as mesmas tanto para as cadeias formadas no mesmo instante. Uma polimerização em batelada em que escolhemos uma determinada conversão $\mathrm{x}=0.8$, sendo ela uma variável independente, Então podemos concluir que todas as cadeias primárias formadas em $\mathrm{x}=0.3$ possuem o mesmo valor de $\tau$, mas para outra conversão $\mathrm{x}=0.5$ por exemplo esse valor é diferente $\tau_{\mathrm{x}=0.3} \neq \tau_{\mathrm{x}=0.5}$.

A probabilidade que um radical polimérico comece a crescer do fim de uma cadeia polimérica criada por cisão aleatória é: 


$$
P_{\sigma}=\frac{\sigma}{\tau+\beta+\sigma+\lambda}
$$

Neste caso, com metade dessa probabilidade o radical formado pela cisão de cadeias (A' na figura G.2), é um segmento que envolve o radical que iniciou a cadeia (pelo menos quando ele foi criado em $x=\theta$ ), $P_{\sigma H}$ ou que englobe a parte terminal $P_{\sigma T}$, denominada, $P_{\sigma T=}$ $\mathrm{P}_{\sigma \mathrm{H}}=\mathrm{P}_{\sigma} / 2$.

A probabilidade que um radical polimérico é terminado por combinação é dado por:

$$
P_{\sigma}=\frac{\beta}{\tau+\beta+\sigma+\lambda}
$$

Em uma polimerização em batelada, a probabilidade que uma unidade monomérica junte em uma cadeia polimérica em $\mathrm{x}=\theta$ tenha um ponto de quebra em $\mathrm{x}=\psi$, densidade de quebra, é:

$$
\rho(\theta, \psi)=C_{b} \ln \left(\frac{1-\theta}{1-\psi}\right)
$$

Onde $C_{b}=k_{b} / k_{p}$, e $k_{p}$ é a taxa de propagação. A forma funcional de $\rho(\theta, \psi)$, para outro reator em operação pode ser obtida de forma similar, significando que o presente método pode ser estendido para qualquer tipo de reator, tão grande quanto seja sua distribuição de tempo de residência de cada cadeia (ou segmento) dado.

O número de cadeias quebradas $\mathrm{m}$ em um dado segmento cujo comprimento de cadeia é $r$ e densidade de quebra é $\rho(\theta, \psi$ pode ser determinada pela geração de números aleatórios que seguem a seguinte distribuição binomial:

$$
\rho_{\text {Binom }}(m)=\left(\frac{r}{m}\right) p^{m}(1-p)^{r-m}
$$

Por causa da mesma expressão para a taxa para quebra de moléculas grandes e a usada para cisão aleatória são parecidas, a probabilidade que uma unidade monomérica junte em uma cadeia em $x=\theta$ e tenha um ponto de cisão em $x=\psi$ (densidade de cisão) segue a mesma forma funcional da equação (G.6):

$$
\eta(\theta, \psi)=C_{s} \ln \left(\frac{1-\theta}{1-\psi}\right)
$$

Onde $\mathrm{C}_{\mathrm{s}}=\mathrm{k}_{\mathrm{s}} / \mathrm{k}_{\mathrm{p}}$. 
Dado que uma unidade de uma cadeia formada em $\mathrm{x}=\theta$ é atacada por um radical polimérico e causa uma reação de transferência até a presente conversão $\psi$, a probabilidade que esta reação de transferência para polímero ocorra no intervalo de conversão $\theta$ par u $(\theta<\mathrm{u}<\psi), \rho_{\mathrm{A}}(\mathrm{u} \mid \theta)$, é dado por:

$$
\rho_{A}(u \mid \theta)=\frac{\ln \left(\frac{1-\theta}{1-u}\right)}{\ln \left(\frac{1-\theta}{1-\psi}\right)} \quad(\theta<u<\psi)
$$

A equação (9) pode ser usada para se determinar não apenas a conversão em que uma cadeia longa quebrada é formada, mas a conversão quando a reação de cisão aleatória ocorre em uma dada unidade.

Por outro lado, do ponto de vista de um radical polimérico que causa reação de transferência para polímero em $\mathrm{x}=\theta$, qualquer das unidades juntas em uma cadeia polimérica podem ser atacadas co probabilidade igual. Portanto, a probabilidade que uma conversão inicial de transferência de radicais primários esteja no intervalo de conversão 0 para $\mathrm{z}(0<\mathrm{z}<\theta), \rho_{\mathrm{A}}(\mathrm{z} \mid \theta)$ é simplesmente dado por:

$\rho_{z}(z \mid \theta)=\frac{z}{\theta} \quad(0<z<\theta)$

As equações (G.9) e (G.10) nos fornecem a relação de como as cadeias primárias formadas em diferentes patamares de conversão são conectados neste sistema reacional.

O número de distribuição de fração de radicais formados instantaneamente (o que significa que o segmento A' da figura G.2 é retirado se a cadeia primária começa a crescer de um radical criado por cisão aleatória) é dado pela seguinte distribuição mais provável:

$$
N_{p}^{\bullet}(r)=(\tau+\beta+\sigma+\lambda) \exp [-(\tau+\beta+\sigma+\lambda) r]
$$

Um número aleatório $\mathrm{r}$ que segue a distribuição mais provável descrita em (G.11) pode ser gerado usando se um gerador de números aleatórios entre 0 e 1 , y como segue:

$$
r=\text { int eiro }\left[\frac{1}{\tau+\sigma+\beta+\lambda} \ln \left(\frac{1}{y}\right)\right]
$$

Onde inteiro [a] indica o mais próximo inteiro não menor que a.

Suponha que a densidade de cisão de uma dada cadeia é $\eta$. Se esse valor $\eta$ é o mesmo para todas as unidades em uma dada cadeia, o número médio de comprimento de 
cadeia quebrado pela reação de cisão é $1 / \eta$, e a distribuição de comprimento e dada pela seguinte mais provável distribuição.

$N_{s}(r)=\eta \exp (-\eta r)$

De forma similar com a equação (G.12), um número aleatório s que segue a distribuição mais provável (G.13) pode ser gerado por (G.14):

$$
s=\operatorname{int} \operatorname{eiro}\left(\frac{1}{\eta} \ln \left(\frac{1}{y}\right)\right)
$$

Para uma dada cadeia, se $s<\mathrm{r}$, a cadeia foi quebrada por reação de cisão até o presente momento, e se s>r, a cadeia ainda não sofreu uma reação de cisão.

\section{Casos com cisão aleatória apenas}

Por causa de o problema ser complicado, trabalhoso, mas não difícil, considere os casos sem quebra de cadeia longa, então todas as reações de transferência de polímeros levam a cisão de cadeias. A técnica de amostragem aleatória é utilizada para resolver o problema. Com a técnica de amostragem aleatória, alguém aleatoriamente seleciona um grande número de moléculas poliméricas de um número infinito de espécies poliméricas e determina as propriedades estatísticas da mistura inteira efetivamente. Quando esse conceito é utilizado em um experimento, a solução analítica deve ser obtida, essa seria a simulação de Monte Carlo sem muitos detalhes.

\section{Método de Simulação}

Suponha que escolhemos uma unidade monomérica juntada em um polímero de uma mistura com reação em $x=\psi$. A figura G.4 mostra o exemplo dessa escolha. 


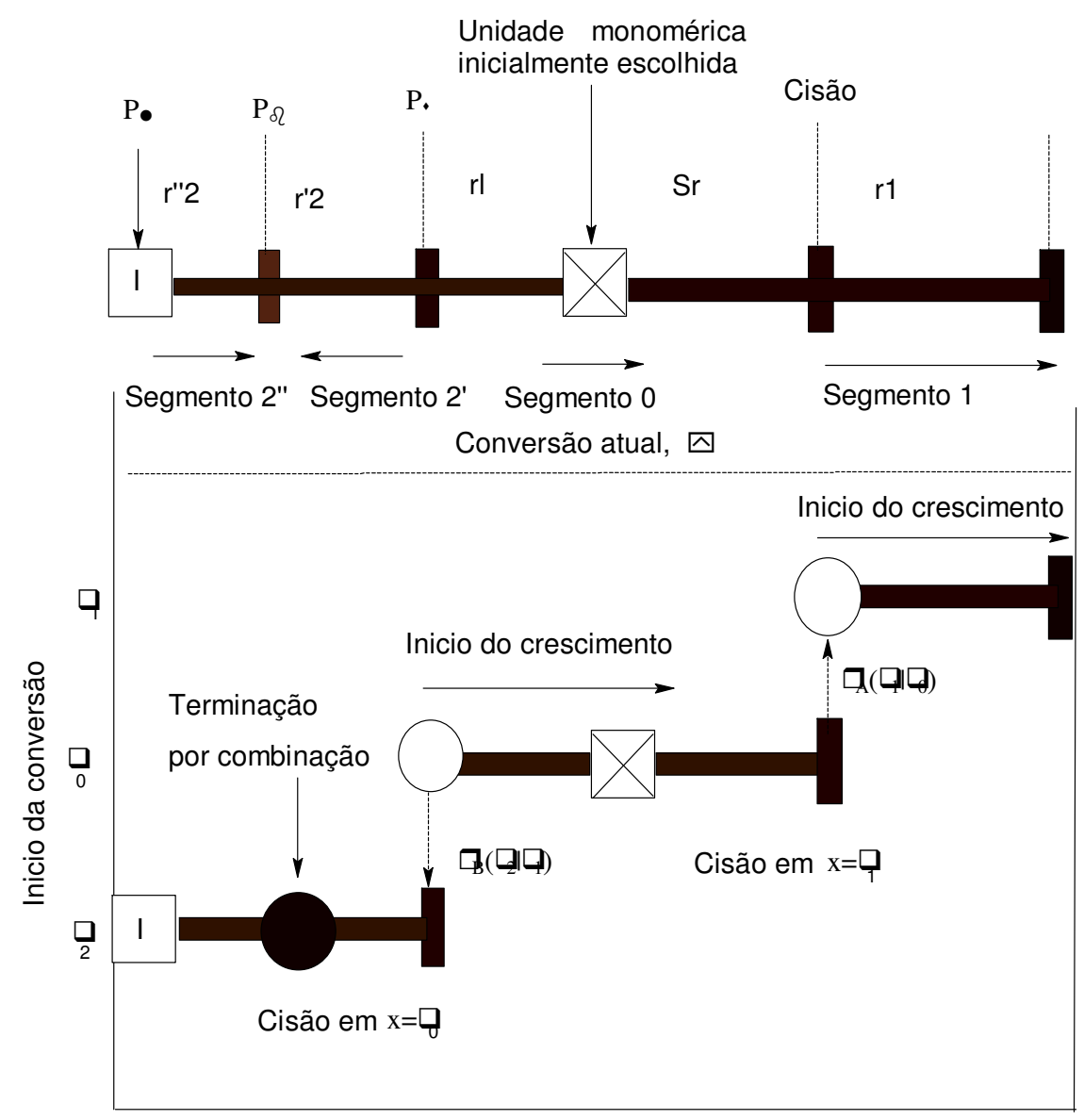

Figura G.4: Exemplo esquemático de uma molécula de polímero formada em polimerização por radical livre que envolve reação de cisão aleatória. A molécula polimérica escolhida é encontrada por segmentos baseados nos níveis de conversão inicial. FONTE: (TOBITA,2000)

Com as reações de cisões aleatórias, os segmentos formados em diferentes patamares de conversões são combinados para se formar uma simples molécula de polímero linear.

No exemplo o polímero consiste de quatro segmentos, cujas conversões iniciais são $\theta_{0}$ e $\theta_{1}$ para os segmentos 0 e 1 , respectivamente, e $\theta_{2}$, para ambos os segmentos 2 e 2 ", com a relação, $\theta_{2}<\theta_{0}<\theta_{1}$. As setas são usadas para indicar a direção do crescimento durante a formação de cada segmento. Os segmentos 2 e 2", são juntados por terminação por combinação, e portanto, as conversões iniciais são as mesmas. Note que a molécula polimérica escolhida por aleatoriamente se escolher uma unidade monomérica é 
considerada por ser escolhida em uma base mássica, então esta é uma cadeia escolhida da mistura reacional em uma base mássica.

Este polímero é gerado na simulação de MC assim, primeiro vamos considerar as conexões de cadeia na direita, começando da unidade escolhida aleatoriamente. A conversão inicial do segmento $0, \theta_{0}$ é determinada escolhendo-se um valora aleatório entre 0 e $\psi$. Uma vez que a conversão inicial foi escolhida, podemos calcular todas as probabilidades e funções apresentadas anteriormente sobre Monte Carlo. Pelo motivo desta cadeia ser escolhida em uma base mássica, o comprimento de cadeia do radical polimérico antes da parada em $x=\theta_{0}$ pode ser determinado gerando-se um número aleatório que segue a distribuição de fração mássica e a localização da unidade inicialmente selecionada pode ser determinada pela escolha de uma unidade aleatoriamente. Entretanto, devido a distribuição instantânea de tamanho de partículas com radical ser dada pelo mais provável distribuição, o comprimento de cadeia em ambas as direções da unidade escolhida aleatoriamente a distribuição segue a fração de distribuição numérica que é dada pela equação (G.11). Portanto o comprimento de cadeia do lado direito do segmento 0 sem a cisão de cadeia $\mathrm{r}_{\mathrm{r}}$, é obtida da equação (G.12), e este valor é comparado com o comprimento, $\mathrm{s}_{\mathrm{r}}$, dado pela equação (G.14) que nos fornece o comprimento caso a cisão tenha ocorrido. Com a competição desses dois comprimentos de cadeia, pode-se determinar se a reação de cisão na metade do lado direito do polímero do segmento 0 ocorreu até a presente conversão $\psi$. Neste exemplo, $\mathrm{s}_{\mathrm{r}}<\mathrm{r}_{\mathrm{r}}$, e, portanto, a reação de cisão ocorreu, $\theta_{1}$, pode ser determinado pela equação (G.9). Com probabilidade de 50\%, as muitas cadeias têm um centro com radical, em que é o caso do exemplo e ela cresce adicionando unidades monoméricas até $x=\theta_{1}$. $O$ comprimento de cadeia que cresce até $x=\theta_{1}$ pode ser determinado pela equação (G.12). Novamente a competição com a cisão de cadeias, equação (G.14) é considerada, e $\mathrm{r}_{1}<\mathrm{s}_{1}$, significando que a cisão não ocorreu neste segmento. Com probabilidade, $\mathrm{P}_{\beta}$, dado pela equação (G.5), o radical do fim da cadeia é juntado com outro radical polimérico pela terminação por combinação, mas esta cadeia não satisfaz a probabilidade $\mathrm{P}_{\beta}$, e o crescimento não é parado por terminação por combinação. Agora atingimos um dos lados finais do polímero.

A seguir devemos considerar o comprimento de cadeia do lado esquerdo começando da unidade escolhida inicialmente aleatoriamente. A conversão inicial, $\theta_{0}$, já foi 
determinada, e a direção do lado esquerdo do comprimento do segmento 0 pode ser obtido da competição dos comprimentos da equação (G.12) e (G.14). Note que por causa de $r_{L}$ não envolver a unidade inicialmente escolhida, $r_{L}=r-1$. No presente caso, $r_{L}<s_{L}$ e a cisão não ocorreu neste pedaço do segmento 0. Esta cadeia pode ter começado o crescimento de um radical polimérico formado pela reação de cisão que ocorreu em $\mathrm{x}=\theta_{0}$, cuja probabilidade, $\mathrm{P}_{\sigma}$, é dada pela equação (G.4), que é o caso do presente exemplo. A unidade que causou a cisão de cadeia em, $x=\theta_{0}$, é determinada escolhendo-se aleatoriamente uma unidade polimerizada antes de $x=\theta_{0}$. Esse processo é equivalente ao que foi feito para se determinar a unidade escolhida inicialmente se a presente conversão e elevada de $\psi$ para $\theta_{0}$. A conversão inicial do segmento 2', $\theta_{2}$, e determinado pela equação (G.10). O comprimento r' ${ }_{2}$ e determinado pela competição entre as equações (G.12) e (G.14), e a reação de cisão não ocorreu no segmento 2'. Em x $=\theta_{2}$, a direção do crescimento do segmento 2' e para o lado esquerdo com probabilidade de $50 \%$ que é o caso para este segmento como mostrado pela flecha da figura. Com probabilidade, $\mathrm{P}_{\beta}$, dada pela equação (G.5), esta cadeia se torna um polímero morto pela terminação por combinação, e o segmento 2" tendo r"' ${ }_{2}$ é adicionado. O comprimento de cadeia $\mathrm{r}^{\text {' }}{ }_{2}$, é determinado pela competição das equações (G.12) e (G.14), resultando em $\mathrm{r}^{\prime}{ }_{2<\mathrm{S}}{ }_{2}$, e a cisão não ocorreu no segmento 2 '”. A possibilidade que o segmento 2 "' tenha começado a crescer por meio dos muito radicais é checada por $P_{\sigma}$ dado pela equação (G.4), mas a cadeia de iniciação não é um desses muitos radicais poliméricos neste caso.

Neste ponto, os comprimento e conversões iniciais de todos os segmentos que formam este simples polímero foram determinados. Esta molécula polimérica possui uma cadeia de iniciação final representada por I. No presente exemplo, a formação de ramificação de cadeias longas não ocorre, e a iniciação final da cadeia e feita por um fragmento de iniciador ou pela transferência de radical (moléculas pequenas). Quando simultaneamente ramificação e cisão são consideradas, esse grupo inicial (I) poderia ser um radical interno, em uma outra, cadeia cuja probabilidade $\mathrm{P}_{\lambda}$ é dada pela equação (G.3). É possível notar que a densidade de ramificação é diferente daquela do segmento inicial em diferentes patamares de conversão, conforme já foi explicado anteriormente que as probabilidade mudam dependendo da conversão (TOBITA,2001).

Um resumo do que foi explicado até agora pode ser visto no esquema da figura G.5 
Funcionamento do algoritimo de Monte Carlo (MC)

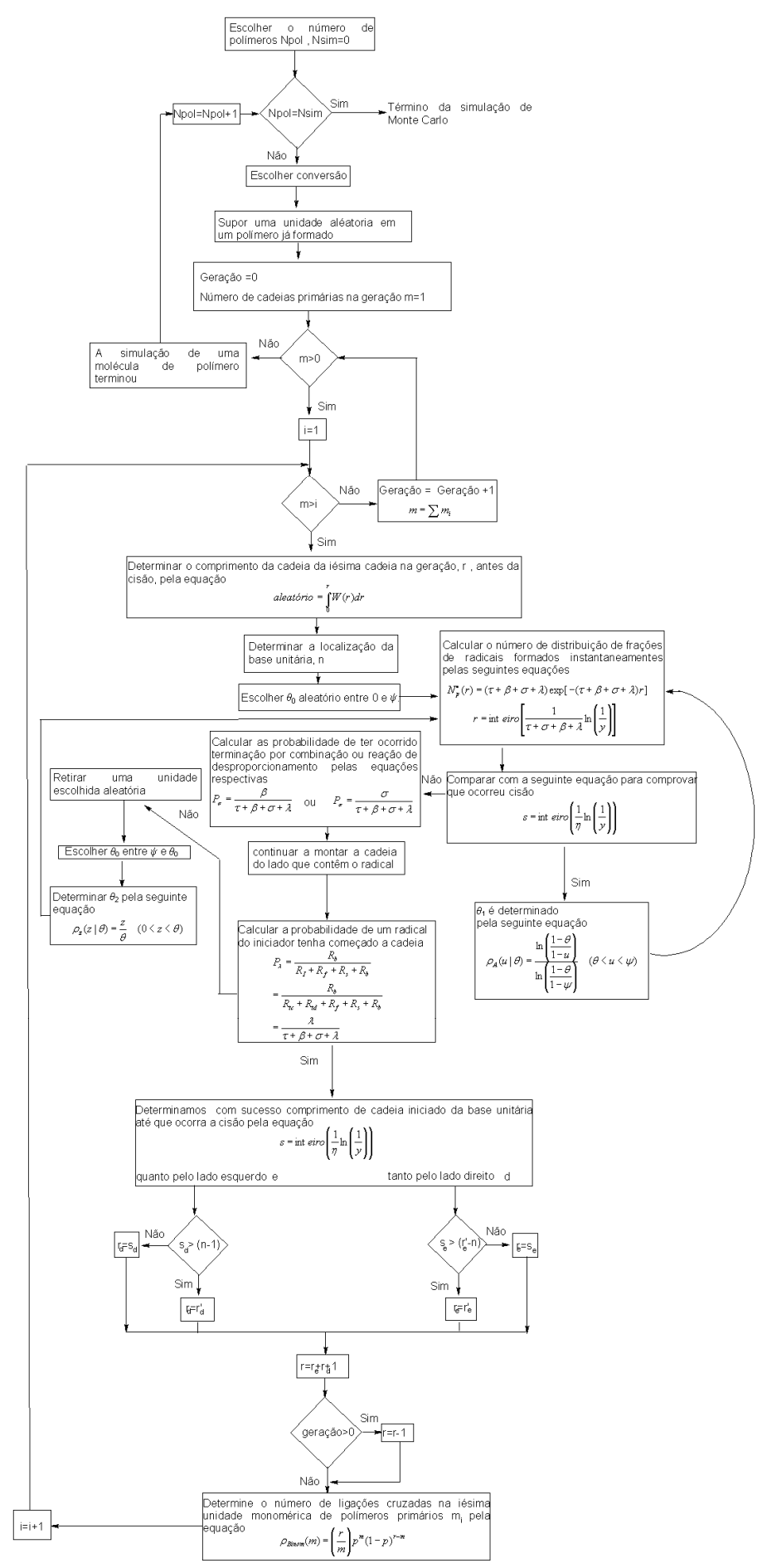

Figura G.5 Funcionamento do método de Monte Carlo 
Com a aplicação do método dos momentos, a solução analítica para o presente caso são as provenientes das seguintes equações de momento.

$$
\begin{aligned}
& \frac{d q_{0}}{d x}=\tau+\frac{\beta}{2}+C_{S 1} \\
& \frac{d q_{1}}{d x}=1 \\
& \frac{d q_{2}}{d x}=\frac{2+2 C_{B 2}+C_{S 2}}{\tau+\beta+C_{B 1}+C_{s 1}}-\frac{C_{S 3}}{3}+\beta\left(\frac{1+C_{B 2}+C_{S 2} / 2}{\tau+\beta+C_{B 1}+C_{S 1}}\right)^{2}
\end{aligned}
$$

onde

$q_{i}=\frac{Q_{i}}{[M]_{0}} \quad, \quad Q_{i}=\sum_{r=1}^{\infty} r^{i}\left[P_{r}\right]$

$C_{B i}=\frac{k_{b} Q_{i}}{k_{p}[M]}=C_{b} \frac{q_{i}}{(1-x)}$

$C_{S i}=\frac{k_{s} Q_{i}}{k_{p}[M]}=C_{s} \frac{q_{i}}{(1-x)}$

Note que $\mathrm{q}_{1}=\mathrm{x}, \mathrm{C}_{\mathrm{s} 1}=\sigma$, e $\mathrm{C}_{\mathrm{B} 1}=\lambda$.

Um problema aqui é que a equação (G.17) não é fechada e um terceiro momento esta envolvido. Uma método de aproximação convencional para evitar esse problema é utilizar a distribuição (SZ) Schulz- Zimm e portanto utilizar a seguinte regra de fechamento, embora essa regra nunca foi justificada teoricamente (TOBITA,2004), o que pode gerar resultados errados vindos dessas aproximações impróprias das equações de momentos como os obtidos por (TEYMOUR;CAMPBELL,1994).

$Q_{3}=Q_{2}\left(2 \frac{Q_{2}}{Q_{1}}-\frac{Q_{1}}{Q_{0}}\right)$

O momento de ordem zero e a equação do primeiro momento (G.15) e (G.16), podem ser resolvidos sem a regra de fechamento e eles resultam exatamente no número médio de grau de polimerização. Por outro lado o peso médio de GP deve ser uma aproximação.

Quando nenhuma ramificação de cadeia longa ocorre $\left(\mathrm{C}_{\mathrm{b}}=0\right)$, e o conjunto de equações de balanço populacional nesse caso será mais simplificado, isso porque as reações de cisão de polímeros ramificadas não são envolvidas. 
Na simulação de Monte Carlo, vários, tipos, de informações, detalhadas, podem ser obtidas, por meio de apenas algumas amostras de simulações. A distribuição SZ é em função de dois parâmetros que podem ser determinados do numérico e do peso molecular médio do grau de polimerização obtidos da simulação de Monte Carlo (TOBITA,2001)

Um teste para verificar o método de monte Carlo pode ser realizado, nas figura G.5 a G.7 apresenta-se casos em que não há quebra de cadeia longa e na figura três um caso em que há quebra de cadeia longa podemos ver que os momentos divergem mais do resultado real de monte carlo, que por ser mais detalhado deve representar melhor o sistema.

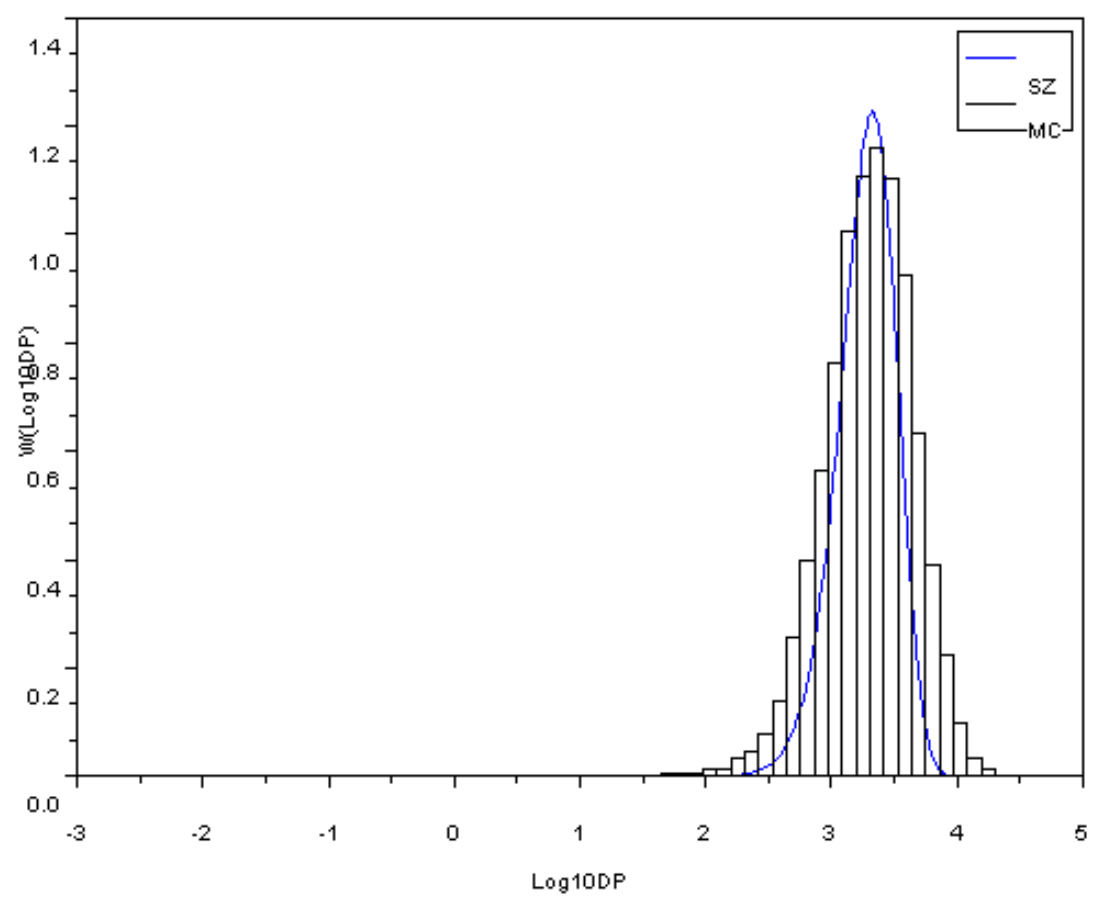




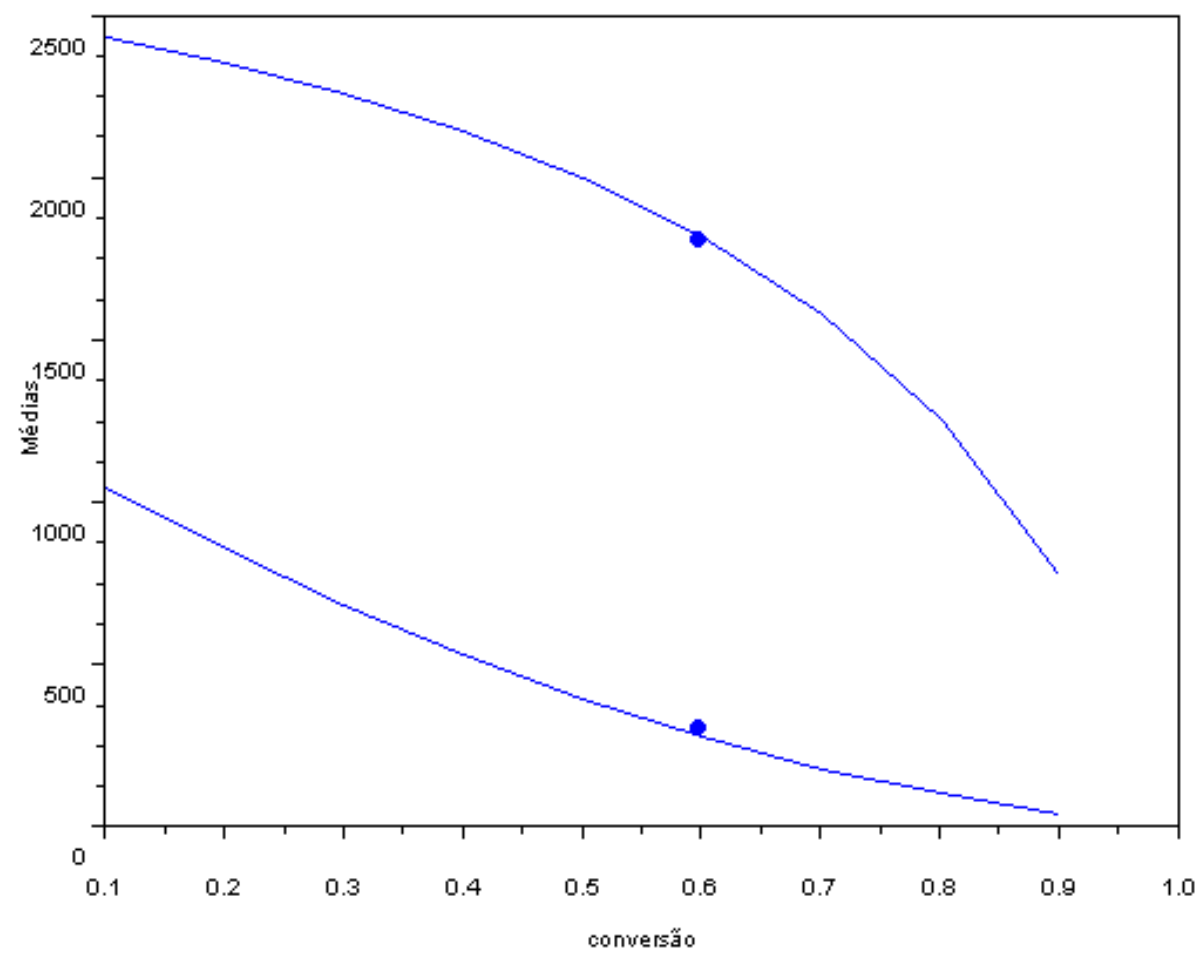

Figura G.5: Simulação de Monte Carlo e comparação com os momentos para o caso, $\operatorname{tau}=0.0003 ;$ Beta $=0 ; \mathrm{Cs}=0.001 ; \mathrm{Cb}=0 ;$ lambda $=0 ;$ phi $=0 ;$ 

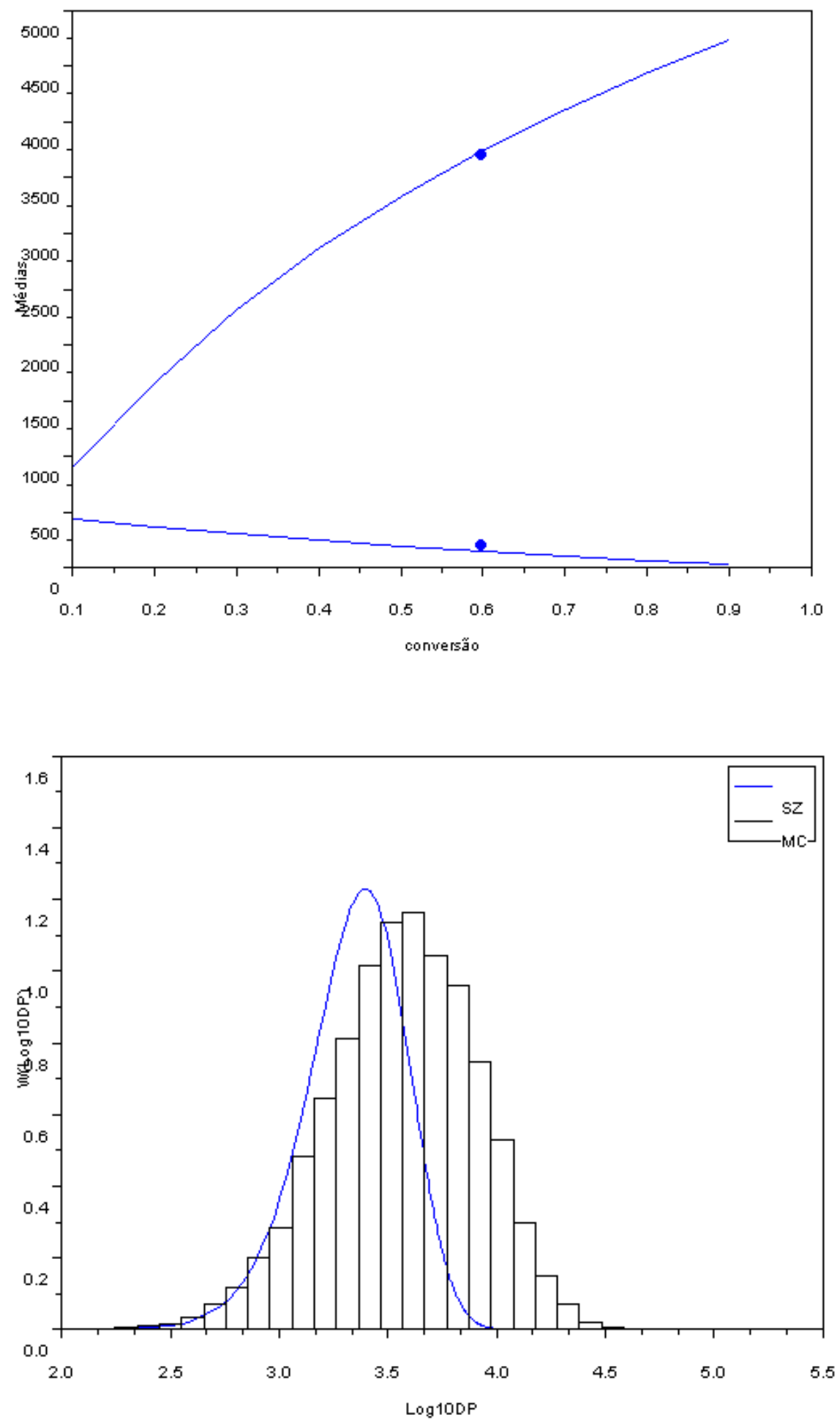

Figura G.6: Simulação de Monte Carlo e comparação com os momentos, para o caso tau $=0.0001 ; \operatorname{Beta}=0 ; \mathrm{Cs}=0.001 ; \mathrm{Cb}=0.01$. 

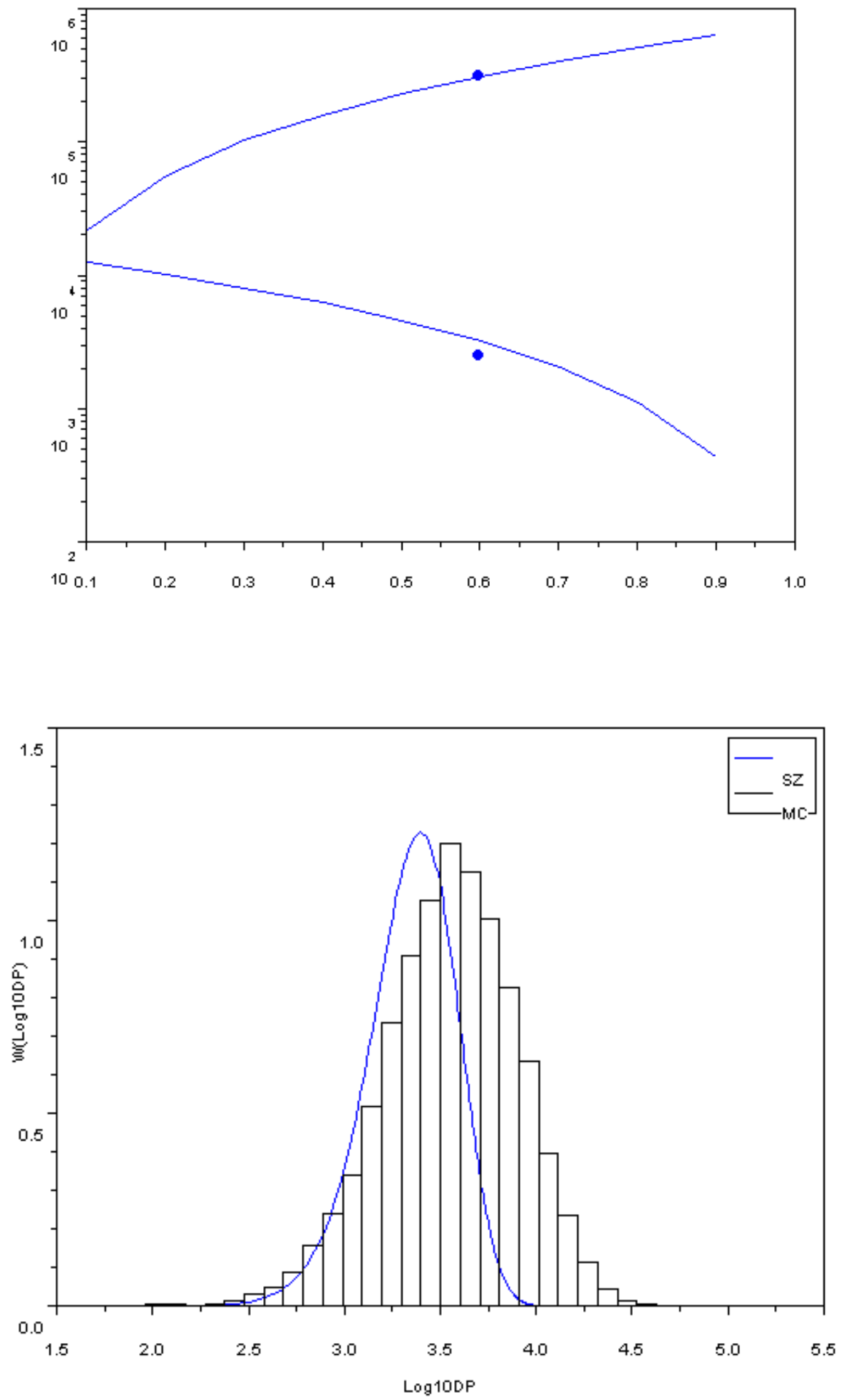

Figura G.7 Simulação de Monte Carlo e comparação com os momentos para o caso tau $=0.0005 ;$ Beta $=0 ; C s=0.001 ; \mathrm{Cb}=0.01 ;$ lambda $=0.2$; 
Na figura G.7 a simulação é feita de maneira mais abrangente que nas simulações anteriores, resumidamente nesse caso o que foi feito foi utilizar mais de uma geração de moléculas, utilizamos na simulação 100 gerações, a primeira geração de moléculas é a descrita conforme anteriormente e nas gerações seguintes pegamos cada radical terminal da cadeia e acoplamos com outra cadeia aleatória até formarmos uma unidade polimérica onde toda a geração anterior foi juntada e continuamos para a geração 2,3,4 e assim podemos gerar polímeros que foram ramificados, explicando detalhadamente esse procedimento teríamos o seguinte, a molécula de polímero na figura G.4 é a geração zero. A cadeia seguinte que será a conexão referente a geração um é obtida assim. A parte iniciada do polímero final (I) agora será iniciada não por uma molécula pequena mas por um radical de uma cadeia longa, cuja probabilidade $\mathrm{P}_{\lambda}$ dada pela equação G.3. Se essa cadeia é conectada à uma cadeia polimérica a cadeia onde será o ponto de conexão desse polímero que vai se conectar é escolhido aleatoriamente da mistura reacional em $\mathrm{x}=\theta_{2}$, notadamente da equação G.10. A estrutura dessa cadeia já foi determinada como visto anteriormente pela simulação da geração zero de polímeros, basta juntar o ponto conectado de um polímero com o ponto conectado de outro.

Quando a terminação bimolecular é envolvida ambos os finais da cadeia poderiam ser o inicio de conexão de uma nova cadeia, entretanto, no exemplo, a outra cadeia não é um final de iniciação de terminação e não pode ser conectado à uma cadeia longa.

As esperadas densidades de cisão dos segmentos são diferentes excetos pelo segmento 2' e pelo segmento 2', cujas conversões de nascimento são as mesmas. A densidade de cisão de cada segmento pode ser determinada pela equação G.6 pelo fato de conhecermos a conversão de nascimento de cada segmento. O número de cisões de cada segmento é determinada pela distribuição binomial dada pela equação G.7. A conversão de nascimento de cada cadeia cindida que iniciou o crescimento de um determinado segmento é obtida pela equação G.9. Uma vez determinada a conversão de nascimento, podemos gerar cada cisão de cadeias como foi feito para determinar a estrutura do lado direito da molécula polimérica mostrada já na figura G.3. Quando a terminação por combinação é envolvida, o outro final da cadeia de cada cadeia cindida poderia ser a cadeia inicial e a possibilidade desse ponto se conectar a outra cadeia longa deve ser considerado. 
Uma vez que todas as cadeias conectadas à molécula polimérica da figura G.3 são geradas (primeira geração), o cálculo continua para a próxima geração até que todas as cadeias se conectem. Nesse estágio, o tamanho, e, a estrutura, de uma molécula, é determinada. Ao gerarmos a um número grande de polímero deste modo as propriedades estatísticas de toda a mistura onde ocorre a reação pode ser estimada.

Alternativamente poderíamos tentar abordar a cisão de moléculas utilizando-se apenas a formulação de balanço populacional. As equações de balanço populacional para os radicais poliméricos, $\mathrm{R}_{\mathrm{r}}^{\cdot}$ (radical polimérico com comprimento $\mathrm{r}$ ), seria:

$$
\begin{aligned}
& \frac{d\left[R_{1}\right]}{d t}=R_{I}+\left(k_{f m}[M]+k_{f C T A}[C T A]+k_{b}\left[P_{1}\right]\right)\left[R \cdot+k_{s}\left[R \cdot \sum_{s=2}^{\infty} \xi\left[P_{s}\right]-\left\{\left(k_{p+k_{f m}}\right)[M]\right.\right.\right. \\
& \left.+k_{f C T A}[C T A]+\left(k_{t d}+k_{t c}\right)\left[R^{\prime}\right]+k_{b} Q_{1}+k_{s} \sum_{s=2}^{\infty}(s-1)\left[P_{s}\right]\right\}\left[R_{1}\right] \\
& \frac{d\left[R_{r}^{\prime}\right]}{d t}=k_{p}[M]\left[R_{r-1}^{\cdot}\right]+k_{f C T A}[C T A]+k_{b} r\left[P_{r}\right]\left[R^{\cdot}\right]+k_{s}\left[R^{\cdot}\right] \sum_{s=r+1}^{\infty} \xi\left[P_{s}\right]-\left\{\left(k_{p+k_{f m}}\right)[M]\right. \\
& \left.+k_{f C T A}[C T A]+\left(k_{t d}+k_{t c}\right)\left[R^{\prime}\right]+k_{b} Q_{1}+k_{s} \sum_{s=2}^{\infty}(s-1)\left[P_{s}\right]\right\}\left[R_{r}^{\cdot}\right](r \geq 2)
\end{aligned}
$$

Onde [CTA] é a concentração de agentes de transferência de cadeia incluindo pequenas moléculas, como solvente, e, iniciador e $\left[\mathrm{P}_{\mathrm{r}}\right]$ e a concentração moléculas de polímero morto com comprimento $r$. As taxas $k_{p}, k_{f m}, k_{f C T A}, k_{t d}, k_{t c}, k_{b}$ e $k_{s}$ são para propagação, transferência de cadeia para monômero, para CTA, terminação por desproporcionamento, por combinação, quebra de cadeia longa, e cissão de cadeia respectivamente. $\mathrm{Q}_{1}$ é o primeiro momento da distribuição de polímero morto, $Q_{1}=\sum_{r=1}^{\infty} r\left[P_{r}\right]$

O conceito de $\xi$ representa a possibilidade de determinado número de pontos de cisão para a obtenção de $R_{r}$, pelo corte em $P_{s}(s>r)$. O problema aqui é que é impossível determinar o valor de $\xi$, por que ele depende de detalhes da estrutura molecular.

Se todas as cadeias forem lineares, o número possível de pontos de cissão serão 2 , e com probabilidade de 50\% um fragmento se tornara um radical polimérico. Portanto, $\xi=1$ para sistemas de polimerização linear.

Agora, se assumirmos esse erro $(\xi=1)$, podemos obter equações de momento e com a hipótese de estado estacionário podemos obter os momentos para os radicais poliméricos. 
Portanto essas equações são substituídas por equações de momentos para as moléculas de polímero morto que podem ser obtidas do balanço populacional para o polímero morto como:

$$
\begin{aligned}
& \frac{d\left[P_{r}\right]}{d t}=\left(k_{f m}[M]+k_{f C T A}[C T A]+k_{t d}\left[R^{\cdot}\right]+k_{b} Q+k_{s} \sum_{s=2}^{\infty}(s-1)\left[P_{s}\right]\left[R_{r}^{\cdot}\right]-k_{s}\left[R^{\cdot}\right] \sum_{s=r+1}^{\infty} \xi\left[P_{s}\right]\right. \\
& +\frac{1}{2} k_{t c} \sum_{s=1}^{r-1}\left[R_{s}^{\cdot}\left[R_{r-s}^{\cdot}\right]-k_{b} r\left[P_{r}\right]\left[R^{\cdot}\right]-k_{s}(r-1)\right\}\left[P_{r}\right]\left[R^{\cdot}\right]
\end{aligned}
$$

Se mudarmos a variável independente para conversão $\mathrm{x}$ usando $\mathrm{dx} / \mathrm{dt}=\mathrm{k}_{\mathrm{p}}(1-$ $\mathrm{x})[\mathrm{R} \cdot$, obtemos as equações de momento.

Neste trabalho utilizamos a simulação de monte Carlo para uma comparação, também com o método do problema inverso. No caso em que verificamos a coerência dele. Em relação à quebra radicalar de cadeias lineares de polipropileno. Como é descrito pela figura G.8. 
(a) Distribuições para quebra radicalar de cadeias lineares, de polipropileno

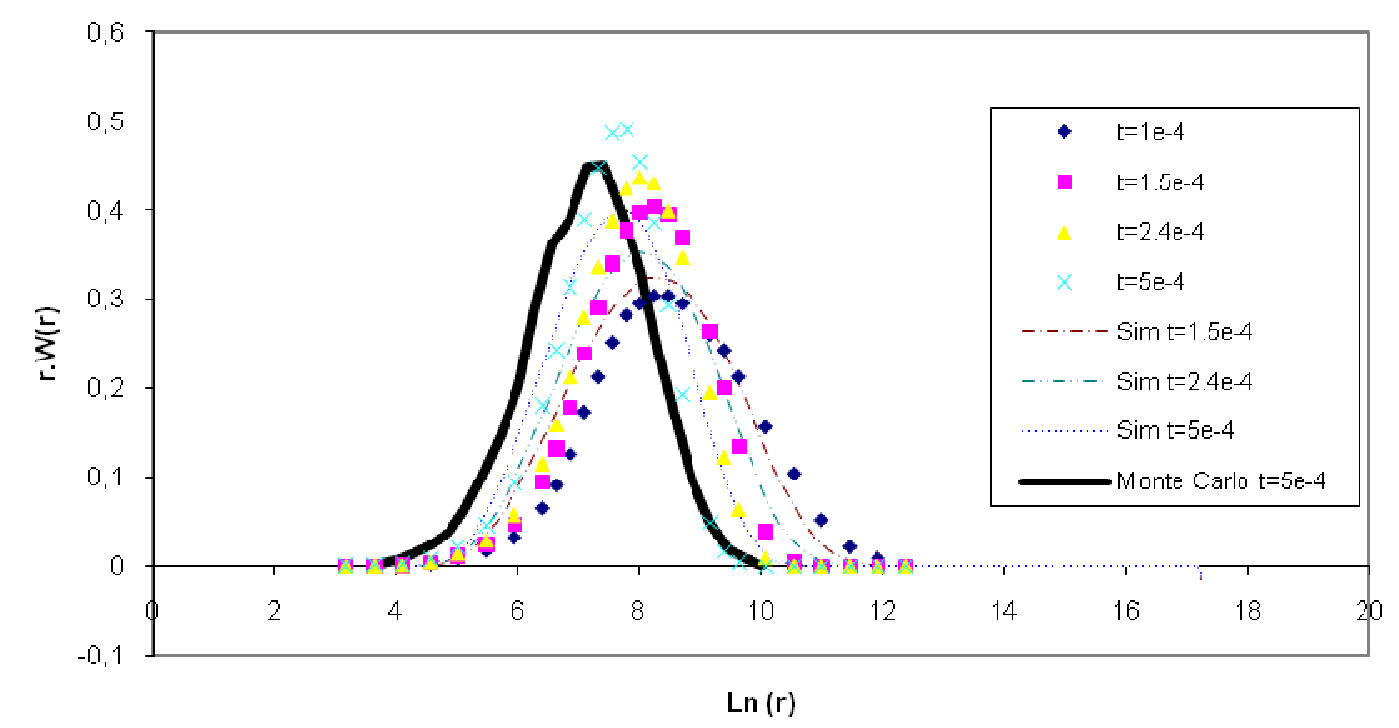

(b) Função cumulativa para quebra radicalar de cadeias lineares, de polipropileno

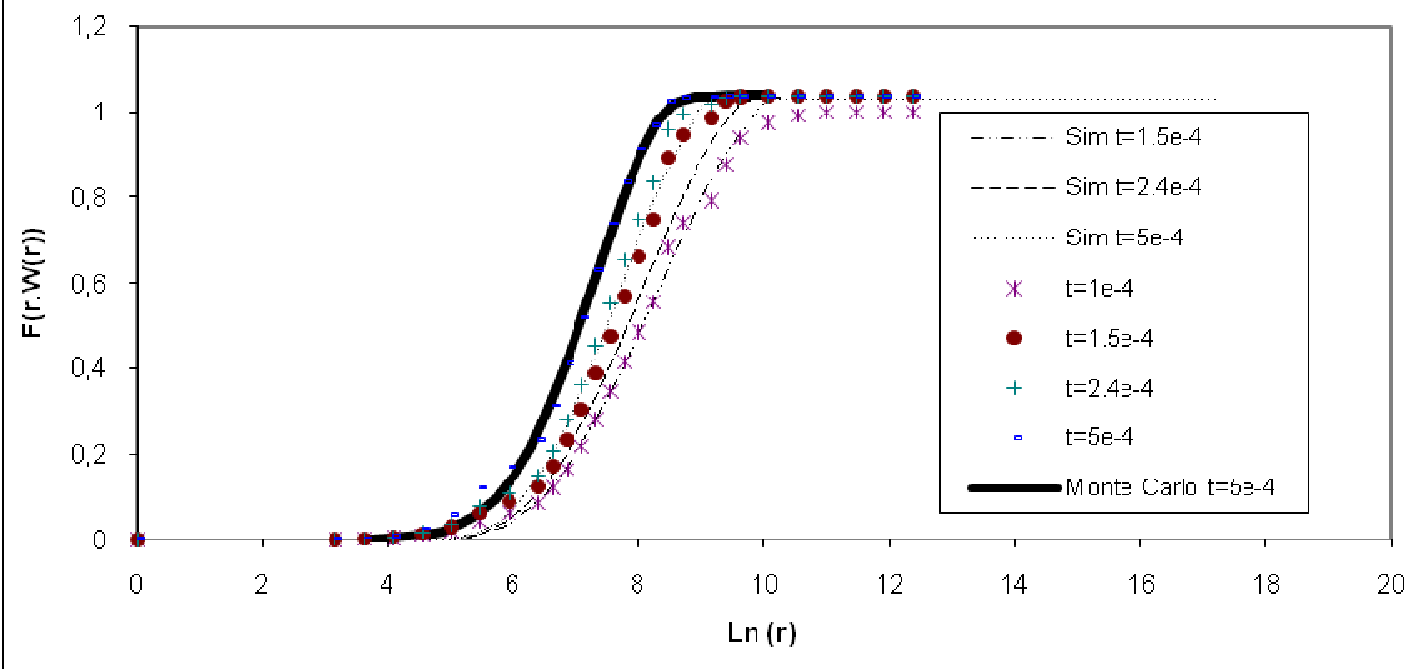

Figura G.8: Comparação dos dados experimentais com as curvas calculadas pelo problema inverso: (a) distribuições diferenciais e (b) funções cumulativas. 


\section{APÊNDICE H: ABORDAGEM MATRICIAL PARA O BALANÇO POPULACIONAL E CÁLCULO DO PROBLEMA INVERSO.}

A equação clássica de balanço populacional (3.1.14), pode ser resolvida assumindose que a taxa de quebra e as funções de seleção são independentes do tempo. Isso será feito transformando-se o balanço populacional em termos de matrizes.

Usando-se a matriz diagonal $\mathrm{S}$ (contendo os elementos de quebra $\Gamma_{\mathrm{i}}$ ), a matriz diagonal $\mathrm{B}$ (contendo os elementos $\mathrm{b}_{\mathrm{i}, \mathrm{j}}$ ) e a matriz coluna $\mathrm{W}$ (que é a própria distribuição de partículas $\mathrm{N}_{\mathrm{i}}$ ) junto com a matriz identidade I. E poderemos escrever o balanço populacional de quebra como:

$\frac{d W}{d t}=A W=(B-I) S$

Se S é independente do tempo, então a equação (H.2) é um sistema diferencial de dimensão $\mathrm{n}$ de primeira ordem linear homogênea que pode ser facilmente resolvido por diagonalização. A é uma matriz triangular e, portanto diagonalizavél, com suas, raízes, características sendo os elementos de sua diagonal, isto é, os valores $-\mathrm{S}_{\mathrm{i}}$. Portanto existe, uma matriz $\mathrm{P}$, que tem a sua inversa $\mathrm{P}^{-1}$, tal que:

$$
\begin{aligned}
& \begin{aligned}
S=- & P^{-1} A P \\
& \text { Então, podemos reescrever a equação (H.1) como } \\
\frac{d W}{d t}= & -P S P^{-1} W
\end{aligned}
\end{aligned}
$$

$\mathrm{W}=\mathrm{PZ}$

Se definirmos a matriz coluna $\mathrm{Z}$ como (H.4)

Obteremos por substituição simples (H.5):

$P \frac{d Z}{d t}=-P S P^{-1} P Z$

Que pode ser simplificado na equação (H.6)

$$
\frac{d Z}{d t}=-S Z
$$

Como S é uma matriz diagonal, essa equação (H.6) pode ser facilmente integrada para a obtenção de (H.7):

$$
Z=\mu_{d} E_{s}(t)
$$

Em que $\mu_{\mathrm{d}}$ é uma matriz diagonal das constantes de integração e $\mathrm{E}_{\mathrm{s}}(\mathrm{t})$ é uma matriz coluna consistindo dos elementos $\exp \left(-\mathrm{S}_{\mathrm{i}} \mathrm{t}\right)$. Tudo que resta fazermos é retornarmos à matriz $\mathrm{W}$ por meio da matriz de transferência $\mathrm{T}=\mathrm{P} \mu_{\mathrm{d}}$ de forma que 
$W=T E_{s}(t)$

A matriz produto para cada classe de tamanho i então nos dá um sistema de equações $|\Sigma|$ para a resolução da fração mássica de cada classe $\mathrm{N}_{\mathrm{i}}$ ao longo do tempo:

$$
\left|\sum\right|=\left[\begin{array}{l}
N_{1}(t)=t_{11} \exp \left(-S_{1} t\right) \\
N_{2}(t)=t_{21} \exp \left(-S_{1} t\right)+t_{22} \exp \left(-S_{2} t\right) \\
N_{3}(t)=t_{31} \exp \left(-S_{1} t\right)+t_{32} \exp \left(-S_{2} t\right)+t_{33} \exp \left(-S_{3} t\right) \\
\vdots \\
N_{n}(t)=t_{n 1} \exp \left(-S_{1} t\right)+t_{n 2} \exp \left(-S_{2} t\right)+t_{n 3} \exp \left(-S_{3} t\right)+t_{n n} \exp \left(-S_{n} t\right)
\end{array}\right]
$$

A determinação dos parâmetros $t_{i, j}$ e $S_{i}$ do sistema $|\Sigma|$ de tamanhos de partículas durante um determinado processo de um sistema, como já vimos se chama problema inverso. Pelo que vimos até agora podemos concluir que o conhecimento das matrizes $\mathrm{T}$ e $\mathrm{S}$ permitem o cálculo da matriz correspondente a função de quebra. Se eliminarmos A das equações (H.1) e (H.2) obteremos para a quebra:

$$
B=I-P S P^{-1} S^{-1}
$$

É possível mostrar que os elementos da matriz $\mu_{\mathrm{d}}$ são os elementos da diagonal de $\mathrm{T}$.

Na prática a matriz de passagem $\mathrm{P}$ é obtida por um algoritmo dado pelo sistema $\mathrm{AP}=\mathrm{PD}$. Se escrevermos isso na forma de índices

$$
\sum_{k=1}^{n} a_{i, k} p_{k, j}=\sum_{k=1}^{n} p_{i, k} d_{k, j}
$$

Desde que $a_{i, k}=0$ para $k>i, d_{k, j}=0$ para $k$ diferente de $j$, e $d_{j, j}=a_{j, j}$, isso pode ser escrito como:

$$
\sum_{k=1}^{n} a_{i, k} p_{k, j}=a_{j, j} p_{i, j}
$$

$\mathrm{Ou}$

$$
a_{i, i} p_{i, j}+\sum_{k=1}^{i-1} a_{i, k} p_{k, j}=a_{j, j} p_{i, j}
$$

O termo $\mathrm{p}_{\mathrm{i}, \mathrm{j}}$, pode, portanto ser calculado pelo $\mathrm{i}-1$ valores anteriores usando a formula:

$$
p_{i, j}=\sum_{k=1}^{i-1} \frac{-a_{i, k}}{a_{i, i}-a_{i, j}} p_{k, j}
$$


Podemos notar que os termos $p_{i, j}$ podem ter qualquer valor para $\mathrm{j} \geq \mathrm{i}$, o que não é surpresa pois a matriz de passagem $\mathrm{P}$ não é única, já que é composta de raízes características dentro de um fator multiplicativo. Isso significa que $p_{i, j}=0$ se $j>i$ e $p_{i, i}=1$. A matriz de passagem é, portanto, da seguinte forma:

$$
p=\left[\begin{array}{ccccc}
1 & 0 & \cdots & \cdots & 0 \\
p_{2,1} & 1 & & & \vdots \\
\vdots & & \ddots & & \vdots \\
\vdots & & & 1 & 0 \\
p_{n, 1} & \cdots & \cdots & p_{n, n-1} & 1
\end{array}\right]
$$

A matriz diagonal $\mu_{\mathrm{d}}$, pode ser definida pelo produto das matrizes $\mathrm{T}=\mathrm{P} \mu_{\mathrm{d}}$, que tem a sua forma:

$$
t_{i, j}=p_{i, j} \mu_{i, j}
$$

Colocando-se $\mathrm{i}=\mathrm{j}$ nesta equação e notando que $\mathrm{p}_{\mathrm{i}, \mathrm{j}}=1$ (como já explicado), os componentes de $\mu_{\mathrm{d}}$, são claramente os elementos da diagonal de $\mathrm{T}$.

Desde que $\mathrm{P}=\mathrm{T} \mu_{\mathrm{d}}, \mathrm{P}$ é a matriz de passagem e já é conhecida da equação (H.10) e por ela chegamos à matriz que representa a função de quebra $\mathrm{B}$ como podemos observar pela figura (H.1). Geralmente a identificação e dos parâmetros de uma soma de exponencial e um problema trivial, porem para um número elevado de pontos como no sistema $|\Sigma|$, o problema se torna bem difícil é necessário uma grande precisão para esse tipo de solução.

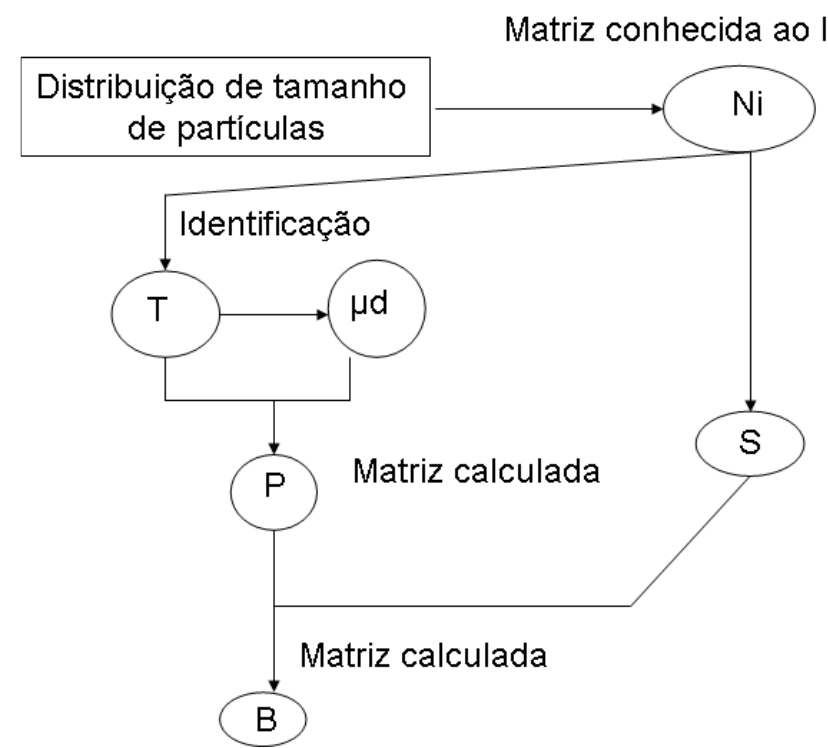

Figura H.1: Metodologia para a obtenção da quebra e das matrizes de seleção por otimização direta. FONTE:(BERTHIAUX;DOODS,1997). 
Examinando a equação (H.8) nos mostra que a matriz $\mathrm{E}_{\mathrm{s}}(\mathrm{t})$ contém apenas os elementos $\mathrm{S}_{\mathrm{i}}$ como incógnitas. $\mathrm{O}$ método de diferenciação sequencial desenvolvido, consiste em fazer uma manipulação matemática do sistema $|\Sigma|$ para isolar esses elementos. Uma vez que a matriz de função de seleção é obtida a determinação da taxa de quebra pode ser calculada por uma simples otimização linear que pode ser realizada com um algoritmo como, por exemplo, o de Levenberg- Marquadt.

Como um problema preliminar, podemos considerar encontrar o parâmetro s na seguinte equação onde a e b são constantes desconhecidas:

$$
\Omega(t)=a+b \exp (-s t)
$$

Vamos supor que temos p pontos (incluindo o 0), e que eles são separados por um intervalo de tempo $\Delta$ t. Então, um sistema $\left|\Sigma^{\prime}\right|$ pode ser definido, pelo seguinte, conjunto, de p equações (H.18)

$$
\left|\Sigma^{\prime}\right|=\left[\begin{array}{l}
\Omega(0)=a+b \\
\Omega(\Delta t)=a+b \exp (-s \Delta t) \\
\Omega(2 \Delta t)=a+b \exp (-2 s \Delta t) \\
\vdots \\
\Omega((p-1) \Delta t)=a+b \exp [-(p-1) s \Delta t]
\end{array}\right]
$$

A constante a pode facilmente ser eliminada formando-se as seguintes (p-1) diferenças:

$$
\left[\begin{array}{l}
\Omega(0)-\Omega(\Delta t)=b[1-\exp (-s \Delta t)] \\
\Omega(\Delta t)-\Omega(2 \Delta t)=b[1-\exp (-s \Delta t)] \exp (-s \Delta t) \\
\Omega(2 \Delta t)-\Omega(3 \Delta t)=b[1-\exp (-s \Delta t)] \exp (-2 s \Delta t) \\
\quad \vdots \\
\Omega((p-2) \Delta t)-\Omega((p-1) \Delta t)=b[1-\exp (-s \Delta t) \exp [-(p-2) s \Delta t]
\end{array}\right]
$$

A constante $\mathrm{b}$ pode ser eliminada utilizando a seguintes correlações que nos resultam em um no número de p-2 equações, como (H.20)

$$
\frac{\Omega(0)-\Omega(\Delta t)}{\Omega(\Delta t)-\Omega(2 \Delta t)}=\frac{\Omega(\Delta t)-\Omega(2 \Delta t)}{\Omega(2 \Delta t)-\Omega(3 \Delta t)}=\cdots=\frac{\Omega((p-3) \Delta t)-\Omega((p-2) \Delta t)}{\Omega((p-2) \Delta t)-\Omega((p-1) \Delta t)}=\exp (s \Delta t)
$$

Baseado nesta relação, $\exp (\mathrm{s} \Delta \mathrm{t})$ é a média dessas $\mathrm{p}-2$ equações e s é:

$$
s=\frac{1}{\Delta t(p-2)} \operatorname{Ln}\left(\frac{\Omega[(p-2) \Delta t]-\Omega[(p-1) \Delta t]}{\Omega(0)-\Omega(\Delta t)}\right)
$$


O procedimento adotado acima pode ser usado para transformar o sistema $|\Sigma|$ pela diferenciação sucessiva da fração mássica $\mathrm{N}_{\mathrm{i}}$ no sistema $\left|\Sigma^{\prime}\right|$ que pode ser utilizado para encontrar os parâmetros de seleção iterativamente.

$\mathrm{Na}$ prática, o parâmetro $S_{\mathrm{i}}$ é facilmente obtido da curva de $\operatorname{Ln}\left(\mathrm{N}_{\mathrm{i}}\right)$ por $\mathrm{t}_{\mathrm{ij}}$ e pode se assumir com já conhecido. A expressão para $\mathrm{N}_{2}(\mathrm{t})$ do sistema $|\Sigma|$ pode ser transformado em uma expressão similar à aplicada no problema preliminar pela multiplicação de cada termo por $\exp \left(\mathrm{S}_{\mathrm{i}} \mathrm{t}\right)$ :

$N_{2}(t) \exp \left(S_{i} t\right)=t_{21} \exp \left(S_{1} t-S_{1} t\right)+t_{22} \exp \left(S_{1} t-S_{2} t\right)$

Essa expressão transformada será chamada de $\Omega_{2}(\mathrm{t})$ :

$\left.\begin{array}{l}\Omega_{2}(t)=N_{2}(t) \exp \left(S_{1} t\right) \\ \Omega_{2}(t)=t_{21}+t_{22} \exp \left[\left(S_{1}-S_{2}\right) t\right]\end{array}\right\}$

Baseado na equação (H.21), $S_{2}$ pode ser determinado ( $t_{21}$ e $t_{22}$ são independentes do tempo):

$S_{2}-S_{1}=-\frac{1}{\Delta t(p-2)} \operatorname{Ln}\left(\frac{\Omega_{2}[(p-2) \Delta t]-\Omega_{2}[(p-1) \Delta t]}{\Omega_{2}(0)-\Omega_{2}(\Delta t)}\right)$

Considere agora as derivadas de $\mathrm{N}_{3}(\mathrm{t})$ adicionadas ao produto $\mathrm{S}_{1} \mathrm{~N}_{3}(\mathrm{t})$ :

$\frac{d N_{3}}{d t}+S_{1} N_{3}=-\left(S_{1}+S_{1}\right) t_{31} \exp \left(-S_{1} t\right)+\left(-S_{2}+S_{1}\right) t_{32} \exp \left(-S_{2} t\right)+\left(-S_{3}+S_{1}\right) t_{33} \exp \left(-S_{3} t\right)$

Multiplicando essa formula por $\exp \left(\mathrm{S}_{2} \mathrm{t}\right)$ resulta:

$\left(\frac{d N_{3}}{d t}+S_{1} N_{3}\right) \exp \left(S_{2} t\right)=\left(-S_{2}+S_{1}\right) t_{32} \exp \left(S_{2} t-S_{2} t\right)+\left(-S_{3}+S_{1}\right) t_{33} \exp \left(S_{2} t-S_{3} t\right)$

Então a forma requerida de $\Omega_{3}(t)$ é:

$\left.\begin{array}{l}\Omega_{3}(t)=\left(\frac{d N_{3}}{d t}+S_{1} N_{3}(t)\right) \exp \left(S_{2} t\right) \\ \Omega_{3}(t)=t_{32}\left(S_{1}-S_{2}\right)+t_{33}\left(S_{1}-S_{3}\right) \exp \left[\left(S_{2}-S_{3}\right) t\right]\end{array}\right\}$

Como $t_{32}$ e $t_{33}$ não dependem do tempo t:

$S_{3}-S_{2}=-\frac{1}{\Delta t(p-2)} \operatorname{Ln}\left(\frac{\Omega_{3}[(p-2) \Delta t]-\Omega_{3}[(p-1) \Delta t]}{\Omega_{3}(0)-\Omega_{3}(\Delta t)}\right)$

De forma similar, a quarta e a quinta classe podem ser expressas como: 


$$
\left.\begin{array}{l}
\left.\Omega_{4}(t)=\left(\frac{d^{2} N_{4}}{d t^{2}}+\left(S_{1}+S_{2}\right) \frac{d N_{4}}{d t}+S_{1} S_{2} N_{4}(t)\right) \exp \left(S_{3} t\right)\right\} \\
\Omega_{4}(t)=a_{4}+b_{4} \exp \left[\left(S_{3}-S_{4}\right) t\right] \\
\Omega_{5}(t)=\left(\frac{d^{3} N_{5}}{d t^{3}}\left(S_{1}+S_{2}+S_{3}\right) \frac{d^{2} N_{5}}{d t^{2}}+\left(S_{1} S_{2}+S_{2} S_{3}+S_{1} S_{3}\right) \frac{d N_{5}}{d t}+S_{1} S_{2} S_{3} N_{5}(t)\right) \exp \left(S_{4} t\right) \\
\Omega_{5}(t)=a_{5}+b_{5} \exp \left[\left(S_{4}-S_{5}\right) t\right]
\end{array}\right\}
$$

É óbvio que o cálculo de $S_{i}$ pode ser feito se conhecendo antes os parâmetros de seleção de índice $\mathrm{i}-1$ e $\mathrm{N}_{\mathrm{i}}(\mathrm{t})$. Isso pode ser feito pela construção de uma formula de recorrência generalizada com ajuda da variável $\sigma_{\mathrm{k}}{ }^{\mathrm{i}-2}$ para os produtos distintos $\mathrm{S}_{\mathrm{i}}$ quando eles aparecem um a um, dois a dois, três a três etc..., até o índice i-2 de forma que:

$$
\left[\begin{array}{l}
\sigma_{1}^{i-2}=S_{1}+S_{2}+\cdots+S_{i-2} \\
\sigma_{2}^{i-2}=S_{1} S_{2}+S_{1} S_{3}+\cdots+S_{1} S_{i-2}+S_{2} S_{3}+S_{2} S_{4}+\cdots+S_{2} S_{i-2}+\cdots+S_{i-3} S_{i-2} \\
\sigma_{3}^{i-2}=S_{1} S_{2} S_{3}+S_{1} S_{2} S_{4}+\cdots+S_{1} S_{2} S_{i-2}+\cdots+S_{i-4} S_{i-3} S_{i-2} \\
\vdots \\
\sigma_{i-2}^{i-2}=S_{1} S_{2} S_{3} S_{4} \cdots S_{i-2}
\end{array}\right]
$$

Então podemos escrever uma formula geral de recorrência para $\Omega$ como já foi demonstrado:

$$
\Omega_{i}(t)=\left(\frac{d^{i-1} N_{i}}{d t^{i-2}}+\sigma_{1}^{i-2} \frac{d^{i-3} N_{i}}{d t^{i-3}}+\sigma_{2}^{i-2} \frac{d^{i-4} N_{i}}{d t^{i-4}}+\ldots+\sigma_{i-2}^{i-2} N_{i}\right) \exp \left(S_{i-1} t\right)
$$

Substituindo-se cada $\mathrm{N}_{\mathrm{i}}$, pela sua expressão em termos de $S_{i}$ e $t_{i, j}$, como na equação (H.9) podemos simplificar a equação (H.31) como:

$\Omega_{i}(t)=t_{i, j} \prod_{j=1}^{i-1}\left(S_{j}-S_{i}\right) \exp \left(S_{i} t\right)$

$E b_{i}$ e $a_{i}$ sendo independentes do tempo

$$
\Omega_{i}(t)=a_{i}+b_{i} \exp \left[\left(S_{i-1}-S_{i}\right) t\right]
$$

Os parâmetros $S_{\mathrm{i}}$ é então calculado como

$$
S_{i}=S_{i-1}-\frac{1}{\Delta t(p-2)} \operatorname{Ln}\left(\frac{\Omega_{i}[(p-2) \Delta t]-\Omega_{i}[(p-1) \Delta t]}{\Omega_{i}(0)-\Omega_{i}(\Delta t)}\right)
$$

Resumindo esse procedimento, usando derivadas formais dos dados experimentais $\mathrm{N}_{\mathrm{i}}(\mathrm{t})$, transformamos o sistema original $|\Sigma|$ em outro sistema $\mid \Sigma$ ' $\mid$, e definimos na equação (H.31) que a extração dos parâmetros de seleção podem ser feitos de forma seqüencial 
usando (H.33). Entretanto, derivadas de ordem alta são necessárias e para o caso em que lidarmos com mais de cinco tempos experimentais precisamos suavizar as curvas para o cálculo do problema inverso, a figura H2 ilustra esses cálculos BERTHIAUX; DOODS (1997), BERTHIAUX; DOODS; VARINOT (1997).

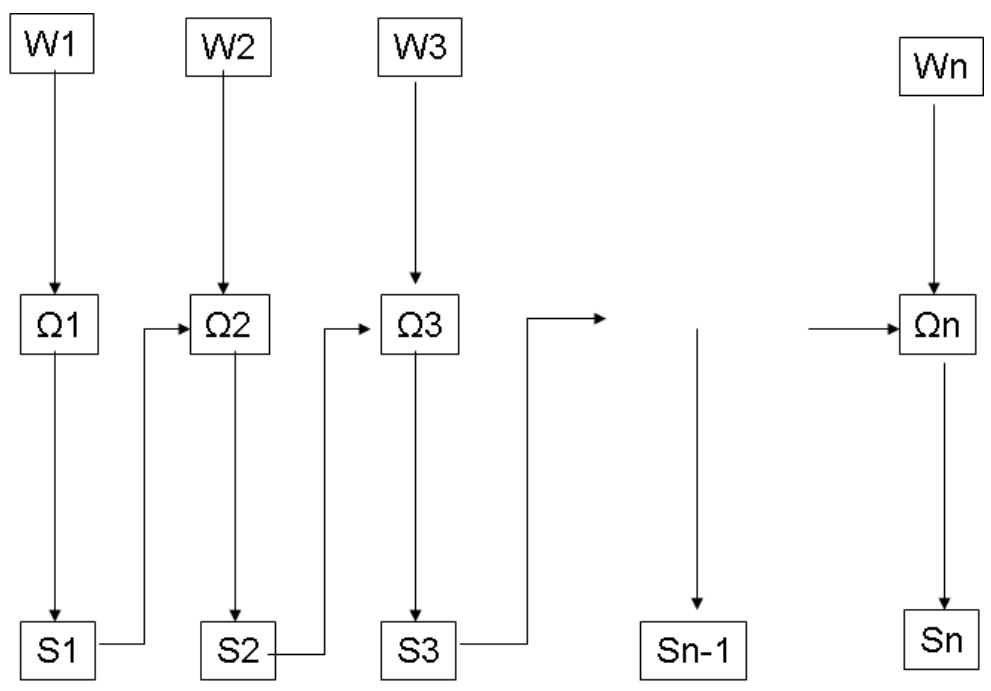

Figura H.2: Determinação da quebra e dos parâmetros de seleção para o método de diferenciação seqüencial. FONTE:(BERTHIAUX;DOODS,1997). 


\section{APÊNDICE I: METODOLOGIA PARA O CÁLCULO DAS DISTRIBUIÇÕES DE PARTÍCULAS FILHAS POR (KOSTOGLOU;KARABELAS,2001)}

Deixando $\mathrm{n}(\zeta)=\zeta \mathrm{f}(\zeta)$, e, as equações (I.1) e (I.2) serão os momentos dos núcleos desconhecidos das funções, e, a distribuição de similaridade conhecida, e, definida como:

$$
\begin{aligned}
& g_{s}=\int_{0}^{1} \xi^{s} g(\xi) d \xi \\
& K_{s}=\int_{0}^{\infty} \xi^{s} n(\xi) d \xi
\end{aligned}
$$

Agora obtemos a seguinte relação ao multiplicarmos a equação (3.4.18) por $\zeta^{\text {s }}$, em ambos os lados:

$$
\gamma g_{s-1}=\frac{\int_{0}^{\infty} \xi^{s-1} n(\xi) d \xi}{\int_{0}^{\infty} \xi^{s} n(\xi) d \xi}
$$

É recomendável que a função desconhecida $\gamma \mathrm{g}_{\mathrm{s}-1}$ seja avaliada pela integração direta, em valores eqüidistantes de s na faixa entre 0 e 2 . Um valor de trabalho inicial do parâmetro, $\gamma$, pode ser determinado ajustando-se a função e- ${ }^{\gamma \zeta}$ na parte superior, para altos valores de $\zeta$, da distribuição $\mathrm{n}(\zeta)$. Uma nova e normalizada função $\mathrm{NN}(\zeta)=\mathrm{n}(\zeta / \gamma)$ é construída e comparada com as forma padrões apresentadas por (KOSOGLOU;KARABELAS,2001). Para todas as possíveis formas que a função de quebra pode obter, e muito bem conhecido, que ela pode ser representada pela seguinte função:

$$
\gamma g(x)=\sum_{i=1}^{n} c_{i} x^{k_{i}}
$$

Agora se $\mathrm{e}^{-\mathrm{t}}$ entrar como um parâmetro da supostamente desconhecida função $\gamma \mathrm{g}(\mathrm{x})$, então podemos mostrar que uma transformada de Laplace dessa função é exatamente o momento de ordem (s-1), que é calculado pela equação (I.2). Usando-se a mesma substituição no cálculo da transformada de Laplace da equação (I.3), seguimos o seguinte rumo nos cálculos:

$$
\gamma g(x)=L\left(\gamma g\left(e^{-1}\right)\right)=\sum_{i=1}^{n} \frac{c_{i}}{s+k_{i}}
$$


$\mathrm{O}$ valor dos parâmetros, $\mathrm{c}_{\mathrm{i}}, \mathrm{e}, \mathrm{k}_{\mathrm{i}}$, podem ser determinados por um ajuste não linear da equação (I.5) à equação (I.3), já calculada. Conseqüentemente, um valor refinado de $\gamma$, ou seja, da taxa de quebra no volume de referência pode ser determinado, na condição em que $g(1)=1$. 


\section{APÊNDICE J: CÁLCULOS QUE DEMOSNTRAM UM AUMENTO DA SIMILARIDADE PARA REATORES, DO TIPO, BATELADA, EM RELAÇÃO À REATORES CONTÍNUOS (NARSIMHAN;NEJFELT;RAMKRISHNA,1984)}

Se definirmos uma função $\mathrm{F}(\mathrm{v}, \tau)$, de forma que $\mathrm{F}(\mathrm{v}, \tau) \mathrm{d} \tau$ é a fração de volume cumulativo de partículas de idade entre $\tau, \mathrm{e}, \tau+\mathrm{d} \tau$ :

$$
\dot{F}(v)=\int_{0}^{\infty} \dot{F}(v, \tau) d \tau
$$

E podemos claramente perceber que:

$$
\frac{\partial \dot{F}(v)}{\partial \tau}=\frac{1}{\text { tempo de residência médio }} \dot{F}(v, \tau)+\int_{v}^{\infty} \Gamma\left(v^{\prime}\right) G\left(v, v^{\prime}\right) \frac{\partial \dot{F}(v, \tau)}{\partial v^{\prime}} d \tau
$$

Que podemos reescrever como:

$$
\frac{\partial\left[\dot{F}(v, \tau) e^{\frac{\tau}{\text { tempo de residência médio }}}\right]}{\partial \tau}=\int_{v}^{\infty} \Gamma\left(v^{\prime}\right) G\left(v, v^{\prime}\right) \frac{\partial \dot{F}(v, \tau)}{\partial v^{\prime}} e^{\frac{\tau}{\text { tempo de residência médio }}} d \tau
$$

Se transformarmos de novo para uma outra variável $\tau^{\prime}=\tau /$ (tempo de residência médio), e representarmos $\dot{F}^{\prime}\left(v, \tau^{\prime}\right)=($ tempo de residência médio $) \dot{F}(v, \tau)$. Nós podemos converter a equação (J.3) em:

$$
\frac{\partial\left[\dot{F}^{\prime}\left(v, \tau^{\prime}\right) e \tau^{\prime}\right]}{\partial \tau^{\prime}}=(\text { tempo de residência médio }) \int_{v}^{\infty} \Gamma\left(v^{\prime}\right) G\left(v, v^{\prime}\right) \frac{\partial \dot{F}\left(v^{\prime}, \tau\right)}{\partial v^{\prime}} e \tau^{\prime}
$$

A equação (J.4) é da mesma forma que a equação (3.2.4), então quando a equação (3.3.2) for verdadeira. Esperaremos uma solução de similaridade da forma:

$$
\dot{F}^{\prime}\left(v, \tau^{\prime}\right) e \tau^{\prime}=f\left((\text { tempo de residência médio }) \Gamma(v) \tau^{\prime}\right)
$$

Para valores grandes de $\tau$ '. Entendemos grandes, como aqueles que satisfaçam (J.6)

$$
\tau^{\prime} \gg>\frac{1}{(\text { tempo de residência médio }) \Gamma\left(v_{\max }\right)}
$$

Onde $v_{\text {máx }}$, é em geral o volume típico das partículas que estão entrando. Claramente se $\Gamma\left(v_{\text {máx }}\right)($ tempo de residência médio) $>>1$. É esperado que a equação (J.5), seja satisfeita para valores razoavelmente pequenos de $\tau$ '. Esta conclusão, se reescrevermos a equação (J.1) como:

$$
\dot{F}(v)=\int_{0}^{\infty} \dot{F}\left(v, \tau^{\prime}\right) d \tau^{\prime} \approx \int_{0}^{\infty} f\left((\text { tempo de residência médio }) \Gamma(v) \tau^{\prime}\right) e^{-\tau^{\prime}} d \tau^{\prime}
$$


Nos mostra, que a função (tempo de residência médio) $\Gamma(\mathrm{v})$, implica em um comportamento de similaridade com essa variável, (tempo de residência médio) $\Gamma(\mathrm{v})$. Portanto, quanto maior o tempo de residência médio, ou, quanto mais o reator continuo se comportar próximo, de um reator batelada, maior a chance de observarmos similaridade nas distribuições. 


\section{APÊNDICE K: ESTIMATIVA DE $\Gamma\left(v_{r}\right)$ E DE $g(x)$.}

É de nosso interesse estimarmos $\Gamma\left(\mathrm{v}_{\mathrm{r}}\right)$, e, $\mathrm{g}(\mathrm{x})$, por meio dos valores de $\left\{\Gamma\left(\mathrm{v}_{\mathrm{r}}\right)\right.$ Constantes $\left._{\mathrm{w}}\right\}$, ordem $=1,2 \ldots$, onde $\left\{\right.$ Constantes $\left._{\mathrm{w}}\right\}$ é definido como:

$$
\text { cons tantes } s_{w}=\int_{0}^{1} x^{n} g(x) d x
$$

Podemos assumir que a função de distribuição de partículas filhas $\mathrm{g}(\mathrm{x})$ é zero para valores de $\mathrm{x}$ menores que $\mathrm{x}_{\mathrm{r}}$, onde $\mathrm{x}_{\mathrm{r}}$ é um parâmetro desconhecido da distribuição. A seguir, se assume que a função de distribuição se comporta como uma distribuição beta no intervalo $\left(\mathrm{x}_{\mathrm{r}}, 1\right)$ para os parâmetros $\mathrm{r}$ e $\mathrm{s}$. A função de distribuição pode ser então escrita como :

$$
\begin{aligned}
& g^{\prime}(x)=0 \quad \text { para } \quad x<x_{r} \\
& =\frac{1}{\left(1-x_{r}\right)}\left(\frac{x-x_{r}}{1-x_{r}}\right)^{r-1}\left(\frac{1-x}{1-x_{r}}\right)^{s-1} \quad \text { para } x \geq x_{r}
\end{aligned}
$$

O momento de ordem $\mathrm{n}$ da distribuição é dado como:

$$
\text { Momento }_{w}=\int_{0}^{1}\left\{\left(1-x_{r}\right) y+x_{r}\right\}^{n} g(y) d y
$$

Em termos da transformação de variável $\mathrm{y}=\left(\mathrm{x}-\mathrm{x}_{\mathrm{r}} / 1-\mathrm{x}_{\mathrm{r}}\right)$. Portanto:

$$
\begin{aligned}
\text { Momento }_{w} & =\sum_{i=0}^{n} \int_{0}^{1}\left(\begin{array}{l}
n \\
i
\end{array}\right)\left(1-x_{r}\right)^{i} y^{i} x_{r}^{n-i} g(y) d y \\
& =\sum_{i=0}^{n}\left(\begin{array}{l}
n \\
i
\end{array}\right)\left(1-x_{r}\right)^{i} x_{r}^{n-i} \frac{\Gamma(r+s) \Gamma(r+i)}{\Gamma(i+t) \Gamma(r)}, \quad t=r+s
\end{aligned}
$$

E com isso podemos facilmente verificar que:

$$
\text { Momento }_{w}=\frac{1}{n+1}\left(1-\text { Momento }_{w+1}\right)
$$

Portanto tendo-se os parâmetros $\mathrm{x}_{\mathrm{r}}, \mathrm{r}$ e s, da distribuição de partículas filhas, a estimativa de $\Gamma\left(\mathrm{v}_{\mathrm{r}}\right)$ por $\left\{\Gamma\left(\mathrm{v}_{\mathrm{r}}\right)\right.$ Momento $\left._{\mathrm{w}}\right\}$ é dada por:

$$
\Gamma\left(v_{r}\right)_{w}=\frac{\left\{\Gamma\left(v_{r}\right) \text { Momento }_{w}\right\}_{w}}{\left(1-\text { Momento }_{w+1}\right)} \quad w=0,1,2 \ldots
$$

Onde Momento $_{\mathrm{w}+1}$ é dado pela equação (K.4). 
Portanto, a média estimada de $\Gamma\left(\mathrm{v}_{0}\right)$, vindo dos valores de $\left\{\Gamma\left(\mathrm{v}_{0}\right)\right.$ Constantes $\left._{\mathrm{w}}\right\}$, $\mathrm{w}=0,1,2 \ldots$ TOTAL-1 é dado por:

$\overline{\Gamma\left(v_{r}\right)_{w}}=\frac{1}{\operatorname{TOTAL}} \sum_{n=0}^{T O T A L-1} \Gamma\left(v_{r}\right)_{w}$

$\mathrm{O}$ desvio padrão do valor estimado de $\Gamma\left(\mathrm{v}_{\mathrm{r}}\right)$, vindo das constantes $\left\{\Gamma\left(\mathrm{v}_{\mathrm{r}}\right)\right.$ Constantes $\left._{\mathrm{w}}\right\}$ é dado por:

D.P. $=\frac{1}{T O T A L} \sum_{n=0}^{T O T A L-1}\left\{\Gamma\left(v_{r}\right)_{w}-\overline{\Gamma\left(v_{r}\right)}\right\}^{2}$

Os parâmetros $\mathrm{r}$, s e $\mathrm{x}_{\mathrm{r}}$, da distribuição de partículas filhas $\mathrm{g}(\mathrm{x})$ são estimados ao minimizarmos a seguinte função objetivo:

erro $=\frac{1}{T O T A L} \sum_{n=0}^{T O T A L-1} \frac{\left\{\Gamma\left(v_{r}\right)_{w}-\overline{\Gamma\left(v_{r}\right)}\right\}^{2}}{{\overline{\Gamma\left(v_{r}\right)}}^{2}}$

Deveríamos então utilizar o algoritmo Nelder e Mead para o caso de uma minimização multivariável sem restrições, e, emprega-lo para estimarmos os parâmetros r, s, e, $x_{\mathrm{r}}$.

Finalmente assume-se a abordagem alternativa de que $\mathrm{g}(\mathrm{x})$ é uma distribuição beta, e, dependente de três parâmetros:

$$
g(x)=\frac{(r+s-1) !}{(r-1) !(s-1) !} \int_{0}^{\frac{x-x_{r}}{1-x_{r}}} \zeta^{r}(1-\zeta)^{s} d \zeta
$$

Nesse caso os fatoriais devem ser interpretados como funções gama, visto que, nem sempre os valores de r e s serão necessariamente inteiros. 